\title{
2.5.3 Leva
}
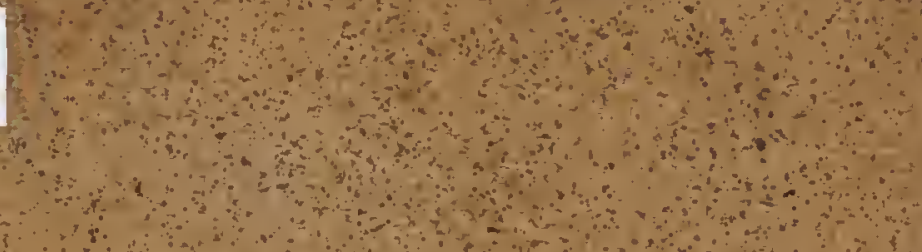

$$
\therefore \therefore=0
$$

a

$\therefore \quad 0$ 


\section{SECOND VOYAGE}

D A N S L'I N TERIEUR

D E L'A F R I Q U E.

TOME SECOND. 



\section{SECOND VOYAGE}

DANS LINTERIEUR

DE L'A F R I Q UE,

P A R

LE CAP DE BONNE-ESPÉRANCE, DANS LES ANNÉES 1783, 84 ET 85 ;

PAR F. LEVAILLANT.

TOME SECOND.

A BRUXELLES,

Chez B. L E F A N $\Omega$, Imprimeur-Libraire, rue de la Magdelaine.

$$
1797 \text {. }
$$




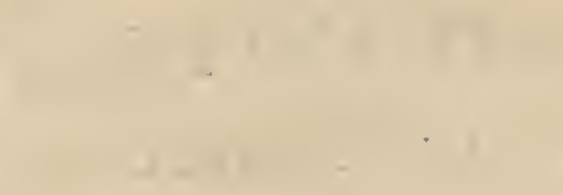

1

1

$+$

. 


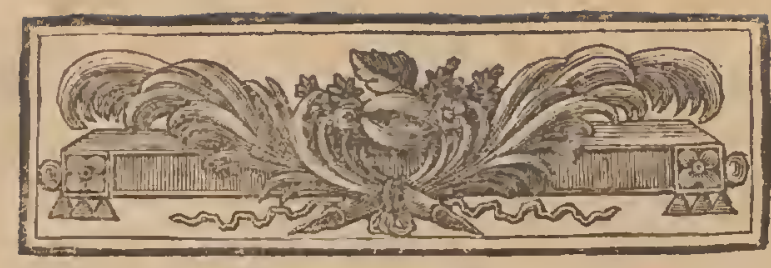

\section{$\mathrm{VOVAGE}$

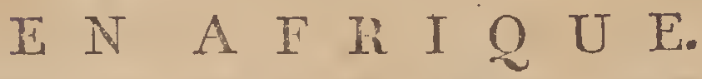

VOYAGE DANS LE PAYS DESS PETITS ET GRANDS NAMAQUOIS.

\section{M}

$\Lambda$ destinéc, depris quelque tems, étoit d'être balotté sans cesse du désespoir à l'espérance. Nous n'avions pas encore fait deux lieues, quand subitcment se présenta derant moi un motif d'espoir et d'allégressc; e'ćtoit des pas de bocufs. A la vérité, leurs traees, sinsi que les bouses qu'ils avoient laissées, parcissoient un peu aneiennes; mais au moins ees vestiges prouvoient qu'un troupeau de bêtes-à-comes avoit passé par là; et soit que ce troupeau appartînt à une horde de Hottentots, soit qu'il fut celui de ce K'laas Baster que je eherchois, je pouvois me flatter, si je le reneontrois, de trouver du secours et des amis.

Tandis que nous misonnions sur ces probabilités, et sur les moyens les plus sûrs et les plus prompes pour rejoindre le troupeau, Kees, s'élanTome $I I$. 
çant avec un cri de joic hors de mon chariot, se mit à courir en arant; et à l'instant même il fut suivi par mes chicns. Assurément ce n'étoit pas pour attaquer une pièce de gibicr, que mon singe montroit cette ardeur; je le connoissois trop poltron. Jusqu’à ce moment, je ne l'avois cncore vu qu'une seule fois, se hasarder et s'iventurer ainsi : c'étoit à mon premier voyage, quand il me découvrit, dans le pays des Caffres, eette souree ì laquelle je donnai son nom.

Une course absolument semblable paroissoit m'annoncer ici une semblable découverte. Je volai done où il s'étoir arrêté; et à deux cents pas de la voiture, je le vis au milieu de ma meute, dans unc largge cavitć extrêmement humide, que les chiens fouilloient et creusoient avec leurs pattes pour $y$ chercher de l'cau.

J'appellai mes gens. Ils viurent avec des pelles et des pioches, et se mirent à creuser le bissin. Effectivement nous eûmes bientôt deux à trois pintes d'eau trouble et un peu saumâtic : pour la rendre porable, j'y jettai, comme dans celle du Krakkeelklip, quelques onces de café en poudre. Mon dessein étoit de la faire bouillir comme au Krakkeel; mais la soif qui brûloit mes gens étoit si cruelle qu'aucun d'cux ne put se résoudre à attend:c. Il fallut done leur livrer cette espèce de boue liquide. En père juste, je la partageai également cntre tous, selon mon ordinaire; ct nous en êtmes très-peu chacun.

Nous nous trouvions au pied d'un petit chânon de montagnes. Il couroit du nord au sud; et se détachant de la grande ehaine que nous avions à l'est, formoit ainsi une gorge dont il étoit impossible à l'coil de suivre toute l'étendue. 


\section{IN A F R Q U E.}

Des troupeaux avoient sćjourné là pendant quelque tems. Par-tout, la terre foulée, y offroit l'empreinte de leurs pieds. Ainsi, ne doutant pas que je ne trouvasse bientôt une horde hottentote qui me donneroit des renseignemens sui le nomade Baster dont m’avoit parlé Gordon, je pris le parti, en suivant la gorge, d'aller à la découverte.

Pour cet effet, il falloit laisser mon eharior, mes équipages et tous mes bestiaux à l'entréc de ia, gorge. C'est aussi ce que je fis. Cependant j'y laissai, cn même tems, pour gardiens, quatre personnes; et leur enjoignis de ereuser er d'élargir le trou, afin, qu'en leur fournissant à elles-mêmes une provision suffisante d'eat, il put, s'il éroir possible, former un abreuvoir pour les' bêtes qui me restoient.

Le nombre en étoit bien diminué. Dès le moment qu'en entrant dans le déscrt, j’avois cessé de rouver du gibicr pour la nourriture de mes gens, je m'étois vu contraint de faire égorger suecessivement tous mes montons. Depuis la nort d'lngland, jc venois, dans la route, de pertic eneore deux beufs. T'outes mes vaches avoient péri. Des quatre chcvaux, il ne m'cn restoit plus que deux; vrais squélettes, dans l'état le plus déplorable, et incapables absolument de faire le moindre service. Il n'y avoit que mes chères qui ne se sentoient point ¿e norreafirentse détressc. Elles avoient même donné constamment du lait; ct ectre ressource joumalière avoit été notre unique salut, puisqu'elle m'avoit permis jusque-lì, de fournir journellement à mes gens un peu de lait, et même à mes chiens, qui, par le dófuut d'cau, cussent pu bientố gagner la rage.

J'emmenai avec moi huit hommes, parmi les- 
quels étoit mon Klass; pour donner à notre recherche une marche plus sûre et plus prompte, je le chargeai d'aller, avee trois de ses camarades, à l'ouest de la petite chaine de montagnes, et de la suivre en remontant au noid; et moi, pendant ce tems, je m'enfonçai, avec quatre chasseurs, dans la gorge enticrement couverte de gros buissons.

Après quelque tents de marche, jarrivai à un sentier qui paroissoit extrêmement battu. Cette découverte, done nous ne pouvions que nous féliciter, glaça d'ćpouvante mes quatre hommes. Ils s'imaginèrent que ce défilé conduisoit à quclque retraite de Boschjesman, et me pricrent de ne pis nous enfoncer plus avant, de peur d'ètre égorgés tous cinq par ces voleurs. Vainement, je leur représentai que le plus grand malheur qui pût nous arriver, dans la citconstance oil je me trouvois, étoit de ne rencontrer personne, et que nous ne pouvions sortir d'embarras qu'en parlant à quelqu'ame vivante; ils he voyoient au bout du sentice gu'une horde d'issassins: et sans oser aller plus loin, ils sarrêtèrent, partagés entre la honte de m'abandonner et la crainte d'être égorgés! Quand le diable scroit là avec tout l'enfer, m’écriai-je, il faudroit que j’ailie lui parler, i’y suis décidé. Au reste, mes amis, si vous avez quelque répuginance à me suivre, je vous laisse la liberté de retourner, et je me passerai de vous.

En parlant ainsi, je m'enfonçai dans le sentier, et je vis avec plaisir qu'ils me suivoient tous quatre. Cependint leur marche n'étoit rien moins qu'assuréc. Tout en avançant, ils raisonnoicnt entre cux sur ce qu'il y auroit à faire, si nous tombions dans unc horde à Boschiosmm, sur les moyens de l'aborder, si notis n'étions pas attaqués par clle; sur 


\section{E N A F R I Q U E.}

ceux de se soutenir et de se défendre, si nous l'étions. Ces eombinaisons de tactique dains mes Sauvages, ees projets raisonnés dans le eas où ee seroient des amis ou des ennemis qu'ils trouveroient, m'amusoient benucoup. Je voyois sur-tout avec phisir que leur peur, toure grrmnde qu'elle étoit, leur avoit pourtant lisissé la tête libre; et qu'en s'alarmant benucoup sur le danger dont ils se croyoient menacés, ils prenoient nérmmoins des préeautions fort sages pour s'en garantir si nous ćtions attaqués.

Elles furcnt inutiles. Après avoir stivi pendant une heure le sentier, nous sortimes de lin gorge et débonehâmes dans la campagne, où nous vìmes Klans et ses eamarades, parcourir un emplacement on il y avoit quelques huttes délabrées. Je leur fis signe de venir se joindre à ma troupe; et pendant ce tems je montai avec la mienne sur une hauteur voisine, d'où, portant les yeux au loin, il m'étoit aisé de m'nssurer si je n'appereerois point dans les plunes d'alentòur les hommes à qui appartenoient ees hutres. Mris sculement, à quelque distance, je décourris, avec ma lunette, plusieturs enbanes que je reconnus pour être celles de Llottentots; et il y en avoit même une, entre autres, qui me parut plus grande qu'elles ne le sont ordinairement. Etoitce là un vmi krial hottentot? Etoit-ee une de ces stations passagères que s'étoir choisi, pour lui et pour ses gens, ce Baster que je cherchois, ct qui vivoit à la hottentote? Miais soit kraal, soit séjour de Baster, il falloit, pour y trouver des renseignemens ou des secours, m'y rendre sans délai; et e'cst ee que je fis.

En mapprochant je vis, avee regret, que toutes étoient vides, comme les premières; elles parois* 
soient même abandonnées depuis plusient's semaines. Seulement, on avoit laissé dans lar grande un de ces moulins à bras dont se servent les colons pour moudre leurs grains. Ce meuble domestique, déposć là, annonçoit un étnblisscnnent dans lequel on se proposoit de revenir; et ce qui le prouvoit encore micux, c'étoient deux petits champs, proprement ensemencés, d'orge et de blé, qui se trou-', voient près de la cabane. Mais que m'importoit dans cette occasion l'apparcnce d'un prochain retour; c'étoit l'homme présent, quu'il me falloit, et hon celui qui devoit revenir. Au reste, au milieu de ces contrariétés, je trourai au moins un motif de consolation; ce fut une source, qui, quoique sammâtre, ainsi que toutes celles que nous avions rencontrées depuis quelque tems, fut pour nous une découverte tròs-agrénble, ot soulagen, pour le moment, notre soif ardente.

Je ne pouvois douter, d'après ces indices, que la horde hotteniote oul le proptiétaire des huttes, ne se fussent retirés avec lcurs troupcaux dans les zyorges et les vallées des montagnes voisines; et mon intention étoit de les y chercher. Niais comme il étoit trop tard pour continuer nos recherches dans le moment, nous les différâmes au lendemain, et nous nous arrangeâmes pour passer la nuit dans la cabane au moulin. Nos feux, faute de bois, furent faits avec des bouses seches, que nous trouvâmes en abondance dans les environs; et j’eus soin quon en entretint plusieurs allumés; me fiattant que si le maître de l'habiation étoit à portće de les voir, il auroit, sans doute, la curiosité de s'en approcher lc lendemain, pour en reconnoître les nouveaux hôtes.

Le lendemain personne ne parut, et nous nous 


\section{E N A T.RI Q U E.}

vîmes réduits à continucr nos recherches. Mais de quel côté les diriger? Voilà ce qui m'embarrassoit. Sûr, au moins, qu'en quiclque endroit qu'clles aboutissent, elles ne pouvoient que m'éloigner de plus en plus de mon camp, je pris le parti d'y envoyer un de mes gens, avec ordic d'amener au licu où j'étois mon charint et mes animaux. Outre que le sol s'y trouvoit moins brûlé, la petite souree devoit suffire pour mes bestinux; et certes, clle promettoit d'être plus abondante que le trou quî avoir été commencé par mes chiens, ct qui dẹja, peut-être, se trouvoit târi. Jo donnai done expressément l'ordre d'empêcher mes bestiaux de dévorer les champs ensemencés.

Pendant que l'on portoit mes ordres an camp, je marchois avec ma troupe vers la grande chaine de montagnes, dans l'espoir qu'élevés là de beaucoup au-dessus des lieux circonvoisins, nous distinguerions sans peine où ćtoient lus possesscurs du kraal abandonné. La ronte, au reste, n'étoit pas embarrassante. Depuis les cabanes jusqu'a la cime la plus haute, elle avoit été tracée pirr les pas des pâtres ex de lemrs bestiaux. Nín ceil la voyoir circular sur le revers des montannes, sa perdre de tems en tents duns les sinuosités; puis se remontrant sur les parties saillantes, aboutii a phatenu le plus élevé.

Dans un autre moment, je me fusse bicn gardé d'entreprendre une marche aussi pénibic; et mêne dans celui-ci, j’en sentois tontes les áificultés. Outre qu'elle alloit, peut-être inutilement encore, nous coûter une journee cntière de peine, je craignois que l'épuisement où nous nous trouvions ne mous permit pas d'en supporter l'cxtrême firtigne. D'ailleurs, si la montagne recéloit en effet des Busch- 
jesman, n'étoit-ce pas exposcr visiblement ma troupe, que dic l'engager dans ces rochers où ils auroient, pour l'attaquer, tant d'avantage. Je ne sentois que trop bien la force de ces réflexions; mais je sentois cncorc mieux, que nous ne pouvions échapperà la détresse où nons nous trouvions, qu'en découvrant des humains qui pussent nous secourir: et quand il ne reste plus gu'unc seule ressource, cxamine-t-on si clic a des dangers.

En route, nous trouvônes à tuer sur le sommet des rochers, quelques damans, qui furent destinés à notre solper. Nous apportions aussi une perite provision de l'eau de la fontaine; parce que nous avions à craindre de n'cn pas trouver sur la montagne : ct en effet, sa cime étoir un immens plateau très-aridc. Nous y arrivâmes après avoir gravi péniblement sous l'ardeur d'un soleil brthlant; réunis snr la platte-forme, nous nous vimes en proie à ses feux devenus presque horisontaux, et elle ne nous offroit pas tm seul arbre pour nous en gatantir. Mais je n'ai pas besoin de dirc que ce i'ceoit pas là In penséc qui moccupoit le plü, er que notre premier soin, quand nous fumcs sur la montagne, fut de promener au loin nos regards de tous côtés, pour y décolvvir ce que nous étions venus chercher avec tant de peine.

Mes Snuvages, avec leur vue perçante, ne laissoient écepper aucun objet qu'elle put atteindre. Gorgcs, vallées, plaines, montagnes, leur ail visitoit toutavec ha plus rigourcuse attcutioil ; ils sembloient même, par unc sorte d'émulation, se disputer à qui d'entre eux découvriroir plutòt ou un homme, ou un troupeau. Hélas! tant de soins n'nboutirent qu'à nous désoler divantage. Par-tott nous ne virnes que lo tableat découragenut d'une afreuse 
solitude. Point d'hommes, point d'animatur; nous paroissions ĉtre seuls au mondc. Le cri plaintif des damans étoit tout ce qui se faisoit entendre autour de nous.

Oh! ce fut alors que la consternation devint génćralc : ct moi-mêne qui, jusqu"à ce moment, avois du moins, au milicu de tant de malheurs, conservé l'esperrance, je la perdis. En vain, je conscillai à nes pauves amis abattus d'appreter les damans pour leur repas; en vain, je les pressai de boirc l'cau que nous avionsapportéc; tous se refusc̀rent à manger de peur d'être obligćs de boire, et à boire de reur de souffir plus encorc.

Il cet rrai que, depuis quelque tems, nos caux ayant toujours étć saumîtres, elles nous avoient mis lì bouche dans un état de gonflenent, d'altérntion et de cloulcur, qui ćcoit devenu une soufirance habituclic. Colles de la veille, sur-tout, avoicnt bcaucoup aggtavé le $1 \mathrm{ral}$; parce que moumns de soif, et séfuics par l'aspect d'une souree, nous nous étions permis d'cn boire bcaucoup. Ia langue, les goncives, l'intíricur même de la gorgece, ćtoient enfinmmés. Dans un parcil ctat des organes endommagés, on conçoit aisćment qu'me nourclle eat saumâtre, loin de désaltérer et de rninîichir, ne pouvoit qu'sugmenter l'inflammation. En route, quclcues-nus da mes llottentots avoicnt tenté de s'cn mouiller la langue; clle leur avoit donnć les douleurs brîlantes d"un caustique; il n'est donc point étommatit qu'ils eusient pour clle cette sorte d'horreur cue donne l'hydrophobic.

Enfin, le soleil étoit déja disprru de la montagne: n'ayant cncore ricn apperçu, nous chcrchâmes un cndroit conmoce pour y passer la nuit; nous allumâmes un feu derricic une grossc roche pour n'être 
point découverts des Boschjesman et nous nous retirâmes. Tous mes Hottcntots, accroupis autour de ce feu, les coudes appuyés sur les genoux, et la tête dans leurs deux mins, gardoicnt ce morne silence qui est l'effet ordinaire d'uñ grand ahattement. Ils finirent enfin, par se coucher à terre et sc préparoient à dormir; cherchant ainsi, dans le sonmeil, unc distraction momentanéc à des maux qui ne devoient renaitre que plus cuisans.

Jc m'étoisétendu à terre, commecux; mais n'ayant pas, comme cux, la faculté d'appeler le sommeil à ma volonté, je m’abandonnai tout entier aux réflexions affreuses que comportoit l'horreur de ma situation. Tantôt, je me reprochois cette crreur d'espérance qui, sans fruit, m'avoit fait braver tant de périls, et qui m"éloignoit de mon camp de plus de huit lieucs; tantôt, je contemplois avec attendrissement les malheureux compagnons de mon voyage, condamnes à souflir avec moi toutes les privations; tantôt, revenant sur moi-mêne, et ne voyant nul remide à cette horrible situation, j'invoquois la mort, et ne songcois qu'aux moyens de hâter son approche; mais l'extrême désespoir souvent touche de bien près à l'extrême bonheur!

Vers unc heure après minuit, Klas, toujours le même, toujours occupć de moi, ct sans cesse aux aguets pour m'annoncer une nouvelle fivorable, s'approcha tout-à-coup, et me dit, d'un ton qui annonçoit les palpitations de l'espérance, quil apperçevoit des éclairs à l'horison, vers la partic de louest; que les nuages paroissoient s'amonceler sur nos têtes et qu'infailliblement nous aurions un orage. Quoique nous eussions étć trompés; dans la plaine, par unc fausse joic, plus cruclle que la certitude mêne de notre malheur, je donnai, mal- 
gre moi, créance au rapport de mon Klaas, ct, entr'ouvrant le mantcau qui m'cnveloppoit, pour considérer les effets de ce nouvel orege, je pressentis, à mon tour, qu'il vicndroit crever sur la montagne, et ąue nous ne manquerions pas d'en resscntir les bons cfiets.

Bientôt j'entendis le bruit de quelques grosses gouttes d'eau, heureux précurscurs d'une pluie abondante. Tous mes sens, $\mathrm{cn}$ un moment, dilatés d'aise et de joic, se r'ouyrirent à la vic. Je sortis hors de ma couverture, et couché sur le dos, la bouche ouverte, je recueillis avee volupté les gouttes que lc hasard y faisoit tomber. Chacune d'elle paroissoit un baume rafrâchissant sur ma langue er sur mon palais desséchés. Ic le répète, la plus pure volupté de ma vic entière est colle que je goûtai en cet instant delicicux, acheté par tant de soupirs et de si longues angoisses. L'averse ne tarda point à fondre de toutes parts; clle tomba trois heures par torrens, le disputant de fracas avec le commerre qui ne cessoir de gronder sur nos têtes. Tout mon monde, couroit ça et là par l'orage, se cherchant l'un l'autre et se félicitant, avec un air de trionphe, de se voir ainsi baigné; ils se scutoient revivie; on cût dit qu'ils cherehoient ì se gonfier, comme pour offirir plus de surface à la pluie et s'en imbiber davantage. Pour moi, je gô̂tois un si doux plaisir à me tremper comme cux, que, pour conserver plus immédiatement ectte fraîcheur bienfaisante, je ne voulus point ôter mes habits. Cependant le froid qui, à la longue, commençoit à me saisir, me contraignit de me dépouiller tout-à-fait et de me replacer sous mon manteat.

Tant de bonheur ne pouvoit être couronné tris- 


\section{$12 \quad \mathrm{O} O \mathrm{YAG}$}

tement. Uis vent d'est vint déchirer en lambenux et cmporter devant nous le reste des nuages; le ciel reprit sa purcté, ct le soleil, qui la veille achevoit de dessćcher nos corps, sembla ne s"élever, ce jour-là, que pour réparer les dégâts de l"orige. Alu reveil, chncun se trouroit un nutre homine; nous étions ressuscités : aussi l'un des prennicis. effees, que nous fit éprouver ce chaigenent incspéré, fat unc fam dévominte. En de parcilles dispositions, quelle ressourec nous offroiene $\operatorname{ces}$ ditmans si rebutés la veille, et quelle avidité avoit tout d'un coup succédé au dégoût universel qu'ils nous avoient d'nbord inspiré.

Tandis que nous étions oceupés à les dépecer pour les fajre cuirc, je m’apperçus, arce surprise, quil me manquoit un de nies gens.

Commc il étoit possible qu’il se füt ćcarté dans Ie voisinage, $j$ "ct1voyai à sa recherche un de ses camarades; minis celui-ci, aprics l'nvoir appellé et cherché en vain, étant revenu sans le trouver, je fus inquict, et avec d'autant plus de raison que personne de nous ne pouvoit dire s"il avoit dispara avant ou après l'orage. Bientôt les inquiétudes se changèrent en alamies; et chacun alors chercha une raison a la dispartution de l'absent : mais les causes qu’ils en domnoicnt étoient toutes également fàcheuses. Selon les uns, il avoit été assassinć par les Boschjesman; sclon d'autres, il avoit péri sous la dent d'une bête féroce, en allant probablement à la découverte de l'eau.

Ces dcux tristes conjectures me proissoient également invraiscmblables. En vain nous avions erré pendant un jour dans ees montagnes; nulle part, aucun de nous n'avoit vu ni Boschjesman, ni même vestiges de Boschjesman. D'ailleurs, quand mène 


\section{E N A F I Q UE.}

il auroit cxisté dans quelques gorges une horde de ces volcurs, quelle apparence qu'ils cussent pu attaquer un homme, sans que nous ne nous en fussions apperçus, sans que Jantje (c'étoit son nom) se fut défcudu et eut appelle à son secours. Ce que je dis ici des Boschjesman, je pouvois le dire d'une bête féroce. Jamais les animaux carnassicrs n'habitent que les cantons abondans en gibicr, et où par: cónséquent, ,ils trouvent unc nourriture facile. Or, dạns celui-ci, nous n'avions vu aucun animal malfaisant; Jantjc, sclon moi, n'avoit pas plus été enlevé par des Poschjostman, que dévoré par une bête féroce. J'avois bien plus à craindre que, lassé de Ia vie pénible et souffrante qu'il menoit depuis quelque tems, il n'en̂t pris le parti de m'abandonner, et ne sc tiut dérobé furtivement la minit; oul, qu’excédé de fatigue et de besoin, inconable de résister darantage à tant de maux, anćanti et mourant, il ne fùt allé, comme les animaux snuvages, rendre les dernicrs soupirs dans queçque licu écarté.

Ces sinistres conjectures me paroissoient plus naturclles que celles de mes compagnons, et cependant clles n’étoicnt pas plus fondées. Pendant qu'ils s'appésantissoient sur les leurs, ct que moi, par prudence, je leur cachois les miennes; ils apperçurent ce Hottentot qui accouroit à nous, ayant les bras tendus et faisant ces démonstrations usitées parmi les Sauvages, quand its one quelque grande nouvclle, soit bonne, soit fâchcusc, ì annoncer.

Arrivé près de nous, il me dit que l'orage de la nuit lui ayant restitué ses forces, il en avoit profité pour essayer de me rendre un service; qu'il s'étoir flatté d'appercevoir, à la faveur des ténèbres, les feux qui pourroient avoir été faits dans 
Ies vallées d'alentour, si par hasard il y en avoit d'allumés; ct que c'étoir dans ce desscin qu'il s'étoit éloigné de moi. "J'ai couru toute la nuit, sans "appercevoir aucun feu, ajouta-t-il; mais au jour, "j'il vu, ì une licue d'ici, sortir d'un krial un "troupcau de moutons, qui s'est répandu dans la " camparync. Ma prenière cnvie a été d'aller m’a"dresser aux conducteurs. Ils ćtoient trois; mais ." conme je ne les connois point, er que j"étois "tout scul, j"ai cru qu'il éroit plus sage de venir "vous avertir, pour savoir ce que vous voulcz "f fairc. "6

Duns l'cxtrémité à laquclle j'étois réduit, rien nc pouvoit m'être aussi favorable que ce que m'annonçoir cer honme. Aussi ses camarades n'entendireitt-ils, qu'avee des transports de joic, le récit de sa clécouverte. Ils lui scrroícne la maii pour le remercier; ils le caressoicut à leur manière, et minvitoient à marcher aussi-tôt vers les pâtres. Moí, de mon côté, je lui témoignai coute ma reconnoissance, ct louai dans tout ceci son intelligence, sa pruidence ce son zèle.

$\mathrm{Ce} n$ nétoi pas assez d’avoir échappé momentanément aux angoisses mortelles de la soif; il falloit cncore échapper, pour ainsi dire, au déscre, en trouvant les moyens d'en sortir; c'est ce que pouvoient seuls nous enscigner les pâtres. Guijés, par Jantje, nows marchûnes avec cmpressement vers cux; mais, malgré notre ardeur commune, mes hottentots trouvoicnt, d'espace en cspace, dans leur route, des morifs de distrnecion : cécoicnt les dépôts c'cau pluviale que, pundant la nuit, l'ornge avoit formés dans certaines cavités des rochers. Ils ne pouvoint se lasser d'admirer ces benux bassins d'un cristal liquide et de la pius pure transparence; 
îls s'empressoient d'y goutter; ct si l'un d'cux découvroit un nouvenu réservoir, il appelloit ses camarades qui s'extasioient de plus belle, et ne manquoient pas d'y goûter encore, et de trouver ses eaux plus abondantes, plus claircs er meilleures : vrais enfans, qui sembloient se russasier pour la soif à venir!

Je sentois au dedans un contentement bien vif, en voyant ces malheurcux Hottentots rire et s'amuscr de nos désastres passés, et satisfaits du présent, ne plus songer anx événemens futurs. J'en étois occupć pour eux, nnis sans leur en faire part. Cependant une pensće m'attachoit plus fortement encore, et l'espoir qu'clle faisoit briller à mes ycux, mettoit le comble au charme que me faisoient éprouver ees sec̀nes, aussi mäves que touchantes. La multiplicité des réservoirs que nous trosvions sur notre route, ma annonçoit que l'orage s’étoit étendu fort loin; et je concluai, avec raison, qu'étant venu de la partic de l'ouest, il avoit dî̀, avant de fondre sur nons, vivifier la pleine où j'avois abandonné mon camp, ct remplir le réscrvoir près duquel j’avois laissé mon vicux Swancpoel avec quatre hommes. Chaque instant me retraçoit leur joic: je les voyois former, à mon égard, les mêmes conjectures consolantes. Je les remerciois tout bas de leur dévoncment généreux.

Enfin, nous arrivàmes au lieu où Jantje avoit vu le troupenu; mais depuis le matin, il s'étoit écarté : nous l'apperçùumes qui passoit au loin sur la croupe d'une collinc. J'allois droit aux pâtres, qui nous apprirent, en effet, qu'ils faisoient partie de la horde de Klaas Baster, ct l'un d'cux s'offirit à me . conduire vers lui.

L'approche d'une troupe comme la mienne, étoit 


\section{I6 $\quad \mathrm{VOYACH}$}

faite pour effiroucher la horde. Je crus, en y arrivant, remarquer quelque mouvement d'inquiétude et de surprise; mais je l'cus bientôt calmée en faisant arrêter to:t mon monde, ę dépurant vers clle Klaas avec le pâtre qui nons avoit accompagné. Je les chargeai de dire de ma part à Baster que je lui apportois une lertre du colonel Gordon, notre ami commul; que j'ćtois, comme lui, un voyageur curieux de visiter le pitys.

A ce non de Gordon, les craintes se dissipirent; bientôt je vis arriver, avec mon ambissadeur, un mulâtre de très'-bonne mine, accompngné d'un autre, mais plus petit et de moindre apparence. Le premicr ćtoit K'las Baster, l'autre se nommoit Piet. Ils étoicnt frères. 'Tous deux m’aborderent avec franchise, et me prirent la main à la hollandoise. Ils en avoient les façons, et parloient trìsbien cette langue. Je leur remis la lettre du colonel; mais ici leur scicnce fut en défaut : ni l'un ni l'autre ne savoit lire. La lettre me fut aussitôt rendue que reçue.

Gordon leur écrivoit de m"obliger ei tout ce qui. dépendroit d’enx; mais n'ayant pa prévoir la détresse oì je me trouverois, il n'ivoit pu spécific: la sorte de service dont $j$ 'aurois besoin. Il me fut très-aisć de suppléer à ce qu'clle offroit d'insignifiant. Les yeux fixés sur le papier, je leur fis la longutue énumćmtion de mes besoins, et leur demandi, au nom de G)rdon, tout ce que celui-ci auroit pu récllenent réclamer à tout hasard.

Aux motifs d'muérêt, quo devoic produire cette recommandtion pissante, jessizyil d'en ajouter d'aitires encore dans la conversation. En avançant vers le kanl, je riconsi aux deux frices tout ce que nous avions éproutvé do lésastres, depuis notro 
départ de la Rivière-des-Elćphans; le désespoir où, jusqu'mu moment de l'orage, nous avoit réduit le manque d'eau; enfin, ecte triste suite d'afligeantes aventures qui m'avoient foreé d'abandonuer mes trois ehariots, et cle laissèr mon monde et mes équimages épars sur la routc. Je leur montrai benteoup d'agitation, en leur racontant tous les obstacles qui naissoient sous mes pas; et j'étois dans le fond trèsaffeeté. Un seerct pressentiment m'annonęoit que ces obstaeles se multiplieroient un jour à tel point qu'il ne me seroit plus possible de les franehir.

Les deux frères paroissoient s'intéresser à mes malheurs. Ils en avoient éeouté le réeit avee attention et sans mintinterrompre; mais arrivés près du kranl, l'ainć rompit tout-à-eoup le silcnee; et frappant fortement la terre avee son pied, consolezvous, me dit-il, avant peu de jours, vos trois ehariots seront iei avec tout votre mplnde.

Quelqu'agrénhle que me fut ectre nouvelle, elle ne m'en parut pas moins étonnante. Il me sembloit même difficile que mes chariots pussent arriver aux montagnes où nous étions; ear, quoiqu'elles fussent inférieures en hauteur au platean sur lequel nous avions passé la nuit; elles étoient eependant eneore très-ćlevées au-dessus de la pl:ine. Au reste, puisque mon hôte me garmutissuit l'exéeution du projet, je devois eroire à sa possibilité. Entrés dans sa hutte, Klatas Baster m'invita ì me reposer. Il me renouvella plus affirmativement encore ses promesses; et ajouta, qu'en ee moment, ì la vérité, il ne pouvoit pas commencer à les effectuer, paree que ses troupeaux étoient à la piture; mais qu'nussi-tôt qu'ils seroient de retour, son frère partiroit avee tous leurs beeufs et le nombre d'hommes nécessaires, pour aller utu secours de SwanteTome 1 II. 
poel et de ses quatre eompagnons; qu'on lcur porteroit des vivires, ct que bientôt je les verrois auprès de moi.

Cette entreprisc alloit porter la joic et l'allégresse dans l'ane de tous mes eompagnons d'infortune. Comme je supposois que, d'après mes premicrs ordres, une partie d'entre eux devoicnt être arrivés à la fontaine où je leur arois dit de se rendie, j'envoyai trois des miens leur en faire part. De la fontaine, ceux-ci étoient ehargés de reprendre la route que nous avions pareourue entre les deux ehnines de montagnes, de reconnoître l'Oliphants-Kop, et de-lin, suivunt toujours la trnee de mes voitures, d'aller annoncer à Swanepoel ct à sa troupe qu'il alloit leur arriver du sceours.

Dans l'après - dìner, Klaas Baster employa ses gens et ceux des miens, qui me restoient, à eonstruirc unc hutte particulic̀re pour mon usage. Vers le soir, son frère partit pour exécuter le projet convenu. Je lui donnai deux fusilicts, destinés à l'escorter et à lui servir' de guide; et d'ailleurs, en passant près de la fontaine, il devoit encore emmener arec lui quelques-uns de mes gens; car ayant à eharger sur les deux voitures, ceux des eftets de la dernic̀re que j’avois abandonnés, il lui falloit bcaucoup de monde.

le tems qu'alloit cxigger ee voyage, me foręoit indispensablement à passer quclques jours dans le kiaal; peut-être mềne, étois-je menacé d'y faire un sćjour asse\% long, puisque je nc pouvois me dispenser de donner à ma earavane, à mes ehevaux ct ì mes boufís mênes, s'il m'en restoit encorc quclques-uns en vic, le repos nécessairc pour se remettre de leurs fatigues. Dans cette inaetion forcéc, il ne me restoit d'autre parti et d'autre res- 



\section{Timn II.}

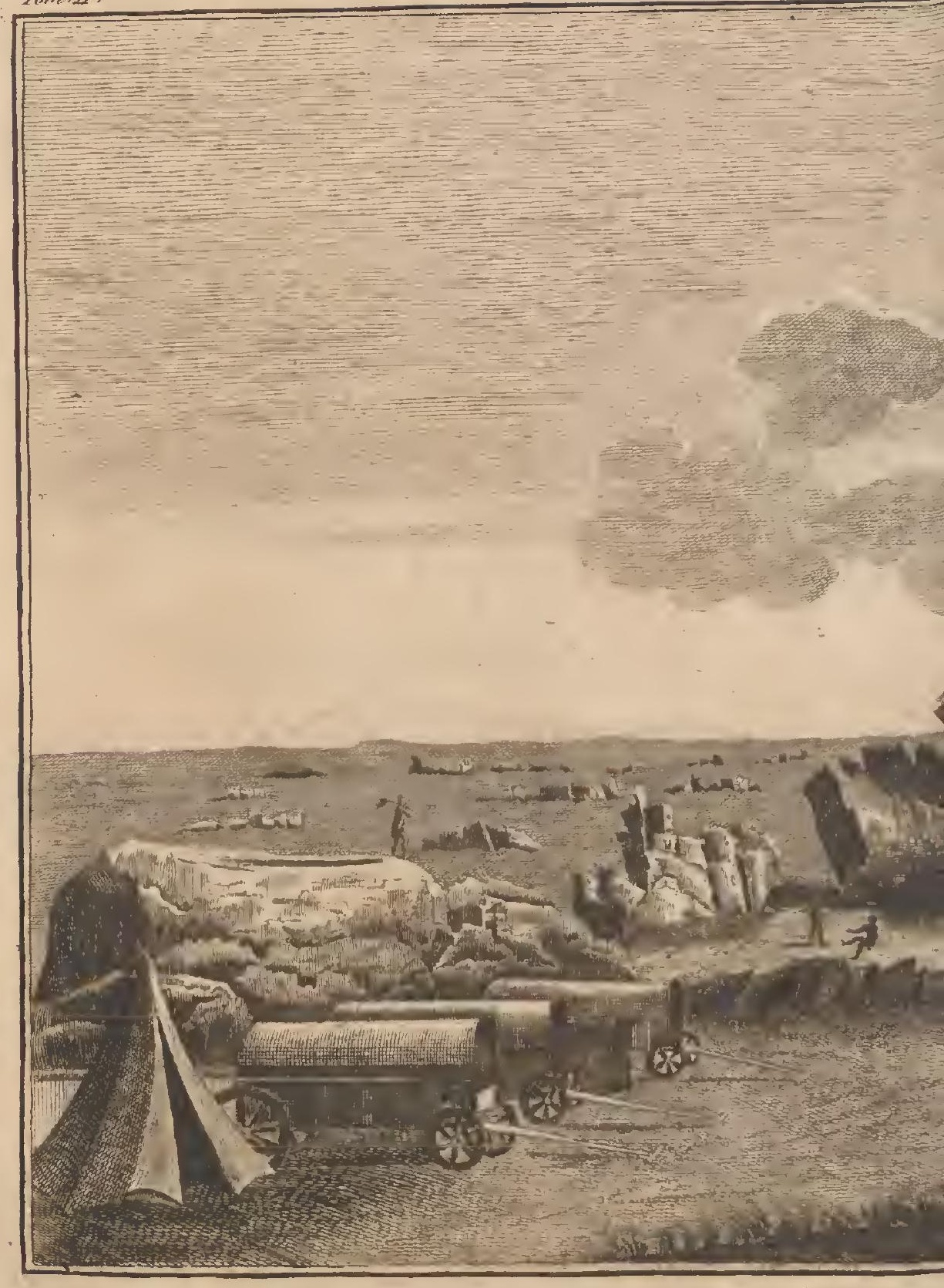

CAMPEMENT 


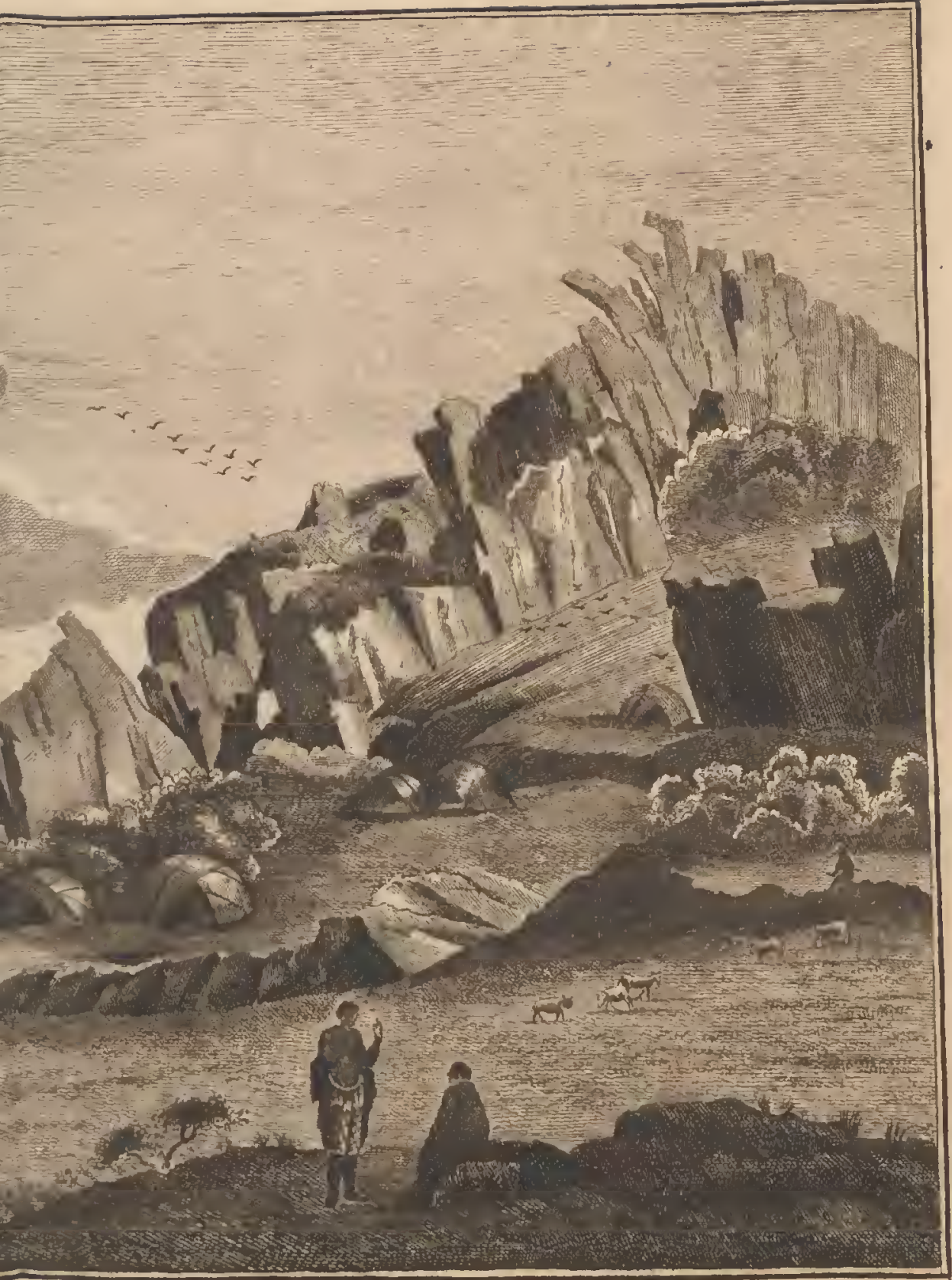

RI)EDE KTAAS BASTER. 



\section{INAFRIQUE.}

source que la chasse. Mes journécs du iendemain et du surlendemain furent done employées à allcr, avce mon hôte ct mon guile, chasser dans les montagnes. Mais le soir du second jour j'ćprotvai, je l'avouc, un mouvement de surprise bicn agréable, lorsqu'approchant du Kiral, je vis flotter mon pavillon près de ta hutic qu'on mavoit construite. Mon chariot et mes gecns y étoient arrivés pendant le jour. A ecte vue, je jettai un cri de joic involontaire; et l'cspérance, depuis si long-tcms bannie de mon ame, $y$ rentra enfin pour la premic̀re fois. Je trouvai même treize boeufs et mes doux chevaux en vic. C"étoient les sculs animaux qui cussent, avec mes chèvres, échappés à la mort.

Du reste, la chasse ne me prometioit, dans ces montagnes, ni de grands plaisirs, ni des objects de collection bien précieux. Le gibicr y étoit infiniment rare; ct je n'y vis guère qu'ume espèce particulièrc de gazelle, nommée par les Hottentnts Krainsi, et par les Hollandois Khip-Springers (snuteurs de rochers), dont aucun suteur n'a encore, jusqu'à préscnt, donné une description parfaitc.

Le kainsi n'a reçu, des Hollandois sa dénomination de sauteur de rochers (klip-springer) que pour la légèreté avec laquelle il saute de roche en roche; et effcetivement, de toutes les espèces de gazclles, celle-ci cst la plus agile. Fille a la grosscur du chevrcuil d'un an, et le pelage d'un gris jatunîtric; mais son poil a ccla de particulier, qu'au licu d'être rond, souple et solide, comme celui cic th plupart des autres quadrupèdes, il est plat, rude, et si peu adhérent à la pcau, que le moincire froissement lc fait tombcr. Aussi rien n'est-il plus aisé que d'épiler cet animal : mort ou vif, la facilité cst la même; il ne faut pour cela, que le frottcr, ou

B 2 


\section{EO VO Y.A G E}

même toucher seulement sa peau. Plusienrs fois il m'est arrivé de chereher à conserver la fourrure de ceux que j'avois tués, et jamais je n'ai pu en venir à bout. Quelques soins, quelques précnutions que je prisse en les écorehant, toujout's j'ai vu tomber en trìs-grande partic lear fourrure, et par consćquent la peati ćoit peu propre à être conservée.

Une autre partieularité de ce poil si singulier, c'est d'être fragile, en sorte que sì vous en prenez entre les doigts un petit faisecau, ct qu'avec les doigts de l'autre main vous venez à le tordre, vous lc brisez comme si c'ćtoit les barbes d unc plume. Au reste, cette dcruičre proprićté n'ipparticnt pas exelusivcincnt au poil du hainsi; je l'ai reconnuc chez quelques especes de quadrupedes qui, conme lui, vivent dans les rochers.

La gazclle dont je purle, differe encore des autres espèces par la forme du sabot. Le siet, au lieu d'être pointu ainsi que le letrl, est arrondi par le bout; ct comme d'ailleurs sa coutume, quand elle saute ou quand elle marche, est de pineer de la pointe de la cortue, sans appuyer aucunement dit talon, elle laisse une empreinte qui la lend reconnoissable entre tous les antilopes d' $\Lambda$ frique.

Sa chair cst exquise ct fort recherchéc, particulièrement des chasseurs. Les panthères et les léoparủs en sont ćgalement très-friands; et jai mène entendu dire à dos Hottentots, que ees animax se réunissent plusicurs ensemble pour chasser an kainsi, et que quand il s'est réfugié sur quelque cone d'une roche bicn esearpée, l'un d'eux va au bas du rocher atcendre sa proic, tandis que les autres s'avancent pour l'attaquer et le forecr à se précipiter du haut de sa retraite. Jc ne crois point à ces 
prétendues associations dans les animax de la famille clu tigre. Tous vivent isolés, et chassent pour leur propre compte. Jc n'ai jamais vu que l'hicune, le jnckal et le elien sauvage se réunir avec ceux de lcur espéce, marcher cr troupes et combiner des projets de tactique, soit pour éventer une proic, soit pour la poursuive et la forecr.

C'est une chasse fort divertissante que celle du kainsi. Il est vrai qu'on ne peut guire le forcer avec des chiens, er que bicntôt, par son inconcevable agilité, il lcur échappe et se met hors de leur attcinte sur quelque pointe de rocher bien isoléc, où il reste des heures cntières, à l'bbri de toute poursuite, et suspendu, en quelque sorte, au-dessus de l'abîme. Misis dans cettc position, il scmble se placer des mieux pour la balle ou la fleche des chasseurs; et sils n'ont pas toujours la facilité de pouvoir le ramasser quand ils l'ont tué, ils ont au moins, presque toujours, celle de le tirer it leur volonté.

Mainte fois j’ai été témoin de ce que peut l'execsive légèreté de cet minal; mais un jour, entre autres, j’on ai vu un exemple qui m’a ćconné. J'en chassois un, ct, par la nature du lieu, il se trouva tout-ì-coup tellenent pressé par nes chiens, qu'il alloit être forcé et saisi. Nul moyen d'échapper. Devant lui étoit un inmense rocher escarpé pelpendicularement, et qui l'urrêtoit tout court. Mais sur ec mur que je croyois un glacis vertical, se trouvoit une petite rugosité, sailimte tout au plus de deux pouces, et que le krinsi avoit apperçuc. Il y saute, et à ma grande surprise, il s'y ticne cramponné. Je crus au moins qu'il alloit en être bientôt précipité ; et mes chicns cux-mêmes s'y attendoicnt si bien, qu'ils comrurent au bas de la 
roche, pour le recevoir et le saisir quand il tomberoic. Je cherchois à le harceler, afin de hâter sa chute; je voulois lui faire perdre l'ćquilibre, et dans ce desscin je lui jettois de petites pierres. Toutà-coup, comme, s'il cut deviné mon projet, il ramasse toutes ses forces, s’ćlance de mon côté, passe par-dessus ma tête, puis, tombant à quelques' pas de moi, m'échappe comme un éclair. Malgré la rapidité de sa fuite, il m’cut été facile cncore de le tirer; mais son saut m'avoit tellement surpris et amusé que je lui fis grace de la vie. Il n'y eut d'attrapé que mes chicns, qui, tout confus de le voir échapper, ne revinrent à moi qu'avec une espèce de lionte.

Avec le kainsi, je ne vis, dans toute la chaine des montagnes, d"autre gibicr que des dassen ou damans. Nćanmoins la race en cst peu nombreuse; parce que les aigles et les autres oiscaux de proic, qui habitent ces montagnes, les empichent de se multiplier.

C'est nin spectacle curieux que colui do la chasse de ces carnivores. Perchés vers la cince et sur les roches les plus escarpées de la chaine, ils guettent au loin le gibier; et leur vue perçante peut le distinguer à des distances énormes. Apperçoivent-ils un de ces damans parmi les rochers amoneclés; ils fondent sur lui avec l'impétuosité de la toudre, l'enlèvent avant qu'il ait eu le tems de gngner son trou, et l'emportant dans leur aire, vont le dévorer ou le liver an bec et aux scres de leur famille affancic.

Pour moi, c'étoir moins à ees petits quadrupèdes, qu'aux vatours ct aux oiscaux de proic, que fen voulois; touiours occupe de ma collection, je me thatoois de trouyer la tine henreusc occasion 


\section{E N A F R Q U E. 23}

d'y ajouter quelques objets intéressans ou neufs; et mon cspérance n'étoit point vaine. Mais comment arriver t̀ portéc de ces oisculux sans ctre apperçu par eux; et quelle possibilité de les attcindre, s'ils m'appercevoient? Je n'arois done qu'un seul parci à prendre, celui de me tenir blotti dans des broussailles, près d'un endroit où il y cût beaucoup de damans; et là, d'atecendre paticmment que quelqu'un d'eux vînt fondre sur clles. La ruse me réussit, car c'est à clle que je ciois plusicurs oiscaux de proic nouveaux et rares, done je donnerai les descriptions dans mon omithologic.

J'ai tué aussi, dans le même canton, un vautour d'un blanc isabelle. Les colons hollandois nomment cet oiscau Witte-hray (corbeau blanc). Il n'est rien moins qu'un corbenu; car c'est positivement un vautour. Les Namaquois lui ont donné le nom! Ouri-Gourap; un autre oiscau très-commun aussi sur ces montagnes, et dont je parlerai de même par la suite, tient par ses carictères du vautour et du corbenu, et forme entie les deux espèces un genre intermédiaire. Son pluntuge est noir ; mais il porte une cravatte blanche sur li nuque, ce qui, dans les colonies, lui a fiit donner le nom de RingHuls-Kray (corbenu à collier). Onl'y trouvenćanmoins assez rarement; mais il est fort abondant duns les rochers où j'écois. Je l'ai nommé le Corbivan.

Quoique toutes ces différentes chasses aient été pour moi l'occasion de plusicurs avchtures, dont quelques-tunes ne scroient peut-être pas sans intérêt pour mes lecteurs, je ne me permets pourtant de parler ici que de celles qui peuvent contribuer en quelque chose aux progrès de l'histoire naturelle; et c'est à ce titre que je vais raconter les détails suivans. 


\section{4}

V O Y A G E

Un soir que j'ćtois revenu d'assez bomne heure au kraal, lun des gardiens des troupenux de Klias Baster vint, avec un grand empressement, hous annoncer qu'il venoit de voir deux ćléphans s'arrêter dans une bruyc̀re du voisinage. Il y aroit peu de nouvelles qui pussent m'intéresser antant que eelleci. Elle me rappelloit tout le plasisir qu'à mon premier voyage, m'avoit procuré la chasse de ces animaux, dans le pays d'Autcniquoi; cr ceux-ci paroissant amnoncer qu'ils passęroient la nuit dnns le lien où ils se trouvoient, je pourois me flatter de les joindire avant qu'ils le quittassent. Il fut donc résolu que. nous irions les attaquer au point du jour; ct en conséquence, je fis fondre aussi-tôt du plomb pour en couler les balles qui nous étoient nécessaires. Mais Klans Baster n'avoit p'us son fusil sur le coup; il voulut l'y remettre; ct selon le sat usage da pays, il employa, pour en venir à bout, un tems considérable à tirer au blane.

Ainsi fut brûlé inutilement, plus d'une livre de ma poudre; ct cependant, c'ćroit bicn moins cette perte qui un'affectoit, que l'imprudenee ce l'opiniàtreté du tireur. Certainemene il ne pouvoit douter que le bruit de ectte longue pétarade, grossi et répété par les éehos multipliés des montignes, ne dut effaroucher les éléphans, et les furcer à se retirer plus loin. Or, c'est ce qui arriva. Le lendemain, eondnits par le pâtre, et accompagnés de plusicurs de mes Hottentots, nous nous avanèmes, avec toutes les précautions possibles, vers la bruyíre; mais nos précantions furent en pure perte : les deux aniniaux avoient quitté le lieu, et nous ne vìmes đ'eux que des fumées et des traces. Nénnmoins, je ne perdis pas l'cspoir de les rejoindre.

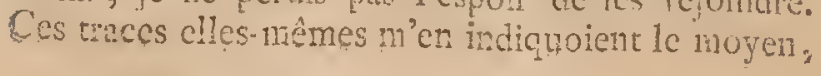




\section{EN $\Lambda$ F R I Q U E.}

si je voulois me résoudire à le suivre; et c'est le parti que je pris.

Nous marchâmes long-tems sur un terrain abominable. Nous allions de saccades en saceades à travers les éboulemens et les quirtiers de rochers détachés des montagnes. Plus paisible, et les sens plus rassis, j'eusse dévoré des yeux ce spectacle d'un effet horrible et bizarac. C'est ici que la nature épuiséc n'a plus de force pour se reproduite! Que de siècles ont, tour-à-tour, vicilli, déraciné, rongé ces barrières formidables! Ansi chaque portion du globe, l'une aprís l'autre, est dévoréc par le tems, ou plutôt le globe entier s'use chaque jour et se fond au sein de l'espace.

Après une marche très-fatigunte, après bien des détours et des circonvolutions, inous revimes enfin, derrière une petite colline, les deux éléphans que nous cherchions; et pour comble de bonheur, le licu nous favorisa tellement, que nous pûmes nous approcher d'cux jusqu’à vingt pas, sans en être apperçus. Klnas Baster et moi, nous ajur.tâmes chacun le nôtre. Le mien tomba sur le coup : éćtoit une fencile: le sien étoit un mâle; il poussa un cri cfroyable qui nous gliça tous d'épouvante, et alla tomber id deux conts pas plus loin. Mes Hottentots lc suivirent. Mais à peine l'eurent-ils ru à terre, que je les entendis erier, à plusicurs reprises et avec tous les signes de la joie, poes-hop, poes-kop. Etonné de ces cris, dont je n'entendois point la. signifeation, j'en demandai l'cxplication au Baster. Il me répondit, qu'on appelloit poes-hop ( tête camuse), unc race particulière d'éléphans qui ne porte point de défenses; que ces éléphans étoient infiniment rares, et que delà venoient les cris de joic ct de surprise qu'avoicnt poussés mes gens; qu'cn- 


\section{$=6 \quad$ V O Y A G E}

fin, les poes-kop, quoique priyés de l'arme qui est propre à tous les autres, étoicne beaucoup plus redoutés que ceux-ci, parce qu'ils étoient plus méchans.

Lorsque jeus bien examinć ces animaux, je me convainquis aisément qu'ils n'étoicnt pas d'une espèce différente des autres éléphans, comme le prétendoit Klans Baster; mais bien une simple varićté ou jeu de la nature. Et depuis, j'ai appris par de grands chasseurs, que, quoique les poeskop soient très-rares, on ne laissoit pas de trouver, de tems à autre, de ces animaux, toujours privés de défentses, à quclque vicillesse qu'ils soient parvenus. CcIni que je venois d'rbatere n'en offroit pas la moindre apparence. 11 n'en auroit certainement jamais eu; car $j$ ’ai fait observer ailleurs, que les défenses paroissent déja aux élćphans dans leur plus grande jemesse. J'ai dans mon cabinet deux de ces défenses, qui noont pas plus de deux pouces et demie de longueur en tout ; et que j’ai arrachées à méléphant qui tetoit encore : il n'étoit peut-ĉtre pas î̉ particularité n'en est une que pour le climat de l'Afrique; mais elle cesse de l'être pour d'nutres contrées; car, autant il est rare, en effec, de rencontrer au Cap-de-Bonme-Espérance des éléphans sans défenses, autant il est rare d'en trouver d'armés à l'île de Ccylan. Ce fait, m’a été attesté par des personnes qui ont passé trente ans dans cette île et, qui y ont assisté constamment ì toutes les chasscs d'éléphans qui se font à ecrtaines époques. Sur cent de ces animax qu'on y prend, c'est un phénomène d'eli rencontrer deux qui soicnt armés, et cncore leurs déferises ne pèsent clles pas plus de cuinze à vinge livres; quant aux femelics, jamais 


\section{E N A F R I Q U E.}

celles du pays dont je parle n'en ont offert sculement la 'trace; tandis qu'au Cap-de-bonne-Espérance elles en ont toutes de plus ou moins fortes, et même les vieux mâles y portent des armes formidables; car il n'cst pas rare d'y tucr de ces dernicrs dont les défenses soient chacune du poids de cent livres; on cn a même eu dans les magasins de la Compa-. gnic qui pésoient jusqqu’à cent soixante livres; c'est ce que mont assuré plusieurs personnes dignes de foi, qui étoicnt chargées de ecete partic au Cap.

Les ćléphans de Ceylan scroient-ils done d'une especee différente de ceux d'Afrique? C'cst ce que je ne puis croire; il est cependant prouvé maintenant que le thinoceros de l'Inde n'est pas de la même espèce que celui du Cap-dc-bonne-Espérance; puisqu'ils ont cntre cux des caractères distintifs, qui les sćparent totalement l'un de l'autre; c'cst ce qu'il faudroit démontrer à l'ćgard des éléphans du Cap é de Ceylun. Les colons et les Hottentots qui avoient ell occasion de rencontrer ou de tuer des ćlćphatts poes-kop, m'ont assur'é qu'ils ścoicnt tous máles. Celui que je venois de tucr avoir dix pieds quatre pouces de hauteur. A juger de son âgre par scs molaires, qui n'ćtoient presque pas usées, il devoit être très-jetine encore. La femelle n'avoir en hauteur qu'un pied de inoins : cétoit la plus grande que j'cusse encore vuc; ses défenses pesoiene vingt livres chacune; cependant dans la suite de ce voy'age, j’ai rencontré des femelles plus fortes que cellc-ci, ct dont les défenses pesoient un ticrs de plus.

Cette taille extraordinaire dans des animaux qui habitcnt unc contrée si stćrile, qui nc prociuti que déc's eaux saumâtres, m'avor teancoup étonné. J'observai aussi que les bestiaux du Baster, étoient d'une 
force et d'une grandcur remarquable : ce double fair me conduisir à une réflexion bien simple. Parcourant, ł mon précédent voynge, lc pays des Caffres et la terre d'Auteniquoi, je navois vu, de tontes parts, que des sites enchanteurs, paturiges toujours verdoyans, forêts magnifiques, rivières et ruisscaux abondans; nulle contréc n’éroit, en apparence, plus lavorable aux herbivores, tant domestiques que sauvages; er némmioins, ils sont, non-seulcment retardés dans leur croissance, mais ils ne parvicunent quà une grandeur et une grosscur médiocre. Au contraire, dans le pays ou je suis actucllement, l'espèce des uns et des autres étoit superbe; et l'eau, mème saumatre, comme on ne l'a que trop vt, y est fort rare, et son sable aride ne nourrit que des plantes chétives, une espice de gramen, nommé dans ce pays herbe au Boschjesman. J'étois done porté naturellenent à penser, que dans les cantons trop humides la sève est trop atueuse et manque de substance nutritive; peuiétre aussi la terre a-t-clle des veines qui produisent des sues différ"cns, plas ou moins nourriciers. Jusqu'ici j’avois été fondé à croirc qu'un temain sablonneux, quel quil soit (cclui par exemple dies Namaquois), devoit produite des sels pernicieux aux plantes qui y croissent, et qui nuisent par consćquent aux bestiax; ct qu'au contrire, lo chamant pays d'Auteniquoi et la Caffreric, dont les terres sont bonnes et bien arrosées, devoient foumir en abondance tous les sues favoribles à la vic. je m'en tiens, sur cout ceci, au fair, plus certain que des conjectures, et laisse, à qui voudra s'cn occuper, le soin de rechercher d'autres causes. J'obscrverai seule nt que, dans le cours de mes voynges, j’ai gén ialoment remarqú que les 
terres trop artosées, produisoient des herbes acides, que refusent les bestiaux qui n'y sont pas habitués. Lus colons nomment ces teries Sure-Vlakte (plaine aigre.

Avant d’abandonner nos deux éléphans, je résolus de faire armcher les défenses de la femclle. Mes Hottentots me conjuroient aussi d"enlever les filets des deux animaux. Cette double opiration employa le reste du jour, et nous força de passer la nuit au milicu même de certe immense boucherie. Les picds, sclon la coutume, les picds, morcenux friands et rares, furent cuits dans la braise. Chacun mit la plus grande adeur à servir cette cuisine que nous n’avions depuis long-tcms fairéc. Mets distingués pour le chef, filets plus communs pour de plus affamés, benucoup de joic et d'appétit de la part de tous les conviés, des eaux abondantes et pures, rien he manquoit à ce souper fameux, que la certitude d"en firire tous les jours un parcil.

C'est ainsi cu'cn amusant mes loisirs, je partageois mes jontnées cntre le plaisir de la chasse et celui de prendre des deux frères nomades les informations les plus préciscs sur le pnys que je me proposois de parconrir; mais la plus agroćable pourmoi, fut, sans contredit, eclle où je vis tous mes effets arrivés au kraal de Baster et mes gens réunis tous chfin autour de moi. Chacun d'cux s'cmpressoit de me rémoigner sa joic; chacun, à l'envi des autres, me racontoit tout ee que mes dangers lui avoient donné d'inquićtude; ce il fallut écouter ce débordement de protestations, par lesquelles tous cherchoient à enchérir sur leurs camarades. Ce fut avec bien du plaisir que j'cmbrassai Swancpoel. Lce bon vicillard aroit désespéré de me revoir jamais; et néanmoins il étoir resté fidellement à son poste. 
Depuis mon départ, lui ct sa troupe avoient vécu, en partic, d'une gazelle-pazan, qui, étant venue boire à lcur réscrvoir, y avoit été tućc par lui. Hcurcuscment pour cux, l'orage que nous avions eprouvé sur la montagne, s'étoit fait sentir de leur côté; ct, en remplissant leur citcrne, il leur avoir assuré, pour quclque tems, une provision d'cau. Ils avoicut même rccouvréc un de mes bœufs que je venois d'abandomer, mourant sur la routc. Désaltéré er ranimé par la pluie, l'animal s'ćcoit rapproché d'cux; et guidé par les feux qu'ils tenoient allumés, il les avoit rejoint. Swancpoel s'écoit flatté de voir également revenir auprès de lui les trois chiens qui m'avoient quitté, mais ils ne reparurent point; et, sans doute, ils seront restés dans le désert, où ils seront devenus sauvages. Au reste, ce qui lui avoit donné le plus de peine dans son petit camp, c'étoit les attaques fréquentes des lions et des hiennes. Les cadavres de tous ces bouf's que je m'étois vu forcé d'abandonner sur ma route, avoicnt, par leurs ćmanntions, attiré une grande quantité de ces animax féroces; et leur nombre, ainsi que lcur fureur, devenoient trìs-inquićtant pour lin petite troupe.

Le rasscmblement de ma caravane exigea de moi, des soins nouveaux, une surveillance assidue, et, par conséquent, une vic plus sédentaire. Il est vrai que la chaine des montagnes ayant peu d'animaux, quelques jours m'avoicnt suffi pour me procurer ccux qua clle pouvoit ajouter à mi collection. Je ne chassai donc plus que pour varier mes occupations ct éviter l'cnnui du désœurrement. Bientôt mĉme, par un événement dont je ne me doutois guère, je fus obligé d'y renoncer entièrement.

Un jour, qu'arec mon fusil, jc parcourois les 


\section{E N A F R I U E. 3 I}

vallées, je vis, à quelque distance, unc Mulatresse qui, montée sur un bouti qu'elle menoit fort lestcment, paroissoit se rendre au kraal. Elle étoit habillée à la hottentote, et conduite par un homme que je recomus pour être de la horde cic Klaus Baster. Dès que le guide m'npperçue, il me montra de la main à la voyageuse. Celle-ci, mettant aussitôt sa monture an trot, vint droit à moi; clle me salua en hollandois, et après avoir mis pied à terre, me pria de l'accompagner au kranl. C'ćtoit une sceur de Klans Baster, fille encore, et vivant dans une autre horde éloignéc de la sienne. Dès le jour même où j'étois venu chez lui, il avoit cnvoyé un exprès à sa sueur, pour lui fairc part de mon arrivéc; et cclle-ci, qui étoit curicuse de me connốtre, accouroit avec empressement pour me voir. Elle avoit une très-jolic figurc. $\Lambda$ la vérité, ec n’étoit ni la taille svelte, ni la candeur nuïve de Narina; un peu d'embonpoint nuisoit à l'agilité de ses mouvemens. Mais elle avoit cn coquetteric et en grâces, tout ce aue donne le souvenir d'unc origine distinguéc; car celle-ci n'étoit point née satuvage, et sc prétendoit, sims doute, d'une nature infiniment supérieure.

Son père étoit un Européen, qui dans sa jeunesse avoit, passć au Cap, et qui, successivement serviteur de la Compagnie, puis valet de paysan, étoit venu à bout, par son travail et son industric, de se furre ì vingt-cinq ou trente lieues plus loin, sur les bords du Groene-Rivier (rivicre verte), une habitation assez considérable. D'abord, il avoit vécu avec une hotrentote; et c'est de cette association qu'étoient nés Klaas Baster, Pict Baster et leur sceur. Mais devenu vain, à nesure qu'il étoit devenu riche, il aroit cu honte de sa femme, et s'é- 


\section{$3^{2} \quad$ VOY A GE}

toit sćparé d'clle pour épouser une blanche. Celleci lui avoit donnć plusicurs enfans, dont deux garçons, qui, âgés l'un de vingt ans, I'autre de vingtdeux, vivoicnt avec leur père dains son habitation, et qui, ainsi que leur mère, devenus ses ennemis, lui faisoicnt passer une vie malheurcusc.

Non-seulement, ces jeunes gens avoient rougi de se voir des fières Mulatres; mais ils avoicnt tant perscicutés, tant vexés, que les malheurcux avoient été obligés de fuir. Lal souur s'étoit retirée chez les Hottentots de la horde de sa mère. Les deux Buster, attachés l'un à l'autre par l'amitié, ne voulant point se séparer, étoient venus former ensemble un ćtablissement plus au sud, dans la plaine. Déja ils avoient défriché successivement deux excollens terrains; ct successivement leurs parens les on avoicne chassés à force ouverte, et en tuant une partic de lcurs bestiaux; plusieur's fois même, ilš avoient cu la barbarie de frupper Klans; car c'étoit principalement à lui qu'ils en vouloient. Pour sc soustraire à leur rage, il étoit venu s'ćtablir, avec son frère, dans les hautes montagnes, où il se flattoit d'être plus aisćment caché. Tous deux mariés à des Hottentotes, ils formoient, avec leur famille er les gens attachés à cux, qui tous étoient leurs parens, 11ne horde composéc de quinze à dix-huit huttes. Néanmoins Klans vivoit dans une inquiétude continuelle; craignant sans cesse d'être découvert et surpris par ses crucls fircres; et tel ćtoit la cause des alarmes qu'il avoit montrées quand jétois venu vers lai arec ma troupe.

Ccux-ci habitoient le Namero. Ainsi Klans étoit, en quelque sorte, ̀̀ la discrétion de ses ennemis; et, à dire le vrai, j'étois écomé de le voir rester dans leur voisinage, vu qu'il s'attendoit à périr d'tu1 


\section{E N A F R I U E. 33}

sonp de fusil, ct que déĭ mênc il avoit été manqué plusicurs fois par cux à ce qu'il me dit. Son malhcur m’intéressoit benucoup. J'cus désiré, c1n reconnoissnnce des services qu'il me rendoit, de le reconcilier avec sa famille; et comme j'allois traverser les cancons qu'ellc habitoit, jc formai lc projet de ce raccomnodement. J.e succès me paroissoit si facilc, que je n'hćsitai pas d"offrir ma médiation à l'infortuné Baster", et que jc m'avançri même, jusqu'ì oser lui répondre d'un traicé de paix, s'il vouloit maccompagncr. Il parut sensible au motif qui aroit dicté mes ofires; mais il déscspéroit d'adoucir la haine de scs implacables parcns, ct me demanda, pour toutc grâce, si j’avois occasion de les'voir à mon passage, de ne point leur parler de luí; ct de lcur cacher même que je l'arois vu. Quant à la sceur, autant par le genre de vie qu'clle avoit adopté, que par la coumure de son humeur, elle me paroissoit tris-heureuse. Scs journécs, tant que jc fus aupres d"ellc, sc dissipoicnt en folics. Ellic étoit sur-tout fort curieuse. Mes chariots ct tous mes équipages l'occupoicnt sans cesse; sans cesse ellc les visitoit; je n'avois ancun meuble, aucun cffet dont elle ne ioulut connoitre le nom ct l'usage. Il fallut, pour lui plaire, ouvrir et vider toutes mes caisscs; cllos ne m’eût pas fait grace du moindic paquet ni de la pius pecite boite. Enfin, clle ne tarissoit pas cic questions sur mon compte, ct souvcnt clle m"en faisoit de si naives ct dc si franches qu'clle miruroit presque rendu curieux à mon cour. Ma barbe, quoiqu'cllc ne fut pas encore trèsgrandc, l'offusquoit singulicrement, elle y portoit la main sans façon, maggaçoir dc toutcs les manières, et me trouvoit, disoit-clle, plus beau que lc plus benu Hottentot. Pour clic, je la trouvois très-bien

Tome II. 


\section{V O Y A G E}

pour le pays où nons étions, et réellement cllc étoit la Vénus de la contréc: ses habillemens un peu rares laissoient à découvert une grande partic de scs charmes; mais elle n'apportoit pas plus d'indécence à les montrer, qu'elie n'eût mis de pudem à les cacher. Un homme moins tempérant n'auroit cu ni favcur à demander, ni refus à redouter.

Cependant je trouvois étrange, qu'ćtant néc d'un blanc, ponvant vivre parmi les blancs et se faire unc habitution conme son père, clle ent renoncée à un pareil avantage. Je lui en fis l'objection, et je dem:mai quel morif lui avoit fait preférer la vic errante des llottentots, et adopter une caste moins considćrée que celle où cllc étoit néc? Sa réponse m'śtonna. J'y trouvai de la raison, et une sorte de philosophic naturelle, qu'assurément je ne m'attendois pas à tiouver dans me tête anssi ćtourdic er aussi folle.

"Il est vrai que je suis fille d"un blanc, me ditelle; mais j'ai pour mìre une Hottentote. Allice ainsi par ma naissance à deux races différentes, j'avois à choisir, cntre les deux, celle avec qui je vivrois. Vous savcz quel profond mépris vos blancs one pour les noirs, et mème pour les sangmêlés comme noi. M'écablir parmî cux, c’étoit m'cxposer ì des opprohres et des affronts journaliers, ou me voir réduite à vivre seule, isolće et malhcureuse; tandis que chez mes Hottentots, j'étois surre de trouver de l'accueil, de l'anitié, des égards. Mon ami, je vous le demande, à mal "place qu'cussic\%-vous fait? Moi, je n'ai pas hésicé entre des anis certains et des ennenis assurés. J'ai préféré le bonheur à l'orgueil. Chez vos colons j'cusse ćtć abrcuvée d'humiliations, chez les gens de la coulcur de ma mère je suis heu- 


\section{E N A F R I Q U E. 35}

Ainsi raisonnoit ma belle Mulâtresse; et si par fois ses folies m'impaticntoient, souvent aussi clle m'étonnoit par son bon sens.

Un matin qu'elle ćtoit venue roder autour de mes chariots et de mes tentes, elle m'appella, toutà-coup, à grands cris; puis me metant cn min un ceuf tout chaud : tenez, me dit-elle, voici qui vous appartient; mais que ceci vous apprenne à ctre moins négligent, et qu’il ne faille plus désormais que je vicmne auprès de vous pour vous donner des leçons de vigilanec.

L'ceuf avoit été trouvé dans des broussailles, et il venoit d'être pondu par la poulette qu'en partant pour mon second voyage, j'avois dounce ì mon coq. A la vérité, ni moi, ni mes gens nous ne nous doutions pas qu'après une route où elle avoit eu tant à souffirir de la fatigne et de la disctte, quelques jours de repos suftirnient pour rétablir ses forces, et qu'elle me donneroit sitôt des cufs. Celuici n'étoir sullement pas le promicr. Au moins je vis dans les environs du nid, des frigmens de coquilles cassées qui annonçoient d'aurres pontes.

Il étoit possible que quelque bête, du genre des fouines, fut renue à notre insçu, en dévorer le produit; mais il y aroit un coupable qu'on pouvoit soupçonner, avec bien plus de rraiscinblance : e'éroit mon singe. 'lel est l'cffet des mauvaises réputations méritées. Y avoit-il dans mon campquelque délit de gourmandise, quelque vol de gloutomnerie, on commençoit d'abord par en ac- 


\section{$36 \quad V O Y A G E$}

cuscr Kees; presque toujou:s l'accusation étoit fondéc.

Je voulus miassurer si, dans cette occasion, e'étoit à lui que je devois m'en prendre; et le lendenuain matin je me nis aux aguets pour attendre le moment ou la poulette ayant poidu, m'en averiroit par ses cris. lices étoit alors sur mon chariot; mais il n'eut pas plutôt entendu le premicr caquer de la pondeuse, qu à l'iustant il s'élança en bas de la voiture pour courir à l"ceuf. Arrèté tout-ì-coup par ma présence, il afiecta une attitude nonchilante, se balanç pendnut quelque tems sur ses pieds de derrière en climnotant des yeux avec un air in1bécille, passa et repiasa plusieurs fois devant noi, en un mot, employa tout ce qu'il avoit de ruse pour me distraire et m'en imposer sur ce qu'il méditoit. Sa manceuvre hypocrite ne fit que me confirmer davantage daus mes soupçons. Mlais je fus bicnrôt convaincu, quand, aynne feint pour l'abuser à mon tour, de toumer le dos aux broussailles, je le vis s'ćlancer rapidentent de ce côté. I’y courus apris lui, et jarrivai au noment où, après avoir cassé l'ceuf, il l'avaloit. On se donte bien que le fripon paya sur le lieu mème la peine de son délit. Je l'écrillai très-vigoureusement; et néunmoins ( tant une nature perverse est incorrigible!) ma coricction, toute verte qu'elle étoit, ne l'empecha pas. d'aller voler encore l'nuf nouvenu.

C'est réellcnent un animal indisciplinable qu'un singe. A la vérité, il a me supériorité d'instinct si parfaite, qu'il peut rendre des services tres-importans; et le nicin, effectivement, dans plus d'une occasion, m"cur avoit rendu de tels. Mais s'il est inventif, s'il vous devient utile, c'est toujours pour lui, et jumis pour vous qu’il travaille. Assurément 


\section{ENAFRA Q UE. 37}

aucun animal sur la terre nest aussi adroit, et, peut-être, aussi rusé quuc eclui-ci. Cẹpendanc si on essaye de l'employer à quelque excreice ou ì quclque ouvrnge de commande, on ne le trouvera plus que gauche, lourd et mal-adroit. Et ce n'est qu'à force de le faire jeuncr et de coups, qu'on parvicnt. ì le dresser à certains exercices; mais il est impossible de le corriger de plusicurs défauts maturels en lui. Lascif, gourmand, voleur, vindicatif et colcre, il a tous ces viecs; et s'il lui manque, disent les Sauvages, celui d'être mentcur, c'est sclon eux, parce qu'il ne veut pas parler.

Persuadé que je ne parvicndrois point à changer la nature du micn, et qu"à moins' de le tenir tous les matins à la chance, jamais je n'auro is un euf; jentrepris de lutter de ruse avec lui, et jexerçai un de mes chicns à courir au nid, dis que la poule faisoit cntendre qu'elle avoit pondue, ct à me rapporter l'ocuf́ sans le casecr. En quelques jours l'animal fut dressé. Mais Kecs, au signal, couroit on même tents que lui vers la pondcise. Alors il falloit disputer à qui des deux auroit l'ouf ; et souvene ec n"útoit pas le chicn, quoique le plus fort, gui l'emportoit. Si cclui-ci étoit vahquent, je le voyois accourir avec joic et déposcr a prise cntre mes nains, suivi du singe qui ne cessoit de grommeler et de lc menacer en grimsęant, jusqu" hे $\mathrm{cc}$ que jeusse pris l'veuf; comme s'il se futt consolé d’avoir manqué sa proie, pourvu que son antugoniste n'en jout pas. Si c’étoir Kees qui avoit ćté le plus habile, il cherchoit à sutuce sur quelque arbre, où, après avoir gobé l'ceuf, il en jettoit les coquilles ì son camatrac, comnes il cût eu l'intention de le narguer; et je voyois revenir celat-ci avec un air honteux sui $m^{\circ}$ avertissoit de sa triste aventure. 
Ces détails pourront paroître minuticux à bien des lecteurs qui ne me liront que pour me critiquer, si toutes fois ils me lisent avant; mais peutctre que, pour benucoup d'autres, ils seront plus utiles que ces deseriptions fastidicuses, ces détails interminables, dans lesquels on les jette trop souvent à-propos d'un insecte, d'une partic d'insecte et des dimensions sans nombre d'un animal. Il mest doux à moi de recommencer mes voyages, de penser, de sentir tout ce que j'ai vu, senti ct pensé; je laisse à de grands génies, le soin de mépriser ces fadaises, et je m'y complais d'autant plus, qu'clles me tiennent bien juste à la hauteur qui mest propre. Du moins tcl a toujours été mon plan; que dis-je, je n'en ai pas; je ne me doute même point de la science qu'il peut y avoir ì farte an live ; mais lc micn, si c'en est un, auru toujours, ì ce qu"il me semble, un grand avantage, c'est qu'il n'est pas fait à dessein, et c'est là aussi la raisun pour laquelle je ne venx sculement pas y songer. J'ai raconté si souvent mes voyages, qu'il ne mest pas difficile de les écriie; et celui de mes amis, pourvu d'une mémoire heurcuse, qui en auroit entendu le récit, poutroit aisément et de la même manière, les écrire à ma place; c'est-là toute la prérention qute j'y mets.

Qunt à la partic si fameuse des voyages, snvoir, les décourertes et les observations nouvelles; on en rouvera (car il le faut bien) quelque chose dans les descruptions particulicres des individus nouventx dont jai hait la conguête en Afrique, et que je donnerai bientôt au public; mais qu'on ne s'attende pas, connme je l'ai dit, à des démonstrations géométrinirioscopiques. Ie m’étendrai avec plaisir sur ies mours at les hobitules kies animax avec qui $j a i$ 


\section{E N A FI Q U E.}

vécu; la plus simple observation de cette nature, nous douncra toujours des résultats plus heureux et bien plus certains, que l'exploration de leurs entrailles fumantes et muettes : vraie charlatanneric, faitc pour tromper d'ignorans admirateurs, et, qui pis est, bien souvent des savans même.

Je m'atracherai plus particulicrement aux partics essentieiles, et principalement aux formes de ces mêmes parties; qquant à l'ensemble de l'animal, c'està-dirc à sa forme extérieurc, une description simple, aidéc d'une figure exacte, suffira toujours pour le reconnoitre et ne pas le confondre avee un autre; mais, à Dicu ne plaise, que jemploic jamais mon loisir à mesurer in longucur, la largeur et l'épaisscur de tontes les dents d'un quadrupède, à domner l'exacte dimension de l'ouverture des yeux, dcs narines, sous toutes leurs faces; la grandeur des trous de chaque vertèbre; la circonférence et le diamètre de l'anus; l'ćpaisscur du rectum et l'aunage de tous les hoyaux, ainsi que in longucur comparéc des poils dans toutes lés différentes parties du corps. Tant de savoir, assurément, ne est pas à ma portće.

J'étois arrivé à la horde, le 23 juiliter, il y avoit 18 jours que je sćjournols; je commençois à̀ languir dimpaticnce, cr je desirois reprendre ma ronte, mais quel-que fur mon empressement ì cet égard, j'avois cru ce sćjour nécessaire pour le repos ct le rétablissement de mes animaux. Téín mes chevaux avoient repris leur vigueur et lcur courage. Des treize bœufs qu’avoient ramené mes gुcns, sept déja étoient assez bien remis, mais il y en avoit six de la convalescence desquels je désespéruis. De tous les animax bi-fourchus, ic bocut -est eclui chez quîi ie développement des forces ritales s'effectue avec le plus de lenteur. Privé de dents incisives à la

$$
\mathrm{C} 4
$$




\section{$40 \quad V O Y \Lambda \mathrm{GE}$}

machoire supcrieurc, il ne peut arracher l'herbs qu'arec ses lc̀ves, qui, étant trop ćpaisses ne lui permettent pas de pincer les filancns courts et succulens desjeunes pousses. Si la fariguc ne lui laisse pas asscz de forces pour ruminer, sil ne trouve pas une bonne qualité da fournge, son estomac, par le défaut de cette seconde mastication si nécessaire, n'a plus à digérer qu'une herbe indigeste et mal broyce, incapable de l'alimenter convenablement.

Mes gens, très-satisfaits de la vie oisive ce tranquillc qu'ils menoicnt dans la horte, m'cxhortoicnt à y rester cuelques jours encore, iffin, disoient-ils, de clonner à mes boufs malades le tems de se rétaJlir entièrement. Matis ma patience étoit épuiséc. Je préférai d’abandonner mes six bêtes; et quoique je ne dusse m'atrendre qu"à une continuité de sècheresse et de nalhcurs, puisque ma marche étoit en raison contraire de celle des saisons; quoique la prudence me conscillât de retourncr at Cap, ct qu'il n'y eît presque qu'une fausse honte qui me fit persister dans mon projer, je résolus de reprendre ma roure et de potisuivre mon voyage chez les Namaquois.

Ma santé n'ćtoit pourtant pas trop assurće; ct il me restoit quelque uncommodité encore, d'un accident qui mavoit tenu dans ma tente pendant huit jours.

De toutes les plantes remarquables de ce canton, celle qui a le pluts fixé mon attention, est ane espèce de géranium ćpineux ì grandes fleurs, a laquelle les Namaquois one donné, dans leur lan. gage, lc nom de Nournp.

Ce geranium a une propriété particulière; c'est quavec le tems, route sa partie intérieure se déwhit entièrement; tandis que son ćcorce reste in- 


\section{ENAFRIQUE. 4I}

ticte. Dans cet état son trone et ses branches sont totalement creux; l"ćcorce alors prend une certaine transparence et lit couleur d'une belle colle de Flandres; jettée au feu, clle ne se brûle point conme du bois, mais se racomit et se tortille comme lc feroit une corde de boyau.

On trouve de ees gíraniums qui portent des fleurs jaunes et c'autres des feurs blanches; mais ce qui prouve que ce ne sont absolument que des variétés, c'est qu'il m’est arrivé de trouver sur le même pied des fleurs de ces deux coulcurs.

Parmi ceux dont je me voyois entouré, $j$ 'cn avois trouvé un superbe, que je mótois amusé à dessiner; apris quoi je l'avois jette imprudemment hors dc ma tente, près de mon chariot. La nuit, réveille far un besoin, je descendis de ma voiture; ct, sans songer au géranium qui sc trouvoit là, je sautai, picds nuds sur cette plante, et m’enfonçai un pied jusqu" la cheville dans ses épines. Ma douleur fut telle, et je poussai un cri si violentque tous mes gens accoururent. Ils me trouvirent soutenu sur tune janibe, et cloué par l'autre sur le tronc ćpincux, sans oser fairele moindre mouvement pour liten retirer. Lc pis de l'aventure, éest que je ne sarois comment me solistraire ì cette torture, et qu'il ne m'ćtoit pas possible d'arracher une partie du pied des épines, sans les enfoncer davantage dans l'autrc. Enfin, on prit lc parti de me soulever en me couchant un peu horisontalement; puis, d'un même cffort et d'un scul coup de main, on retira la plante.

L'opération fut cruelle. Némnmoins je la supportai tranquillcment, parce que je crus qu'clle seroit la domic̀re de mes douleurs, et qu'il n'y avoit plus, pour ctre gućri, qu't' arrêter l'infammation. Dans 


\section{$4=$ \\ VOYAG L}

ce desscin, je me fis envelopper la chevilile et le picd avec un cataplasme de lait et d'herbes, que me firent mes Hottentots; et je me mis au lit, ne doutant pas que le jour dipies je ne pusse marcher à mon ordinaire. Mais quel fut mon étonnement, quand le lendemain je sencis mos souffrances beatcoup augmentées, ct que je me vis le pied, la jambe et la cuisse même si prodiegicuscment enflés qu'ils ne pouvoient sc prêter à aucun mouvenont. Klaas Baster et ses llottentots, en me voyant dans cet état, déclarèrent que la plante qui m'avoit blessée ćtoit vénimeuse, et qu'il n'y avoit que des bains de lait chaud qui pussent me guérir. J'adoptai ce régime, et je restai pendant huit jouits couclić, sans sortir de dessus mon matelat. Entin, le huitiène jour, l'enfinte disparut totalement; mais quoique je pussc me soutenir sur mes picds, ma jumbe néanmoins étoit d'un brun verdâtie; et ce ne fut que plus de trois mois après ma blessure, qu'clle reprit sa coulcur naturelle. Ales gens nommerent la plante, depuis mon accident, gift-doorn (épine empoisonnce).

Tel étoit létnt de ma santé, au monent où je me disposois à partir. Toutes les inquiétudes m'assailloient à la fois; et de tututes parts je ne voyois que des sujets de crainte. J'nvois fait des échanges avec Klaas Baster pour une trentaine de moutons, afin de me former un nouveau troupenu. Je volllus mênie que pour la routc ils s'accoutumassent, ainsi que mes chèvres, à ne pas s"écrrter de mon camp; ot dans ee desscin, je les fis garder pendant quelques jours, près d'elles, autour de mes chariots et de mes tentes. Mais ce n"étoient pas les moutons qui me devenoient les plus nécessaires pour mon voyage. Comment l'entreprendre avee sept 


\section{EN A F R I Q UE.}

beufs seulement en état de servir, tandis qu'il me falloit trois attelages entiers?

La hordc étoit trop éloignce de toute habitation, pour pouvoir me flatter d"cn acheter quelques-uns dans le voisinagge. A la vérité, j'avois compté sur lc Baster; mais celui-ei ayant commencé à défiricher quelques terrains pour y semer les grains qu'exigeoit la consommation de sa horde, ses boufs lui devenoient nécessaires. Tout ce que je pus obtenir, à foree de prières et d'instances, ec fut un attelage. "Voyez-vous ces hautes montagnes du

Camis, me dit-il ? là, vous en trouverect autant qu’il vous en faudra : quant aux moyens de vous gerai mon frère de vous y conduire; il prendra le nombre d'hommes et la quintité de boufs " qu'crigcront vos chariots; ct quand il vous aura a portée d'avoir de nouvelles bêtes, il revicndra ici avee les siennes."

Cette proposition étoit, dans les circonstances, ce quic je pouvois désirer de plus favorable. Elle me donnoit les moyens de reprendre non voyage. Que pouvoir de plus pour moi lc Baster? et que pourois-je lui demander davantage? Cependant j"avois formé un sutre vou encore; c'ćtoit de l'emmener avee moi. J'allois traverser la contrće des grands Namaquois. Or, je n'ignorois pas qu'il avoit voyagé che\% ce peuple, qu'il étoit comnu dans la plupart de leurs hordes, qu'il parloit très-bien leur langue, et que par conséquent il pouvoit m'être infiniment utile auprès d'eux. La difficulté étoit de lc détermincr à me suivre. Vainement je l'avois pressenti plusicurs fois sur cette complaisance; toujours il m'avoir paru y répugner; quoique cepcndanz il cut déja voyagé avec M. Gordon, et mème 
avec le voyageur anglois, M. Paterson ( 1 ). Enfin, jessayai de le gagner par la séduction de sa sœur, de sa belle-socur et de sa femme. J'intéressai cellesci à ma demande par quelques jolis cadeaux que je leur fis; et en effer, elles réussirent si bien qu'il n'eut plus à mobjecter que la crainte d'être rencontré et attaqué par ses frères. Mais lui ayant représentć qu'enyironné de tous mes gens, et sous la protection de mes armes et des leurs, il n'avoit rien à craindre de ses frères; ec l'ayant assuré surtout que s'ils osoient approcher de mon camp et tenter quelques voies de fait, i'écrirois au colonel Gordon, pour obtenir du gouvernement leur punizion, il se rendit enfin à mes instances.

Nos conditions furent bientôt faites. C'ćtoient quatre rixdalers par mois, du tabac à discrétion, et de la quincaillerie suffisamment pour qu'il pût acheter quelques boufs, lorsque nous serions chez les grands Namaquois. Cependant, quoiqu'il eut accepté sans hésicer ces propositions, sans qu’il m'eut même demandé à en ajouter aucune autre, je m'apperçus qu'clles ne le fiattoicnt que foiblement. Én effet, ce traitement étoit peu de chose pour un homme qui possédoit huit cents bêtes à laine et plus de deux cents bêtes à cornes, et qui, par conséquent, pouvoit, dans sa condition, ètre regardé comme riche. Mais quand je lni eus proposé par jour une ration d'enu-de-vie, alors il ne put se contenir, et sa joie éclata. Quoique, vivant loin de la colonic, il eut eu peu d'occasions de boire de ecte liqueur, il l'aimoit passionnément.

(1) Ce dernicr a publiè une relation de son voyage, qui a été traduits en françois. 


\section{E N A F R I Q U E. 45}

Pcndant mon sćjour auprès de lui, je l'en avois régalć quelquefois; et de tous les ressorts qui pouvoient remuer son ame, celui-ci étoit le plus puissant.

Cependant il mit à nos arrangemens une condition, c'est que je le ramenerois à sa horde. Cette clause contrarioit un peu mes vues; car quoique des obstacles sans cesse renaissans me fissent presque désespérer du succès de mon voyage, j’en con- * scrvois némmoins la volonté. Il est vrai que ces obstacles m'nyant forcé à revenir sur mes pas, il dut men coûter beaucoup moins de ramener le Baster avec moi.

D'après cette supposition que je ramenerois le Baster à sa horde, la famille nie supplia de la protéger, à mon retour, nuprès du gouverneur, et d'obtcnir pour clle la liberte du port d'armes, qui est défendu à tous les Hottentots, et qui étoit nécessaire à ceux-ci, hon-sculcment contre l'attaque et les incursions des Boschjesman, mais encore pour se garantir des vexations de leurs parens, qui déja plusicurs fois les avoicnt désarmés. Avec la même légércté que je m’étois engagé pour l'autre objet, je promis de m'intéresser pour celui-ci : il est vrai que ce dernier ne m'exposoir pas à un manque de foi; que si je n'étois point dans le cas de solliciter de vive voix cette grace, j’avois la faculté de la demander par écrit, ct qu'en me séparant de Klaas Baster, je pouvois lui remettre en main une lettre de recommandation poul M. Gordon et pour le nouvenu fiscal.

En attendant, je donnai à la horde dix livres de poudre, ct du plomb en proporrion, ct leur laissai un fusil pour se défendrc pendant l'absence du frère; ce présent lui fut d'autant plus agréable que 


\section{$46 \quad \mathrm{VOY} \Lambda \mathrm{G} \mathrm{E}$}

depuis long-tems clle manquoit de munitions. Je fis à chacun des individus qui la composoient quelque cadeau particulier. Les femmes sur-tont ne furent pas oublićes; mais la sceur mien demanda un auquel je ne m'attendois pas. Trois jours après mon arrivée à la horde, une de mes chiennes avoit mis bas et m'avoit donnc luit petits. Moi, qui crois que la nature ne se trompe jamais, et qu'une mère peut nourrir, quelqu'cn soit le nombre, tous les animaux qu'ella a portés, à moins que quelques circonstances particulières ne la privent de nourriture, j’avois laissé ma chienne nourrir tous les siens. Ils pouvoicnt par la suite me devenir utiles et remplacer tant ceux que j'avois perdu, que ceux dont il étoit possible que d'autres accidens me privassent encore. La Mulâtresse alloit me quitter; pour dernier témoignage d'amitié, elle me demanda un de mes jeunes chiens; et d'abord je le lui refusai. Mais elle y mit tant d'instances, clie me pressa tant, qu'il fallut céder. Comment résister à la soeur de deux hommes auxquels tous mes gens et moi nous cicvions la vic!

Le 1o 2ont, je me mis cn marche. Mon intention étoit de passer la nuit à Poes-kop-Heuvel; c'est ainsi que nous avions nommé le licu où avoient été tuć les éléphans. Les cadavies de ces animaux subsistoient encore en partie. Mais soit la vue, soit l'odeur de ces corps, mes boufs prirent l'épouvante, et ils s'agiterent tellement dans leurs traits qu'il fallut les dételer au plus vîte. $\Lambda$ peine libres, tous prirent la fuite, et ils retournèrent au galop vers la horide, où l'on fut obligé de courir pour les ramener.

Déja, le matin, lorsqu'on les avoit mis aux voitures, ils s'étoient effurouchés, ce l'on avoit eu beau- 


\section{EN A F R I Q U E.}

coup de peine à les itteler. Les suites funcstes que pouvoient avoir ces caprices dangereux m'efirayoient d'avance, et ils me rendirent plus douloureuse encore la perte de mes anciens attclages. A combien d'accidens alloient m'exposer des animaux si mal dressés! Que do craintes! que d'inquiétudes nouvelles! Heureuscment $j \mathrm{j}$ en fus quite pour ce premier jour d'alarmes. Ces bétes, qui me donnoient tant licu de craindre poul mes gens et pour mes chariots, s'apprivoiserent facilement : clles firent même fort lestement, dans les trois journées suivantes, vingt-quatre licues à travers les montagnes et par les chemins les plus affreux, où nous ne trouvâmes qu'une sculc fois de l'cau, qui cncore étoit détestable. Heureusement que nous en eûmes dans quelques fosses de la rivière de l'Epine-Noire (Sivarte-Doorn-Rivier), aì nous campàmes le troisième jour dans l'après-midi; de tròs-grands nimosas bordoient la rivière le long de son cours.

Pendant qu'on détcloit, m'étant avancé pour examiner le lietr, je vis, avec autant de joie que de surprise, un chariot que garioiont quelques Hortentots. Je les accostai, et leur fis différentes questions sur la cause qui les amenoit dans ce lieu. Mais bientôt ils changèrent mon allégresse en inquiétude, cuand ils m'apprirent que le chariot appartenoit à Pict Pinard, qui les avoit pris à son service et avec leyud ils venoient d'arriver. Pinard étoit ce grand chasseur, ce conreur des bois, dont jai parlé ci-dessus, et dont il est question dans l'ouvrage de Paterson. Il avoit voyagé avec le colonel Gordon; et au moment de mon départ du Cap, il étoit venu s'offrir pour voyager aussi avec moi. Nais, sur sa rćputation, j’avois refusé ses offres; j'en ai dit ailleurs les morifs, et c'étoit avec 
un vrai chagrin que je le rencontrois dans ma route.

Cependant il me rendit un scrvice. Comme il s'étoit annoncé au Cap pour venil chasser aux éléphans chw les grands Namaquois, Serruricr, successeur de mon ani Boers dans l'emploi de fiscal, avoit espéré qu'il me rencontreroit, soit dans la route, soit chez ce pcuple; et, dans cet espoir, il l'avoit chargé pour moi d'un paquet et d'me lettre.

Le paquet venoit de Hollande, et il m'itoit cnvoyé par Temminck, qui, curicux d'avoir dans sa collection un calao, d"une especce particulic̀re, me prioit de le lui procurer; ajoutant que cet oiscau se tronvoit en Afrique, et me le désignant par un bec qu'il m'envoyoir. Temminck ne se trompoit pas. Le calizo dont il me parloit est récllement un oiscau africain. On le voit même assez. fréquemment à la côte de l'est; mais il est si filrouche, si méfiant, si difficilic à approcher, qu'il seta nécessairement toujours très-rarc dans les cabincts. Pendant tout mon premier voyage, je n'avois ćté qu'une scule fois à portée d'en tirer un; cétoit dans le pays d'filteniquoi; et comme si j'eusse prévu le vou de mon ami, je m'étois histé de lui en faire lhommage et de le lui envoyer par Bocrs. Le désir qu'il me témoignoit d'en avoir un mettoit pour moi un prix inlini à celui que je lui avois fait passcr; et je sentois quelque plinisir it penser qu'au moment où je recevois sa demande, il recevoit peut-être l'oiscau qu'il désiroit.

Les nouvelles que me donnoient, et sur la Hollande, Tenminck, et sur le Cap, Serrturier, m’étoient, dans les circonstances présentes, infiniment agréables; mais j’eusse désiré les recevoir par une autrc voie que celle de Pinmed. 1a rencontre de 
cet homme me sembloit de matuais augure; je m?alamois de le voir dans mon voisinge; et mes craintes, conme on le verra, ne se trouvìrent que trop bien fondées.

Quoiquil eut suivi une autre rotite que moi, son voynge n'avoit pas ćté plus hemreux que le mien, et il venoit d'épronver, comme moi, le fléar de la sécheresse ce la discte des fourrages; mais comme il n'aroir qu'nue voiture et peir de monde, il s'en étoit mieux tiré. Il me fallît encend"o le prolixe et interminuble récit de ses prouesses, dont je firs grace au lecteur, car jamais histoire ne fut compréc plus longuement; et d'après le service qu'il venoit de me rendre, je me voyois pourtant obligé de lécouter.

$\Lambda$ l'cntendre, il se rendoit chez les grands $\mathrm{Na-}$ maquois, sans autre projer que celui de chasser les ślćphans et de faire le commerce de l'ivoire. Mais je connoissois assez l'aventurier, pour me défier de ses déclarations. J'avois vu d'ailleurs de quoi ćtoit composée sa pacotille; et je n’ignorois pas, moi, qui voyageois aussi, que ce n'ust point avec des quincailleries, dt tabac et des liçueurs fortes quion tue des élćphans. Son seul ct réritable but éroit l'achat et le commerce des bestiaux; ct sil annoncoit avec tant d'affectation de prétendus projets de chasse, cc n'écoit qূu’un prétexte pour détourner loin de lui les soupçons et les yeux de l'atminiscration. Ceci exige une explication

Les bestinux sont un des objets dont in Compagnic s"est réservéc exclusivement le commerce avec les Satwanges; clle en défend le trafic sous des peines très-rigontreuses. Mais dans des contrées aussi éloignécs de la surveillance du gouvemenent, conment l'cmpêcher? et quand il manque de force Tome II. 


\section{$50 \quad \mathrm{VOYAGE}$}

pour faire exécuter même ses loix judiciaires, où en trouveroit-il pour l'observation de ses loix fiscales? La prohibition dont il s'agit cst d'autant plus facilenent éludéc, que personne n'est spécinlement chargé de la maintenir, que tout le monde est intćressé à la frauder, et qu'avec l'assurance de l'impunité on a de plus celle du bénéficc.

Encore, si les fraudcurs n'étoicnt coupables qu'envers le gouvernement! mais que d'iniquités! que de crimes et d'horreurs! Quclques colons, bien armés, se réunissent enscmble; puis, tombant tout-à-coup stir unc horde isolée, ils obligent ceux qui la composent de leur amener tous leurs troupeaux, ils choisissent les bêtes qui lcur conviennent, et en donnent le prix qui leur plait. Que peuvent, contre ces brigancts redoutables, de malheureux Sauvages à qui les armes ì feu sont inconnues! S'ils entreprennent de résister, s'ils se permettent même quelques murnures, lcur vie n'est pas cn sûreté. Aussi, à peine savent-ils les contrebandiers en campagne, qu'ils s'cmpressent d'ćloigner leurs troupeaux et de les envoyer dans les bois et dans les montagnes, où ils les tiennent cachés. C'est le seul moyen qu'ils aicne pont: sc préserver du pillage; et c'est celui qu'ils cmplvient tolls.

Mainte fois il m'est arrivé de venir dans une horde, et de ne pas y trouver une scule picce de bétail; parce que, jugé d'après les faits d'autrui, on m'y regardoit comme un de ces prétendus trafiquans de buetris, dont"la prćsence est un féau. Pour dissiper ces préventions défavorables, il falloit qu'en vivant quelcue tems avec les Sauvages, ils apprissent à me comnoitre, ou que mes gens les instruisissent des motifs qui me faisoient voyager; alors 


\section{$\mathrm{EN} A \mathrm{FRIQUE.} \quad 5 \mathrm{I}$}

Ja confiance se rétablissoit. On me racontoit les abominations qu'ivoient commises les scélérnts avec lesquels on $\mathrm{m}^{2}$ avoit confondu. Je voyois les troupeaux reparoitte; et si je voulois en achecer quelques bêtes, on me laissoit le maître du choix; toutes étoient à ma disposition. Je contracto is loyalement, je payois de même; ct j'avois, en partant, la consolation d'cntendic ces bouches qui, jusqu'alors, avoient madit les blancs, avouer enfin qu'il en étoit quelques-uns qui ne méritoicni pas d’être hais.

Assurément je ne soupçonnois point Pinard d'être un de ces achetcurs à coup de fusil. Sans doute il vouloit contracter autremcnt qu'cux, puisqu'il étoit scul de sa couleni", et qu'il portoit avec lui les trois sortes de marchandises que recherchent, par-dessus toutes les autres, les Sauvages : la quincailleric, l'cau-de-vic et le tabac. Néanmoins je craignois l'indiscipline et le désordre que pouvoit mettre dans ma troupe un parcil homme; et bientôt il me prouva que je ne malamois point vainement. It conduisoit avec lui trois tonneaux de cette mauvaise cau-de-vic que fabriquent ef vendent les colons; mais at gout qu'il montroit pour cette liqucur, sa cargaison devoit être bicn silégéc, avant qu'il fut arivé chez les Namaquois. Dìs le soir, il en prit une telle dose, que le peu qu'il avoir de raison se trouva entièrement troublé. Dans cet état, ses tonnenux étant abandonnés à la discrétion de ses Hottentots, ceux-ci en frent les honneurs à ma troupe; ct avant la nuit, ses gens et les miens furent ivres. Au milieu de cette orgic dégouttante, Pinard balburiant cherchoit à débaucher mes Hottentots et à les engager de quittcr mon service pour s'attacher au sicn; c'ćtoit pour cux une séduction.

D 2 
bien puissante que l'aspect de ces trois tonneaux en peicc; et je vis un moment où leur ancienne inclination pour moi alloit être étoufféc par l'appât subit de cette enu-de-vie qui alloit être à Icul discrétion.

Le lendemain, on reconmmença à boire dès le point du jour. L'empressement fut mêne tel, qu'avant que les voitures fussent artelées, rout le monde, exeepté mon Klatas et trois oul quatre de ses camarades aussi raisonnbles que lui, se rrouva ivre de nouvczu. Cependunt il falloit partir; ce pour préserver mes voitures d'aceidens, je n'avois d'autre ressource que d'en conficr la conduite à ce peu de gens sagyes qui avoient encore leur raison. Swanepocl lui-mêne, Swancpocl, qui jusqu'alors avoit mérité de moi tant d'éloges, étoit hors d'état de servii; et sćduit par les invitations de Pinard, il venoit de s'cnivrer avec lui. J'atendis némmoins, pour lui témoigner mon mícontentement, que nous fussions en miarche. Lui, mortifié de mes reproches, veut me prouver qu'il est en état de conduire nia voiture. En vain je lui ordonne de s'éloigner; il s'approche en chancelant, et cherche à s'elincer sur le siege, mais les pieds et les mains Iux manquene tout-à-coup, et tandis que, par des cris affreux, je tâche de faire arrêtcr le chariot, la roue de devant lui passe en sauzoir sur le corps; et celle de derrière alloit même lui ćcraser la tête, si , par un mouvement nachinal, il ne se füt éloigné de sii direction.

Je le erus sans vic; mes conducteurs le regarderent également comme mort, ct déja ils accoutroient pour le ramasser, quand, tout-i-coup, je le vis, se relever lui-même, et me dire gaicment, ce n'est rien. Malheureux! m'écriai-je, tu vas sentir 


\section{E N A R R U E. 53}

bientôt que c'est quelugue chose. $\Lambda$ peine avois-je parlé qu'il tomba sans connoissance. Te le tis étendre sur le matelat de mon charior. Mais bicntôt le mouvement de la voiture le fic revenir à lui; cr ce fut alors qu'il sentit ses douleurs, accrues encore par les sccousses ct les cahots; le moindre ébranlement lui laisoit pousser des cris horribles. Ccpendant il ne m'étoit pas possible d'arrêter. Nous n’avions pas trouvé la moindre verdure sur les bords de la rivière près de laquelle nous venions de camper. Klass sc flattoit d'en trouver vers la RivièreVerte, qui étoit éloignéc de trois licues; ct nous étions pressés d'arriver à celle-ci. MIais comme l'atttre elle contenoit peu d'cau ct pas plus d'herbage, nos bêtes étoicur si firtiguées qu’il fallut pourtant arrêter pour leur donner quelquie repos.

Cette halte me laissoit le tems d'examiner l'écat du blessé et de voir si l'on pouvoí lui proçurer du sccours. Je le fis déshabiller. Il avoit deux côces cassées, et les partics fracturécs formoient même sous la penu une sorte d'éminence. Dans des circonstances aussi fàchenses, que faire? que décider? Il filloit des opcrations chirurgicales, uin pansement selon les regles de l'art, un traitement suivi; et n'ayant cn ce semte, ni connoissances, ni moyens, je me voyois furcé d'abandonner le malacic à lat nitture, c'est-à-dire, à ses souffrunces et à la mort. Il poussoit des hurlemens affreux; il me supplioit, à mains jointes, de lui brûler la cervelle avec un de mes pistolets, pour abréger ses doulcurs; son ćtat me déchiroit l'amc. Mais bicntôt ma pitié se changea en colere, quand j'appris que, dans un moment où je m'ćtois éloigné de lui, il venoic encore d'avaler une demi-boutcille d'ean-de-vie, que lui avoit apportéc, en cachette, un des gens de Pinard. 
$\mathrm{Oh}$ ! eombien alors je maudis la mauvaise fortune qui m'avoit fait rencontrer ce malheureux chasseur chont l'ivrognerie étoit, à mes yeux, la véritable cause de la mort de Swanepoel, et dont la présence ponvoit causer encore d'autres désordres dans ma caravane! Quelle satisfaction j'aurois cue de pouvoir me séparer de lui, en restant sur les bords de In Rivière-Verte et lui laissant prendre les devants ! Mais cette séparntion devenoit impossible, parce que le lit de la rivière manquant d'eau, il falloit en ehercher une qui en cît. D'ailleurs, deux de mes attelages ne m'appartennut point et ne m'ayant été prêtés que pour me conduire jusqu'au Namero, je ne devois point oublier qu'ils étoient nécessaires aux deux frères pour cultiver et ensemencer leurs terres; et que par conséquent je devois les leur rendre le plutôt qu'il me seroit possible.

Une réftexion ecpendant me rassuroit sur les desordres que je voyois naître. Si j'ivois lieu de craindre la présence de Pinard, la mienne, peutêtre, étoir encore plus à redonter pour lui. Jamais mon caractère franc et décidé n’avoit pu se eontraindre sur une conduire équivoque on sur une mauvaise action. Dès la veille j'avois témoigné hautement mon mécontentement ì cet ivrogne. Avant le départ, je lui avois renouvellé mes reproches, duton le plus ferme et le plus appuyé; ct je venois de remarquer depuis notre campenent, que, confus et embarrassé devant moi, il paroissoit éviter ma présenee; ee qui me faisoit croire que si j'étois cncore obligé de marcher quelque tems avec lui, il se tiendroit éloigné de moi et de mes ģens, ct que probablement il chereheroit à me quitter, dès que les circonstances le lui permettroient.

Le lendemain nous nous remimes en route cl? 

cotoyant toujours le lit de lin rivic̀re. Enfin, après quatrc heures ct demie de marche, nous trouvâmes dans ce lit une cavité considérable, qui, heurcusement pour nous, contcnoit de l'eatr, et qui cin avoit même assez pour les deux caravanes ct pour toutes nos bêtes. On y trouva aussi quelques tortues que mes plongeurs pêchèrent, et qui nous foumirent pour le moment, un aliment aussi sain qu'agréable. L'endroit où nons nous arrêtâmes, porte en hotrentot le nom de Gariche.

Swnepocl étoit toujours soufirunt, et il désiroit avoir du sang de rhinocéros à boire. C'est-là un de ces remèdes qui, je ne sais pourquoi, se sont accrédités chez les colons, ainsi que chez les Sauvages. On le croit excelicnt pour les luxations, fractures, et généralement pour toutes les maladies internes; mais on ne tue pas toujours des rhinocéros quand on le veut, et je n'en avois point lì tे ma disposition. Au défaut de sangr, le malade avaloit copicusement de l'enu-dc-vie. Pinard l'avoit assuré que cctte boisson sculc le guériroit.

Pour moi, qui m'érois imaginé qu'après son accident il alloit, pour le reste de ses jouts, prendre l'cau-de-vie en horreur, j’étois étonné de le voir se livrer à cette intempérance effoyablc. Mhis je fermois les yeux sur ces excès et le regardois comme un de ces malades abandonnés, à qui l'on permet tout, parce qu'on désespire de leur vie.

Qui croiroit que ce régine affrcux opéra la guérison du malade, du moins il ne lui fut pas nuisible. On raisonncra tant que l'on voudra sur cette cure niraculcuse; certainement, malgré lc succès dont je l'ai vu suivi, je n'aurai garde de le conseiller en pareil cas; mais soit que l'cul-dc-vie l'ait općrćc, soit qu'on ne doive l'attribucr qu'à la seule nature, 


\section{$56 \quad \mathrm{~V} O \mathrm{YA} \mathrm{GE}$}

et que ce soit l'énergic dẹs forees vitales qui nit consolidé cl. \% le malade ce ressoudé, en quelque sorte, ses os fracturés; je dois assurer ici que sans pansement, sans appareil, sans aucun ménagement, mon vicil ivrogne se trouva entièrement guéri, et que, six scmaines après son accident, il reprit ses fonctions, sans que depuis il ait resscnti la moindre doulcur.

Le chemin que nous avions fait depuis la $\mathrm{Ri}$ vière-Verte me rapprocha du Namero; et déja nous nous trouvions près des montagnes du Camis, qui se présentoient majestueuscment à l'est du pays où 1c Baster m'avoit annoncé que je pourrois trouver à me tournir les attelages qui miétoicnt nécessaires. J’étois enpressé d'y arriver. Nais ayant trouvé dans notre route une source chammante, nomméc OogFontyn (Fontaine de l'neil), dont les caux abondantes, donces et limpides, nous nnnonçoient une station agréable, les deux frores, sétuits par la fraicheur du licu, ne proposèrnt d'y camper; et, malgré mon impaticnee, je cédai à leur désir. Vers le soir, quelques Hottentots du voisinage étant venus puiser de l'eau à la fontaine, ils parument frappés de l'excessive fatigue oit se trouvoicnt nos bouts, et ils m'annoncirunt que jamais des animaux aussi affoiblis ne pourroient mener mes roitures sur li cime du Nanero que je veulois traverser. Che pareille réflexion ne pouvoit que minquićter beatcoup. Jo consultai les donncurs d'avis, sur le parti que javois à prendre: "A cyulque distance d'ici "et dans les montagnes, me répondirent-ils, est "l'hubitation de Van der Westhuysen; enroyez "vers hii un homme de votre troupe pour lui de"n nander des relais: il peut rous en domer, et "stircruent il ne vous les refuecri pis"s. 
Ce nom de Van der Westhuy'sen fit pâlir les deux frères : c’étoit celui de lcur père, et il letr annonçoit, comme très-près d'eux, des dangers qu'ils croyoicnt éloignés. Ice vicillard devoit être sur les bords ou à l'embouchure de la Riviere-Verte, où étoicnt ses possessions; mais la sécheressc excessive et le manque d'eau l'vooit forcé de se recirce avec ses bestiaux dans les montarnes, où il possédoit cncore une autre habitntion. I.cs deux Basters craignoicnt, en m'accompagnun jusques-lì, de rencontrer leurs frèes blancs, et de s'exposer à des insultes et à des violences nouvelles. Cette idéc les avoit même tellement eftinyés, que, sans songer à leurs cngagemens avec moi, sans s'cmbarrasser de ce que je pourrois devenir, ils pritent le parti de sc recircr à l'instant même, d'cmmencr lcurs bœufs, et de me laisser dans mon cump avec mon atrelage, mes chariots et mon monde. Il m'cût été facile de leur montrer l'odicux d’un parcil procédé; je préférai de les rassurer sur leurs craintes, en leur promettant que je ne logerois poine clicz leurs parens, que je resturvis sur l'habitation le moins qu'il me scroit possible, et que, quant à cux, je lcur assurerois l'incognito, en les tenant cachés dans mes tentes. Wh promesse les calma. Ils conscntirent à tenir lis lcur, et restèrent.

D’après l'avis que m'avoient donné à la fontaine les Hottentots, j'envoyai un exprès à Van der Westhuysen pour obenir de lui des relais; ct, en cffet, lc lendcmain je reçus les attelages qui moétoicnt nécessaires. Parvenu sur la hautcur, je fis arrêter ct camper à quelque distance de la maison, ainsi q̣ue je l'ivois promis aux cicux Basters; ils s'urrangèrent pour rester cachés dans mon camp; et moi, r:cndant ce tems, j’allai chez leurs purens faire mavisite. 
La famille me connoissoit déja de réputation; et d’ailleurs Pinard, qui avoit pris les devants, et qqui étoit allé desecndre chez elle, venoit de lui parler de moi avec quelques détrils. Elle me reçut très-obligeamment, me fit des reproches de n'être pas renu, comme Pinard, lui demander un logement, et me renouvella ses offies de service en tout ce qui dépendoit d'elle. Certe famille consistoit en deux fils, done un hant de six pieds, ct deux filles, l'mne grande et fort jolic, l'autre inbécilc. Au reste, dins toute notre conversation, il n'y avoit que trois des enfans ct leur mère qui prissent et tinssent lit parolc. I.e bon-homme, vicillard sepruagénaire, compté pour rien dans la maison et regardé comme nul, éruir assis dans un coin, où il ćcouroit sans mot dire. Depuis long-tems sa femme l'avoit mis au régime du silence; ct, sous prétexte d'épargner ses poumons, qui quelquefois souffroient d'un asthme, ellc lui représentoit, dès qu'il osoir se permettre d'ouvrir la bouche, qu'il alloir sc fatiguer, et le prioit de se taire.

L'intortuné payoit bien cher l'échange qu'il avoit fait de ses femmes hottentotes pour une fenme blanche. Dominé, dès le commencement, par ectre mairresse impérieuse, il en éroir devenu l’esclave; et c'est par mene suire de cette foiblesse qu'il s'éroit vu forcé d'entrer dans la conjuration qu'elle avoit formée contre les enfans diu premicr lit. Confus ct humilić du rôle qu'il jouoir, il paroissoir souffirir de ma présence. Quclquefois pourtant il se hasardoit it me sourire avec affection; mais éctoit à la dérobée, et d'un air inquiet qui me faisoit voir qu'il craignoir d'être apperçu de sa femmc.

11 éroir né en Allemagne, er je parlois sa langue. Par pitié pour sa peine, autant que par égard pour 
son titre de maitre, je voulus le mettre pour quelque chose dans la conversation, et lui fis, en allemand, diverses questions sur sa patric, sur le tems où il l'avoit quittéc, sur les circonstances qui l'avoient conduit en Afrique, enfin sur certains déails qui pouvoicnt l'intéresser. Il y parut sensible, et déja mîme la joie s'ćpanouissoit sur son visage : mais sa fenme, craignant apparemment, ou qu'il ne parlât d'elle, ou qu'il cût trop de plisisir, l'interrompit brusquement et le fit taire, pour me parler de la France. Madame se prétendoit Françoise d'origine. Sa mère, disoit-clle, étoit Provencale; elle-même, quoique née $\Lambda$ fricaine, avoit écé ćlcvée à la languedocienne; ct pour me le prouver, clle me prononęr quelques phrases d'un baragouin inintclligible, qu'elle prétendoit être du françois. Probablement clle n'cntendoit pas plus que moi ce jargon bizarre; mais elle affectoit de s'en scrvir de tcms en tcms, et persundée que le témoignage le plus convaincant de son origine étoit l'accent du pays, clle cu mettoic tant ì son prérenciu patois, elle faisoir de tels efforts et de contorsions de bouche si ridicules, que javois toutes les peines du monde à mompêcher de rire. Les deux fils et leur" ginde sceur écoutoient ces merveilles, bouche bénnte, les yeux stupidement attachés sur lcur mère; ct plus ses mots devenoient inintelligibles, plus leur admiracion pour clle scmbloit s'accroìtre. Pour partager er pour augmenter les plaisirs d"une joumée anssi amusante, la dame avoir envoyé chercher un sicn frère, nommé Engclbrecht, lequel demeuroir ì quelques lieues de là. Engelbrecht ne vint point le même jour; mais la joie des assistans n'cn fut point troubléc pour cela. Pinard avoit fait apporter de l'eau-de-vie en quantité. Toute inté- 
ressantc qu'ćcoit la conversation, on l'interrompic pour boire; et comme, faute de gobelets, on fut obligé de sc scrvir d'écuelles, en pcu de trms toutc Ia maison, sans cxecpter la mèrc ct ses dcux filles, fut complettement ivrc. Pour moi, que ce dénoucment laissoit libre, j’en profitai pour me retirer, et $j$ vins passer la nuit dans mon camp.

Engclbrecht arriva dès le matin chcz sa soeur. Il amenoit avcc lui sa famille qui ćtoit plus nombicuse que l'autrc; et cctte arrivée avoit ćté célćbrée par quelques rasadcs d'eau-de-vie. Aprc̀s cc préliminairc, quelqu'un proposa de venir me visiter dans ma tente, et bientôt je vis arriver toutc la sociétć. Unc pareille dćmarche scinbloit m'annoncer ics choses obligcantes; mais les cerveaux étoicne échauffés de boisson. Cc fut Engelbrecht qui parla le premier; et cet homme qui ne m'avoit jamis vu, cet homme qui me devoit des égards à plus d'un titre, nc mªdressa la parole que pour me demander, d'un ton grossier, pourquoi j'avois admis dams ma troupc un scélérat tel que Klaas Baster?

Cette impertinente question m'annonçoit que le sectet de la présence du Baster étoit comnu : or, il n'y avoit que Pinard qui cût pu me trahir sur cet objet. Avant de nous rende chez les Van der Westhuysen, javois exigé de lui le plus profond silence sur l'arrivće des deux frères : il me l'avoit promis; mais qucllc confiance avoir dans les promesses et la discrétion d'un ivrogne! Indigné de son procédé infamc, cc fut à lui que j’âressai d'abord la parole; ce j'avone que dans ma colère je lui parlai très-rudcment. Ma réponse au frère fut très-sèche; j’annonçai hautement ì la sociétć que si quelqu'un s'avisoit de faire à Klans Baster la plus légère insulte, dìs-lors il sc déclaroit mon en- 


\section{E N A F R I Q UE. 6 I}

nemi, et que je le regarderois comme le mien. Enfin, je mis duus mon geste et dans mes cxpressions tant de chaleur, que personne n'osa me répliquer un scul mot. $\Lambda$ u reste, ce qui me rendoit si fier et si hardi c’étoit la présenee mène du père. Quoiqu'il ne se permît point de parler, j'étois bien sûr d'être arouć interieurement par lui : j'avois cru démêler ses sentimens cachés; et tandis que je m'échanffois pour ses deux fils, il me sembloit lire dans ses yeux le plaisir qu'il ressentoit de me voir defendre deux malheureux, qui n'ćtoient tels que parce qu'ils étoient ses enfans.

Pour détourner un entretien dont on s'ćtoit flatté de tircr un meilleur parti, la belle-mère m'invita de venir diner ehez clle avec toute sa compagnie; et moi, sans témoigner ni humeur ni ressentiment, jaeecptai, et je suivis la bande joycusc, fort embarrassé néanmoins de savoir comment s'exécuteroit la fête et quel rôle j'allois jouer dans ce banquet solemnel.

la maison étoit d'une scule pièce, longue de vingt pieds environ, sur ncuf ou dix de large; ses muls, fabriqués simplement avee de la terre, étoient de toutes parts sillonnés de lézal'des et de larges fentes. Cecte galerie, ou plutôt cette vaste grange, n'olliroit pour toutc fenêtre qu'un seul trou, boutché avec le fond délabré d'un vieux tonneau. On pouvoit, à travers les trous nombreux du toit, tombant en ruine, distinguer, sans quitter sa place, si le cicl étoit triste ou serein; mais ses arrosoirs naturels ne manquoient pas, lorsqu'il pleuvoit, d'inonder la chambre et ceux quil l'habitoient. On faisoir le feu dans un angle à côté de la porte : de cheminée, on n'y avoit jamais songé; ct la fumée avoit à choisir, à la vérité, pour purger ce re- 


\section{$62 \quad V O Y A C E$}

paire, ou le toit, ou les murs lézardés, on la porte, ou la fenêtre. Dans l'angle opposé à la porte d'entrée, se trouvoient ramassés en tas, et ì peine reconverts de nattes à demi pourries, tous les grains de la réeolte, pour la consonmation de eette nombreuse famille.

Quant aux meubles de ce riant palais, ils répondoient parfaitement au portrait que je viens d'en faire. Une table raboteuse, fixéc à dicmeure sons Ia fenctre, et tolijours chargée d'unc bouilloire d'enu bouillante et de quelques jittes écornées. Treis petits coffres roulans, servoient tout à la fois de sièges er d'armoiris; et, lorsqu'il y avoit compagnie, on y appliquoit dessus des planehes brutes à défaut de banes. Dans un troisiène angle, à eôté du tas de grains, sélevoit le sopha des époux. Ce grabat, on cette espece cie lit, faif avec quatre pieux fichés en terre, et sur lesquels on avoit cloué une peati de beeufs, servant de matelats, étoit eneore surmonté d'un énorme tas de peaux de moutons, graisseuses, puantes et mal préparées, qui tenoient lieu de eouvertures et de coucher au reste de la famille, qui, pêle-mêle, dormoit sur le plancher. Entin, contre le mur, vis-ì-vis la fenctere, se voyoit un moulin a bras pour la mouture du bled. Telles sont en raccourci les voluptés dont se rep.issent les hiabitans de ce séjour enchanté. A peine la compagnic fut-elle rassembléc, que je vis les deux filles et les deux fils de la patrône, aidés de quelques Ilottentots, se mettre en devoir de moudre la quantité de farine qu'alloit exiger tant de nouveaux venus., Le monlin demandoit quatre travailleurs vigoureux, et la compagnie se relnyoit tour à tour pour eette besogne. Cependant le feu pétilloit dans lâttre, attendant un mouton tout enticr, 


\section{E N A F R I Q U E. 63}

tout frais écorché, qui pendoit à la muraille, et qui devoit former le senl mets de ee fameux repas. L.es hommes tiroicnt leurs pipes et commençoient à fumcr. Pinard, très-libéral d'eau-de-vic quand it cn buvoit sa part, en avoit apporté une abondante provision, et la société ne manquoit pas de se désaltérer de tems en tems.

Pour moi, déja rnssasić de tant de féćries, j’nvois senti mon creur se soulever ì lit vue de ce mouton hideux pendu au mur, et dont le sang couloit encole sur le plancher; et bientôt la chaJcur du feu, l'épnisseur de la fumée des pipes, l’odeur insupportable qu'cxhaloit, ec lin sueur des personnes occupécs au moulin, et le corps huileux des Ilottentots, er le rabac des fumeurs, et ces halcines empoisonnécs d'enu-cle-vic, me portèrent à la tête, et finirent par me rendre malade. $\Lambda$ ces petits inconvéniens se joignoit le bruit assourdissant du moulin, bruit si affreux que les assistans étoient contraints de crier à tue-tête pour s'entendre. En vain, par égard, je fis des efforts pour résister ì la douleur et ne point quitter l'assembléc; il fallut céder au dégolit : tout tournoit autour de moi; j'étois plus ivre qu'aucun des conviés, quoique je n'eusse encore bu que du lait; je sortis et recournai à ma tente, où bientôt l'air purr ct le calme m'eurene rétabli. Mais ce qui pourra donner unc véritable idéc de ectte bachanalle hottentote, e'est que personne ne s'apperçut que je manquois au dîner.

L.c lendemain, lorsqu'on eut appris qu'cn effet j'avois déserté lâchcment, on me plaignit d'avoir perdu à dormir une nuit si agrénble; mais ces regretes étoient mêlés de railleries et d'une sorte de commisératión. On comparô̂t ma conduite avec 


\section{$64 \quad$ VO Y A G E}

celle du lientenant Paterson. Tous se répandoicnt en ćloges sur ce voyageur, qui, cn leur prodiguaut d'excellent vin de Bordeaux, s'étoit montré un athlete invincible, soit qu'il fallut fumer, soit qu'il fallut boire; et je scntois très-bien que l'admirittion qu'avoit excitée cette tête forte n'oftioit pas des résultats favorables à la foibtesse de la mienne.

Tuut ceci m"indiquoit que Paterson s'étoit conduit en homme sage et avisé. Obligé de vivre avec des irrognes et de dépendre d'eux, à raison des services qu'il en atcendoit, il avoit eu la prudence de se prêter aux circonstances et de sé conformer à leurs goùts : moi-même j'aurois adopté sa politique et suivi son exemple, si mon tempéramment cût pu s'y plicr. Mais à une aversion insumontable pour les excès du genre de celui-ci, se joigtroit une impuissance physique; et quoique capahle de stipporter des fatigues de tout genre; je ne l'ćcois point pour les abus de la boisson et sur-tout pour celui des liqueurs fortes.

Mon intencion, en revenant chez Van der Westhuysen, étoit d'obtenir de lui et de son beau-frère qu'ils me vendissent chacun un attelage. Piet Baster éroit recoumé à sa horde avec les siens; er mes breuls, joints à ceux que j'avois achetés de son frìre, ne me suffisoient certainement pas pour pouvoir me rencterc en route avec trois chariots. Inquict de la position embarrassante où je me trouvois, j"ctois impaticut d'cn sortir; mais les têtes avoỉent été tellement dérangées par les libéralités de Pinard, que ni ce jour-là, ni le suivant, il ne me fut possible de fuirc ma proposition : et l'on men croira sans peine, quand je dirai qu'en trois fois vingt-quatre heures, huit hommes et six femmes vidèrent 


\section{E N A F R I Q U E. 65}

vidèrent un half-aam d'eau-de-vie, c'est-ż-dire, quatre-vingt pintes. Il est vrai qu'on passa les trois nuits sans se coucher; que les journées, à l'exception du peu de sommeil qu'obtinrent l'accablement et l'ivresse, furent cmployées totalcment ì boire, et que Pinard l'Amphytrion savoit merveilleusement exeiter son monde, et par ses leçons, et par son exemple, et que peut-ĉtre que ses gens ne s'en firent pis faute non plus.

Le quatrième jour enfin, la compngnie, lassée de boire, s'útart trouvec un peu rassise, j'entamai près de Van der Westhuysen et d'Eugelbrecht ma négoeiation. Leur réponse fut qu'ils ne pouvoient n' l'un ni l'autre me vendre un seul boeuf, parce $\checkmark$ tils n'avoient absolument que ceux qui leur ćtoient nicessaires; et en cela ils ne me trompoient point: mais ils m"annoncèrent que si je voulois me rendre dans les montagnes du Camis, je trouverois là des colons qui me fourniroient ceux dont je pourrois avoir besoin. C'étoit Klaas Baster qui m’avoit fait venir au Namero, en m'assurant que jy verrois des atteliges à acheter. Du Namero l'on me renvoyoir au Camis, et j'avols à craindre de n'etre pas plus heureux. Mais, d'un autre côté; quel parti prendre? et après tout, puisque sans un nouvel aehat de boufs je ne pouvois sortir du lieu où j'étois, ne devois-je pas courir les risques d'un voyage qui devenoit ma seule et unique ressource?

Le fils aìné de la maison s'offrit de monter ì cheval avec moi et de me servir de guide au Camis. Assurément cette proposition étoit faite pour me plairc. Je l'acceptni avec reconnoissance; mais je demandai à y mettre une condition : ce fut que Klaas Baster seroit du voyage. Depuis qu'on avoir su dans la fanille que je l'em-
Tome II. 


\section{V O Y A G E}

menois avec moi; depuis que j'avois eu occasion de déployer à ce sujet mes sentimens vis-à-vis d'elle, je m'étois fait un devoir de le tirer de la tente où il se tenoit caché ct de le faire vivice ostensiblement dans mon camp avec mes autres compagnons. Les parcns paroissoicnt ne plus s'affecter de sa présencc; mais ce n'étoit pas asscz pour moi, ct je voulus absolument le reconcilicr avec eux. Jusqu'à ce moment, l'ivresse, dont ils n'étoient point sortis, m'avoit cmpêclié d'exécuter mon projet. Le laisser dans mon camp pendant que i'irois au Camis, c'étoit cxposer ce brave homme, à qui j'avois tant d'obligations. Il se pouvoit que les têtes s'ćchaufassent de nouveau sur lui, ct qu'on profitôt de mon absenec pour lui jouer quelque tour. Duns ecte incertituảe, le scul parti qui me restoit étoit de l'emmener avec moi; et ce fut par ce motif que j"en fis la proposition au frire, quoique de la part de celui-ci je m'attendisse à un refus. En effer, il parut d'abord hésiter; mais ćbranlé par la ferme résolution où il me vit de rejetter ses services, s'il n'acceptoit point ma condicion; honteux de s'être avancé, ct de paroître rougir de son lì̀re en ma préscnee, il se décermina enfin; et le lendemain, à la pointe du jour, nous partimes tous trois, suivis de quelques-uns de mes Hottentots.

Nous avions à l'est la chaine du Camis. Arrivés au pied des premières montagnes, nous ne trouvâmes que des sentiers étroits et tortucux, par lesqucls il nous fallut gravir, sans pouvoir nous servir que rarement de nos chevaux. Après une marche très-fatigante, ces routes csearpécs nous conduisirent à une gorge profonde' dans laquelle couloit une riviere que mon guide me dit être la RivièreVerte, ct qui prend sa source dans ces montagnes. 


\section{E N A F R I Q E.}

Quelqu'instruit que me parut le jeune homme dans la connoissance locale du pays, son assertion me scmbloit d'autant plus invraisemblable qu'ayant côtoyé pendant long-tems le lit de la Rivière-Verte, je n'y avois pas vu une goutte d'eau courante, et que celle-ci couloit à pleins bords. Cependant il ne se trompoit point. Miais cette cau avoit à traverser des sables et dẹ terrains brîlés qui la tarissoicnt et l'cmpêchoicnt d'arriver jusqu'à la plaine, quand elle n'étoit pas très-sabondante.

L'intention de mon guide, en me conduisant dans la gorge, étoit de m’aboucher avec un colon qui avoit là une habitntion, c'est-à-dire, une mat1vaise cabane dans laquclle il vivoit. J'y achetai six boeufs, qui devoient m'être livrés lorsqu'a mon retour je repasserois par ce liev. Plus loin ce plus avant dans les montagnes, je trouvai un gitc semblable, dont le maitre me vendit, aux mènes conditions, trois autres bêtes, en m'offrant de passer In nuit sous son toit. Le soir approchoit, et le froid étoit déja excessif. Il fut même tcl que je no pus dormir, et que jc passai la nuit à grelotter, enveloppé dans mon manteau, qui me servoit à la fois de matelat et de couverture. Au retour de la lumière, je ne fus plus étonné de cctte froidure si rigoureuse : la terre étoit couverte d'un pied de neige.

NTé dans la zône torride où j’avois passé ma première jeunessc, je derois être sensible au froid; ; $c$ t quoique j'eusse appris à m'y endurcir pendant mon séjour en France, les trois années que je venois de passcr en Afrique m'avoient rendu ma sensibilité première, en me faisant vivre dans une température qui se rapprochoit de celle dans laquelle j'avois pris naissance. Avec une pareille susceptibilité, it m'é$\mathrm{E} \approx$ 


\section{VO Y A G E}

toit extrênement pénible d'avoir à subir les frimats d'un climat glacial. Je ne sais quel journaliste, en parlant de mon premier ouvrage, a dit que je voyagcois en satrape, parce que $j^{\prime}$ avois avec moi trois chariots : certes, si lc critiquc eût pu me voir dans la cabanc du Camis, il füt convenu que le satrape n'étoir pas roujours à son aise.

Le maitre de la case m'avoit prévenu que plus loin, vers le nord-ouest, demeuroit un autre habitant qui, plus riche que lui en bestiaux, pourroit mon vendre davantage. Malgré la répugnance que je me scntois pour entreprendie unc nouvelle course par un tems aussi dur, jc partis. Pendant toute notre marche, qui fut des plus pénibles, nous êtmes à cssuyer une neige continuelle. Elle tomboit à gros flocons, comme dan1s les pays les plus scptentrionaux de l'Europe. C'ćtoit une grande imprtdence à nous, de nous aventurer ainsi dans des circonstances parcilles, car la neige, empêchant de découvirir le sol sur lequel nous marchions, nous riscluions sans cesse de nous rompre le coll en tombant avee nos chevaux; cependant, par un bonheur sur lequel nous ne devions pas trop compter, nous arrivâmes sans accident sur une habitation pitoyable, où nous trouvâmes, dans une mauvaise hutte, 11n vicillard avancé en âge qui sc chauffoit à un feu de bouse de vache, dont il m'invital de m'approcher.

Transi et morfondu, ce fut avee bien du plaisit que je trouvai à me réchauffer; quoique je ne pusse le faire que dans une position très-incommode et aceroupi à la hottentotc; la cabanc étant trop basse pour y rester debout. Clocte à ce bienfait de l'hospitalité, joignit celui de nous présenter du lait et du pain, les seules subsistances qu'il eut en sa dis- 


\section{E N A F I Q U E.}

position. Je me contentai du lait, parce que le pain ayant été pétri, au moins pour un quart, avec les égrisures de la meule qui avoir moulu sa farine, je ne voulois point user mes dents ì manger des pierres. Le soir, notre patron nous régala d'un hacunel (mouton gras), quil fit tuer, et qui fut mieux reçu de ma troupe que son lait.

Pour moi, je enusois avee lui, j'étudiois son caractère, et je cherehois à deviner par quels moyens je le dérerminerois à me vendre les bueufs dont j’avois besoin. Tant de préenutions étoient inutiles. A peine eus-je formé ma demande qu'il me ferma la bouche par un refus net: sorte de réponse peu consolante pour un homme qui, dans l'espoir d'en reevoir une autre, avoit bravé le froid et la neige. Cependant en tâtant le vicillard dans la conversation, je m'étois apperçu que quand j’avois parlé eal-de-vie, ses yeux s'étoient ranimés; et je me flattois que ce moyen d'ćloquence me serviroit mienx auprès de lui que toutes les prières et toutes les instances possibles.

J'avois avee moi denx facons d'eau-de-vie de Franee; $j$ en fis apporter un, et versai quelques rasades au bon-homme pour le mettre en belle humeur; puis, qunnd je vis son visnge s'épanouir, je renouvellai ma proposition. Elle ne fut point rejetrée eomme la première fois; mais némmoins il ne l'aceucillit qu'avee froideur. J'essayai d'échauffer, par quelques rasades nouvelles, ce eommencement de bonne volonté ; et dans l'intervalle, je lui représentai, avee le plus de chaleur qu'il me fut possible, et la situntion désastreuse où je me trouvois, et le service important qu'il alloit me rendire, s'il vouloit contribuer it m'ent tirer. Je m'avunçai mêne jusqqu’à le laisser mầtre des condi- 


\section{$70 \quad \mathrm{VO}$ Y A G $\mathrm{G}_{2} \mathrm{E}$}

tions, et promis de payer, sans rien rabatire du prix qu'il fixeroit aux deux attelages que je lui demandois. C'étoit-là lui mettre la main dans ma bourse; mais la nécessité m’y forȩoit, et il consentit enfi1 à me céder, pour cent quarante rixdalers, quatorze boufs.

Le froid ne m'avoit pas permis de reposer la nuit précédente; il m'cmpêcha encore de dormir celle-ci, et il fallut la passer à eauser avec Clocte, accroupis tous deux auprès de son feut.

Le pis de l'aventure, c'est que le matin quand le patron eut cuvé son cau-de-vic, il he se ressouvint plus des promesses de la veille, et que par conséquent il ne voulut plus les tenir. Heureusement il me restoit encore de sa liqueur favorite. Je recommenęai l'épreuve du jour précédent, et elle réussit de nouveau. Clocte renouvella sa promesse; mais, pour empêcher gu'il ne la retirât encore, j'exigeai, quand il l'eut donnéc, qu'il me conduisît dans son pare, et que lit je pusse choisit les bêtes qu'il venoit de me vendre. A l'inspection des dents et de cornes, toutes me partrent avoir plus de dix ans de service; et nénumoins j'ćtois trop heureux de les trouver.

De retour dans la cabane, je lui fis mon obligation payable au Cap, et tirce, à l'ordre d'un de ses amis, sur Serrurier, le nouveau fiscal. Mais ces quitorze breufs achetés ne me formoient qu'un attelage; et j’eusse bien désiré en aroir deux. Ainsi done, en ecrivant le billet, je proposai à mon homme de lui en faire un du double, et de lui acheter par conséquent le double d'inimaux. Pour donner diz poids à certe proposition, je l'accompagnai d'un grand verre d"eau-de-vic. Il avalat tranquillement ta boisson; puis il ajouta, sans s'émouvoir, que 


\section{E N A F R I Q UE. ?}

non-seulement il ne me vendroit pas une bête de plus, mais qu'il me eonseilloit même avee franchise de lui laisser les atutres; que je venois de faire un marehé de dupc; qu'à six lieues plus avant dans les montagnes étoit une horde hottentote où j'aurois trouvé à eonclure des achats bicn autrement avantageux que le sicn; et qu"au sur-plus il m'exhortoit lui-même à m'y transporter.

Cet aveu naîf, tout grossier qu'il ćtoit, ne pouvoit manquer de me plaire, puisqu'il m'indiquoit le moyen de completter mes attelages. Malgré la neige qui tomboit toujours très-abondamment, je donnai aussi-tôt des ordres pour le départ, et je demandai à Cloete des renseignemens pour me rendre à la horde. Mais quand il fallut nous mettre en routc, je me sentis tout-à-coup tellement transi, tellement pénétré du froid, que la force er le courage me manquant à la tois, je rentrai dans la cabanc et me contentai d'enroyer mes gens, en leur liviant toute la quincaillerie que nous avions apportéc avec nous, et les chargeant de l'employer pour acheter autant de bœufs qu'ils pourroient en avoir.

Dans ees hautes montagnes du Camis, licu le plus élevé peut-être de toute l'Afrique méridionale, l'air est si vif et si euisant que le tempéramment le plus robuste en est affeeté. Soit que je fusse mal disposé, ou que le froid fùt augmenté réellement, comme je n'en doutai point, je ne pouvois plus me réchauffer. Mon dos restoit glacé, tandis que le feu près duqquel j'étois accroupi, me brûloit les jambes. Si par fois, pour dissiper l'engourdissement que me causoit une attitude si gênante, j'essayois de sortio hors de la eabane, l'nir, oppressant tout-ì-coup' ma poitrine, me coupoit la respirntion; je haletois; 


\section{$72 \quad$ V O Y A G E}

il me sembloit que j’allois étouffer; et bientôt je me voyois obligé de rentrer dans la cas : Il est vrai que là j'avois à souffrir d'un autre inconvénient; cclụi de la double fumée que donnoient ì la fois et nos tonrbes et la pipe du patron. Mais des deux maux entre lesquels il the filloit choisir, celui-ci au moins étoit le plus tolérable; et je m'y résignai, en attendant le retour de mes gens.

Ils revinrent, amenant avec cux sept bcenfs et deux vaches; qui, joints aux sept boufs que j'avois conservés des miens, aux quatorze que m'avoir vendus Klaas Baster, et à ceux que je venois d'acheter au Canis, me formoient quarante-quatre bêtes d'attelage. Ce nombre, quoiqu'insuffisant encore pour completter entièrenent celui dont j'avois besoin, sufisoit au moins pour me donner les moyens de continuer mon voyage; ct il me laissoic le tems d'attendre une occasion plus avantageuse et plus fivorable qui me permit de faire mon dernier achat. Ainsi, sans rester plus long-tems dans ce climat glacial, je pris congé de mon vieil hôte, et je regagnai mon comp, en recueiliant sur ma route les animaux que j'avois achetés. Le froid étoit augुmenté encore, puisqu'en beaucoup d'endroits je trouvai de la glace épaisse de deux pouces. La neige d'ailleurs ne cessa de tomber pendant tout le tems que nous fümes dans les montagnes; et quoique je m'artendisse à souffrir extrênencent de la route, 1léanmoins l'assurance de retrouver bientôt dans la plaine une atmosphère plus douce, lia joie surtout de me voir délivré de ces inquićtudes désespérantes qui m’avoient aftigé si long-tems, furent pour moi une distraction si puissante qu'à peine mapperçustje de la rigueur du cicl.

Je ne revis le solcil qu'en arrivant dans cette valw 


\section{E. N A F R I Q U E. 73}

léc qu'arrose la Rivière-Vertc. Là, ranimé par la vue de cet astre bienfaisant, réchaufté par ses rayons, je marchois gaiement sous son influence salutaire, quand tout-à-coup nia troupe fut arrêtée par des cris qui paroissoicnt partir du haut de la montagne. Nous jettâmes les yeux de ce côté, ct nous vîmes une douzaine de zèbres qui, réunis au pied d'une roche, à l'abri du vene, s"y chaufoicnt au solcil.

L'espace qui nous séparoir d'eux étoir extrêmement cscarpé, et nous ne pouvions les approcher qu'en faisant un long détour qui eût cxigé une marche trop Iongue er trop pćnible, et consumé inutilement un tems que je n'avois point envic de perdre. nćanmoins, pour leur firire peur et me donner le plaisir de les voir courir, je tirai un coup de fusil. Le licu où nous nous trouvions ćtoit très-fivorable à une répercussion d'écho; et en cffet, l'explosion, après avoir retenti à nos côtés, alla frapper la roche au pied de laquelle étoient les zc̀bres, et revint se répéter à nos orcilles.

Les zèbres, qui, trompés par la répcrctission du bruit et croyant qu'il venoit du baut de la montagne, descendirent de leur roche au grand galop, et accoururent vers nous, en cherchant à fuir par lat vallée. Cependant, quand ils nous curent apperçus, ils se détournèrent, firent un crochet; puis, gagnant le côté de la montagne opposé à celui qu'ils xenoient de descendre, ils disparurent.

Lne femelle scule, ou moins effarouchée sans doure, ou trop farighée pour gravir la hauteur, abandonna la troupe et continua de suivre le vallon. Jusque-là j'arois, quoiqu'avec peine, retenu mes chicns. Mris quand $j c$ vis l'animal à portćc d'être chassé, je les lîchai, et bientêt ils l'evrent attcint. lager sur-tout la joic noit de si près que, de tems 


\section{$74 \quad V O Y A G E$}

en tems, il lui mordoit les jarrets et les cuisses; et comme c'étoit le plus grand ct le plus fort de ma meute, à chaque coup de dents il emportoit la chair ou la peau. Van der IVesthuysen fils et moi nous courions à cheval, suivis de mes Ilottentors qui, bien qu’à pied, n'alloient guère moins vîte que nous. Enfin, nous parvinmes à entourer la bète. On lui jetta un neud coulant qui l'arrèta; puis l'ayant attachée à la queue de mon cheval, je m'en fis suivre.

D'abord elle suivit asscz tranquillement. Mais soit que la vue des chicns l'inquiétât, soit que la doulcur de ses blessures devint trop forte, après unc centaine de pas elle commença à donner des saccades au cheval qui, ripostant par des ruades, la faisoit cabrer. Cc manc̀gc impatientant m'arrêtoir dans ma marche. Pour le terminer, je formai le desscin de monter l'animal lui-mêtnc. Ẻn vain mon compagnon et mes Hottentots voulurent-ils m'en détourner, en me présageant quclque malheur; le plus grand malheur qui put m'arriver étoit d'être jetté à terre : or , je n'étois pas homme à être arrêté par la crainte d'une chûte; ct je désirois śavoir s'il ćtoit possible de suhjuguer cet animal sauvage que les savans nous representent comme indomptable, et ccla par un simple préjugé ; car il s'en faut de beaucoup qu'il le soit réellement, comme on va le voir; et les Sauvages, dont le témoignage sur ce point doit avoir plus d'autorité que celui des savans naturalistes, lc croicnt très-propre à servir de monture.

Pour me garantir des morsures de la bête, on la musela; on la détacha de mon cheval, et je sautai sur son dos. Sa résistance fut médiocre, et moindre que celle d'un cheval qui n'auroit point encorc été 


\section{E N A F R I Q E.}

dressé. Bientôt même elle marcha aussi tranquillement que mon cheval; et je la conduisis ainsi, pendant plus d'unc licue, jusqu'à l'habitation du colon chez lequel j’avois acheté mes preniers bocufs. Cette éprenve heureuse tme satisfit tellement que je formai le projet de la garder et de m'en fiuire une monturc. Mais pour cela il cût fallu auparavant la panser et la guérir, et ses bicssures étoient trop considérables pour que moi ou mes gens nous osassions l'entreprendre. Je renonçai done à mon dessein. Je crus qu'abandonnée à clle-même et à son instinct, elle sc rétabliroit bicn plutôt et bien plus sûrement; et dans cet espoir, je voulois lui rendre la liberté; mais les Hottentots du colon che\% qui nous nous trouvions, nous supplièrent de la lcur abandonner, afin de sc régaler de sa chair qu'ils trouvent trèsdélicate; et en conséquence elle fut tuée et dépécćc à l'instant même.

Peut-être parmi les personnes qui lirone ce fait, y en aura-t-il qui prétendront qu'il ne prouve rien; et qu'un animal, farigué d'une longue course, affoibli par des blessures, surcharge d'un poids noutveau pour lui, devoit devenir traitable et plus docile. Ce raisonnement, il est vrai, peut s'appliquer à l'homme; il a même licu pour les animaux domestiques, qui nés paticns, ou devenus tels par l'éducation, se soumettent sans résistance au jougg qu'on leur impose, et souffirent même assez tranquillcment les coups et les blessures, ainsi que les remèdes destinés à les guérir. Mais il n'en est point ainsi des animaux sauvages ct des bêtes féroces. Toute contrainte est insupportable à ceux-ci; la souffrnnce les irrite, des douleurs aigues les rendent furieux; et leur rage forcénéc s'cxalte mên:e à un tel point que si dans leur eaptivité ils ne pu- 
vent point se venger sur leur ennemi, ils se détruir sent cux-mêmes.

Il paroit quedans le nombre des animaux qui sont épars sur la surface du globe, il en est un certain nombre que la nature a destinés au service de l'homme : au moins le caractìre qu'elle leur a donné paroît-il ou plus doeile, ou plus aisé à dompter; et c'est cette différence particulière qui les distingue de ceux qu'un nacurel féroce rend dangereux ou nuisibles. Ia propriété dont je parle indique véritablement ln supériorité de l'homme; et sans aller en reehereher la eause dans des miracles et des rêves mystiques, il suffit de l'expérience à ect égard, pour exciter toute notre admiration.

L'homme, dans les différentes contrées du globe, a su dompter, apprivoiser, faęonner à son service, aecoutuner à sa domesticité, plier à ses usages, plusicurs espèces d'animaux divers. Mais je suis persuadé qu'il cn est beaucoup d'autres encore qu'il pourroit se rendie propres; et dans ce nombre je mets le zèbre et le coungha, qui, par leur légéreté, leur force, la beauté Ale leur robe, deviendroient pour lui une conquête aussi précieuse que brillante.

Comme le rèbre sur lequel j'ivois tenté mon expérience étoit une fémelle, et qu'il étoit à présumer qu'un mâle seroit naturcllement plus indocile, je m'étois proposé de renouvellar l'épreuve sur un mâle, sil m'arrivoit d'être assez heureux pour $\mathrm{m}^{\prime} \mathrm{en}$ procurer un; mais pendant tout le cours de mon voyage, j’en ai cherehé vainement l'oecasion et n'ai pu la trouver; et quoique rien ne soit plus aisé à un voyageur qui pareourt l'Afrique, que de chasser et de tuel de zèbres, il est trèsdifficile d'en atcraper de vivans, à moins d'avoir 


\section{E N A F I Q U E.}

d'excellens ehevaux de course, qui ne soient point fatigués d'une longue marche; et eneore faut-il chasser ces animaux dans quelque plaine, car pour peu qu'il y ait des montagnes dans le voisinage, les zèbies $s^{3} y$ mettent bien vîte à l'abri de la vîtesse des chevaux qui ne peuvent gravir aussi lestement qu'cux. Malgré ce défaut d'un double essai, je n'en suis pas moins convaineu qu'il est possible d'apprivoiser et de rendre domestique le zèbre.

Cet assujettissement, je l'avoue, exige des soins, de l'adresse, de la patience, enfin une éducation suivie et raisonnée. Cependant l'institution, quelque parfaite qu'clle soit, ne réussit pas également auprès de toutes les espèces: il en est qui naissent lourcies et stupides; et celles-ci joignent à leur manque d'intelligence unc opiniâtreté résistante ct un naturcl récalcitrant, qui s'opposent aux progrès de l'édueation. Peut-être même, si l'on vouloit aller plus loin, que les espèces les plus perfectibles sont celles qui, par leur genre de vie, obligées à des combats, à des ruses, à une continuité de gुuerre ou offensive ou défensive, ont plus d'oceasions pour dévclopper leurs facultés, pour exerecr leur instinet, enfin pour réfléehir; si, en parlant des bêtes, il est permis d'employer ce mot, qui pourtant leur apparticnt aussi bicn qu’à nous. Le lion, qu'on nomme le roi des animaux, parce qu'on le croit sans doute le plus méchant, est lui-même un des plus aisés à dompter. Sans citer ici en preuve tous les faits que raconte l'histoire sur l'attachement et la reconnoissance qu'a montrés quelquefois ce prétendu roi si redoutable, je me contenterai de rapporcer le témoignage du citoyen Desfontaines, aujourd'hui démonstrateur de botanique 


\section{$78 \quad$ VO Y $\triangle \mathrm{GE}$}

au Jardin National des plantes. Pendant son séjour sur les côtes de Barbarie, ce voyageur naturaliste à vu mille fois des enfans jouer et badiner dans les rues avec un lion qui se prêtoit innocemment à ces agaceries, comme eût pu faire un jeune chien.

Les conséquences qui résultent de ces réllexions seront sans doute traitées de paradoxes par une certi le classe de savans, qui a plutôt fait de trancher les questions que de les examiner. Avec deux ou trois gros principes de prétendue philosophie, et quelques phrases sommantes et impératives, on a bientôt détruit les expériences de l'habitude et de l'obscrvation locale. On se fait un systême dans son cabinet, on érige ses préjugés en axiome; ils parcourent un cercle d'adulateurs et de gens dévoués; qui, voulant ol feignant de croire tout ce qu'on leur débite avec autorité, transmettent l'erreur à de plus dévots encore, et voilà la nature jugée dans un quatrième étage, parce qu'il n'y a rien à répondre à des sentences, et qu'en fait d'observations, il est plus facile de croire que de douter.

Quant à moi, je répéterai jusqu’à satićté : j’ai $\mathrm{vu} ;$ et les pages les plus ćloquentes, et les discours les plus brillans ne parviendront jamais à m'en diss!nder.

Oui, j'ai vu dans les déserts de PAfrique une quntité prodigicuse d'acquisitions à faire, qui augmenteroicnt nos jouissances en diminuant nos travaux. Bien plus, je suis convaincu qu'il seroit facile de nous appropricr les plus grands quadrupèdes, tels que le buffic (I), le kana, le pazan, le

(1) $\Lambda$ l'cgard de ce quadrupdde, les immenses fardeaux qu'il traine chaque jour sur les rivages du Tibre dispensent de toute 
coudou, le buballe et le tzciran. Combien les petites gazclles ne prospércroient-clles pas dans nos climats méridionaux; il n'est pas jusqu'à certaines espèces de volatiles dont nous ne pourrions peupler nos basse-cours. A notre honte, la Hollande, dont le climat est bien moins favorable que le nôtre, s'est déja rendu familic̀res bcaucoup d'espèces qui y croissent et multiplient comme dans leur pays natal. Indifférens à tout usnge qui ne sanctifie pas le caprice et la légćreté, on se garderoit bien d’aller saisir chez un peuple voisin, unc institution respectable, et l'on a bien plutôt fait de ridiculiser son sang froid, sa sagesse ct sa prévoyance, que de chercher, à son exemple, les moyens d'en recueillir des fruits. J'ai compté, avec autant d'étonnement que de plaisir, dans les basse-cours des Hollandois, plus de vingt espèces de canards et d'oies sauvages, qui nous sont inconnues; et je les y ai vu se multiplier comme les antres oiscaux domestiques de nos climats. Dans ce nombre j'admirois cette superbe espèce de sarcelles de la Chine (I), dont nous n'avons pas même la dépouille danns nos cabinets d'histoirc naturelle. L'oie de la Chine, l'oie d'Egypte, l'oie de Barburic; les différens canards du Cap de Bonne-Espérance; la sarcelle de In Caroline et bicn d'autres, ainsi que les hocos d'Amérique, figurent souvent sur les tables de la Hollande. Mais comment aurions-nous songé à des espèces étrangères, nous qui négligeons celles de notre propre pays? Et non-seulcment ces animaux prosperent sur les marais glacés de la Hollande,

autre reffexion; et le bulle d'Afrique est d'une espece bien supericure, pour la force, à celui d'ltalie.

(1) Voyez les planches enluminces de Buffon, $N^{n} \cdot 3 \oplus 5$. 
mais on en obtient des métis en croisant leurs races. Le luxe seul a quelquefois porté chez nous les riches à tenter, pour leurs plaisirs, quelques essais frivoles en ce genre. Lcs faisans de la Chine, les paons et les pintades, qui commençoient à se multiplier d'une façon à encourager nos tentatives, bicn loin d'avoir inspiré aucun but d'utilité et d'abondance, après avoir servi d'ornement et de parade dans les jardins de nos oisifs, ont depuis été totalemeni négligés. J'ai souvent proposé de pnreils essais ; j’aurois parcouru la Hollande d'où j'aurois rapporté toutes les espèces déja aclimatćes; j’y aurois pris toutcs les instructions nécessaires à leur éducation; je me serois enfin volonticrs établi le précepteur de ces animaux utiles: mais même pour un emploi de cctie nature il falloit des protecteurs et l'appui de tel homme en place ou de quelques grandes dames, qui trouvoient probablement fort singulier qu'un homme voulût sacrifier son tems ex innginât quelque nouvenuté pour le plus gुrand bien de son pays. Il est à croire que sous un gouvernement libre on s'occupera davantage de l'utilité publique; que les voyageurs seront récompensés; qu'un pauvre hère, dévoré de l'amour 'de la science, ne sera plus réduic à ruiner sa fortune, pour les menus plaisirs d'un tas de frélons dévorateurs et stupides, et qu'enfin les récompenses et les emplois ne seront pas toujours le partage de tant de conseillers fameux, mais de celui qui véritablement a travaillé et fair des découvertes utiles. Ce n'est pas de cela seul qu'il s'agit, et je vois pour l'avenir bien d'autres voux à forincr.

Notre route nous obligen à côtoyer les bords de la Rivic̀re-Verte: la fraicheur de cette vallée riante, 


\section{EN A F R I Q UE. 8 r}

fiante, les sinuosités qu'elle parcourt, les points de vue qui se reproduisoicnt à chaque pas, sous des formes diverses, remplissoient mon imagination des plus douces pensées; je foulois un tapis de verdure et de fleurs; les côteaux environnans, chargés d'arbustes et de plantes brillantes, offroient à mes yeux autant d'abris que de bosquers délicieux; c'étoit un jardin cianss le sein d'un désert.

Parmi ces familles nombreuses de fleurs et de plantes encore vierges, j'cn remarquai plusieurs qui éroient magnifiques; j'en distinguai une qu'il m'eût été difficile d'oublicr, c'est ce géraniun dont j'avois appris si douloureusement à connoître la piqûre et dont je portois encore les stigmates. J'en vis beaucoup, les uns à fleurs blanches d'autres aे flcurs jaunes. Peu exercé à l'érude des flcul's, er toujours plus disposé à les adorer qu”à les flétrir, javois pris dabord celles-ci pour des espèces différentes; mais j'cus bientôt changé d'idée, lorsque je m'apperęus qu'une mène tişe portoir soivent à la fois des fieurs jaunes er des blanches, ee là-dessus je bitis aussi mon idyle.

Adieu vallons, côteaux, géranium et fleurs de toutes les espèces, tapis de verdure, bords enchantés, douces rêveries, adieu; nous allons rentrer dans les glaces.

Pour regagner lc Namero, il nous falloit traverser encore une autre chaine de montagnes couvertes de neige; ainsi, en moins de huit heures de marche, nous cumes successivement trois saisons, c'cst-à-dire, detix hivers partagés par un été; mais ce changement subit de température nous donna aussi à tous un enrouement, qui ne se dissipn que plusieurs jours après notre recour chez Van der Westhuysen.

Tome $I I$. 


\section{2}

$\mathrm{VOYAGE}$

Le premier objer que je vis là, en mettant pied à terre, fur cc maudit Pinard, quc ma mauvaise fortune m'avoit fait rencontrer pour mon supplice: j’eusse donné rout au monde pour on ĉrre débarrassć; mais le bourreau vine à noi tout exprès pour me dire, qu'il s'étoit hait un plaisir de m'attendre.

Mon intention éroit d'accorder à mes Hottentots er aux bestiaux que j'ancnois, un jour de repos, et de repartir lc lendemain. Mais la famille Van der Westhuysen me représenta qu'ayant des bêtes nouvelles dont je ne connoissois point cncore l'allure, je conrois quelques risques en les cmployant sans épreuves préliminaires. Elle s'engagea, si je voulois lui prometre de rester trois jours de plus chez elle, à me prêter des relais quî me conduiroicnt jusqu’à la rivicte Kanssi; j'acceptai, quoique je mattendisse à beaucoup d'impatience contrc Pinard, et d'ennui de la part des buveurs.

Par un hasard singulicr er impossible à prévoir, les choses toumèrent autrement. Pendant mon absence, Engclbrecht étoit allé plusieurs fois dans mon camp causer avec mes Hottentots. Un jour que la conversation rouloit sur moi, ils lui parlèrent de ce divertissement de mon premier voyage, que dans ma relarion jai appcllé la folle journée, ct où, pour les distraire d'une trop furte ration d'eru-de-vic que j'avois eu l'imprndence de leur" donner, j'imaginai de les faire danser, en jounte de la guimbarde. Cette fête burlesque n'étoir point sortic de leur mémoire. Ils ne se rappeiloient qu" vec transport ex enthousiasme l'instrument qui leur avoit donné tant de plaisir; et d'après leurs éloges, Engelbrecht, persundéqu" un hommequi jouoit de lis guimbarde étoit un excellent musicien, et qu'un musicien parfait savoit toucher tous les ins- 


\section{E N A F R I Q U E.}

trumens, avoit imaginé à soln tour de m"employer à recrécr la société rémic dans l'habitation.

Il avoit che\% lui une manière de violon, qui, suspendu au mur près de son foyer, $\mathrm{y}$ séchoit en silence, sans en avoir été décroché une senle fois diepuis dix ans. Pour surprendre agréablement la compngnie, il l'envoyal chereher sccrètement; puis, quand je fus dans l'asscmblée, il me le mit en main, en me priane d'cmployer mes talens à la divertir. On aura une idéc de ce qu'étoit l'instrument, quand j'aurai dit que ses cordes avoient été faites par Enģelbrecht lui-même. Néanmoins je le pris, et j'y raclai quelques contredanses, qui à l'instant, et comme par magie, mirent en mouvement tonte la compagnie. Cette musique me déchiroit le tympan; mes dents grinçoient de déplaisir ; mnis toutes les oreilles la trouvoient délicieuse, et l'on ne cessa de sauter que quand la lassitude eut épuisé les fores. Le lendemain, hommes et femmes vinrent en troupe me supplier de me prêter de nouveau à leurs plaisirs. Le surlendemain, ce furent mêmes instances. Enfin, mes trois journées se passèrent presque tontes entières à gratter les boynux du violon; et la cohuc se trćmoussoit d'aise autour de moi.

Au milieu de ce sabat, il y avoit une chose qui m’étonnoit; c'est que la danse occupât tous les instans, et qu'on cut oublić la liqueur favorite. Mais depuis l'arivéc de Pinard, et par ses libéralités, il s'cn étoit tant bu, qu'on avoit fini par la trouver détestable et s'en dégoûter. Jaloux de témoigner ma reconnoissance à une famille qui m?avoit rendu des services et qui alloit m'en rendre cneore, jc crus pouvoir remplacer Pinard; et j'enroyai chercher dans mon chariot une cave remplie 
de flicons. Elle contenoit des liqueurs fines de la Martinique, pat la dame Anfoux. C'étoit-là une provision d'appareil, que je réservois pour les grandes occasions. Je comptois m'attirer de grands remercimens en la présentant à ces hommes demisauvages; mais javois bien mal calculé. Ils atouvèrent les liqueurs trop douces et les rebutèrent. Quane aux dames, après les avoir gouttées toutes, et assez largenent, les tines après les autres, elles leur donndrent, à la vérité, la préférence sur les mauvaises eaux-he-vie du Cap; mais elles décidèrent, comme les hoinmes, à l'unanimité, que les recettes et les fabriques de la dame Anfoux ne valoient rien pour la colonic.

Ces gosiers robustes, accoutumés depuis quelques jours à une boisson âcre et brìlante, se troulvèrent affadis par une boisson liquoreuse et sucréc. Les buveuses se plaignirent de maux de ceur; et ce fut alors qu'elles maudirent bien sinecrement les liqueurs des flacons. Pour moi, qui, arec l'intention de régaler d'une manic̀re distinguée cette bonne compagnie, n'avois réussi qu’à faire des mécontens et des malades, $j$ 'étois très-fâché de voir la dernière journéc de mon séjour se terminer par un pareil dénouement. Ainsi jallois perdre en un instant tout le fruit de mes trois jours de musique. Heureusement j'avois, parmi mes provisions, des citrons du Piquet-berg et d'cxcellente eat-de-vic de France. Je mavisai de faire du punch un peu roide; il fut trouvé divin. La gaieté reparut, les maux de coxur se dissip̀rent, et cette journée se termina, comme clle avoit commencéc, par une allégresse universclle. Dès long-tems on n'oubliera au Namero Paterson et son vin de Bordcaux; mais long-tems aussi l'on y parlera, je crois, et de ma 


\section{E N A FRI CUE. 85}

musique, et de ma danse, et de mon punch à la diable.

Il ne me manquoit plus, pour partir content et m'applaudir de mon·séjour dans ces montagnes, que d'achever de reconcilicr Klass Baster avec sa famillc. Plusieurs fois déja je m"étois hasardé à parler de lui à quelques-uns d'entre cux, et ils m'avoient paru assez bien disposés. La continuité des plaisirs sembloit avoir éteine les haines. Son frc̀re lui-même, pendane tout notre voyage du Camis, avoit vécu avec lui en bonne intelligence. D'ailleurs, j'espérois beaucoup de la disposition favorable oil se trouvoient les esprits et de la gaieté affectucuse que venoit d'inspirer le punch. Je proposai done un traités de paix, ou plutôt un raccommodement avec le malheurcux proserit; ct d'un consentement gećnéral, ma demande fut accordéc, sans la moindre réclamacion.

A l'instaut même, je courus annoncer dans mon camp cette bonne nouvelle à Klaas Baster. Je revins lc présenter à sa famille; et non-sculement il se vit accucilli sans le moindre signe de mncune, mais tous successivement lui présentèrent la main : ce qui chez les colons, comme je l'ai dit ailleurs, est le témoignage d'amitié le plus authentique. Quoique lc bon vicillari, par crante de sa femme, ll' cût pas osć montrer ses sentimens pour son fils, il leur donna carrière dès qu'il lui fut permis de les avoucr. Lui-même, il lui versa rasade, il erinqua le premier avec lui, et lui fit amitić. Le Baster, hors de luimêne, manquoit d'expressions pour remercicr ses parens et pour me témoigner sa reconnoissance. Je jouissois de sa joie; j'étois heureux de son bonheur, ct je m'applaudissois divoir pu cnfin m'acquiter en partic envers un homme it qui mes gens et moi nous devions la vie. 


\section{6}

VOVAG $\mathrm{H}:$

Ce fut Van der Westhuysen qui le iendemain, selon sa promesse, me prêta les attclages qu'on mit à mes voitures. Nous partîmes dès le matin.. Luimême, avec sa famille, monta un charior particulier, et fut du voyage, parce que je m'étois engagé, ainsi que lui, d'aller coucher chez Engelbrecht. Son fils â̂né, par politesse et par égards, voulut conduire le chariot que je montois. Tel est l'usage chez les colous; c'est-là une manière d'honorer quelquin, et l'un des plus grands témoignages de considération que l'on puisse domer. D'nprès les idées reçues, je ne pourois, sans lui faire un affront, me refuser à cet homeur. Mais à pcine fut-il sur le siège, que, mettant les beetl's aul galop, il me conduisit ventre it terre. Ce préjugé est entcore un de ceux qui ont généralement licu dans la contrée. En pareil cas, un ģuide ne croit montrer son talent qu'en menant le plus lestement qu'il iui cst possible : dût-il crêver ses bêtes, il veut faire preuve de prouesse. En vain je priai le mien de modérer les siennes. Les chemins śtoient détestables, et les cahots me faisoient craindre is chaque instant que la voiture ne versàt et ne fut brisée; mas il cût cru son homneur compromis d'aller au pas, et sa gentillesse me coûta deux cruches de jus de limon, qui furent cassées, et que je regrettai benucoup.

Quclque irréparable que fut, dans les circonstances, cet accident, je m'en consolai néanmoins,

- parce qu'il cût pu m'en arriver d'autres, beaucoup plus zonsidérables auxquels je venois d'échapper. Mais je fus désolé, quand, quelque tems après avoir mis pied a terre chez Engelbrecht, je vis arriver Pinard. La présence de cet homme étoit devenue un supplice pour moi; cr il sembluit qu'il eut juré de ne plus me quitter, 


\section{E N A F R I Q E. 8 ?}

L'emplacement de l'habitation d'Engelbrecht étoit infiniment plus agrénble que celui de son beallfrère; malgré cela sa maison, ou pour mieux dire son hangard, étoit, s'il est possible, encore moins logeable, et annonçoit le peu de soin du maitre et 'l'insolicince, à cet égard, de toute la famille, qui étoit très-nombreuse. En entrant daits la pièce qui servoit de refuge à tout ce qu'il y avoit de monde sur cette habitation, je fus assailli par une troupe d'enfuns de tout âge, que je pris d'abord tous pour des Basters, ou métis Hottentots et des vrais Hottentots; mais je fus vertement redressé. Lc père et la mère s'apperęurent de ma méprise : honteux d'avoir des enfins si nésligés autour d'eux, ils s'cmpressèrent de me montrer les leurs; et il falloit l'œil d'un père pour les reconnoìre; car ils étoient les uns tout à faits nuds, les autres couverts de lambenux de peaux de mouton, toutes dégoùtantes de fange. Quant à la lille ainée, qui avoit fit une toilette en règle, clle vint s'offrir à moi dans ses plus heaux atourss; s'étant imaginée de s'afitubler la tête do la plus bizarre coëffure que $j$ 'cusse jamnis vue. Une espèce de bomnet, composé entièrement de plumes noires d'aniruche, ombrageoit le front de cette grande poupée. Je la louni beaucoup sur son ajustcment; clle fit des-mines, cut l'air de rougir de ses attraits, et finit cependant par moffrir un gros paquet de magnifiques plumes blanches, et que, sans gêne, je lui payai trois rixdalers. Bien plus, il s'établit entre nous $11 n$ petit projet d'association, d'où il devoit résulter de grandes fournirures de sa part, et de la nienne, en échange, quelques cadeaux de rixcialers.

Je dois pourtant avouer que les quatre jours que je passai sur cette habitation, furent marqués par 
des témoignages vrais d'amitié; nous bûmes du punch, nous fìmes de la musique, et dansâmes unc grande partie de toutes les nuits : les jours, je chassois. En parcourant toutes les montagnes des environs, je remarquai plusieurs belles plantes dont les dessins font partie de mon porte-fetrille. Les zćbres, les pazans et les conciounias sont assez communs dans tout ce pays; mais singulièrement effarouchés par la chasse continuclle qu'on leur fait, il est très-difficile de les aborder à la portée du fusil. Les cléphans se montrent aussi beaucoup dans ces parages; mais n'y sćjourncit guère, se temant de préférence dans les environs de la mer, où les dunes leur scrvent d'abri. Malgré la quantité prodigieuse de bestiaux que possédoit Engelbrecht, il ne voulut jamais sc défaire d'un supcrbe attelage de douze boufs noirs, qu'il me montra avec une sorte d'ostcntation. Il est vrat que je n'en avois jamais vu un aussi égal ni aussi bicn assorti; ct malgré la somme de deux cents rixdalers que j"en offris (prix excessif pour le pays), je ne pus l'obtenil; en revanche, je fis l'acquisition de plusieurs moutons et d'une vache que je fis tuer et saler pour mes gens; j'augmentai cncore ma provision de tout le tabac qu'on put nue éćce. Engelbrecht devant dans peu fare un voyage au Cap, je profitai de l'occasion, qui sembloit être la dernière puisque je ne devois plus trouver d'habitation sur ma roure, pour écrire à mes amis. A mon départ, mon hôte attela à na voiturc les hœufs dont j'ai parlé, et il moffrit non-seulement de me conduire jusqu" it ì Grande-Rivière, mais fournit aussi mes autres voitures de relais vigoureux, alin de ménuger mes bceufs. Quand je me remis en routc, Pinard me suivir cncore. En vain, pour me débarisser de lui, 


\section{E N A F R I Q U E. $\quad 89$}

jc m’arrêtai après quatre heures de marehe, près d'une source que nous trouvâmes sur notre routc; en vain, je fis dresser mes tentes dans l'espoir que, nc eroyant pas sa journéc assez pleine, il mareheroit en avant et me laisseroit; mais il fit, comme moi, halte ì la source, et je vis qu'il faudroit un éclat pour me séparer tout à fait de cet ennuyeux.

Le lieu nourrissoit.une quancité immense de gelinottes. Elles venoient par millicers boire à la sour$c c$, sans que notre présence parût les effirouchcr; et c'étoit-là, pour notre euisine, une manne abondante. De ma tente, je tirois sur leurs volées avec mon grand fusil, qui, à ehaque eoup, en tuoit au moins une vingtaine; mais eette ehasse me fic faire une remarque que je erois importante.

Les oiseaux, ainsi que les autres êtres vivans, ne possèdent pas tous au même degré la scnsibilité physique. Il en est qui suceombent à la moindre doulcur, tandis que d'autres résistent à de fortes souffrances. Tous les ehasseurs savent, par excmple, qu'il suffit de la plus légère blessure pour abattre unc bécasse, et que souvent elle est plutôt tuće par sa ehûte qụ̣ du eoup qu'elle a reçu. Moi-même, j'en ai ramassé plusicurs qui étoient mortes, quoiqu'elles n'eussent eu qu'une légère blessure par un grain de plomb. La gelinotte du Cap, au contraire, paroît avoir, ou des organes peu sensibles à la doulcur, ou une sorte de eourage qui la lui fait supporter jusqu'au moment de la mort. Quoique j’eusse tiré au milicu de la volée, et que par conséquent mon coup cut porté tout enticr, il étoit très-rare qu'il cn restât sur la place dautres que celles qui avoient les âles eassées ou reçu le coup à la tête. La nuće reprenoit son vol, et les blessés fuyoient avec elle. Mais si 


\section{0}

on la suivoit de l'wil, bientôt on les voyoit s'en nétacher et tomber sans donner aucun signe de vic; ct, même après qu'elle avoit disparu, on pouvoit en suivre la trace, en ramassant les mortes sur la route.

Ce que je dis ici des volatiles, on peut également le dire des quadrupèdes. Souvent même il existe, pour ln sensibilité, une très-grande différence entre des animaux analogues; car ufre blessure assez légère dans le corps, fait périr la panthère et le léopard; tandis qu'avec des côtes rompues et la tête fracassće, le chat, beaucoup 'plus petit, vir er se guérit en peu de tems. C'est aux anatomistes et aux physicicns ì nous dire quelle est la cause véritable de cette étonnante diversité. Je remarquerai seulement qu'il est des individus dont le corps offre à la fois, et des parties extrnordinairement sensibles, et des parties qui paroissent ne l'étre aucunement. Et pour ne citer qu'un seul excmple, le porc-épic du Cap a les os de la tête si fragiles, que d'un seul coup de baguctte vous lui casscrez le crâne et le ferez périr; mais en vain vous le frapperez sur lc corps à grands coups de bâton, vous ne pourrez le tuer. Au reste, ne croyez pas que ccte sorte d'impassibilité soit un effet de la dureté de sa peau; il l'a, au contraire, très-délicate; et la preuve en est que si, du bout des doigts, l'on pince quelques-uns de ses piquants ou de ses poils, il suffit de les tirer légérement pour arracher en même tems toute la partic de la peat dans laquelle ils se trouvent inplantés.

En mémoire des oisenux que j’avois eu occasion de tuer à la source, je la nommil Fontaine des gelinoltes; elle est nomméc dans le pays MatjesFontyn (Fontaine des mattes). Peu s'en fallut que, 


\section{E N A R I Q E. 9 I}

dans la colc̀re oì me mettoit Pinard, je ne la nommasse Fontaine du tourment. Cet homme acharné à me suivre, comme sill se fût fait une loi de mc désoler, marcha encore de conserve avec moi la jouméc suivantc. Pendant la route, je cherchois dans ma tête qualques moyens de me débarrasser de lui; ct je le comnoissois si ténnce que je désespérois d'y réussir. Enfin, arrivé au Kaussi, je crus en avoir trouvé l'oecasion.

Ce torrent étoit à sce, comme presque tous cenx que, depuis quelque tems, nous avions cu à traverser. Mais son lit étoit creusé dans des rochers, et je ne doutois pas qu'en plusicurs endroits ils n'cussent des cavités qui conticndroient de l'eau. La vraiscmblanee de ma conjecture, jointe au site romantique du licu, me détermina à dresser là mon camp. J'annonçai mêne à Pinard que j"étois résolu à y passer unc semaine entičre; et pour qu'il n'en doutât pas, je renvoyai les attclages d'Engelbrecht. Pour lc coup, il prit son parti; il continua sa route, ct cnfin j’en fus déburassć.

Ce que j'avois conjecturé se vérifia promptement. A peine cus-je envoyé quelques-uns de mes gens à la découverte de l'cau, qu'ils revintent m'annoncer qu'ils en avoient trouvé en vingt endroits. J'etois campé très-près des énormes montagnes granitiques, à travers lesquelles le Kaussi s'étoit ollvert un passage. En se creusant un lit, le torrent avoit donné aux rochers mille formes bizarres, qui amusoient l'eeil, et qui, lorsque l'eau étoit abondante, devoient former des cascades naturelles d'une grande beauté. En général, l'emplacement oì se trouvoit mon camp étoit aride. On y voyoit peu de pâturages, ou au moins ils ne. s'y montroient gne par bouquets; mais il étoit couvert de hauts 
mimosas, fort épais, et lcur ombrage nous devenoit d'autant plus agréable, que, depuis la Rivièredes-Elćphans, c'étoient les premiers grands arbres que nous rencontrions.

Un botaniste auroit fait ici unc ample moisson de plantes différentes, notamment de plantes grasses dont le pays abondoit; je pris les dessins de celles qui me parurent les plus remarquables, entr'autres, d'un magnifique ixia, très-élevé, dont les fleurs, fort nombreuses et d'un rouge foncé, récréoient la vue. Je remarquai encore d'énormes et hautes touffes de la grande euphorbe, dont toute la plaine étoit parsémée. Les Sauvages se servent du latit de cette plante pour empoisonner les fièches dont ils font usage pour la chasse du grand gibier. Je voulus essayer la propriété vénéneuse de cette plante; ct, malgré los reprósentations de mes Iottentots, je mis sur ma langue une petite goutte de son suc lniteux, qui me causa, pendant plus de deux heures, unc cuisson insupportable. Je coupai sur ln plante une rouelle, que je présentai à mon singe; il lit en arrière un saut d'effiroi, et s'enfuit à une grande distance, sans plus vouloir se rapprocher de moi.

Klaas Baster me parla en homme instruit de cette euphorbe; selon lui, c'étoit dans le moment où nous nous trouvions, colui de sa floraison, que son suc est le plus actif, ct c"est alors aussi que les Sauvages en font lcur provision. Pour le recueillir, ils pratiquent sur la plante de petites incisions, par lesquelles il découle; et on le reçoir dans des vases particuliers, descinés à cet usage. D'abord sa couleur est laiteuse et blanehe; mais bientôt elle devicnt brune; elle s"épaissit, et forme une sorte d'électuaire qui, cn se concontrant de 


\section{E N A F R I Q U E. 93}

plus en plus, acquiert une vertu plus active et plus meurtrière.

C'est avec certe pâte mortelle que les chasseurs enduiscnt lcurs flèches. Liexpéricnce leur ayant appris que très-rarement une flèche ortinaire suffit pour abattre une pièce de gros gibier, ils ont imaginé de l'arrêter subitement dans sa fuite, en ğlaçant et congulant son sang par l'effer prompt et infaillible d'un poison subtil. Pour qu'il meure, il faut que le vénin arteigne le sangr er s'y mêle; néanmoins, par un effet inconcevable, l'animal, quoiqu'cmpoisonné, n'en est pas moins un alimene sain, comme je l'ai dit aillenrs.

L'extrémité des flèches est faite d'un fragment d'os, bicn acérć. Si on y employoir du fer, l'acrivité du poison attaqueroir le métal, qu’il convertiroit en rouille; et il sc détachcroit et tomberoit avec cette rouille. Quand on y joint une pointe de fer, on a soin de placer la pâte de façon que le métal 11 'cn soit pas touché.

Dans les lieux où il y a de petits réservoirs d'eat que fréquente le gibier, les Sauvages emploient contre lui l'euphorbe d'unc autre manière encorc. Ils la coupent par tranches; jettent les rouclles dans le bassin, en ayant soin d'agiter l'cau de tems en tems pour faciliter l'infusion; puis, quand ils la croient sufisamment cmpoisonnéc, ils en retirent les morcenux, parce qu'aucun animal n'oseroit $y$ boire s'il les y appercevoit. Certe méthode, beaucoup plus sûre que la première, scroit en même tems très-destructive, si le gibicr n'avoit un instinct qui l'cn grarnntit. On assurc qu'il est des espèces dont les sens sont si exquis, qu'elles peuvent distinguer sans pcine l'cau cmpoisonnéc, et que jamais, pendant le jour, elles ne s'y laisseroient trom- 


\section{4 \\ $\mathrm{VOYAGE}$}

per. Aussi a-t-on soin, tant que le soleil est sur l'horison, de se tenir près du réservoir pour les en ćcarter, et de ne le laisser libre que quand la nuir ne permet plus à l'œil d'y rien discerner.

I.'instinct animal est une qualité occulte difficile à définir; il résulte sans doute de la combinaison des élémens dont tout être vivant est composé, lesquels répugnent à tout ce qui n'est pas de leur nature; mais ceci même rend plutôt compte de l'effet qu'il n'explique la cause. L'homme a aussi son instinct qui l'approche de ce qui est bon, l'eloigne de ce qui est nauvais. Mais l'homme social le perd bien vîte, et souvent il ne lui donne pas le tems de se développer. Les Sauvages, au contraire, et tous les animaux libres, l'exercent et le perfectionnent sans cessc. Plusieurs fois j'ai trouvé des bassins empoisonnés avec l'cuphorbe; et quand l'cau étoit tranquille, jappercevois à sa surface une légère couche luisante, d'une huilc brun-verdâtre, qui étoit le poison. Or, si ma vue suffisoit pour distinguer ce foible indice, combien ne devoit-il pas être sensible pour des animaux qui, presque tous, l'ont si parfaite! J'aurai bientôt occasion de revenir sur cettc matic̀re, et je rapporterai mâme des expériences qui prouveront que Klaas Baster, en me parlant des effers de l'cuplorbe, ne m'avoit point trompé.

Au reste, quoique cette façon de se pourvoir de gibier paroisse devoir produire beaucoup, elle est cependant bien moins avantageuse qu'on ne le croiroit; parce que, si les bêtes qui viennent boire sont trompées par la vue, elles sont bientôt averties par le goût, et se retirent. J'avois un jour empoisonné une mare d'eau : il y vint, dans la journée, plus de quatre mille gazelles (spring-bock); et 


\section{E N A F R I Q U F. 95}

neanmoins je n'en cus que trois, avec une hienne que j"y trouvai le lendemain matino, et qui étoit morte dans la nuit. Une harde de gazelles se rendclle au bassin, les premic̀res ou les plus altérées cherchent d'abord à s'abreuver; mais à peine ontelles touché l'eau qu'elles s'en éloignent avec effroi, et la troupe fuit à l'instant, sans s'approcher du. pièce mortel.

In parcourant le lit desséché du Kaussi, je trouvai différentes sortes d'oiseaux aquntiques, et spécialement ees ennards sauvages que les colons appellent berg-end (canard de montayne). Ils nageoient et s'śbattoient dans de petits bassins des rochers, qui conservoient encore de l'eau, et où peut-être ils n'avoient jusquc-là jamnais été troublés par aucun humain. Vis-à-vis d'un de ces réservoirs, j'avois trouré une caverne dans laquelle je venois passer des heures entières à épicr ceux de ces oiseaux que je désirois me procurer.

Un jour que jy étois caché, je vis arriver au bassin un élan-gazelle, le kana des Hotrentots. Sa vue me fit d'autant plus de plaisit qu'il n'écoit eertainement pas seul dans le canton, et qu'obligé, depuis longtems, de nourrir ma troupe aux dépens de ma bergerie, j'eusse étć fort aise d'alimenter notre cuisine du produit de notre chasse. Ma gazelle m’eût épargné quelques moutons; mais, pour lc moment, je n'avois que du plomb dans mon fusil, et je craignois d'y couler une balle, de peur que le mouvement et le bruit ne la fit fuir. Néanmoins, conme elle n'étoit qu'à dix pas de distance et que j'avois deux coups à tirer, je me hasardai de les lui lâcher ensemble, et, en effet, elle tomba dans l'eat, où elle se noya.

Ravi d'une bonne fortune sur laquelie je n'avois 
pas tron compté, je courus à mon camp cherche: du monde pour enlever ma proie; et cn même tems j'emmenai avec moi quclques chasscurs ct mes chiens, afin de battre les environs et de chercher si nous ne trouverions point quelques autres kana; mais il fallut, pour cette fois, nous contenter de cette sculc pièce.

Un jour que nous descendîmes le lit dù torrent, avec mes chasscurs et mes chicns, dans l'espoir de trouver quelques pièces de gibier à tuer; tout à coup mes chiens donnèrent; ct bientôt nous vìmes devant nous une panthère, couchće sur une gazelle qu'elle dévoroit. Notre préscnce ne parut nullement l'intimider. Elle jettoit sur nous des regards de fureur et ne quittoic point sa proic. Nous étions sept tireurs, ct ne courrions pas grand risque en 1'attaquant. Lorsque nous fûmes à cinquante pas, elle se souleva en tourṇnnt la tête, et scmbloit chercher parmi nous celui sur qui elle s'élanceroit. IMon fusil ćtoit chargé à balle. Je Ia tirai. Blesséc du coup, clle prit le parti de fuir, ct reçut, dans sa retraite, quclques légères blessures encore. Enfin, elle alla se réfugier, cent pas plus loin, au fond d'un rocher creux qui bordoit la rivière. Mes chicns l'y suivirent et l'y tinrent en arrèt; mais, quoiqu'clle perdit banucoup de sang et fut nécessaircment affoiblic, ils n'osoicnt point l'attaquer. Nous montâmes sur les roches du bord opposé, et delà un de mes gens lui tira un second coup qui la tua. Alors mes chiens se jettèrent sur clle, et avant que je fusse arrivé pour l'enlever, ils l'avoient déja tellement déchiréc que sa fourrure n'étoit plus bonne à rien, et je l'abandomnai.

Mes Hottentots n'avoient garde d'y renoncer comme moi. Ils se proposoicnt de s'en régaler, 
et l'emportèrent. A mon prenier voyage, j’avois en la curiosité de goûter du tigre, uniquement pour savoir quel gout avoit la chair de ce terrible carhivore. Mais eux, d'après cet essai, ne doutoient pas que je n'eusse trouvé, conme eux, le tigre un mets exceilent; et, en conséquence, ils offirent de me garder, pour ma houche, certaines parties choisies de notre panthère. Je rópondis, en riant, que jamais je ne pourrois me résoudre à manger c'tır animal qui peut-être avoit dévoré quelque Hottentot. Cette raison n'étoit guc̀re propre à convaincre mes Sauvages; car, pour me prouver lc contraire, ils ouvrirent l'animal, et me frent voir qu'il n'avoit dans l'estomach qu'une certaine quantité de glaise, avalée dans une ragre de faim, et quelques portions de la gazellc. Quoiqu'il en soit, je la cédai en entier à mes ğens, er me réservai seulement deux pintes de graisse qu'ils en détachèrent : c'est un remède qui, dans la colonie, passe pour un excellent résolutif dans les tumeurs et les ulcères.

Lin regagnant mon camp, je trouvai une belle espèce d'cuphorbe, que je crois nouvelle, et dont je pris le dessin, que je place ici. Cet euphorbe ne ticnt à la terre que par quelques racines foibles; il s'éleve seulement ì la hauteur de neuf à dix pouces, et ressemble pariatement is un concombre, dont il a la forme et la flexion arquée. Il conticnt un suc laiteux taès-abondant qui ne m'a pas part aussi caustique que celui de la grande euphorbe. Sa coulcur, d'un verd-jaunâtre, nuancée d'une belle teinte violette vers la racine, lui donne un air très-appétissant; mais malheur à celui qui en mangeroit, car il est, à ce qu'on m'assura, un poison violent. Plusicuts de mes Hottentots, ct mon Tome II. 
vicux Swanepoel, qui connoissoient parfaitement cettc plante, m’apprirent que les colons lađnommént noordsche-kull.

A mesure que, dans mes promenades, j'apprenois à connoitre les environs de mon camp, je m’étudiois aussi d̀ distinguer les plantes et les fleurs, qui par-tout s'y trouvoient en foulc. Nulle part encore, depuis que j'existe, je n'en ai vu d'aussi magnifiques pour la vivacité ou la variété des couleurs, ni d'aussi curieuses pour la singrularité des formes. A chaque pas, j'en trouvois de nouvelles; et à chaque pas je m'arrêtois involontairement pour jouir d'un si riant spectacle. Combien j'en vis qui, transportées dans nas parterres d'Europe les plus riches, en auroient fair l'ornement ! et que de fois je regrettai de n'être pas un botaniste profond! Qui sait, me disois-je à moi-même,.si, dans ce nombre, l'art n'en trouveroit pas benucoup qui foumiroient à nos étoffes ces belles et indestructibles teintures que, jusqu'ici, nous avons cru exclusivement propres a l'Inde? Qui sait s'il n'y trouveroit pas de nouveaux remèdes pour quelques-unes de ces maladies dont il abandome le traitement parce qu'il en mécomnoît la cure?

Humilié de mon ignorance, qui ne me permettoit, à cet égard, qu'une admiration vague et sans but, je me contentai, comme je l'ai dit, de dessiner celles des fleurs qui me parurent les plus extriordinaires et les plus belles. Je recueillis des graines. de celles qui étoient en maturité. Enfin, j'essayai d'en dessécher et d'en conserver plusieurs dans le papier, selon la méthode usitée chez les botanistes. Ce dernier moyen est celui que j’ai le moins employé. Outre qu'il est impossible à exécuter pour les plantes grasses, il me rebutoit par l'excès et la 
Tome 2. PI. II.

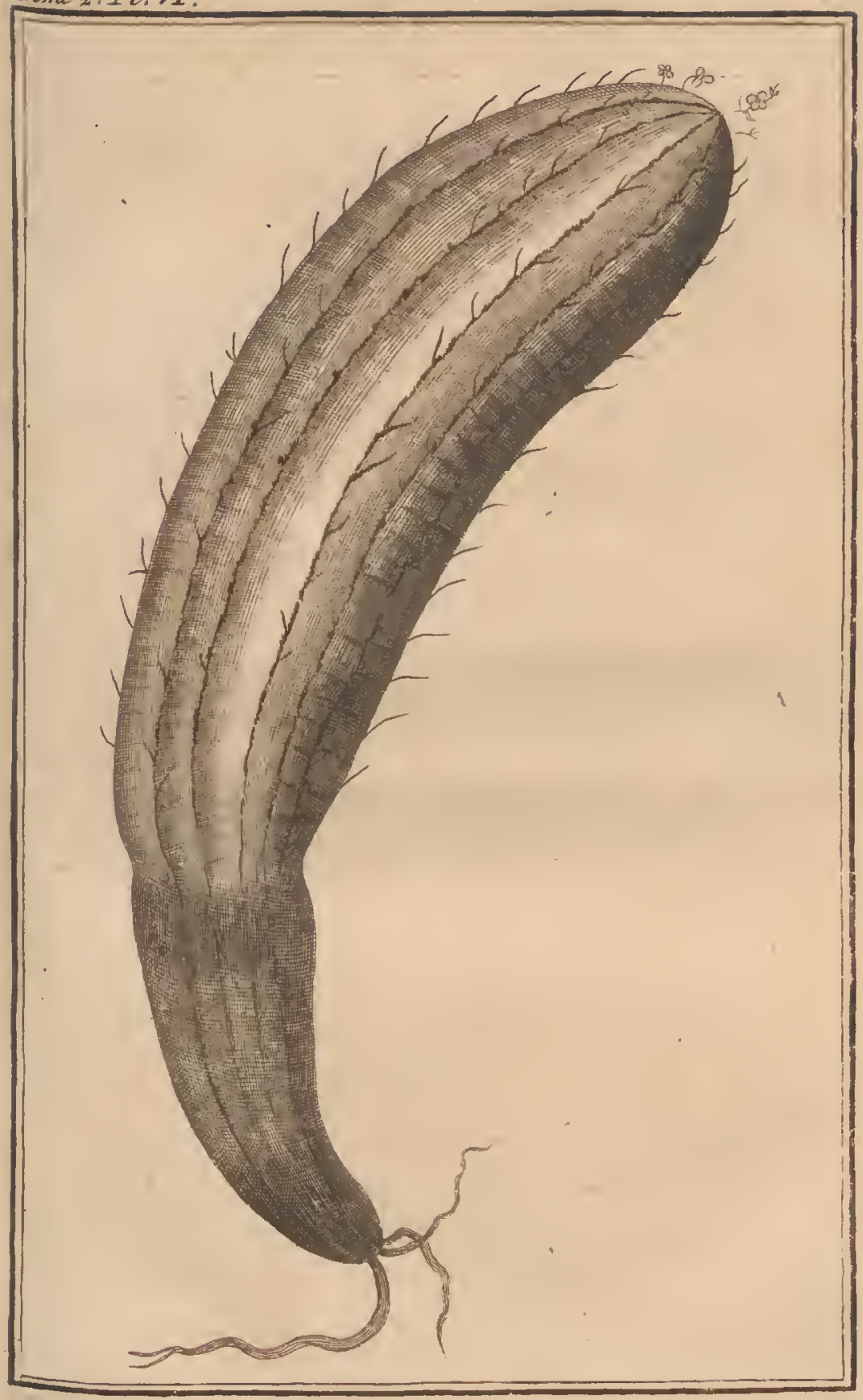

EUPHORBE - CON COMIBIRE 

longueu des détails minutieux et inuciles qu'il exige. Je dis inutiles, car est-ee conserver une plante que d'estropier toutes ses formes, en l'écrasant et l'applâtissant entre deux feuilles de papier? est-ee posséder une fleur que de la eueillir pourpre en $\Lambda$ frique, et de l'apporter on Europe eouleur de tabae ou de pelure d'oignon? cnfin, est-ce eonnoitre leur nature que de l'étudier sur des feuilles mortes et décolorées?

Depuis que ln coquetteric des modes a tant multiplić ces fleurs artificielles qui sont entrées dans la parure des femmes, l'art du fleuriste s'cst appliqué à travailler aussi pour l'honneur et les progrès de la botanique; et l'nin trouve, en ce geure, des choses étonnantes, chez le eitoyen Venzel, l'artiste de Paris le plus renommé pour ce talent. C'est dans une maison de Paris que j’ai vu, pour la première fois, ces plantes artificiclles à les fleurs, avec lcurs fruits, lcurs tiges, leurs feuilles et leurs raeines même, étoient exécutćes avec une vérité étonmante et dans leur grandeur naturellc. Pour en imposer cncorc davantage à l'oil, la plupart de ces plantes étoicnt plaeées dans des pots, remplis de sable ou de terre siche. Jamais l'art n'imita micux la nature. Ce n'est ni lc mensonge grossicr de la gravure ni l'aspect mort de l'herbier. Ici cout est vivant; la plante semble végéter; et d'un coup-d'œil vous saisissez son ensemble et ses détails. Aussi ai-je vu à Paris des plantes d'Afrique, que je n'avois pas pu reconnoître dans des herbiers, et qu'a l'instant même j'ai reeonnu dans cette colleetion. C'cst aux botanistes à prononeer sur cette méthode pour l'avancemcnt de leur vaste scienee. Sans doute, il n'est pas possible, quelque grand que soit un cabinet, d'y présenter en relief toutes les plantes connues. $\mathrm{G} 2$ 


\section{0}

Mais ne pourroit-on pas au moins y avoir les genres? et parmi les espcees, joindre aux genres celies qui seroient les plus curieuses et les plus instruçctives?

Le i I septembre, je me remis en route, dans l'espoir que Pinard auroit sur moi assez d'avance pour que je n'susse plus le malheur de le rencontrer. Déja les chaleurs commenȩoient à se frire sentir ; le eicl étoit chargé de nuages; le tonnerre s'étoit fit entendre plusicurs fois avee un grand fraeas; enfin, tout mannonçoit des ornges : et ecpendant il ne tomboit pas une gouttc d'eau. Cette sćcheresse cxtrême m'inquiétoit benucoup. Je eraignois de ne trouve: par-tout que des rivières desséchées, et n'avois d'espoir que dans les citernes et bassins naturels que le hasard pourroit m'ofirir.

Après deux heures de marche, nous en trouvâmes un, formé par un énorme rocher plat. Més chicns l'avoient pressenti; mais il étoit empoisonné avec de l'etiphorbe, et je trouvai même, à quełque distance, les tronçons de lia plante qui avoient servi. à cet usage, et qui déja ćtoicnt desséchés. Quand j'artivai, je vis ma meute oceupéc à se baigner; mais deux des chicns avoient bu de l'enu empoisonnéc, et ils étoient sur le bord du réscrvoir, attaqués de convulsions horribles. Je fis sortir du bassiu ceux qui se baignoient; ct sans doute ils n'avoient point bu, puisqu'ils ne se trouvèrent pas incommodés. Quant aux deux malades, je leur fis avaler, à plusicurs reprises, de l'huile de eachalot. Elle leur procura un vomissement qui les sauva. Cependant ils furent affectés, pendane plus de quinze jours, des suites de leur aceident. Leurs jambes s'étoient. tellement roidies qu'ils ne pouvoient plier aueune articulation. Pendant tout ce tens, il fallut les lais- 


\section{ENAFRIQUE. IOI}

ser sur les chariots, et ils ne voulurent absolument. prenúre aucune autre nourriture que du lait. Ce fut un grand bonheur pour nous que lcur empressement à boire nous cut avertis du danger. Sans cela peut-ĉtre mes Hottentots, sans défianec, auroientils conduit les bestiaux à cet abreuvoir; et peut-être même quclques-uns d'entre eux se scroient-ils cmpoisonnés en se désaltérant.

Quelle que soit la dose d'cuphorbe qu'on jette daus une quantité d'eau, je suis persuadé qu'cllc n'en infectc pas la massc enticre. Le venin, selon moi, cst un suc résincux qui, par sa mature, ne. pouvant sc combincr avec le liquide, mage à sa superficie et y forme cette liuile verdâtre ct hiisante, qu'avec un peu d'attention on y distingue à la vuc simple, quand l'cau est tranquille. J'essayai sur moi-méme la propriéré de cette huile; ct avec une petite paille, $j$ 'cn pris, ̀̀ la surface du bassin, une goute que je mis sur ma langue. Elle m'y causa cette sorte de doulcur, semblable à la brûlure, que causc un caustique. Jyc pris ensuitc, dans le creux de ma main, de l'eau du réscrvoir; puis, après avoir eu soin d'écarter, cn soufflant, la liqucur huileuse qui la surnageoit, j'y plongeai lc bout de ma languc, et ne pus y discerner aucune saveur étrangère.

Cepcndant, toutc hardie qu'étoit mon expéricnce, je n'osai en pousser la témérité jusqu'à boire et avaler cettc cau; mais je la présentai ì Kees, qui, par la finesse de son odornt, pouvoit m'indiquer, d'unc manière sûre, si clle avoit du dangrer. Il la flaira, et séloigna aussi-tòt. Cette épreuve ne me - satisfaisant point encore, et voulant réussir à täomper, s'il étoit possible, les sens exquis dic mon singe, j'exprimai une certainc quantité de suc d'cu- 


\section{$102 \quad \mathrm{VOYAGE}$}

phorbe et la jettai dans du lait que je lui préscratai à boire. Poür le coup, il y amroit été pris, car non-sculcment il goûta le lait sans montrer la moindre répugnance; mais il l'auroir probablement tout avalé, si je ne l'eusse retiré de dcrant lui; il n'en fut -mêne pas incommodć.

A la vérité, la dose ćtoit peu considúrable, parce que je ne voulois pas risquer la vic d'un animal qui m'etoit utilc. Peut-ĉtre aussi le lait devient-il l'antidote de l'euphorbe, et Kees avoit-il avalé à la fois et le poison et son remède. Si ce fait ćtoit vrai, il deviendroit une découverte intéressante. Au resste, j'aurois désiré la confremer par plusieurs cxpérienccs, cn faisant avaler successivement à un animal et du suc d'cuphorbe en quaatité sulfisante ct du lait. Mais dans ces déserts et avec des ?̂projets d'un aussi long voyage, je n'avois, pami mes animaux, aucune bête qui ne me fût nécessaire. Il me fallut donc remette l'épreuve à d'utres tems; et à ce desscin, j'emplis un flacon d'une certai-ci quantité de lait d'euphorbe que je gardai pour dies circonstances plus favorables.

L'opinion générnle des colons sull le suc de cette plantc, est qu'il donnc la mort en coagulant le sang, et que par conséquent c'est un poison stupéfiant et narcotique. Pour moi, j'en doute fort, d'après les convulsions cftroyables que commencèrentà éprouver mes deux chicns, lorsqu'ils euren: bu de l'eau du bassin. Au reste, si les colons ne se trompent pas, il faut que lia plante change de nature, sclon le climat et lc soi ; puisqu'ćtant un narcotique en Afrique, clle est regardée comme un hydragogue en Europe.

J'avois trop à craindre du voisinage d'une cau empoisonnée, pour rester la plus long-tems. Mal. 


\section{EN A F R Q Q E. IOS}

gré la surveillance extraordinairc que $j$ 'avois ordonnéc, quelqu'un de nes animaux pouvoit aller y boire. Il me parut donc prudent de m"en éloigner au plutôt; et je continuai ma routc.

Nous étions dans le pays des petits Namaquois. A deux licues au-delà du réservoir, nous apperçumes quclques individus de cette peuplàde, occupés à garder des troupeaux, mais qui, épouvantés à l'aspect de ma caravane, prirent la fuitc. Jc piquai ver's eux pour les rassurcr et pour leur demander quelques renscignemens; car ayant à parcourir un pays inconnu, je ne pouvois trouver des secours et d'instructions que dans les hordes qui l'habitoient. Ils mapprirent qu’à une licue plus loin étoit une horde de leur nation, dans laquelle vivoit une femme blanche ì qui appartenoit les troupeaux qu'ils gardoient.

Nous nous rendìmes au lieu indiqué, et nous trouvâmes cffectivement un kraal, composć d'une vingtaine de huttes. La femme blanche étoit debout devant la sicunc. Elle avoit, comme les Namaquoises, un vêtement de pcaux tannćes; mais cllc ne portoit point cepcndant, comme clles, ni le kros ni le petit tablicr. Pinard, en passant, l'avoit prívenue de mon arrivéc; aussi fus-je reçu d'clle comme quelqu'un qui est attendu. Entré dans sa hutte qui n'étoit ni plus grande ni plus ornéc que les autres, elle me conta que son mari avoit vécu dans cette horde dont il étoit devenu le chet, et qu'elle-mêne, à sa mort, ayant hérité de son autorité, avoit continué d'y vivrc. Ét en effet, au ton dont clle donna ses ordres, je m'apperçus bientôt qu’ellc étoit diame ex maîtressc. Ses enfans n'avoicnt, comme lcur mère, que des pcaux pour vêtement; et sans leurs longs cheveux, je les aurois pris, a 


\section{4}

leur teint rembruni par le solcil, pour des enfans de Namaquois, et j’y cussc été d'aucunt plus aisément tronpé, qu'ils ne parloient que la langue namaquoisc.

Klaas Baster étoit le seul de ma carnvane qui sut cet idiôme. C'étoir celui de son enfance. Quoique différent de la langue hottentote, que je connoissois déja, il avoit néanmoins les trois mênnes clappemens, ct me paruz fondé sux les mêmes principes généraux. Sculement je remarquai que ce petplc cmployoit plus fiéquenment ces sons rauques qui, tirés précipitanment du gosicr, coupent les mots et les rendent, pendant quelque tcms, inintelligibles pour. les oreilles d'un étrangrer.

Les enfans savoient que parmi les effets dont étoicnt chargés mes chariots j’avois divers assortimens de verroteries, et ils eussent bien désiré en obtenir de moi quelques-mns poul parer leurs casaques, à l'imitation des Ilottentotes. Klans Baster, ćtant le seul auquel ils pussent exprimer leur vœu, ils le supplièrent d’inteicéder auprìs de moi; je me fis un plaisir d'accédér à leur dcunate, et j’accompagnai même mon présent de quclques mots namaquois que m'avoit appris Klans Baster et que je hasardai.

Lorsqu'il m'arrivoit de vouloir parler aux $\mathrm{Na}$ maquois leur idiôme, ils m'ćcoutoient jusqu'ì la fin, avec patience et attention; ils cherchoicnt à me comprendre; ct quand ils m'avoient deviné, non-sculement c'étoit pour eux un plaisir, mais chacun, reprenant ma pensée, se faisoit un devoir de m'cxpliquer ce que j’aurois dû dirc. D'après cette bonhomınic de caractère, ct cette prévenance affectueuse, je dus être surpris de trouver, dans les enfons de la commandante, des inclinations tout à 


\section{E N A F I Q U E.}

fait contraires. THais c'étoicnt des cnfans. J'cn conclus que leur rire tenoit à la petite malignité de lcur âgc; ct ce qui me lc fait croire cncorc, c'cst que je n'ai vu, en parcille circonstance, aucun Namaquois rire de mon It age.

Je ne maarrêtcrai poine à détailler les mours et les usages de cetec horde de petits Namaquois, qui sc rapprochent infiniment de ceux des autres peuplades voisines, dont $\mathrm{je}$ parlcrai incessamment. Quane à lcur habillcment, il diffère peu de celui des Hottentots de la côte de l'cst, et s'il cst cntre cux, sur cet objet, quelques différences, clles sont si légè̀es qu'elles ne méritent pas d'être rapportécs. Un voyageur intelligent, qui a plusicurs peutples semblables à peindre, doit, s'il veut intércsscr son lecteur, les lui représenter en masse, et ne s'arrêter aux détails particuliers que pour ccux qui, par plus d'invention, par des progrès dans quelques aits, anmonecnt une supériorité qui les distinguc. Ic remarquerai sculcment qu'en génćral les petits Nimaquois sont plus robustement taillés ct pas si maigres de figure que les Ifottentors des cnvirons du Cap.

Ia veuve avoit cnvoyé à mon camp du lait de scs troupcaux. A son excriple, toutes les femmes de la horde en portèrent aussi des lours, et ce tribut volontaire cut licu pendant mon séjour dans le kraal. Il me rappelloit ces jours agréables de mon premicr voyage, où, tous les matins, la jeune Nirrina venoit mipporter le lait de ses chèvres, qu'ellemême avoit traitcs. Mais quelle différence! au licu de ces panicrs si jolis et si propres dans lesquels la charmante Gonaquoise m'offioit son présent, je ne voyois ici que des sébilles de bois, grossic̀rement travaillées, et dont les bords étoient enduits 


\section{TO6 VOYAGE}

d'une incrustation butireuse et rance, qui rebutoit à la fois et l'odorat et la vue. Mes Hottentots, peu difficiles sur les recherches de propreté, s'accomodoient très-bien du cadeau des Namaquoises. Pour moi, à qui il donnoit una répugnatıce invincible, je me contentois du lait de ma ménageric, et j'abandonnois à ma mente la portion du lcur que ne consommoient point mes gens.

Lc soir de mon arrivéc, il y eut bal; car il faut remarquer que parmi les plaisirs que l'hospitalité des Sauvages cherche à procurer aux ćtrangers, la danse tient toujours le premier rang. Ces fêtes bruyantes auroient pu m'anuser une première fois; mais javois entendu si souvent les ha ha, les ho ho, qu'ils nc m'intéressèrent que foiblement. Cependant mon attention fut réveillée par un des musiciens, qui joula de la flûte d'une manière à mintriguer et à piquer ma curiosité. D'abord, après avoir embouché son instrument, il en tiroit des sons très-ćclatans; puis, interrompant tout à coup, il répétoit les dermières phrases de son air, de façon à imiter un écho parfait. Cettc variation sur un instrument à cordes ne m'eutt pas étonné; mais elle n'est pas à beaucoup près aussi facile sur un instrument à vent. Je voulus connoître la méthode de cet homme; elle étoit bien simple, et consistoit à sortir sa flûte d'entre ses lèvres, pour la mettre dans une de ses narines. Alors il souffloit, comme auparavant; et ajoutant au vent du nez un petit nasillement, qui assourdissoir le son, il imitoit l'écho si parfaitement qu'il ćtoit impossible de ne pas s'y méprendre.

La fomme blanche étant, dans toute la horde, la seulc qui sût le holiandois, c'étoit la senle aussi avec qui je pusse nientretenir. Je n'oublierai pas 


\section{E N A F R Q U E.}

107

qu'un jour, où clle me vantoic bcaucoup l'exeellenee du pays qu'clle habitoit, elle avanęa, pour m'en convaincre, que jamais on n'y avoit vu de puces. A l'entendre, c'étoit-là un bienfait singulier de la nature et une partieularité du climat. Mais cette nature, dont la boaté prétenduc l'avoit garantie des puees, ne la garantissoit point d'un autre parasite plus ineommode et, suivant moi, plus dégoûtant. Là malheureuse en ćtoit eouverte, ainsi que ses sujets.

Une autre ineommodité, plus insupportable encore, et qui disting"noit ce lieu si fortuné, e'étoit des milliards de mouches et de moucherons. Ils formoient des nuées, dont le kraal se trouvoit enveloppé et les huttes remplies. Mes chariots et mes tentes en furent mêrue tellement inondées, que, pendant les quatre jours que je passii dans le kraal, je fus obligé de coucher la nuit en plcin air.

Quoique ee pays, dont on me vantoit tart la bonté, fut stérile, il nourrissoit pourtant, en animaux domesciques, les cspèces les plus belles et les plus vigoureuses que j'aic vacs en Afrique. J'y achetai plusicurs chèves, dont ehaeune me donnoit par jour autant de lait que la meilleure de mes vaches; et elles ne me coutèrent que quelques briquets et quelques couteaux.

Les bcufs sont ćgalement plus forts que dans les colonies de l'est; mais par l'édueation qu'ils recoivent ils sont partagés en trois classes; savoir, boufs de charge ou de trait, boufs de monture et boufs de guerre. Je ne dirai rien sur les deux premières, parec qu'elles sont eonnues chez les autres peuplades sauvages, et même dans les eolonies, eomme je l'ai déja dit, et ils se dressent de même; seulement je remarquerai que les boufs de mon- 


\section{IOS VOYAGL}

ture manaquois, beaucoup supérieurs au cheval pour la fatigue, ne lui cédent guère que pour la vîtesse : on choisit pour cêt usige ceux yui sont Ies plus petits et les plus hauts sur jambes.

Quant aux boufs de gucre (bakely-osse), ce fut dans cette horde que j'cn vis un pour la première fois; et ecci prouve combien s'est trompé Kolbe, qui avance qu'ils sont d'usnge chez tontes les nations hottentotes. Leur nom vient de la destination à laquelle on les cmploic. Pour cet exercice, on préfère ceux qui sont les plus féroces et les plus indomptables; ils servent daus les batnilles. On les pousse contre l'ennemi; et, à sa vue, devenus furieux, ils fondent sur les hommes, les foulent aux picds, les déchirent à coups de cornes, et le poursuivent mêtme dans sa fuite, jusqu'à ce qu'ils l'aient mis à mort. On les cmploie aussi pour défendre et protéger les troupcaux. Naturellement courageux, non-seulement ils peuvent résister aux bêtes fćroces, mais ils osent nême les atzaquer; et jamais une hicrite, quelque affaméc qu'clle soit, n'approchera d'un 'troupeau, si clle y voit deux ou trois de ces redoutablès compagnons et gardiens; ils osent même, en nombre, fairc tête à un lion.

Les moutons, aussi haut montés sur jambes que nos chèvres, sont en même tems, pour la grandeur, d'une espèce supérieurc aux nôtres. Cependant ils n'ont point cette large et énorme queue graisseuse, qui distingue ecux du Cap et des colonies. Mes Hottentots, accoutumés sclon le goût de leur nation, à n'estimer une viande qu'autant qu'clle est très-grasse, montroient de la répugnance pour des animaux qui n'offroiene qu'un fouct maigre et effilé, prondant jusqu'à terre. Les moutons 


\section{E N A F R I Q E E. IOg}

qu'a aujourd'hui la colonic hollandoise viemnene d'Europe. Primitivement elle n'en avoit point; sans doute ceux qu' on y transporta étoicnt sans larges queues, puisque cette singularité n'est point connue en Europe. Ils seront devenus tels sous le cicl d'Afrique, par l'effet de la nourriture, du climat et du sol, et ils y auront formé cette variété distincte qu'on y voit anjourd'hui. Il m'en restoit cncore un de ceux cue j'avois acheté en route, et beaucoup de Namaquois qui n'en avoient jamais vus de pareils, ne pouvoient se lasser de l'admirer. La veuve les connoissoit : clle m'assura même que quand son mari étoit venu se transplanter dans la contréc, tous ceux qu'il avoit cmmenés du RoyeSand sa patric, étoicnt de l'espece du mien; mais qu'avec le tems cette proprićé avoit disparu, et qu'à la troisicme génération leur quene étoit devenuc effiléc, comme celles que je voyois. La laine de ces montons n'ćtoit point frisée ni dolice au toucher; au contraire, ils avoicnt de longs poils plats, très-luisans et durs, et nuliement propres cnfin à ĉtre filés.

Avant de quitter la horde, je m'acquittai, par quelques présens, envers ccux qui la composoient, du lait qu'ellc m'avoit foumi abondamment pendant mon sćjour. La commandante me demanda un peu de poudre et du plomb : clle en manquoit absolument, et iraignoit, qu'entouréc de Boschjesman, ils ne vinssent l'attaquer la nuit; sur-tout si, ne l'entendant plus tirer, ils en soupçonnoient la causc. Quand Pinard avoit visité sa horde, elle lui avoit fait part de ses craintes et demandé quelques provisions; mais il s'y étoit refusé durcment, en répondant que j'allois passer bicntôt, et qu'étant abondamnent fourni, $j c$ pourrois l'approvisionner. 


\section{IO VOY A GE}

Quand même je n'aurois’ pas eu, pour obliger certe femme, des motifs de reconnoissance, je l'cusse fait encore par pitié. Sculc de son espèce au milicu de ces déserts, éloignée de cinq liẹucs de tout autre kraal, soutenue uniquement par une poignéc d'hommcs, il lui falloir beaucoup de courage et d'intrépidité pour se maintenir dans une position si inquiétantc. A sa place, très-peu d'individus auroient montré autant de formeté; aussi étoit-ce une de ces héroïnes gucrièces dont j’ai parlé dans mon premier voyage. Elle montoit trèsbien un cheval, fusilloit hardiment les Boschjesman quand ils venoient se présenter, et couroit les lions comme en Europe d'nutres femmes courent le chevreuil. Je lui donnai quelques livres de poudre et la quantité de plomb nécessaire. C'étoit-là pour elle un cadeau précieux; ct certes elle ne polivoit en faire qu'un bon usage.

Le colonel Gordon m'avoit quclquefois parlé au Cap, d'un matelot nommé Schocmmaker, qui, ayant déscrté du scrvice de la Compagnic, s'ćtoit retiré dans le désert et vivoit actucllement chcz les Namaquois. Ce fugitif, au ripport de Gordon, qui l'avoit comu dans ses voyages, étoit un très-honnêtc homme; ct le coloncl, dans l'cspoir que je pourrois en tirer quelques services, mavoit même fait remettre une lettre pour lui, en même tems qu'il m'cn avoit envoyé une pour Klaas Baster. Jc . ne me sentois, pour le moment, aucun motif bien pressant de voir Schocnmaker; mais la lettre du coloncl pouvoit, dans sa solitude, lui être trèsagréable; et en conséquence je crus l'obliger en la lui portant. Ce n'étoit-là qu'une complaisance de ma part; ct cependant cette attention devint pour moi une occasion de bonheur, et me va- 


\section{E N A F R I Q U E. I I I}

lut des services que j'étois bien loin d'attendre.

Schoemmaker, devant être connu de la veuve, je demandai à celle-ci quelques renseignemens sur son compte. Elle me dit qu'il vivoit actuellement à douze lieues par-delà la horde, ct m'offrit de m'y faire conduire. J'acceptai la proposition d'autant plus volontiers, que pour arriver à ce marin devenu nomade, il me falloit traverser une autre horde qui étoit un démembrement de celle-ci, ct dans laquelle la veuve pouvoit, par sa recommandation, me procurer un bon accueil.

J'y arrivai en cinq heures de marche; et sans doute on y étoit prévenu de ma visite, puisqu'à mon approche le chef vint avec quelques-uns de ses gens au-devant de moi pour me marquer sa satisfaction et me recevoir. Hors d'état d'entendre ce qu'il nue disoit et d'y répliquer, j'y répondis, sans mon interprète, d'une manière simple et très-intelligible, en lui présentant un cadeau, composé d'un bout de tabac et de quelques quincailleries, parmi lesquelles étoícnt deux excellens couteaux. Mon présent parut lui faire le plus grand plaisir; et pour me témoigner combien il étoit sensible au service que je lui rendois, il tira d'un petit sac de peau qui pendoit à son bras, un mauvais couteau tour usé, qu'il me montra en haussant les épaules; me donnant à entendre, par ce geeste, combien un pareil meuble lui étoit devenu inutile.

On voit ici qu'on peut contenter un Sauvage à peu de fraix: un misérable couteau, un bout de tabac, un verre d'eau-de-vic, font plus d'effet sur une horde entic̀re que l'entrée d'un ambassadeur, fût-il Turc, et que les profusions de ceux qui les envoient; tant il est vrai que l'état de nature est à l'état de société ce que la santé est à la maladie; 


\section{II $2 \quad \mathrm{VO}$ Y A G E}

et tandis qu'il faut bien des recherches pour désennuyer dans celle-ci, il suffit de bicn peu pour satisfaire dans celle-là.

Notrc chef étoit accompagné d'un sien frère ainé, qui, comme lui, avoit été chef de horde, et qui, fatiğué apparemment de tant d'honneur, avoit philosophiquement abdiqué, ct ćcoit venu vivre ici dans la retraice ec le mépris des grandeurs. Certe ci-devant majesté reçut aussi de moi un témoignage de respect dans le présent que je. lui fis d'un petit couteau et d'un peu de tabac.

A peine le chef avoit-il reçu mon présent, qu'il s'étoir empressé de le partager avec son frère; et rous deux, par une générosité admirable, avoient aussitôt cniployé leur coutcau ì couper le bout de tabac, pour le distribuer à ceux de leurs camarades qui les accompagnoicnt.

Probablement l'intention des deux frères étoit de me prévenir aussi par un présent; et sans doute ils avoient, à ce sujet, donné d'avance des ordres. Au moins, quoique nous fussions à cinq cenes pas de la horde, je vis arriver deux moutons gras, qu'ils me pric̀rene d'accepter.

La vraie politique pour se faire considérer chez les Sauvages, c'est de leur en imposer par quelque chose d'extraordinaire qui peut les convaincre que la race des Blancs est supéricure à la leur. J'avois un pistolet à deux coups, je le déchargai sur les cieux moutous, leur cassi la cervelle à tous deux. Mes Namaquois connoissoient l'explosion d'une arme à feu; ils avoieut vu des fusils cntre les mains de quiclques colons; mais ils ne comnoissoient poine de pistolets, et îls ne pouvoient comprendre (c'étoit leur expression) comment un instrument si petit étoit aussi méchant qu'un gimaid. Mon coq 
et ma poule n'avoient pas été pour cux un moindre sujet de surprisc. Ils admiroient la familiarité de ces animaux qui, à leur ordinaire, venoient roder et se promener autour de moi. Ils s'étonnoient de les voir aussi privés qu'un bøuf; mais ils ne concevoient pas de quel usage pouvoient m'être, en voynge, des oiseatix d'une trille aussi médiocre. Klans Baster me servoit d'interprète dans cette conversation, et j'avoue qu'elle m'amusoit beaucoup.

Nous nous rendîmes au kraal, qui écoit composé d'environ vingt-cinq huttes, et par conséquent peu nombreux. Le soir, quand les troupeaux furent revenus du pâturagge, les femmes m'apportèrent du lait; et il y cn avoir une si grande quantité que plus de la moirić fut perdue; mes thiens eux-mêmes y renoncèrent. Pour Kees, après avoir couru de terrine en terrine assouvir sa gourmandise, il avoit été obligé d'y renoncer comme elux.

Après ces prélinininires, la danse commença, et, comme pour me faire plus d'homeur, elle eur lieu près de ma tente. Il ne me fut pass possible de goûter un setl instant de repos. Pour mon monde, la joic les avoit enivrés. La même chose arrivoit toujours dane des haltes pareilles. Outre la bonne chaire et les plaisirs, on étoit encore dispensé du travail; enfin, on sc retira au point du jout pour dormir; et moi, quoique harnssé par le spectacle et les cris de cette multitude, je saisis non fusil, et suivi de mes chiens j'allai batire la campagne.

Le lieu ne m'annonçoit point une clnasse heureusc. Je ne découvrois au loin sur les montagnes que quelques arbrisseaux clạir semés; et dans la plaine que des plantes grasses, sans un seul arbre; je vis benucoup de vautours, mais à une si grande Tome 11 . 


\title{
I 14
}

\author{
$\mathrm{V} O \mathrm{Y} \Lambda \mathrm{GE}$
}

hautenr, que je ne pus en tirer aucun; ils me parurent d'une espèce absolument différente de ceux que je connoissois déja. Je rencontrai anssi plusicurs troupes d'autruches, mais qui ne se laissèrent pas approcher. Les rochers étoiente couverts de corbcaux, et la plaine d'alloucttes; je n'apperçus enfin pas un oiscau mre à tirer, et ne tuai, dans ma journéc, qu'un seul animal digne de remarque. C'étoit un liève de l'espèce de ccux que j'avois autrefois rencontrés dans le Karow et qu'on y connoît sous le nom de roode-gat-haas (lièvre à cul rouge). Il' a les oreilles moins longues que le lièvre ordinaire, et les pattes de derrière proportionnellement plus basses. Sa coulcur est généralement rousse; le ventie blane, comme notre lic̀vre d'E.1rope. Je ne crois point qu'aucun naturaliste air parlé de cet animal, que je regarde comme une espèce et non comme une variété; ce qui me confirme encore plus dans mon opinion, c'est qu'on trouve dans le même pays d'autres lièvres qui sont absolument pareils à ceux que nous avons en Europe; ils sont sculement plus petits. Les Hottentots, qui généralcment ont une répugnance invircible pour la chair du lic̀vre, ne voulurent absolument pas gautter de celui-ci, quoiqu'ils me le vissent manger avec plaisir; car en effet, il étoit très-bon, et plus délicat que l'autre espèce.

Il $\mathrm{y}$ avoit un animal que j'cusse bien désiré de me procurer, et que je cherchai en vain; c'étoit celui dont la fourrure servoit de kros ou de manteau à plusicurs hommes de la horde; comme la rête et les pattes en étoicnt retranchées, je n'avois pu reconnoître, ni son espèce, ni ses Viais carnctères. La couleur bleu grisâtre de sa fourrure, la longucur de son poil sur l'épine du dos, me rap- 
peloient assez ces mêmes partiss d:uns l'hiemne, décrite par Buffon, et çue j’ai cu occasion de voir plusicurs fois en Europe; mais la petitesse de l'individu ne s’accordoir pas avec la description; ct je pense que c'étoit une espèce d'isntis. Les Sauvages m'assurèrent, que l'mimal se cache sous terre, et y élève ses peties; du reste, sa fourrure est fine et très-belle, ce j'on achetui plusicurs pièces.

A mon départ, le chef me domna quelques hommes pour m'accompagner et me conduire chez Schocmmaker. Jc vis, cn arrivant, un petit homme en bonnct rouge, et dans le costume d'un matclot hollandois. fiutour de lui étoient plusieurs petites filles, charmantes, entièrement nues, et dont la plus âgée n’avoit pas neuf ans. Fien de plus intéressint que lc spectacle de cette jolic famillc. Scs graces, scs caresses sémilllantes, son agréable physiononic, sa nudité même, l'offroicne à mes ycux sous l'inage d'une nichée d'amours. Depuis doaze ans, leur malhcu: cux protectcur avoit céserté, ct In crainte détre arraché de sa retraire l'avoit condamné à des inqutićtudes continuelles. Toujours isolé, toujours occupé de fuir la société de ses semblables, it monoit une vie crrante, et n'osoit rentrer dans la colonic.

Dans unc parcille situation, ma présence ne pouvoit que l'alarmer beaucoup. Le train dont j'étois suivi, le corrige qui m’accomparnoir, ma coulcur, mon arrivéc subite et inattenduc, tout devoit cere d'un présage sinistre pour un homme qui sans cesse apprélicndoit de se voir trahi, poursuivi ou arrêté. L'effroi se peignit sur son visagé; les enfans même, alämés it nion approche, s'écartèrent et s'enfuirent.

Mon premier soin fut de dissiper ces terreurs 


\section{6 VOYA GE}

dont jétois la causc innocente. Pour les terminer le plus promptement possible, je dis au fugitif, que je venois le saluer de la part de M. Gordon, et lui remettre une lctre de lui, dont j'ćtois porteur. Au nom du colonel, la joie reparut sur ce visage si constcrné; je ne fus plus pour Schocnmaker qu'un ani, ce il s'cmpressa de me le prouver en me donnant la main. Alors le petit essain se rapprocha de lui, et ce fut à qui l'accableroit de plus d'amitiés. Pour moi, plus cnvicux du bonhcur done il pouvoit jouir dans une parcille situation, que franpé de la ciuse de ses alarmes, je me promettr is déja de le rassurer plcinement, et de lui obtenir, à cet égard, toutes les garanties; mais, à cela près, des cruintes qui l'agitoicnt sans cesse, quoiqu'il n'y et̂t point de vic plus douce ni plus libre que colle qu'il nenoit actucllement, il est clair, par le parti qu'il prit dans la suite, qu'il no falloit pas un grand effore pour l'cu détacher, é le rendre aux embarras de la socićté. Car, à mon retour au Cap, étant parvenu à obtenir sa grace, il n'cn fut pas plutôt instruit, qu'il revint avcc toute sa famille, abandonnant ses huttes, ses femmes, ses chasses, et ectte enticre possession de soi-même, poui laquelle je vendrois, moi, par centaines, les plus beaux empires.

Ne sachant pas lire, il me pria de lui fairc lecture de la lettre du colonel; et après l'avoir entenduc, il moflrit de m'obliger cn tout ce qui dépendruit de lui. Sans me prévenir, il doma ordre, qu'on atht un beuf et quclques moutons, pour ĉtre distribues at mes gens. Enfin, ses femmes, toutes Hottentotes, qui, à won approche, s"etoient crchées, sc montrèrent peu à peu; je lcur distribuni quelques petits cadcaux, ainsi qu'aux cnfans. J'ai 


\section{E N A F R I Q E E. II}

dit ses femmes; car il cn avoit plusicurs; et en cela il avoit usé amplenent de l'indépendance que lui donnoit son genre de vie. Sa horde n’étoit même composée que de ses femmes, de ses enfans, et de scpt ou huit Hottentots attachés à son service. J'ai domné au lieu, où étcit campće cette horde, le nom de Serrail. Depuis, j'en ai rencontré, dins ma route, trois semblables; mais les sultans de cellescine ressembloient guc̀re à Schoenmaker : c'étoient des scélérats dont jauri occasion de parler duns In suite.

Depuis mon départ du Namero, je remarquois que mes attelages maigrissoient et dépérissoient insensiblement, quoique cependant je les eusse bien ménagés, et qu'ils n'cussent commencé à me servir, qu'après avoir quitté le Kaussi. Mais le pays n'avoit que des herbes siches et quelcues arbustes; er cette nourriture, à laquelle ils n'étoicnt point accoutumés comme les troupeaux mamaquois, leur étoit contraire. Schoemmaker s'en ćtoit apperçu. Lui-mêne me conscilla de quitter au plutôt la contrúc; et il moftrit, si je voulois lui donner deux jours pour faire ses arrangenens, de me conduire avec ses bceufs jusqu’ a la Grande-Rivière. Une pareille proposition ne ponvoit manquer de m'ètrc agréable. Je l'acceptai, et j'employai les deux jours de délai à visiter et à connoître le pays et les montagnes.

Il n'ćtoit pas meilleur que cclui que je venois de quitter. Point d'animaux. Dans les detux jours, je uc trouvai, pour ajouter à ma collection, qu'un étoumeau d'une especce nouvclle. Quant au grand gibicr, je n'en vis nulle part; et cette disette, Schoenmaker l'attribuoic aux tigres et aux lions, gui, trop multipliés sur ce coin de terre, l'en écur- 


\section{$113 \quad \mathrm{O} Y \mathrm{Y}$ i $\mathrm{GE}$}

toient, disoit-il. Pour moi, j'elr accusois moins les butes fúroces que le manq̧ue d'cal et de vivres.

Au reste, quelle qu'en fut la cnusc, ce défruc de gibier me fâchoit bcaucoup. Il n'y avoit que quatre 1rois que j'étois en route, et dépa cependant javois colsoinmé, pour la nourricure de mes gens, plus de bceufs et de mouions que pendint les scize mois cntiers de mon premicr voyage. D'un côté, les ratark avoient considérablentent diminué nes provisions; ic l'autre, betucoup de bestiaux mietoint morts en route, par les accidens, la fatigue et ia soif; mais ce qui me chagrinoit psr-dessus route chose, c'est quaprès avoir acheté de nouveaux atteluges; j’állois ne voir obligé de les remplacer par d'autres encore.

Suns espoir de trouver, sur la route que je suivois, un pays meilleur, vingt fois j'avois formé le desscin de tourner à l'est. Je connoissois un peu les confins de la Caffrerie, et me flatrois qu'entre la chaine du Catris et les Tambouquis qui bordent le canton des Caffres, je trourerois peut-être quelque passage heureux qui me permeteroit de parvenir dans la contréc oricntale. Te savois d'ailleurs que les hautes montagnes qui accupent le contie de l'Afrique méridionale donnent naissance à beaucoup de rivières, dont les unes se rendent à l'ouest dans l'Atlantique, tandis cue les autres vont, par un cours contraire, se perdre dans les mers de l'est. Je n'ignorois pas que ees dernières sont à la fois et plus nombreuses et plus fortes que les autres ; et j'esperois qu'un suivant leur cour's et les vallées qu'clles traversent, je pourrois sortir de la contrée maudice où je me voyois sans cesse arrèté.

Une scule considération me retenoit. Je touchois presclu'uu canton des giruffes. Dipuis long-tems 
c'étoít l'objet le plus ardent de ma curiosité que ces̀ animaux, si peu connus des naturalistes et même des habitans de lil colonic. Un des premiers motifs de mon voyage avoit été de les étudier et de les connoitre; et je me serois reproché toute ma vie d'en avoir eu l'occasion et de m'y c̀tre refusé.

D'un autre côté, les rêves de l'imagination venoient m'agiter sans cesse et m'insinner qu'au delà de la rivière je trouverois un pays plus ngréable, plus fertile, plus facile à traverser; ct je me laissois abuser par des chimères qui n'avoient d'autre fondement qu'une envic cxcessive de rencontrer des objets nouvenux.

Klass-Baster et Schocnmaker me faisoient d'aillcurs cent récits qui échauffoient ma crédulité. A les entendre la Grande-Rivière ne tarissoit jamais ec ses bords étant couverts d'ahleres magnifiques, j’y devois trouver toutes les commodités d'un campement agréable. lls me parloient d'oisenux rares, d'hipopotames, de rhinocéros, de giraffes, ct enfin de toutes sortes de différens gibiers qui abondoient dans ce lieu tant vanté et çui une faisoient désirer bien vivement de m'y voir arriver.

Je trouvai dans tout ce canton une grande quantité de petits vautours d'un blanc istbclle, de la même espèce que celui décrit par Buffon, sous le nom de vautour d'Egypte; les Namaquois nomment cet oiseau Ouri-Gourap, corbenu blanc. Les montagnes me fournirent quelques belles plantes dont je pris le dessin, entrautres deux benux lys à une scule corolle, l'une d'un rouge cramoisi, ct l'autre d'un jaune citron.

Schocnmaker ajant fini scs préparatifs ct donné ses ordres avant de partir, fit arecler tous ses bœufs à mes chnriots, et nous nous nimes en route sans 


\section{$120 \quad V O Y A G$ E}

delai après avoir laissé quelquies lirres de poudre à sa horde pour la défendre des boschjesninn, en eas qu'ils vinssent l'attaquer pendant son absence. En moins de cing heures de marehe nous arrivâmes à la vue d'une horde de Petits-Nannacuois. Mais comme ma caravane pouvoit l'effaroucher, Schocnmakcr pris les devants pour la prévenir. C'étoit la plus considérable que j’eusse cncore vue; elle n'avoit pas moins de einqunnte à soixante huttes, partagées cn trois parties. A notre approche, tous ceux : qui l'habitoient se réunirent. Jamais je n'avois vu tant de Sauvages rassemblés; c'étoit un eoup-d'œil imposant. D'abord la curiosité fit avancer tout le rinonde; je fus cntouré. 'l'ous vouloient me voir ct m'approcher, tolis parloient ì la fois, et ic 11 'cntendois qu'un bourdonnement, qui, quoiqu'assourdissunt, m'intéressoit néanmoins par le ton d'amitié qu'il respiroic.

Bientôt s'ćleva une voix de femme qui domina toutes les autres et les fit taire : e'ćtoit celle d'une vieille Hottentote nommée Kilkocs. Ellc passoir dans toute la contríc pour une sorcière. La troupe s'ouvrit pour lui donner passage. Elle s'uvanç vers moi, en poussant des cris affreux. Ses hullemens m'inquictèrent. Ie craignis qu'elle ne voulut annoncel l'horreu" que lui iospiroit ma préscnce, ct que me désignant à la horde eomme un homme enncmi ou suspect, clle ne l'ameutât contre moì. Qui l'eût cru! c'étoit pour me témoigner sa joic qu'elle mugissoit ainsi. En mahordant, elle me prit rudenent le visage avec les deux mains, et m'embrassa de même. A eés clémonstrntions d'amitié en suecédèrent d"sutres, entremêlées de sauts, de gambades ct de folies de toutc espèce. Tantôt ellc me parloit avec un feu et une volubilité inconce. 


\section{E N A F R I Q E. I I I}

vable; tantôt adressant à la troupe des discours auxquels je ne comprenois rien, elle me montroic de la main et venoit m'appuyer le poing sur l'estomac.

J'avois auprès de moi mon interprête, Klans, Baster. Mais vainement je lui demandois l'explication de ce que me disoit la pythonisse : à peine avoit-il commencé à me rendre une de ses phrases qu’elle en avoit déja achevé dix autres. Enfin cependane, elle s'énonça clairement, ct avec un geste très-significatif, aucuel il ne m'étoir pas possible de me méprendre, clle me denanda de l'eau de mon pays. A ce langage fort intelligible, je répondis par une rasade d'cau-kle-vie, que je lui fis verser dans un grand gobelet et qu'clle avala tout d'une balcine. Alors ses extravagances recommencèrent encore plus vivement qu'nuparavant. Elle dansoit, chantoit, rioit, pleuroit tout-à-la-fois : et de tems en tcms venoit me préscnter son gobelet à remplir. Il se remplit si souvent que la parole et le mouvement lui manquant tout-à-coup, il fallut reporter lì prêtresse en son temple.

Jusques-là je n’avois vu dans la sorcière qu'une bacchante, unc énergumìne, ou plucôt une folle. Rien de cet astuce, de ce ton d'inspiré, de cette affectation de science profoncie, de cette charlatanneric enfin que comporte cet art prétendu. Ne pouvant deviner les moyens par lesquels une pareille extravagante avoit pu donner une si hate opinion de sa supériorité sur ses camarades, je demandois ì connoitre par quels faits clle avoit manifesté ses talcns, et je vis que sa réputation n’étoit fondée que sur l'ignorance, les préjugés, et une crédulité absurde. La scule preuve qu'on m'alléçua de son pouvoir, c'est qüc son troupeau n'é- 
toit jamais attaqué par les tigres et les lions; mais ce troupeau consistoit en six moutons et trois viches; ct d'ailleurs il faut remarquer que les bestiaux de la horde, quoique très-nombreux, écoicnt euxmêmes rarement insultés, parce qu'indépendamment die la qrantité de leurs gardicns ils avoicnt encore, pour les défendre, beaucoup de hoenfs de gucre. Ainsi les vrais sorciers, c'étoicnt les dupes de la sorcière, puisqu'eux seuls avoient les moyens de garantir son minça bétail.

Les hummes, er particulic̀rement les hommes ignorans sont frappés de tout ce qui est extrnordiunire. Je ne doute pas que la grande renommée de Kakoes ne fut due à ses folies mêmes, qui, pour" des Sauvages, puroissoient avoir quelque chose de stmaturul; et Schoenmaker et Khas Baster, qui maintc fois m'avoient deja entretenu de la fameuse Kakoes et de ses hauts lairs, ne doutoient nullement eux-mêmes qu'clle ne fût récllcment une grande magicienne. Mais ce qui m'étonnoit davantage, c'est qu'une femme de cette espèce cut imaginé d'c̀tre sorcière; puisque cette idée de s'élever au-dessus des autres par des fourberies, suppose une adresse supéricure à l'intelligence d'un Sauvage, et une sorte de caleul qui dépatsse la somme des combinaisons que peuvent former ces cerveaux inexercés. Mais l'expérience' a démontré bien aillcurs cette possibilité, et du plus au moins, il n'est pas mal-à-propos de croire un peu aux sorciers. Au reste, citclice que fut l'opinion que ma pythonisse devoit inspirer, il est certain que la terreur de sa prérendue puissance étoit infiniment utile, non-sulement ì sa horde, mais cncore aux hordes voisines. Le licu quelle habitoit sembloit benucoup plus stir yue tous les autres; on venoit on troupe 


\section{E N A F I Q UE.}

se réunir autour d'cile; ct voilì pourquoi la horde étoit si nombreuse. Les boschjesnian cux-mèmes la redoutoient. Jamais es voleurs ne venoient exercer leurs brigandigges sur le territoire qu'elle avoit choisi pour sa dencure; et clle aroit même pris sur eux un tel enpire que si quelqu'un de lcurs vols parvenoir à sa connoissance, ellc partoir à l'instant sculc et sans escorte, alloir au fond de leurs bois et de lcurs retraites les menacer de sa colère, et les forçoit à restituer les objets rolés.

Le pay's des Petirs Namnquois s'étend, en longitude, depuis les montagnes du Ca:nis jusqu'à la mer occidentale; et en latitude, depuis le Namero jusqu'aux bords de la Grande-Rivicre. D'après les renscignemens que j'ai pu prendre sur le nombre des habitans de toute ccte contrée, c'cst, je crois, porter sa population a son plus haue point, que de lui accorder six mille ames; mais des insultes et des atraques trop-fréquentes des Boschjesman, et plus que cela l'aridité du sol, la diminue annuellencnt; un jour peut-êtrc mĉme, la race de ce pcuple s'stcindra ce sera anéantic comme tant d'autres de PAfrique mćridionale.

Le Peti-Nenaquois, quoique d'une assez belle stature, est nćnmoins inférieur pour la taille aux Caffes et aux Gonaquois; ct ce fait m’a donné licu de faire une remarque intéressante et que je crois neuve : c'est que pour les qualités morales ct physiques, les peuples de l'cst, dans ls partic d' $\Lambda$ frique néridionnle dont je parle, sont de be:tucoup supérieurs à ceux de l'oucst; tandis que les animaux de la dernic̀re contrée l'emportent infuniment sur ceux dc la première.

Kolbe a écrir que les Perits-Namaquois pratiquent la circoncision, et qu'ils se retrancbent un 


\section{I24 V O Y A G E}

des resticules. J'avois avec moi la traduction hollandoise de l'ouvrage de cer auteur; er partout, cn visitant les peuplades qui se rencontroient sur ma route, j’avois soin de vérifier ses assertions. Souvent même il m'arrivoit de faire mes questions lc livre à la main; je puis donc certifier que les Namaquois ne protiquent jamais la semi-castration, qui n'est en usage que chez les Gheissiguois, nation hottentote situéc plus à l'est sur les bords de la Grande-Rivière, et dont je parlemi bientôt. Quantr à la circoncision que Kolbe dir être pour les Namaquois un acte de religion, j'assure qu'elle est inconnue chez eux; ct il en est ainsi de la religion clle-imême, à moins qu'on ne regarde comme croyance religieuse la confiance qu'ils avoient en la sorcellerie de Kakoes.

Les femmes de la horde avoient accueilli trèsfavorablement mès Hottentots. Cette communica. tion cut des suites très-douces, et mit mes gens à portće de voir des attraits forts singuliers; mais plusieurs d'entre eux pousscirent l'indiscrérion jusqu’à dévoiler les tendres mystères de l'amour : ils vinrent me dire à l'oreille que quelques-unes d'elles avoient ce prolongement bisarre dont j’ai donné la description er le dessin dans mon premier voyage. Klaas Baster m'assuroit même que dans toutes les hordes namaquoises j'en trouverois de pareils. J'eusse désiré m'assurer s'il existoit quelçue différence entre ceux-ci et celui que jarois vi dans une atitre partie de l'Afrique; quoiqulil m'eût été facile d'obtenir beaucoup pius, elles refusèrent de satisfaire à si peu. Persuadé, d'après l'assertion de tout mon monde, que je ne verrois absolument rien de nouvenu, je respectai tant de pudeur et ne voulưs plus être curieux. 


\section{E N A F R I Q E. 125}

Le pays est peu fertile. Ce défaut de fécondité oblige souvent les habitans à changer de demeure. Aussi, parmi toutes les.pcuplades de ces cantons, n'en cst-il aucune qui soit nomade et errante autant que celle-ci.

Au Cap et dans les colonics, on croit, quoique sans preuves, que la contrée a des mines d'or. Peutêtre, un jour, la compagnie tentera-t-elle de s"en assurer, en envoyant sur les lieux des minéralogistes habiles. Jusqu’a ce moment, moi je dirai, que je n'ai tróuvé ni indications, ni vestiges, et que nulle part, dans aucunc horde, je n'ai vu aucune trace de ce cruel métal.

Il n'en est point ainsi du cuivre. Dans toutes j'ai apperçu des bracelets, des colliers, des boucles d"oreilles de'ce métal. A la vérité, quelques-uns de ces ornemens étoient si bien travaillés et si polis, qu'ils ne pouvoient être qu'un ouvrage d'Europe, et le fruit d'un commerce avec les Blanes. Mais aussi, $j$ 'ch ai vu beaucoup d'autres, qui, par la bisarrerie de leurs formes, et la grossièreté de leur travail, annonçoicnt ćvidemment, qu'ils avoient été fabriqués par les Sauvages cux-mêmes. Er ce qui me le prouvoit encore mieux, e'est que ces bijoux avoient conservé des matières hétérogènes et chatoyantes, lesquelles indiquoient, et l'imperfection de la fonte, et l'ignomnce de l'ouvrier.

Quant à la manière d'employer les ornemens dont je parle, elle est la même pour les Namaquois que pour les autres Sauvages. Cependant, j'ai remarqué chez cux quelqués bisarreries particulières. J'ai vu des individus porter à une oreille six boucles d'une même forme, ct n'en porter aucune a l'autre. J'en ai vu, avoir un bras entièrement garni de bracelets depuis le poignet jusqu'au 


\section{I $26 \quad \mathrm{VO} \mathrm{Y} \mathrm{A} \mathrm{G} \mathrm{E}$}

coude, et avoir l'autre entièrement nu. Enfin, i’cn ai vu, dont le visage étoit coloré et peint d'un côté en compartimens, tandis que de l'autre il ćtoit peine arec d'autres dessins et des coulcurs différentes. J'ai remarqué, en général, beaucoup de got̂t pour les ornemens chez les Petits Namaquois; car leurs kros et tous leurs vêtemens étoicnt cxtrômencne couverts de verroteries et de grains de cuivre enfilés et atrachés dans toutes les parties à leurs habillemens; ils en avoisnt mème jusque dans leurs cheveux, quii étoient graissćs d"unc manière vraiment dégoûtante. Plusieurs d'entr'cux avoient la tête couverte d'une croute rouģcâtre composće de gruisse et d'une ponssicre conleur de brique, qui leur cmpâtoit tellenent tous lęs cheveux, qu'on cût dit qu'ils avojent une celotte de ciment pour coëfurc. Ceux qui pouvoient étaler ce luxe de parure, étoient aussi ficrs que nos petits-maitres, lorsquils peuvent scconer une tête charğcée de proudie, de pommade et d'olcurs; le metp-kros, ou tabelier de pudeur des femmes, portoicht des rangs de verroteries qui leur penduient jusque sur les pieds; du reste clles ćcoicnt habillées conme les Hottentotes dont j’ai déjà parić. Les nates étant très-rares dans ce canton, vu cu'il n'y a point de roseaux, la plupart des hiates étoient couvertes de peatix d'animaux, ct spécialoment dis peaux de mouton ct de berif.

La contrée des Petits Namacuois n'a d'autres pluies que des origes; encore n'est-il pas rare d'avoir des anuécs où ils manquent entièremient; et c'est à ce manque d'caux plivinics, qulil fatt attribuer spécialement son peu de fécondité; comme c'cst à sa position topostaphique, qu'clle doit son défaut de piluic. Depuis le Namero jusqu’à la Grande- 


\section{E N A F R I Q U E. I $\quad 127$}

Rivière qui la terminc, son tcrrain s'eldeve peu à peu, "ct les montagnes, au contraire, s'abaissent insensiblement. Par-delà la Grande-Rivière, les montagnes s'élèvent, au contraire, tout à coup, et lc terrain redescend jusqu’à un autre chainon de rochers, situé plus loin; de sorte qu'elle se trouve enfermée, conme un bassin, entre les deux chaînes. D'après cette situation, il est aisć de voir, que, n'ayant ni forêts, ni hautes montagnes qui arrétent les nuages, tous ccux qui viennent du nord, passent librement sur clle, et vont sc rendre au Camis, où elles crèvent et se resolvent en pluie duns les fonds, et en neige sur les sommets, qui sont les plus élevés de toute la partie sud de l'Afrique.

Ces remarques sont d'accord avec les obscriations météorologiques. Lorsque la saison pluvicuse commence pour le Cap er pour les colonies, jamais de ce côté on ne voit les pluies s'étendre par-delì le trentième degré, c'est-ì-dire, par-delà le Camis. Si alors on est au pied de ces montagnes, du côté sud, on y éprouve une mousson régulic̀re; mais si on se transporte plus loin, tout change alors, et l'on $n^{\prime} y$ voit plus une goute de pluic. Mĩoi-même, penilnt mon séjour dans ce pays des petits Namaquois, j'ai vingt fois été témoin, de la manic̀re lia plus évidente, de l'attraction des nuages par le Camis. A les voir arriver noirs et chargés, je croyois qu'ils ailoicnt nous inonder; mais ils passoicnt rupidement sur nos têtes, pour s'y rendre; et nous Jaissoicnt à sec. Au reste, s'il les empêche d'arroser la terre sur leur passage, il les y renvoic en fleuves et en rivières, puisque tous les torrens de ce pays ont leur origine dans les monts Camis, et, sans cette ressource, tou- 


\section{VO Y A G E}

tes ces contrées seroient inhabitables et privées d'hommes.

Avant de quitter la hordc de la sorcière, je tentai de me procurcr, chcz ces pastcurs, un ccrtain nombre de moutons; parce que, ne trouvant point de cribicr, je ne pouvois nourrir mes gens quavec la chair de mes troupcaux. Mais la même mison qui m’engageoir à lcur en achercr, les empêchoit aussi de m'en vendrce. Vainement j'employai la médiation de Kakoes. Quoique cette femme, par intérĉt pour les Blancs, qu'clle aimoir, disoit-elle à la folic, et par reconnoissance pour mon eau, qu'elle goûtoit cncore plus que les. Blancs, cherchât à mobliger, je ne pus acquérir que six moutons. Il cst vrai qu'il m’cût été plus facile d'avoir des bœufs, et qu'on m'en auroit même vendu pardelà mes besoins, -si j'avois consenti à donner, en échange, des couteaux, du fer ou du laiton. Mais je me trouvois trop inécontent de mes derniers attclages, pour cn acheter d'autres, qui probablement ne valoient pas micux; et d'ailleurs, ma pacotille de quincailleric étoir déjà tcllement dininuée par mes achats précédens, que je voulois réscrver, pour des besoins plus pressans, tout ce qui m'en restoit encore; ce les Petits Namaquois ne se soucioicnt guère des verrotcries doni ils étoient pourvus abondanment.

Schocnmalier, yui connoissoit le pays, sétoit chargé de nous guider dans notre route. Il me c.nnduisoit nord-est, vers les Kooper-bergen (montagncs de cuivre); ct après cing heures de marche, il me fit cételer sur los bords d'un petit ruissenu qui s'cn échnpoit. La halte écoit murusisc, comme on le verra bieniôt; mais curicux d'observer ces montagnes, qu'on m'avoit dit contenir des mines 


\section{EN A F R Q U E. 129}

de cuivre très-riches, j'étois bien aise de les eonnoitre, et mon guide me fit voir une ancicnne fouille, commencée par les ordres d'un gouverneur du Cap, et maintenant abandonnéc. Par-tout, en parcoulant les différens sites que nous visitions, je trouvois des morceaux de mincrnis éclatés, dont la pesanteur mondiquoit une mine riche. Mais c'étoit du cuivre vierge, et particulièrement des cristallisations, que je cherchois. N'ayant pu, malgré plusieurs heures de rravail er de recherches, réussir à men procurer, je me contentai, faute de micux, de quelques échantillons de malaquitc. A dire le vri, quoique je les aic rapportés en Europe, j'en faisois peu de cas; et c'est avec cette froide indifférence, qu'à mon retour à Paris, j’cn fis l'offre à Romé de l'Isle. Mais je m’érois trompé, ce naturaliste les apprécia de manière à me faire regretter de n'en avoir pas conservé une plus grande provision.

Les montagnes dont je parle sont granitiques et micacées. L'arbre le plus remarquable, le plus commun, er en nême tems le plus agréable qu'on y trouve, est une espèce particulière d'aloès, nommé parles Namaquois karap, par les Hollandois kookerboom. (arbre à carquois), et par les botanistes aloès dichotome. Cet aloès s'élève jusqu'à vingtcinq et trente picds de hauteur : sa tige est lisse, et sa peau est blanche. Dans sa jeunesse, et lorsque cette tige n'a encore que quatre ou cinq picds de hautcur, il se termine par une scule touffe de feuilles, quil, s'épanouissant comme celles de l'ananas, forme, comme lui, une couronne, du milieu de laqualle sortent tautes ses fleurs. En vieillissant, il pousse, sur ses côtés, des branches la. térales, d’une sininnétrie et d'une réģularité parfai. Tome II. 


\section{I $30 \quad \mathrm{VOYA} \mathrm{GE}$}

tes; ct qui de même ont chacune, à leur extrêmité, une couronne pareillc à cclle que je viens de décrire. Lc kooker-boom réusșit beaucoup mieux sur la montagne que dans la plaine. Au lieu de racincs longues et profondes, comme les autres arbres, il in'en a qu'une très-foible, par laquelle il est attaché au sol. Aussi lui suffit-il de trois pouces. de terre, pour croître jusques sur les rochers mêmes, ct parrenir à toutce sa beauté. Mais sa racine le souticnt si mal, que d'un coup de pied.j'ébranlois et renversois par terre les plus gros. C'est avec son tronc, lorsqu'il est jeune, que les peuplades de l'oucse font leurs carquois; et de cet usage est venu le nom que lui ont domné les colons.

Le tems que je venois d'employer à visiter la mine, avoit consumé toute mon après-dinner. Je ne revins à ma caravane qu'aux approches de la nuit, et je trouvai que mes gens avoient campć. Quoique nous fussions dans une gorge ressertée entre des montagnes, et que par conséquent le campement fût très-défavorable, il ćtoit trop tard pour en chercher un autre. Mais le pis de notre position, c'est que la gorge se trouvoit si étroite, qu'elle ne nous permettoi: pas de nous entourer de feux, comme à l'ordinairc, et qu'il ne fût possible d'en avoir que dcux : cncore brûloient-ils très-mal, fautc de bois see. Tout homme qui voynge dans les déserts d'Afrique, ne sauroit jamais prenire trop de précautions. J'en fis l'expérience cette nuit-là même; er j’cusse dû être sur mes gardes, puisque quelquesmus de mes Hottentots maverrirent quils avoient entendu des lions. Mais Ihabitude des dangers rend témérnirc. A force de virre dans des alarmes et des risques continuels, on finit par s'y accoutumer; $\mathrm{ct}$ ecte confianee, mère du couritge, diminue en effet beaucoup les clangers. 


\section{- E IN A F R Q UE. I3I}

Vers les dix heures, tandis qu'assis en cercle aurour d'un de nos feux, nous étions occupés à prendre du thé, tout à coup mes boufs, qui avoien remonté le ruissean pour chercher des paturages, accoururent vers nous à toutes jambes, traversirent le camp avec la rapidité de l"éclair, et disparurent. Mon premicr mouvement fut de courir aux arines; et celui de mes gens de crier aux Boschjesman. Ces Boschjesman étoient leur grand objet de terreur; et comme il n'y en avoit arcun qui les affectât autant, c’étoit toujours celui çui se préscntoit ciabord ì lem inngination.

Pour moi, je ne crus point à ce danger; ct ce qui the rassurn, fut, d'un côté, la contenance de mes shiens qui ne changèrent point de place, et do l'autre, l'efiroi de kiees, qui se jetta sur moi, en. me tenant serré très-fortement. Cortes, ni le singe, ni les bocufs, n'eussent témoigné autant d'épouvante à l'approche des Boschjesman; ct mes chiens, au licu de rester, pour ainsi dire, cn arrêt, cusscunt couru à leur rencontre pour les atraquer. Dailleurs les beufs, après s'être éloignés de nous par frayeur, s'cn étoicne rapprochés par instinct. Leurs ycux, ainsi que ceux de tous mes animaux grands et petits, étoient fixes vers un même point; et ce point, cn mindiquant le licu ct la nature du danger, m'annoncoit, à ne pas m'y méprendre, ou un tigre ou nin lion.

Duns de mareilles circonstances, que fuire? La prutence ne nous pemettoit pas d'aller en avant pour l'ottaguer; et l'obscurité de la nuit s'y opposoit. Il fillut done, jusqu'au lever du soleil, rester sur le quivive : dans des inquićrudes et des alames incertines, mille tois plus péribles qu'm danger

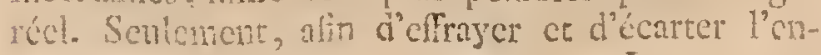




\section{$1.32 \quad V O Y A G E$}

nemi, nous tirions de tems en tems quelques coups de fusil vers l'endroit qu'indiquoit le regard de nos bêtes. Nos fusillades n'empêchèrent pas les lions de faire entendre, dans différentes parties de la montagne, leur rédoutable et lugubre cri. Mais ce qui augmenta de beaucoup nos craintes, et avec fondement, ce fut un de mes bxufs , qui, à quarante pas de nous, se débattit pendant quelcue temis, et poussa ces beuglemens sourds d'un animal soufirant, et qui meurt. Nous ne doutâmes pas qu'il aroic été surpris par un des lions.

Enfin, le jour, en éclairant l'horison, termina les longues et douloureuses angoisses de ma caravanc. Pendaut la nuir, les lions s'étoient on effet approchés de notre crmp, et nous retrouvânes leurs traces en plusiems endroits. J'allai au lieu où j'avois entendu le bouf se plaindre, ne doutane point qu’il n'eût été dévoré; mais à notre grande surprise, nous vimes qu'il avoit été blessé d'une de nos balles; il étoir mort', mais cntier. Je le fis dćpecer aussi-tôt, et m'empressai de quitter un lieut où, sans avoir éprouvé benucoup de dommages, nous avions eu néanmoins de grandes craintes.

Le gite le plus prochain oû nous pussions nous arêter étoit l'emplacement d'une ancienne horde, où se trouvoit une petite fontaine saumâtre, et qui n'étoit qu'à trois lieues de notre dernier camp; nous suivîmes, pour y arriver, le penchane des montagnes; mais elles étoient tellement couvertes de kooker-booms que, dans l'impossibilité d'avancer, je fis précéder mes voitures par ceux de mes gens qui étoicnt inutiles à la conduite, et les chargeai d'abattre à coups de pieds tous ceux de ces arbres dont le nombre s'opposoit à notre marche. Il y en cut un pourtant qui me frappa tellement par sa 


\section{ENAFR I Q U E. 133}

beauté qu'à ce titre je le fis épargner. Il avoit neuf pieds huit pouces de circonférenec, et eouvroit par l'envergure de ses branches un espace de plus de eent picds de diamctre.

J'appris de Schoenmaker qu'un nommé Van Wyk avoit habité le lieu oì nous nous trouvions, et je domai ì cetce fontnine le nom de ec colon nomade. Après avoir fait reposer là mes attelages, je continuai ma route. Nous débouchâmes des montagnes par une sorte de passage ou de défilé gu'on appelle le Poort; et nous entrâmes dans une plaine immense, dont je ne pus appercevoir toute l"étenduc, parec que le jour commençoit à baisser. Enfin, nous arrivâmes en pleine nuit à Brand-hraal (Kraal brûlé), aneien cmplacement d"une horde namaquoise.

Ma caravane avoit marché tout le jour, sans avoir fait plus de sept lietes et demie, tant les ehemins étoient mauvais. Nos boufs tomboient de lassitude; et pour eomble de nalheur, je ne voyois ni une seule goute d"cau ni une branche d'arbre. Cependint il falloit faire des feux pour la nuit. Je me souvenois encore de la nut piécédente; et quoiqu'en rase campagne je n'cusse pas les mêmes risques à courir, je voulois néanmoins n'cin courir aueun. Faute de bois, on ramassa done des bouses sèches, et on alluma des feux, qui servirent tant à éearter les bêtes féroces qu’à nous garantir d'un vent glaeial de sud-est qui nous faisoit grelotter. L'élévation du terrain de Brand-Krail ne devoit pas peu contribuer au froid que nous ressentions; car, d'après mes observations, je trouvai que la plaine où nous nous campions étoit élevéc au-dessus du niveau de la mer au moins de trois mille picds. 


\section{$134 \quad V O Y \wedge \mathrm{GE}$}

- Le lendemain, la lumiere du jour me permit de voir la longue et aride plaine où nou's ćtions. Je fus ulacé doufroi, cin mesurant de l'oil cet cspace jommense que nous avions à traverser. Toul ćtoit sable ex cailioux. A peine, de loin en loin, appercevoit-on quelques peties aloès dichotomes épars, ct unc infinité de couties énormes d'euphorbe. D'espace en espace, cette mer de sable écoit hérissée de monticules peu élevés, mais ces tertres diminuoient de hauteur, à mesure qu'ils s'avançoient vers le nord: l'on cût dic que la terre finissoit à l'horinon.

Plus ce désert étoit désolant, plus il falloir s'empresser d'en sortir. Nous dirigeâmes notre marche vers un petit grompe de collines qui, vu de loin, nue parut restcmbler à colui de la Baic-Falso, qu'on momme Jèver pendance, et qu'à raison de cete ressemblance japuellai de même. Je me flattois d'y trouver quelq̨ue cavité ou bassin qui conciendroit de l'su pour mes bestiatux; et mon cspérance me senbloit d'atutant mietx fondée que je vis quatre honnes qui en descundoicnt. Pour me faire entendre et remayuer d'eux, je tirat un comp de fusil. Mon dessin, si la roche n'avoit poine d'eau, etoit de leur deminder où je pourrois en trouver. Je ne doute ras quils ne m'eussent apperçu, mais ils dispururent tout-à-coup, et vainement $j$ 'allai, avec quelques-uns de mes wens, à lewi recherche, inutilenent nous les appellanes par nos cris a nous ne punncs- ni les déterminer à se nontrer, ni cícouvrir. où ils s'étoicne cachés.

Mis situation, au milieu de ce Aéscrt aride, deveruit très-inquiétantc. Je consultai Schoenmaker, qu, par la combisance particulicte qu'il avoit du puys, puturit seul me tirer d'embaras, If m'sn- 


\section{E N A F I Q U'E. I35.}

nonęa qu'il y avoit une fontaine à quatre licues plus'loin; mais qu'il lui seroit difficile de la trouver, la plaine n'ayant ni bois ni uutres objets pareils qui pussent lui servir de renseignemens; je n'avois donc guc̀re à compter que sur un hasard heurcux. Cependant, en feuretant les divers monticules que nous allions rencontrer, il ćtoit possible que nous découvrissions le lieu où étoit la source, ct c'est le parti que je proposai.

En effet, après six heures d'une inarche trèsfatigante, j'apperçus sur un tertre huit hommes qui paroissoient nous épier et oisserver notre arrivée. Nous marchâmes vers cux : à notre approche, ils s'enfuirent; mais il y avoit là, dans un cnfoncement, plusieurs huttes, et sans doute c'ćtoient les leurs. Une habitation dans un pareil désert, dans un lieu qui n'offroit aucun genre de pâturage, m'annonçoit que ces gens étoient des Boschjesman. Malgré leur nombre, nos armes nous mettant en état de ne rien craindre d'cux, nous nous rendîmes aux huttes; notre présence venoit de mertre tout le monde cn fuite. Nous n'y trouvâmes que quelques pièces de viandes sèches et hun sine de sauterelles; mais nous vimes la source que nous cherchions avec tant d'empressement; etquoiqu u' cille ne fût pas abondante, elle suffit, quand nous l'cûmes élargie et creuséce, à abreuver toute ma curavane.

La grande fatigue qu'avoient souffert mes attelages depuis deux jours et le besoin qu'ils avoient de repos mobligeoient de camper lì. D'un autro côté, j'avois à craindre qu'en y passant ln nuir, les propriétaires des huttes ne profitassent de l'obscurité pour venir m'attaquer et me surprendre. Je me mis en garde contre lours insultes par un gand 


\section{V O Y A G E}

nombre de feux allumés et par une garde exacte, qui effectivement les empêchèrent d'approcher; et le lendemain, au moment de mon départ, jc fis faire une décharge génćrale de toute mon artilleric, afin de les avertir que si l'cspoir du pillage les engrageoit à me suivrc dans ma route, j'étois en état de me défendre et de ne rien craindre. Cependant, on lcur annonçant que je ne redoutois pas de les avoir pour ennemis, je me conduisis en ami arec cux. Je respectni les droits sacrés de l'hospitalité, dont je venois de jouir à la vérité par ma plcine-puissance; mais en conquérant généreux, non seulcment je défendis qu'on touchât à leurs petites provisions, je laissai encore dans la plus apparente des huttes, du tabac, plusieurs objets de quincaillerie et quelques morceaux du bocuf qui m'étoit mort dans les montagnes.

Vers les clix heures du mutin, nous fimes halte au pied d'un groupe de roches graniciques, couvert d'aloc̀s kooker-boon. Lc lieu n'ayant point d'cau, je m'attendois à m'y reprître d'idéces tristes, et ne comptois guère y trouver un phénomine dont l'aspect, nouvenu pour moi, me causa une joic très-vive: c'étoit un nid monstrucux qui ocçupoit une grande partie d'un grand et fort aloès, et qui, composé d'une multitude de cellules, servoit de retraite ì une quantité immense d'oisenux de la même espèce. Déja plusieurs fois Klaas Baster et Schocnmaker m’avoient parlé de ces constructions singulières; ct jusqu't̀ ce moment cncorc lc hasard ne m'avoit point mis à portée d'cn' voir. Jc restai long-tcms à examiner celle-ci. A chaque instant, il en sortoit des volécs qui se répandoient dans la plaine; tandis que d'autres revenoient portant dans lcur bec les matériaux néces- 
saires pour se construire un logement ou pour réparer le leur. Chaque couple avoit son nid dans l'habitation commune; c'ćtoit une vraic républiquc. Nous connoissons plusicurs espèces d'insectes q̧ui vivent ainsi dans une mêne demcure ot qui montrent des habitudes sociales. Il cst même de ces associations chez ccrtains quadrupcdes; niais jusqu’à présent on n'en connoissoit point encore chez les oisenux. Au restc, $j$ 'ai eu plusicurs fois licu d'ćtudier ccux-ci, et j'en parlerai ailleurs plus au long.

Du tertre au grand nid, nous allâmes camper ct passer la nuit, cinq licues plus loin, à la Fontainedes-Zìbres. Ce mot fontainc m'annonçoit de l'ça ; mais certe eau étoit si saléc qu'aucun de nous ne voulut $\mathrm{cn}$ boire, $\mathrm{ct}$ si peu abondante qu'on ne put y faire désaltérer mes boufs.

Ia journée suivante fut beaucoup plus pénible encore, parce que les sables, en devcnant plus fins, devenoient en même tcms plus mobiles. On avoir mis quatorze bouts à chaque voiture, on relnyoit d'heure en heure, et némmoins les roucs enfonçoicnt si avant, la chaleur ćtoit si accalblantc, ils étoient tcllement affoiblis par la fatigue ct par le manque d'eat, et de nourriturc, qu'ils avançoicnt très-peu. Moi-même, soit effet physique de la température, soit effet moral de l'inquicétude affreuse que me donnoit certe nouvelle et triste situation, jc me sentois abattu et sans cournge; l'aspect de cet horison silenticux ct sans bornes fatiguoit cettc fois-ci mon imagination d'un rêve trop púnible ct. trop long.

Heurcusement quelques heures de marche nous rendirent l'espoir. La plaine changea tout-à-coup; le sable cr le sol sc montrèrent couverts d'un gra- 


\section{I $3^{8}$}

men particulicr, qu'on nomme herbe des Boschjesman, et dont ces Sanvages mangent la graine. Les collines elles-mêmes avoient un aspect moins nud; on y découvroit quelques petits arbustes rabougris parmi de grands alòs dichotomes, allant ça et là entre les rochers micacés, dont les rellets brillants éblouissoient nos yeux; la plaine étoit parscméc de gros morceaux de quartz, blanes comme la neige, et dont la base ou partie qui touchoit à la terre avoit la teinte er la demic transparence de la prime d'éméraudc. Probablement le sol contenoit des molécules métalliques qui, pénétrant les portions du quartz qu'elles atteignoient, leur donnoient cette conleur. Au moins, dans les fentes des blocs et des rochers, je trouvai des pyrites cuivreuses et des cristaux culorés en verd.

La terre sur laquelle nous marchions étoit couverte d'herbe; et j'espérois que cette herbe, quoique sèche, feroit unc pâture pour mes bestiaux, puisque ceux du pays la mangent très-bicn dans cet état. Mais, malgré la faim qu'ils éprouvoient depuis long-tems, ils la rebutèrent. Il est vrai que par sa grande sécheresse clle étoit tranchante, et que ceux qui tentèrent de la brouter curent bientôt la langue et les lèvres ensanglantées.

J'aspirois, avec l'impatience de l'afliction, au moment d'arriver à la Grande-Rivière, à ce fleuve qu'on me disoit ne jamais tarir et dont on m'avoit peint les bords si agréables et si rians. A chaque instant, je craignois de voir mos attelages, avant de les atcindre, tomber épuisés, comme les premiers. Mes ycux se portoient en avant, pour chercher les arbres nombreux, qui, disoit-on, couvroient ses bords; et les arbres ne paroissoient point encore; seulement nous déconvrions devant nous les 


\section{E N A F R I U E. 139}

énormes montagnes aux picds desquelles on me dit que ce flcuve couloit; mais leur aspect nud et brûlé n'annonçoit gucuere ce grand changement sur lequel je m'ćtois reposé.

Mais bientôt j'entendis au nord-ouest le mugissement des flots. Ce bruit qui annonçoit notre salut fit tressaillir mon coeur d'allégresse, et involontaircment mes gens poussèrent tous un cri de joic. Nos tourmens alloient done finir une seconde fois! J'allois donc voir enlin une rivière! car depuis celle des éléphans je n'avois trouvé que des torrens, ou desséchés, ou qui ne contenoicnt que quelques amas d'unc eau croupic et boucuse. Pour jouir plutôt d'un spectacle si doux, je montai à cheval avec mon Klaas, et courus vers le licu qu'indiquoit le bruit. Tous ceux de mes gens qui lliétoient pas occupés aux voitures se mirent à courir avec moi; mon singe, mes chiens, tous ceux enfin de mes animaux qui étoicnt libres, partirent en même tems. Nous yaloppions tous pêle-mêle; c'étoit à qui arriveroit le premier. Cependane ic me laissois précéder de quelques pas par mes bêtes, bien sùr que leur odorat et leur instinct me guideroient par la route la plus courte. Les aboiemens, les cris, la joie et les transports de ce groupe galoppant resscmbloient plus à une bacchanale qu'a une caravane de voyageurs affamés. Je jouissois, à moi seul, du plaisir de tous. Mille sentimens confus m'agitoient à la fois, et mes yeux involontairement se remplissoicnt de larmes. Pen d'hommes sur la terre ont cu à souffir des peines pareilles aux miennes; mais peu d'hommes aussi ont ćprouvé des plaisirs aussi vifs.

Mon premier mouvement, en arrivant à l'eau, fut de m’y jêter aussi-tôt, afin de me rafrầchir, en 


\section{I $40 \quad \mathrm{~V} O \mathrm{Y} \mathrm{A} \mathrm{GE}$}

même rems que je boirois. C"étoir satisfaire à la fois deux besoins très-pressans; ct mes grens, ainsi que tous mes animaux en fircut autant.

Le fleuve offroit un coup-d'œil majestueux; et en effer sa largeur, dans les endroits de son cours les plus resserrés, étoit celle qu’à la Seine lorsqu'clle cutre dans Paris. Cependant, à juger de sa hauteur ordinaire par une grève de deux eents pas qu'en ce moment il laissoit à découvert, il devoit avoir baissé considérablement, par l'effet de la sécheresse. Aussi voyoit-on s'élever au-dessus de ses eaux beaucoup de roches, qui sans doute se trouvoient couvertes lorsqu'il étoit dans son plein.

Ses bords, dans une griande largeur, étoient garnis d'arbres de différentes espèces, et en telle quantité qu'ils y formoient une sorte de forêt. C'étoient des mimosas, des ébénicrs, nommés par les indigènes sabris, des abricotiers sauvages dont les fruits éģaloient en bonté nos abricots d'Europe, diverses sortes d'arbres; ct, en arbustes, une espèce de saulc, remarquable par un fruit en grappe et que nous nommâmes raisins sauvages. Tout cela étoit peuplé par une infinité d'oiscaux dont les chants ne m'étoient point encore connus.

J'étois ravi de joie en contemplant ces differens objets. Je m’applaudissois de n'être déterminé à cette route, en rejettant l'idée d'en chercher une par l'est; et déja je me berçois de l'espoir d'enrichir tout-à-coup, et considérablement, toutes mes collections. Cependant je cherchois, pour l'cmplacement de mon camp, un lieu qui cût des. pâturages frais; ct par-tout je n'appercevois au loin que des herbages brûlés. Klaas, que j'envoyai à la découverte, revint m'annoncer qu'il n'en avoit point trouvé d'autres. Schocnmaker lui-même et 


\section{E N A FRIQUE. I I I}

Klaas Baster, quand ils furent arrivés, s'étonnèrent de l'état où étoir ce rivage qu'ils m'avoient représcnté sous des couleurs si nvantageuses, et ils en attribuc̀rent le chnngement à la sécheresse qui avoit régné pendant la saison pluvicuse; sécheresse cclle que de mémoire d'homme, on n'en connoissoit point unc pareille.

Il s'ensuivoit de ces observations que j'avois fort mal pris mon tems pour voynger; mais les regrets ne me fournissoicnt pas un remede à ma situntion, et il m'en falloit un. Dans l'état de fariguc et de foiblesse où étoient nos animaux, je ne pouvois guc̀re songer à leur faire traverser la rivic̀re : ils y aurojent tous péri; et d'ailleurs la rive opposée ne paroissoir pas oflirir plus de fourage que celle où nous nous trouvions. Ma seule et dernière ressource étoit donc de faire chercher de nouveau un canton qui futt moins brûlé. J'cnvoyai tout mon monde à la recherche; et vers le soir on revint m'en amnoncer un oì l'herbe des Boschjesman étoit un peu moins desséchéc qu'ailleurs. Il est vrai qu'il falloit" deux lienres aux bestiaux pour s'y rendre; mais n'ayant point à choicir, je me vis forcé, pour quelques jours all moins, d'user de ce secours, tout pénible qu’il étoit; ct cr*tconséquence je réglai que tolıs les matins buit de mes gens, bien armés, iroient conduire le troupeau et le rameneroient le soir. Il ne fut pas nécessairc d'y envoyer mes chevaux. Le fleuve nourrissoit en quelques endroits une sorte de rosenux dont ils mangeoient avec grand appétit les sommités et les jeunes pousses. J’avoistrouvé aussi de petits concombres épineux, de la grosseur d'un cenf de poule, qui nous faisoicnt une nourriture excellente, ct dont les feuilles ćtoicnt pour cux une friandise. Bientôt mêmẹ ils surent les 


\section{I42 VOY $\wedge$ G E}

trouver sans inoi. Quant à mes chères et à mes moutons, ils s'accommodoient trìs-bien des fenilles et de l'écorec des arbrisseanx qui croissoient à l'ombre des grands arbres. Il n'y avoit que nos bouts et nies vaches quic je ne pouvois soustraire aux cfiets de l'intempérie de la sison; et de tous les bestianx c'étoient pourtani les plus nécessaires.

Pon nous, le voisinge de la rivière atciroit dans la plaine une quantité considérable de gibier qui nous prometoit une nourriture suffisante. Nous avions en abondanee des gazelles spring-bock, des zèbres, des coudoux, des autruches et des oiseaux. de toute cspèce. D'ailleurs, la pêche nous offroit cncore une ressourec.

Il est vrai que, n'ayant fuit pêcher qu'ì la ligne, nous ne primes que deux espèces de poissons : l'une, semblable à nos carples du Rhin; l'autre noire, sins écailles, longue de quinze à dix-huit pouces, ee de la forme du barbeau. Le fleuve en avoit beaucoup d'autres espèces plus petites que nous prenions avec notre filct et qui nous faisoient d'excellentes fritures.

Cette riviere contenoit aussi benucoup d'hippopotames; de tout côté je les entendois mugir et soumer. Curienx de les obiserver, je montai sur la pointe d’unc roche élevée qui avançoit dans le fleuve, et j'cn vis un marcher et sc promener au fond de l'cul. Mais je remarquai que sa couleur qui, lor'squ'il est scc, sc montre grisâtre, et qui, lorsqu'il n'est qu'hnuide ct mouillé, paroit bleuâtre, sembloit alors d'un bleu très-foneć.

Je le tmi au moment qu'il remontoit à la surface del"eau pour respircr. Mics gets. accourts au coup, le poussèrent au rivage. C'étoit une femelle trèsvieille; dans lcur surprise et poutr exprimer sn gros- 


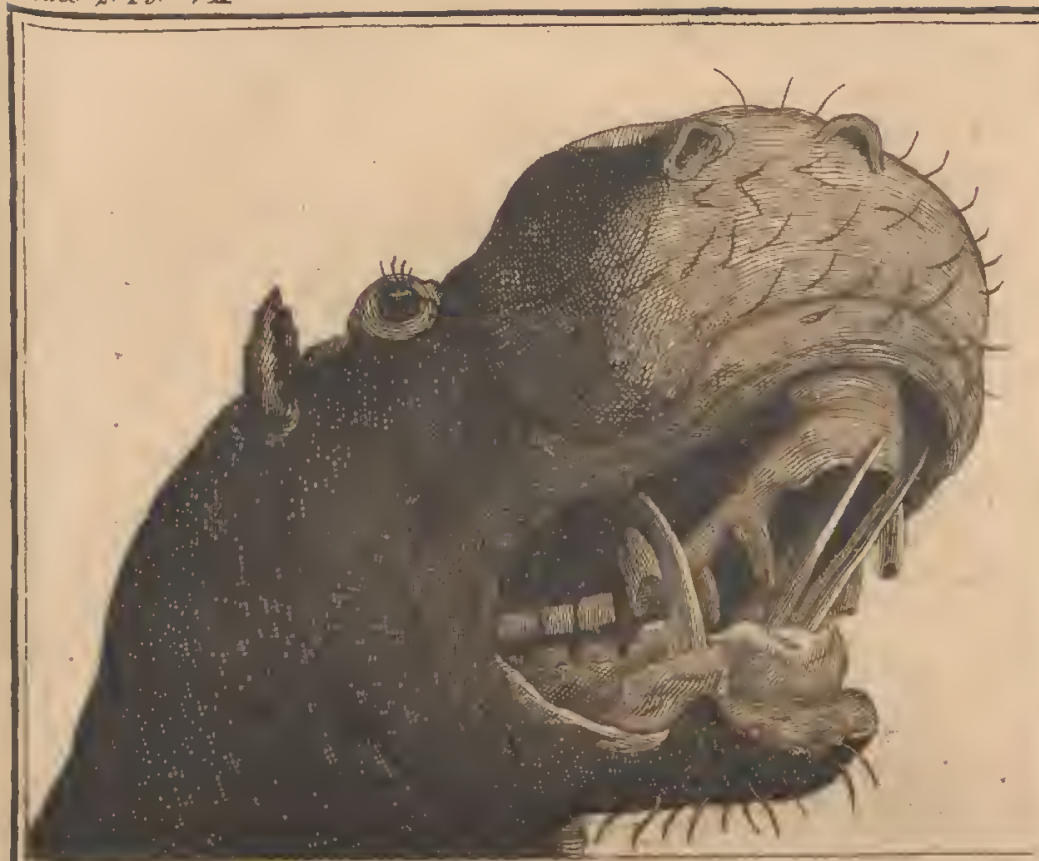

TËTE D'HIPP OPOT AME MÁLE

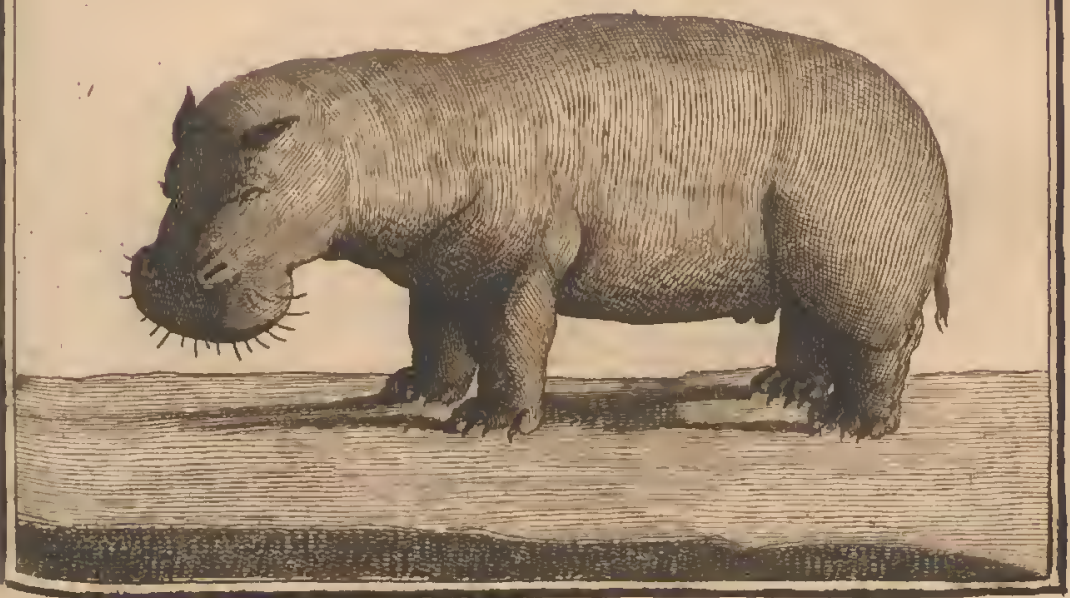

HIPPOPOTAME FEMELLE . 



\section{E N A F R I Q U E. 143}

seui, ils l'appellìrent la grand-mère du fleuve. J'ai conservé ses. défenses; elles ont dans leưr courbure six pouces de long, et trois pouces trois lignes de circonférence à prendre au-dessus de leur racine; ne trouvant aucune des figures qui représentent cet animal ressemblant, le lecteur me saura gré de lui en offrir une ici beaucoup plus correcte.

En me promenant sur la grève, je trouvai, parmi les cailloux roulés dont clle étoit couverte, des agathes herborisées, des onix, des cristaux do fausse anéthiste, et sur-tout beaucoup de morceaux de quart\% avec des accidens singuliers. Mais je vis une pierre extrnordinaire et à laquelle, jusgu'à présent, jé n'ai pu encore donner de nom.

Elle est grosse comme une muscade, chatoyante comme l'opale ou l'neil de char, et d'une coulcur plus rembrunie, avec une zone couleur d'or : elle fait feu au briquet. Depuis mon retour on Europe, je l'ai cherchée en vain dans le commerce et dans les cabinets, et ne l'ai trouvée nulle part. Les naturalistes et les jouailliers ne la connoissoient point. Elle est actuellement en Hollande chez l'un de mes amis, Raye de Breukelward, et elle fait partie de son précieux cabinet.

Il y avoit aussi, sur le rivage, de petits bancs d'un sable pesant et noir qui n'étoit autre chose que des fragmens de cristaux. Quoique la petitesse du sablon m'empêchât de compter les facettes, je l'aurois pris pour des pareelles de grenats, parce du'approché de ma boussole, il en faisoit mouvoir l'aiguille. Peut-être, au reste, cet effet de magnétisme étoit-il dû̀ à des parties ferrugineuses, étrangères aux cristaux, et qui, en noircissant la masse totale, leur donnoient à elles-mêmes la couleur qu'elle avoit. 


\section{4}

V O Y A G E

Les arbres et les arbustes contenoicnt, comme je l'ai dit, une quancité immense d'oiseaux d'espèecs nouvelles. Il y cn avoit sur-tout heaucoup de petits, sur une bruyère à fleurs jaunes eampanulćes, et sur une sorte de jasmin, semblable, pour ses feuilles et ses fleurs, au jasmin d'Espagine, mais presque inodore.

Chaque espèee avoit son arbre de prédilection, qu'elle ne quittoit pas. Par exemple, il y avoit un buisson épineux sur lequel je voyois des centaines de petits perroquets, et je ne les voyois que là; parec que sans doute ils étoient attirés par les fruits et les noyaux du buisson. Cet oiscau, plus gros que cclui qu'on appelle improprement moineau du Brésil, a le bec d'un jaune saffrané tirant sur le rouge; le cou par devint, est eoulcur de rose; le front est plus foncé; la queue, très-courte, est verte, nuaneće de rose et de noir; le eroupion est bleu ct le reste du corps verd. C'est une espèee nouvelle.

En très-pen de tems, aidé de mon Klaas, qui, pour les chasses eonecrnant ma colleetion, étoit devenu très-intelligent et très-adroit, j'eus coutes les especes d'oiscaux que je pouvois désircr. Mais ceux à qui nous déclarâmes particulièrement la guerre furent les perroquets que je viens de deerire; paree qu'étant bons à manger, ils servoicnt à notre cuisine. Toujours èn très-grand nombre sur un même buișson, il m'étoit aisé d'en abattre plusicurs d'un. eoup; muis il étoit diffieile de les retirer de l'intérieur du buisson; ear les épines me déchiroient et ensanglantoient, les mains; et eet ineonvénient inévitable étoit.mêne si douloureux ģue souvent il me rebutoit.

L'arbuste dont je parle, a ses épines alternes 


\section{E N A F R I Q U E. I 45}

à chaque œil : l'une, supéricurc, droite-aigue et longue; l'autre, inféricure, également dangereuse, er courbéc comme la griffe d'un oiseau de proic. Les Namuquois nomment cette plante $c a-$ roop. Je l'ai nommé la truitresse; parec qu'en avançant la main dàns le buisson, l'épine droite vous picue, et qu'cn la retirutut, la courbe vous accroche et vous déchire.

Nalgré cette singularité, jusqu'à présent aucun matumaliste, at moins à ma connoissance, n'en a parlé, pas même Patcrson; qui eependant doit l'avoir vue, puisqu'elle ese très-abondante sur les bords du flcuve, et qu'il accompagnoit Gordon, quand celui-ci domna au flcuve le nom de Rivière d'Orange. N'ayant pas vu la fleur de cet arbrisscan, je l'ai dessinć tel que je l'ai trouvé, avec son fruit sculement; gui, quand il est mûr, est d'un rouge foncé. Les perroquets seuls cassent son noyau ct cn mangent l'amende; mais la chair en est mauvaisc.

Les rchis de Schocnmacker avoicnt benucoup souffert des fatigues de la route; et la mauvaise nourriture du licu n'éto pas propre à les rétablir. Il me pria de permettre qu'il me quittât. Moi, qui voyois qu'il n'avoit d'autrc motif pour sa retraite que le dépérissement de ses bouls, je lui proposai, s'il vouluit consentir à m'accompagnel quelque tems encore, de renvoyer à son halitation ses atteliges er ses gens, et de les fure escorter par quatre de mes chasscurs. Il y consentit; et en conséquence, comme il connoissoit la livière, et que mes boufs, dans lcur dépélissement, n"étoient point c1 état de ine rendre le moindre scrvice, il me conscilla de la remonter plus haut; m'assurant que j'y trouverois pour eux des fourrages meilleurs.

Tome II. 


\section{I $46 \quad \mathrm{VO}$ Y A G E}

L'avis étoir sage; je le suivis. Mais, dans l'impossibilité oì nous étions de côtoycr le fleuve à cause des forêts d'arbres qui le bordoient, il fut résolu que nous retourncrions sur nos pas jusçu”a la Fonlaine des Zébres, et que dể, perçant au nord, nous viendrions Ie regagner. Arrivés à la Fontaine, nous indiquâmes à mes chasseurs la route que nous allions tenir, afin, qu’à leur retour, ils pussent nous retrouver; ct tandis qu'ils partoient avec les équipages de Schoenmaker, nous avançîmes de notre cốté.

Trois heures de marche sufirent pour nous ramener aux bois qui bordent le flcuve. Mais, cn y cntrant, nous apperçumes, non sans effroi, les traces toutes fraîches de deux lions, que nous jugeâmes mîle et femelle, ct qui, pur conséquent, étoient fixés dans ce canton. Le voisinage de ces deux terribles hôtes nous donnoit licu de craindre quelque attaque dans la nuit, et nous obligcoit à redoubler de surveillance; et sur-tout à tenir, autour de mon camp, de grands feux allumés pour les ćcarter. Mais la nuit approchoit, et pelit-être n'étoit-il pas aisé de trouver promptement la quantité de bois sec qu'exigeoient ces feux.

Un heureux hasard nous en fournit par-delì nos besoins. Le fleuve, dans ses débordemens, avoit entrainé beaucoup d'arbres de toute grandeur et de toute espèce. $\Lambda$ deux cents pas de nous étoit un énorme mimosa qui en avoit arrêté un gyind nombre. Ils s'y ćtoient amoncelés en pile, et formoient un bûcher naturel et d'une immense grosscur.

Mes gens, sans se donner la peine de prendre cc qui leur ćtoit nécessairc, y mirent le feu; ct cn un instant, nous cûmes un incendic, qui dura non- 


\section{E N A F R I Q UE. I 47}

seulcment pendant la nuit entière, mais fort avant encore dans la matinée du lendemain. Le lieu, à une grande distance, fut éclairć cornme en plein jour. Mais l'embrasement étoit si violent, et les flammes, par la hauteur à laquelle elles s"élevoicnt, lançoicnt au loin une telle quantité d'étincelles et de charbons, que non camp, quoiqu"à deux cents pas, ne lüt pas à l'abri de cette pluic de feu, et qu'il fallut même prendre des précautions pour garantir mes poudres. Les arbres, à la ronde, furent tous brûlés sur picd. Ceux même qui étoient à plus de cinquante pas, eurent leurs feuilles grillées. 11 est vrai que l'éclat de l'incendic écarta les lions; mais il fit disparoître aussi les oiseaux, et le matin nous n'en vînes plus un seul, quoique, pendant la muit, nous en eussions entendu voler beaucoup, et que plusieurs même, trompés et aveuglés par la lucur du feu, fussent venus se jeter dans les flammes ou périr dans la fuméc. Ces feux dévastateurs, dont j'ai souvent couvert des plaines immenses, ces forêts embrnsées par moi, pour ouvrir un passige ì ma caravane, ou bicn pour ćcarter les animaux féroces; cette puissance de destruction dont je m'environnois à mon gré, avec une poignée d'hommes, quelques armes misérables, le mince attirail d'un brigand, tout cela reportoit souvent ma pensée en arrière, et me rappeloit les histoires de ces brigands bien plus fameux, bien plus iliustres, bien plus honorés, et bien autrement impérieux; portés à la domination, insolens dans leurs volontés, remplis de caprices; ct je m’étonnois de ce que, dans ce ferment de passions qui agitent les hommes, on ne vit pas plus souvent des villes entières livrées aux flammes avec leurs habitans, leurs richesses et leurs arts, et de grands poëtes, à la suite $\mathrm{K} 2$ 
148

V O Y A G E

de ces grands spectacles, érigent en héros les furieux qui s'en amusent, et les proposant pour modèles aux furicux qui leur succéderont.

Na promenade du matin n'offrit rien de nouveau à mes recherehes. Mais en longeant le bois du rivage, je fus fort étonné d'entendre quelcues coups de fusil, et je demandai à Schoenmaker, qui m"accompagnoir, de quelles mains ils pouvoient partir. Lui, qui avoir demeuré sur les bords de la GrandeRivière, et qui par consćquent eomoissoir la contrée, me dit que ces tircurs étoient probablement Mathys Moodel et Bernfry, qui chassoient aux hyppopotames.

Je connoissois de nom ees deux hommes, dont l'un, comme Schocnmaker, étoit un déserteur de la Compagnic. Mais je savois aussi, que bien différens de ce brave honme, c'étoicnt les scélérnts les plus déterminés peut-être qu'cût toute l'Afrique. J'avois entendu parler de leurs forfaits, et je n'ignorois pas que leur nom étoit en telle cxécration, qu'on les avoit proscrits jusque dans les Colonies mêmes.

D'après ces connoissances, je ne concevois pas trop comment ils s'étoient procuré de la poudre. Il est vrai que pour de pareilles gens rien ne devoit être sacré, et qu'ils pouvoient en aroir eu par quelque vol ou quelque assassinat nouveau. D'un autre côté, il étoit possible qu'ils eussent rencontrí Pinat; ct que, par crainte ou par avarice, il lcur en eût vendu pour du bétail.

Tandis qu'en marchant nous rasonnions. sur ces conjecturcs, nous apperçumes nos deux chasseurs. C'écoit Pinard lui-mêine, accompagné d'un homme que je pris pour un Hottentot Baster, ct que Schoenmaker me dit être Bernfry. 


\section{E N $A$ F R I U E.}

La vue des deux lions dont la veille nous avions apperçu, les traces, ne m'eut pas inspiré plus d'horreur; mais la présence de Bernfry sur-tout fit pâlir Schocnmaker. Il ivoit etté le voisin de, ce bandit, lorsqu'il habitoir les bords de la Grande-Rivière; et, par les querelles journalières qu'il avoit avec lui, il s'étoit vu obligé de s'en éloigner, ct d'aller fixer sa horde dinns le lieu où je l'avois rencontré.

Les deux chasseurs nous avoient apperçus; ils vintent à nous. Schocnmaker, animé de ressentiment à la vac de son cnnemi, et obligé de se contenir, n'eut que le tems de me dire, en baissant la voix : tenez-vous bien sur vos gardes, ic malheureux vous joucra quelque tour.

Pinard m'aborda, pour m'apprendre gu'à une demi-licue plus loin je trouverois un campement favorable pour mon monde ct mes bestinux, er il s'ofirit de my conduirc. La nouvelle me devenoit d'autant plus agréable, que c’étoit précisément là ce que je cherchois. Je m'y rondis, sous sa conduite, avec toute ma caravane; mais il ne m'avoit pas dit que j'y trouverois sa voiture, er l'idée de me voir condamné de nouveau à son voisinage m'affliger benucoup. Cependant, comme je lui devois une sorte de reconnoissunce pour l'avis qu'il venoit de me domner, je le priai d"entrer avec son compagnon dans ma tente, quand clle fut dressćc; ct leur fit scrvir du thé, du café, du chocolat ct deux bouteilles de vin. Mon intention, en leur procurant ainsi tue après-dinnéc à- ta holiandoise, étoit de les occuper et de les distraire jusqu' nuit, ct par là d'évitcr cntre Schoennaker et Bernfry des démêlés qui auroicnt ćté inévitables, s'ils n'avoient pas été tous deux sous mes yeux.

Mon espérance fut trompéc; cr ce furent les K 3 


\section{I5O VO Y A G E}

précautions mêmes que j’arois prises pour ćviter une querelle qui la firent naître.

Pinard, mauvais plaisant er naturellement grossier, voulut dans la convcrsation s'égrayer aux dépens de Schocmmaker, et le tourner en ridieule sur son ancien ćtat de matclot. Tel est le préjugé des colons africains : regardés au Cap comme des paysans, cux-mêmes regardent avec mépris les subaltcrmes qui sont au service de la Compagnic.

Schocnmalier paroissoit affecté des lourdes ironies du chasseur; cependant il se contenoit, et répontoit à ses sarcasmes sans aigreur et sans colc̀re. Mais Pernfry s’étant avisé de lui lancer aussi son épigramme, eet homme, que jusques-là j’avois toujouis vu si doux et si paisible, sentit tous ses ressentimens se ranimer à la fois. Il cntra dans une colc̀re effroyable, qu'il ne me fut pas possible d'arrêter; et avec cette violence qu'a lì rage quand elle ne se possècie plus, il reprochil au railleur l'assassinat de plusicurs Namaquois qu"il avoit tués pour voler leurs bestiaux, celui d'unc jeune Hottentote, qui, ayant été la victime de sa lubricité, l'étoit devenuc de sal fureur jilouse; et d'autres horrcurs pareilles dont le récit me ģlaçoit d'effroi. Bernfry, sans désavoucr ces abominations, ne répondoit à son cnnemi qu'avec les expressions d'une rage égale à la sicnne. Enfin, d'une main le saisissant au collet, et de l'autre prenant son fusil, sor's, lui dit-il, infame matelot; tu verras qu'un coup de poudre de plus ne me couttera ricn pour te joindre ì ceux dont tu parles.

Ils sortirent, en effet, tous deux, détcrminés ì se battre; et dans la colc̀re où ils ćtoient, je ne doute point qu'un des dcux, et tous deux peutêtre, n'eusscnt péris. Je me jettai entre cux pour 


\section{E N A F R I Q U E. I5I}

les séparer. Pinard s'y opposoit, et me criọit de les laisser se battre; c'cût été pour lui un spectacle agréable. Schocnmaker lui-même résistoit à mes efforts. Enfin, cependant je vins ì bout de l'arracher à son ennemi; et poussant celui-ci hors de ma tente, je lui dis de se retirer.

Cette avcntüe m'affecta extrêmement; j'y entrevoyois des suites très-fâcheuses, et ne pus dormir de toute la muit. Si Bernfry avoit eu un premicr tort dans la querelle, cn plaisantant son adversairc, cclui-ci s'en étoir donné bien d"autres par la violence de ses emportemens. Obligé de ménager tous ccux avec quij et che\% qui j'avois à vivre, j’eusse désiré n'avoir à me plaindre, ni de Schoemmaler, du zèle er de la fidélité duqual je ne pouvois jusqu' ì ce moment que me louer, ni de Bernfry, dont les crimes peut-être étoient exagérés. Je pouvois me rendre maitre et des uns et des autres, et leur imposer à tous la loi. Mais il cut fallu agir toujours, comme j'eusse dît agir dans cette circonstance; et de promeneur que je voulois être, me rendre dominuteur et chel dans ces contrées paisibles. C'étoir benucoup trop d'cmburras pour un chasscur d'oiscanx. J'ainois mieux traite: ccte aftaire à l'europécnne, par des procédés civils ct tout niais.

Doprès mes maximes, je fis inviter, le lendemain matin, Pinard et son camarade, à venir déjeûner avec moi. Schocnmaker fut de la partic. Les têtes s'éroicnt un peu calmécs pendint ln nuit. D'aillcurs, pour ne pas les échauffer de nouveau, j'cus soin qu'on ne scrvît ni cru-de-vie, ni vin; ct ma précaution cût tant de succès, que je réussis à réconcilier les trois personnages, et à les déterminer ì se toicher dans la main, sclon le protocole d'anicić hollandois. 


\section{VO Y A GE}

Bernfry avoit son domicile et ses troupenux din? une horde ćloignéc de quelques licues. Il me proposa d'y conduire les miens; m'assurant que nulle part dans le canton, je ne trouverois, pour les rétaklir, un mcilleur herbage. Quclque intéressant que fǘt cet avis, je voulus le vérilicr, avant d'y donner confinnce. Je me rendis sur les licux avec mon Klans et I3erniry, ce vis que celui-ci ne m'avoit point trompé. Nul pâturage, depuis lc $\mathrm{Na}$ mero, ne s'étoit même montré encore aussi bon. $\Lambda$ la vérité, on n'y tronvoit que l'herbe des Boschjesman, à laquelle mes animaux n'étoient point habitués. MTais le pays n'en fournit point d'autre, et cette herbe au moins, quoiqu'un peu sčche, ne lisissoit pas d'être abondante.

Bcrufry resta dans sa horde, en attendant que j'y revinsse avec ma carnvanc. Pour nous y rendre, il nous avoit fallu six heures de marche, quoiqu’à chevai; et par conséquent je ne pouvois regagner de jour mon camp. Dans la crainte de m'égarer, pendant la nuit, sur tune route que nous ne connoissions pas, je pris le parti de coucher à la horde, et nous revinmes le lendemain matin, en chassant devant nous six moutons que j'avois achetćs, et deux chèvres qui venoient de mettre bas.

A mon arrivée, je trouvai un nouvenu sujet de peinc. Pinard, profitant de mon absence, avoit renouvcllé ses efforts auprès de mes gens, pour les détncher de mon service, et déjà il avoir réussi à débaucher Klaas Baster et l'un de ses Hotrentots. je fus indigné de cette perfidic nouvelle; mais je le fus bicin plus eneore de l'ingratitude et de l'infidćlité de ce Bastcr, qui, s'étant engagé à moi, étoit à mes gages. Dans mon juste ressentiment, 


\section{E N A F R I Q E. 153}

je le fis venir; et sans lui adresser aucun reproche, je lui mis en main l'argent dont nous étions convenus, et lui dis de sc ietircer à l'instant, parce que je ne voulois plus de ses scrvices.

Ce congé l'humilia beaucoup. Swancpocl profita de ce noment de honte pour lui remontrer sa faute; ct il parla même avec d'autant plus de chalcur, qu'il pouvoit me rendre un grand service cn me le ramenant, puisque ece homme savoit la langue des différcns peuples che\% qui nous allions passer. Bref, la négociation fut si heurcuse, que deux heures après, le Baster vint me demander cxcuse de sa sottise, me pricr de la lui pardonner, et me remettre mon argent. Pour lui prouver que j'oubliois tout, je lui fis préscnt de ce qu'il avoit reçu. Mais Pinard n'cut pas plutôt appris ce dénoument de sa trahison, que, cringnane les justes reproches auxquels il devoit s'attendre de ma part, il fit acteler à l'instant son charriot, ct partit sans dire mot à personuc.

Les continuelles sotrises de cet homme imprudent et inconsidéré, étoicnt pour lui d'un mauvais présage. Avec unc parcillc conduite, sans ménagemens et sans égards, il ne pouvoit manquer de courir à sa perte che\% des Sauviges, naturelicment francs ct bons, mais très-irascibles et terribles dans leurs vengennces. On se rappelle ce que j'ai dit de Pinard. Cet hommic niavoit d'autre but, que de fairc fortune dans ses voyages, et s'inciuiétoit fort peu du résultat des miens. Il ne vonloir que piller, intimider, dévastcr. Dans un pays comme celui que nous habitions, tout cela ćtoit fort aisć; mais sans génic, sans moyens, sans aucun plan, il n'étoit pas aussi aisé d'arriver à ses fins sans malcneontre, ct tôt ou tard il pouvoit être pris au dépourvu. C"cst ce qui arriva. 


\section{I54 V O Y A G E}

Si j’avois pu le voir avant sa disparution subite, certainement l'humanité m'eut fait un devoir de l'avertir des dangers inćvitables auxquels il s'exposoit. Il en a été la victime. Ses Hortentors massacrés, sa pacotille et ses ćquipages pillés, lui-même n'échappant au meurtre que par une espèce de miracle; tel est le suceès qu’a éprouvé ce voyageur turbulent. Malgré toutes les raisons que j’avois de me plaindre de lui, j’atteste que si j'eusse pu être averti à tems de ses périls, mon prenier mouvement auroit été de voler à son secours. Mais son aventure ne m'est parvenue qu“à l'époque de mon retour; et alors il y avoit plus de quatre mois qu'clle s'étoit passéc.

L'impossibilité où je me trouvois pour mes bestiaux, de rester plus long-tems dans le campement que joccupois, m'obligeoit d'en chercher au plutôt un autre plus favorable. Schocmmaker m'avoit parlé d'un bois situé le long du fieuve, et propre à reniplir mes vues. J'allai le visiter; et le trouvan tcl qu'il m’avoit été annoneć, j’y transportai ma caravanc. Mes tentes furent dressées au bord de l'eau, mais hors des limites qu'elle pouvoit atteindre dans ses débordenens; et comme tout m'indiquoit que j’allois ĉtre obligé de séjoumer là pendant quelque tems, je fis construire un parc, pour y retirer pendant la nuit ceux de mes animaux que je roulois garder près de moi.

Mion intention étoit de n'cnvoyer au paeage de la horde de Bernfiry que mes bêtes ì come. Je n'avois point à eraindre qu'elles fussent enlevées par les Boschjesman. La horde étoit assc\% nombreuse pour être à l'abri de l'atiaque de ees voleurs. D'ailIeurs, je fis escorter le troupeau par quatre de mes gens, bien armés, qui devoient le garder nuit et 


\section{E N $\Lambda$ F R I U E.}

I 55 jour; ct en cas d'evénement, je pouvois d'autant plus aisćment voler a leur secours, que, de mon camp au pâturage il n'y avoit pas plus de quatre licucs.

Tous mes veeux étoient que mes boufs se rétablissent dans ce nonvel herbagc. Sans cela, je me voyois arrêté de notiveau, et il me devenoit impossible de continuer ma routc. Quant àmes chèvres, mes moutons er mes chcvaux, je n"étois point embarmasś pour lcur noumiture. Par-tout, sur lc rivarge, ainsi que dans $1 c$ bois, ils trouvoient une grande quantité de ces concombres barbus qu'ils aimoicnt tant.

Nous autres, outre les moyens de subsistance que nous offroit abondamment notre pêche ct notre chasse, nous avions encore la ressourec des hippopotames, qui, très-nombreux dans le fleuve, étoient, par une circonstance particulière, trèsaisés à tircr, du lieu que nous occupions.

L'enu, cu certains endroits, avoit peu de profondcur, et formoit des bas-fonds. Ailleurs, plus profonde, clle renfermoit de ces cavités que les gens du pays appellent Zee-Koe-Gat, (trou d'hippopotane.) Ces amphibics venoicnt ordinairement dans le jour se retirer là, et nous regardions comme à nous ccux qui s'y trouroient cngagés; parce que, quand ils en sortoicnt, ils étoicnt obligés de traverser le bas-fond, ct s'y mettoicnt à découvert, ce qui nous donnoit une grande facilité pour les tircr; quand, pendant lc jour, nous n'avions pu les obliger à sortir du trou, nous les y retenions toute la nuit par des feux que je faisois allumer sur lc grêve; de sorte que le lendcmain, ayant besoin de manger, l'animal étoit obligé de sortir de l'cau, ct de passer devant les chnsseurs postés sur sa route. 


\section{$156 \cdot V O Y A G E$}

Cette chasse nous en procuroit autant que nous en avions besoin, et mes gens 11'cn tuoient plus que pour avoir les peaux. IIs avoicnt changé mon camp en une manufacture de chanbocks (I). De toutes parts on n'y voyoit presque que des peaux manufacturées, et déjà leur imagination cxaltée, formant des spóculations de commerce, s'enivroit d'avance des gains qu'ils devoicnt faire un jour.

Les montagnes offroicnt en abondance une sorte de lièvre, scmblable, pour la taille et la forme, au lic̀ve d'Europe, mais dont la robbe approchoit de celle du lapin de garenne. Nous avions aussi à foison, dans le bois, des gelinottes différentes de celles que je connoissois, des perdrix de la grande espèce, nommées faisans par les colons, et sur-tout une quantité d'oiscaux nouveaux que je n'avois pas cncore vus. Ceux-ci devenoient précieux pour ma collection, et je passois une partic ces jours à me les procurer tous.

Je trouvai aussi benucoup d'insectes et de chrysalides sous l'écorce des mimosas. Nulle part encore je n'avois vu ces arbres s'élever à une hauteur aussi gigantesque que dans ce licu. Leurs épines avoient souvent jusqu'à scize pouces de longueur. On lit dans la traduction du voyage de Paterson, cn parlant du mimosa, que l'immense circonférence de ses branches et le lisse de son écorce, offrent a the multitude prodigicuse d'oiseanx, un asile contre les oiseaux de proie, le serpent et les

(1) Les chanbocks sont des fouts on especes de houssines faits de la penu du rhinocéros ou de l'hippopotane; ces derniers sone préfirés en ce quils sont plus solples ct moins cassants, mais les autres sont plus, jolis. 


\section{E N A F R I Q U E. 157}

autres reptiles, qui les détruisent ainsi que leurs reufs.

Cette phrase est expriméc d'unc manière confuse qui ne présente à l'esprit nucune idéc nette. II n'est pas aisé de concevoir comment unc écorce lisse ct des branches d"une immense circonférence forment pour des oisenux un abri sinr contre les oiseaux de proic. L'auteur ou le traductcur ont voulu dire sins donte que la quantité des branches et leur entrelassement fournissent une retraite aux. petits oiscaux, et cuuc le lisse de l'écorce empêche les reptiles de monter fncilement sur l'arbre pour les dévorer. Mais je ne sais où lauteur a vil ces écorces polics dont il faic mention. Sans doute c'est de l'aloés dichotome dont il veut parler'; car pour le minnosa nilotica, je ne connois point d'arbre aussi rabotteux et done l'écorec soit aussi pleine de rugosités.

Sparmann a ćcrit aussi, en parlant de cet arbre, que le touffic de son feuillage lui faisoil trouver un abri contre lcs ardeurs du soleil. Si Sp:mmann s'est réjoui quelquefois de l'abri que lui offroit le mimosa, assurćment c'est qu'il n'est pas difficile, ct que dans certaines circonstances on se contente de peu. Pour moi, j’ai déja dit, et je le répc̀te, que l'ombre de cet arbre ese si claire qu'clle noircit à peine le lícu où elle porte; ct l'on conviendra de la vérité de cette asscrtion, si l'on songe à son nom qui, le rangenne dans la classe des mimes ou des sensitives, amnonec des feuilles clair-senjées et fort petites. Je dois à la fleur et à l'écorce du mimosa nombre d'insectes curicux; mais je n'ai point vu qu'il donnât tant d'ombre, à moins qu'il n'y en ait plusieurs entnssés les uns près des auries. 


\section{$158 \quad \mathrm{~V} O \mathrm{Y} \wedge \mathrm{GE}$}

Au reste, si je me suis permis ecs remarques, c'est parce qu'un voyageur ne doit ricn taire de ce qui, dans les seienees, peut donner licu à une erreur. Je sais ce que méritent d'égards deux naturalistes aussi estimables que Paterson et Sparmann; mais leur réputation même fait naitre le devoir de les combattre : plus ils sont dignes d'estime, plus il est à craindre que par trop de confiance on ne se trompe avec cux; au reste, ceci n'est peut-être qu'une faute de traducteur.

Bernfry venoit somvent de sa horde me rendre visite dans mon canp et me donner des nouvélles de mon troupenu. Mais rarenent il y venoit sans amener avec lui quelques-mes de ses femmes. Il en avoit beaucoup, et entre autres de Grandes Namaquoises fort jolies, ct même des filles des Boschjesman plus agréables encore que les Namaquoises en ce qu'clles sont moins noires.

Klaas Baster, voulant mettre à profit le séjour que j"étois obligé de faire sur la Grande-Rivière, fit avec Bernfry des arangemens, et lui loua, pour son propre compte, deux de ses femmes. Il est vrai que j"entrois pour quelque chose dans ce marché, et que le Baster, empressé de me montrer de l'atrachement et de réparcr sa faute, vint me présenter les deux benutés et moffrir le choix entre elles. 11 jugeoit mal de mes besoins, et bien plus mal de mes désirs. Le lectur ne veut pas de mes confidenees : que j"aurois à ce sujer de jolis contes à lui faire, de tableaux rians à lui offrir, de belles solitudes, de benux rêves à parcourir; mais c'est pour cela même que je poussai si loin la continence. Le Baster, pour s'éviter l'embarras du choix, ćpousa les deux sultanes à la fois. C'étoit-lì peutetre un désordre; je le permis pour en éviter de 


\section{E N A F R I Q U E.}

plus grands, et je fus le complice et le témoin de leurs joies.

A son exemple, plusicurs de mes gens firent, soit avec Bernfry, soit avec d'autres fenmes, des arrangemens semblables; de sorte qu'en peu de jours j'elis dans mon camp sept mćnages.

Un jour que Bernfry étoit venu me rendre visite, il me dit qu'en côtoyant la rivière, non loin de mon came, il avoit apperçu un hippopotame fémelle qui, sortant du bois, sembloit se rendre vers un zce-koe-gat avec son petit. A la taille du jeune animal, il le croyoir un nouveatl-né, âgé tout au plus de huit jours. Jusqu'alors je n'avois point encore vu d'hippopotame aussi jeune, et l'envic d'exnminer colui-ci me fit voler au licu, suivi de Bernfry et de quelques-uns de mes chasscurs. Mon empressement étoit tel, et je courois si étourdiment clic je commis une imprudence dont les stites pouvoient devenir funestes, ou pour moi ou pour quelqu'un de mes compagnons.

Arrivé près de la rivière, et sautant d'me roche ì l'autre pour me mettre à portéc de mieux voir, jappercus un animal qui me croisoir; et sans me donner le tems de l'examiner, je le tirai et lui cassai la cuisse. C'étoit le petit hippopotame lui-même. Nous courumes à lui, pour lui couper le passage et l'empêcher de gagner l'cau. Mais à peine l'avions-nous joint, qu’ì quelques pas de là, sur les bords de la rivière, se montra la mère, qui, avec des rugissemens aftireux, accourut vers nous, en ouvrant une gueule cffroyable.

Cetre apparition subite à laquelle nous ne nous attendions point, fit sur nous une telle impression de terreur que nous ne songeâmes tous qu’h fuir au plus vîte, et que chacun même, poù courir 
plus lestement, jetta son fusil. Je ne balançai poine à cn faire autant du micn, qui ćtant déchargé me devenoit inutile pour me défendre. La mère, ayant recouvié son petit, ne chereha point à nous poursuivre, et rentra paisiblement avec lui dans l'eau. Sa retraite nous pernit d'aller reprendre nos fusils. Mes chasseurs me dirent que si je voulois revoir le jeune animal, je pouvois l'atcendre sur le rivage, et qu'il ne manqueroit pas d'y revenir bientôt avec sa mère, soit parce qu'il étoit cncorc trop jeune pour rester long-tenns dans l'ceu, soit parec qu'il ne pouvoit $y$ tetter.

Ce projet, d'après ec que nous venions d'ćprouver, me paroissoit entrainer trop de risques. Je crus qunil écoit moins dangereux d’aller attaquer cette nère dans son ćlément, et que là, moins à découveri, clle s'occuperoit plus à se eacher et ¿̀ nous fuir qu't nous poursuirre. Mes conjectures ćtoient fondées. Fn moins d'un quart-d'heure, malgré ses ruses et ses memaces apparentes, clle fut tuéc avec son petit, et mes nigeurs les poussèrent tous deux au rivage.

Ic fis porter dans mon camp le jeune animal : mon dessein étoit de l'enployer à ma cuisine, si sa chaire étoit bonne. Je la trouvai excellente; elle tenoit, pour le goût, du pore et du velll.

Quant à la mire, on l'écorcha et on la travailla cn place. J'avois donné ordre qu'on m'apportât une jatte; je la remplis de soln lait, qui me parut beaucoup moins désagréable que eclui de l'éléphante, et qui le lendemain se changea presclue totalement en crême. Je lui ạ trouvé un goût d'amphibie et une odeur sauvagine, dont la première scnsation étoit de rebuter. Cependant, à défuut d'un autre, 


\section{EN A F R I Q E. $16 \mathrm{t}$}

je m'en scriois accommodé, ct j'avoute même qu'avec le café, il étoit agréable. .

L'éclat de nos feux pendant la nuit, le bruit de nos armes pendant le jour avoient averti de notre présence plusieurs hordes de Grands Namaquois, situées à quelques lieues de nous, de l'autre côté de la riviere; et ils venoient souvent me rendré visite dans moll camp.

J'avois aussi quelquefois celle de Caminouquois, qui demetrojent plus loin. Tous me rémoignoient de l'amitié; je les accueillois tous avec le même sentiment; ct jamais aucun d'eux ne s'en retournoit snins emporter avec lui une charge du produit de mes chasses. Ces cadeaux, qui n'étoient rien pour moi et beaucoup pour enx, me faisoient des amis dans toutes les hordes. 'Tous s'empressoient de venir me voir, et tous m'engageoient à aller chez cux ì mon tour.

Ces allées et venues, ce spectacle de ces bons Sauvages qui se livroient à moi par troupenux, sans crainte, sans défiance aucune, me ramenoient toujours à mon caractère naturel, qui ese celui de la douceur, de la tolérance, de lamour du repos; et - jamais l'idéc de conquête et d'empire, qui naît quelqucfois des obstacies ct de la résistance, n'étoir plutôt chassée que par la communication douce et franche de ces hommes maturels : par-tout où je les rencontrois, tous leurs efforts tendoient à m'attirer:

Pour $\mathrm{m}^{j} \mathrm{y}$ déterminer d'une manière plus puissante, les Grands Namaquois me disoient qu'à deux journées au nord de leur canton je trouverois beaucoup de giraffes et de rhinocéros. Jusquà ce moment, comme je l'ai déja dit, je n’avois point encore vu de giraffes. La partie d'Afrique que j’avois

\section{Tome II.}




\section{$162 \div$ VOYAGE}

parcourue à mon premier voynge n'en nourrit point; ct celle que je venois de parcourir à mon second n'en a pas davantage, parce qu'elles ne passent ja'mais la Grande-Rivière. Qunt aux rhinocéros, j’en avois rencontre deux dans unc de mes chasses, mais n'ayant alors que mon fusil ordinaire, je m'ćtois biell gardé de les attaquer.

Depuis long-tems on m'avoit prévenu sur les dangers quon court en irritant un parcil ennemi ; et l'expérience m'en a depuis convaincu plus d'une fois. Parnai les animaux d'Afrique, l'élćplant seul est plus fort que lui, et il en a peu dont l'atrque soit plus impétueuse; aussi il n'en est aucun qui soit aussi dangereux. Le tigre se fait entendre regulièrement chaque jour, au lever er au coucher du solcil; et en avertissnt ainsi de sa présence, il prévicnt de se mettre en garde contre lui. Le lion, dont l'habitude est d'attaquer pendant la nuit, s'annonce par des rugissemens; et d'ailléurs, malgré la férocité de ces deux tyrans des déserts, il sufit d'tun grand bruit pour les effinyer ec les faire reculcr tous deux. Il n'en est point ainsi du rhinocéros. C'est à la fois un triître que rien n'mnonce, un agresseur que rien n"epouvante, et un furieux que coute résistance rend implacable.

Non séjour sur la rive gauche du fleuve m'nvoit mis à portéc de parcourir tout le canton qui ćtoit autour de moi; ce qui me donnoit l'envie de connoître l'autre rive. Pour cela il falloit traverser la rivière, et les Sauvages qui venoicnt me visiter la passoicnt à la nage : ills m'avoient cusseigrné un güú, mais trop éloigné de mon camp; de sorte que je fis construire un radcalu pour me servir toutes les fois que je voudrois passer sur la rive droite.

La premic̀e fois que je l'essiyni, j'avois auprès 


\section{E N A F I Q UE. I63}

dé moi deux Caminouquois qui etoient venus à mon camp. A la vue de ma machine, ils restèrent extasiés. Moi, pendant ce tems, j’admirois, de mon côté, l'ignorance grossière ct le peu d'industrie de tous ces Africains, qui sans cesse cxposés à ĉtre éventrés par des hippojotames ou à se noyer lorsqu'ils traversent des rivières débordées, sont peutĉtre sur le globe entier les sculs Sauvages qui n’aient point cincore imaginé de pirogues.

Jc passai la rivière sur mon radcau avec mon Klans et les deux Caminountois. Mais à peine avions-nous pris terre, qu’i nos yeux se présenta un spectacle bien désolant : c'étoit une sagaic ensanglantéc, près de laqualle gissoir le cadavre d'un homme qui avoit été dévoré en grnnde partic par un lion. A son vêtement, et à ce qui restoit encore de son visage, les deux śtrangers reconnurent un de leurs camarades, qui depuis huit jours manquoit à son kraal, ct qui cn étoit parti seul pour venir me voir. On distinguoit très-bien sur la terre les traces de la bête féroce. Pendant quelque tems il s'étoit défendu contre elle, et l'avoit même blessée, ainsi que l'annonçoit le sang dont étoït teinte sa lance; mais il avoit succombe enfin; et tel cst le malheur de l'infériorité qu'ont, dans ces sortes de combats, des hommes privés d'armes à feu.

Nous rendimes à ses tristes restes les dernicrs devoirs; c'est-ầ-dire, qu’à la manière des Sauvages, nous couvrîmes ses entrailles et ses os brisćs d'un monccan de picrres. Après cette cérémonic, à laquelle je me fis un devoir de satisfaire comme cux, ils me quittèrent, pour aller porter à leurs camarades la nouvelle de l'événement; et moi, aftligé de mon côté, d'avoir été, quoique très-innocemment, la cause involontaire de la mort d'un homme, je 


\section{I64 VOYA GE}

renonçai à la chasse que je projettois, et revins à mon camp.

Bientôt j’eus épuisé ce que les dcux cantons offroient de curieux pour ma collection; et je n'eus plus d'autre veut ta faire que celui d'en sortir au plus vîte. Mais I'état où étoient mes attèlagges s'y opposoit. Forcés de se' nourrir d'une herbe nouvelle pour eux, ils étoient devenus de vrais squelettes. Jamais je n'allois les visiter, que je n'cusse le désespoir dans l'ame. Ceux de mes gens. qui étoicnt préposés à leur garde, quand au bout de huit jours je les faisois relever et les mppellois au camp, ne revenoient guère sans m'annoncer qu'il étoit mort quelques bêtes. Depuis einq scmaines je séjoumois sur la rivière, dons l'esproir que nous éprouverions quelque pluic qui reverdiroit les herbages; ct pendant tout ce tems il n'avoit plu qu'me fois : encorc étoit-ce si foiblement, qu'à. pcine la poussière en avoit ćté abattue.

Cependant la saison des grandes chaleurs venoit de commencer; nous tonchions au mois de novembre; et par-tout la terre brûlée ne me laissoit plus d'espérance. Mes Hottentots eux-mêmes ne cachoient pas lcur découragement. Pour moi, plus accoutumé qu’cux à réfléchir sur l"avenir, et plus intéressé aux malheurs inévitables qui nous attendoient, j'étois consterné. De toutes parts entouré d'obstacles insumontables, je voyois arriver le moment où il me seroit aussi difficile de regagner le Cap, que de continuer ma route. En vain je moccupois, jour ez nuit, des moyens de sortir d'enbarras; mais, soit que je restasse, soit que je partisse, je ne voyois que mort ct désolation de toutes parts. Mon courage succomboit sous ses assauts multipliés. 


\section{E N A F R Q U E. I 165}

Plusicurs fois déja j’avois remarqué que, quand le cicl se couvroit autour de moi, la riviere, vingtquatre heures après, augmentoit régulièrement de cinq ou six pouces, er ne reprenoit son niveau qué quelques jour's après.

Le mpport constant de ces deux faits entre eux ne pouvoie manquer de me frapper; et j'en avois conclu que le fleuve prenoir sa source dans quelque chaine de montagnes, où les nuages qui passoient sur ma tête alloicnt sc rendre et se dissoudic. Mes excursions de l'autre côté de la rivière m’avoicnt d'ailleurs confirmé encore dans cette conjecture. Souvent, en gravissant des montagnes, j'en avois apperçu d'autres qui, placées en amphithćâtre et s'élevant toujours de plus en plus ì mesure qu'elles s'éloignoient, alloient se perdre au loin.

Mr lunetre m'avoit même fait appercevoir, que toutes les fois qu'au zénith de mon camp nous avions des nuages, il pleuvoit dans la chaine au nord-est; et alors j'étois assuré de voir, le lendemain, une crue de la rivière.

Que n'aurois-je point donné pour être dans ces montagnes lointaines qui n'éprouvoient point la sécheresse qui nous dévoroir! Muis comment m'y rendre? Et d'ailieurs peut-être, malgré lcurs pluies, manquoient-clles d'herbages. Au moins ma luncte ne m'y nontroit qu'une supcricic aride, sans bois ni verdurc. Ainsi, de quelque côté que je portasse mes regallds, je n’appercevois que des sujets de découragement. Cependant il falloit prendie un parci et me tirer de l'embarras désespérant où je me trouvois.

Dans l'état de dépérissement mortel où étoient mes becufs, tout mªnnoncoit que je devois ne plus

$$
\text { L } 3
$$




\section{I66 V O Y A G E}

compter sur eux et les regarder comme morts. Privé d'attelages, ma seule ressource étoir done de chercher à conserver mes effets, mon monde et mes autres animaux domestiques. En laissant tout cela dans le camp, j'étois sûr que la troupe ne manqueroir pas de nourriture; et la fidélité connue de Swanepoel me réponcioit de mes charriots. Moi, pendant ce tems, je pourois m'absenter quelques semaines, parcourir la contréc au-delà de la rivière, et y négocier par moi-même, dans les différentes peuplades que j'y trouverois, de quoi remonter mes voitures.

Mon excursion me permettoit, en même tems, de chercher des girnfes et d'en tuer quelques-unes; et ce plaisir devoit me dédommager au moins des fatigues et des dépenses d'un voyage malheureux, cntrepris contre saison.

Je fixai mon départ au vingt-huit octobre; et partis, cmmenant avec moi huic de mes fusilicrs, au nombre desquels étoit Klaas Baster, ct huit Namaquois, qui consentirent à m'accompagner. Tout le reste de mon ancienne caravanc demeura au camp, sous les ordres de Sivanepoel. La nouvelle fut composéc de quatre chiens, de mon singe Kees, de deux chevaux, de six bceufs de charge, que j'avois loués pour porter mes effets, mes provisions, et même quelques instrumens, tels que mon quart de corcle et ma boussole, et de dix-huit personnes : car Bernfry m'avoit demandé d'être du voyage; $e t$, à dire le vrai, j'aimois autant voir cet homme à côté de moi, qu'auprès de mon camp; Jorsque je n'y serois plus.

Nous traversâmes la rivière sur le radcau, ct la côtoyâmes, cn la remontant et suivant ensuitc son cours, dans l'espoir que nous apperceverions 


\section{E N $\triangle F$ R I Q U E. I 167}

quelques giraffes que le besoin de boire $\mathrm{y}$ attireroit.

Les Namaquois qui conmoissoient le canton, me conseillèrent de camper, après six heures de marche, et de quitter la rivière le lendemain, dans l'espérance de trouver les giraffes dans la plaine.

Pendant la nuit, nous fümes inquiétés par les rugissemens de trois lions, dont l'un s'approcha mème si près de nous, qu'un de mes gens l'apperçit. Certe alerte, en troublant notre sommcil, nous mit dans le cas de partir de meilleure heure qu'z̀ l'ordinaire.

Quoicue j'eusse deux chevaux, j'allois à pied comme la troupe, dans la crainte de les fatiguer; et je réservois leurs forces pour les occasions de chasse qui se présenteroicnt. Abandonnés à cuxmêmes en toutc liberté, ils suivoicnt tranquillcment la caravane, sans jamais s"en écartel que pour aller cherchel: de côté er d’autre les concombres barbus qui faisoient leur scule nourriture.

Pendant une partie du voyage, cet aliment se préscnta par-tout avec assez dobondance; mais, à mesure que nous nous éloignâmes de la rivière, il devint plus rare. Enfin il manqua tout-à-fait; et la disette dherbage fut même telle que je les ai vus (on aura peine à le croire, et le fait est pourtant vrai,) saisir avidement les crottins que rendoient nos boufs, et se battre tous deux, pour se disputer ce résidu excrénentiel d'une herbe digérée.

A cette seconde journée, nous fûmes obligés de faire, comme à la première, six grandes lieues vers l'ouest, et vinmes camper près d'une source, qui, sortant du pied de quelques roches, ct ornée de verdure le long de ses bords, présentoit un site très-agréable. 


\section{V O Y A G E}

Au moment où j'y arrivai, un secrútaire étoit occupé à y boirc. Je le turi d'un coup de fusil, et de son nom, j'appellai la source, Fontaine du secrétaire.

Les Hollandois ont donné à cet oiseau le nom de secretaris (secrétaire, ) à cause de la touffe de plumes qu'il porte derrière lit tête; attendu, qu'en Hollande, les gens de cabinet, quand ils sont interrompus dans leurs ćcriturcs, passent leur plume dans leurs cheveux derriere l'oreille droite, ce qui inite un peu lat huppe de cet oiseau.

Buffon, parlant du secrétaire, dit qu'il n'est connu au Cap que depuis peu de tems; et la preuve qu'il en donne, c'ese que Kolbe, er d'autres écrivains postérieurs à celui-ci, n'en disent rien. C'est là avancer un fait futux, et vouloir le prouver par un autre fait aussi peu vrai que le premicr.

Le secrétaire est connu dans les colonies, et sous son nom de secrelaris, et sous celui de slangvreeter. C'est, sous cette dernière dénomination, qu'en parle Kolbe; ct certes il le connoissoir, au moins d'aprés le rapport d'autrui, puisqu'il donne l'énumération exacte de toutes les espèces de nourritures qui sont à son usage.

Il est vrai que dans sa description il traduit lc mot hollandois slang-ureeter par le mot françois, pélicun, et que par conséquent il fait une scule espèce de deux espèces bien différentes. Mais Kolbe n'ćtoit point naturaliste; ct son ouvrage renferme tant d'autres crreurs, qu'il scroit étonnant de n'y pas trouver celle-ci.

J'ai été plus surpris, je l'avoue, de voir nos naturạlistes modemes, même ceux qui ont parlé du secrétairc avec le plus de détails, ne faire aucune mention de trois protubérances osseuses et émous- 


\section{E N A F I Q U E. $\quad 169$}

sées qu’il a au pliant et à la dernic̀re articulation de ses ailles, mais infiniment moins apparentes que dans le jacana ou dans le canicki.

Cettc omission ma paru étrangre dans Buffon sur-tout, qui ne l'a point décrit d'après des relations écrangères, mais d'après un individu qu'il avoit sous les yeux, et qui, je crois, étoit dans le cabinet de Mauduit. Cependant elle est essentielle, puisqu'elle ôtc au secrétaire un de ses principaux caractères distinctifs, et que les protubérances dont je parle, sont une des armes de cet oiseau, ainsi que je le dirai tout-à-l'heure.

Jc me permettrai encore une remarque sur ce que Buffon cn a ćcrit. Selon lui, lc secrétaire diffire des autres oiscaux de proie, par un naturel craintif; ct sa timidité est même telle, dit-il, qu'attaqué par ses ennemis, il n'a, pour sa conservation, d'autre ressource que la fuite. C'cst lit une erreur. Ceux qui ont pu étudier cet oiseau, savent que, vivant particulièrement de reptiles, il est continuellement en guerre avec eux; qu'il les cherche par tout et les attaque avec courage. Je cite, sur cette asscrtion, le témoignaģe de Qucrhoent; et moimême j'spporicrali en preuve le fait suivant, dont j’ai ćté le témoin.

En descendant d'une montagne dans une fondric̀re très-profonde, j’apperçus presque perpendiculairement au-dessous de moi, un oiseau qui s"élevoit et s'abaissoit très-rapidement, avec des mouvemens fort extraordinaires. Quoique je connusse très-bien le secrétaire, et que j'on eusse tué plusicurs ì la terre de Natal, il m'étoit impossible, dans la situation verticale où je me trouvois, de recomnoître celui-ci, et ne le soupçomai qu'à son manège. En effet, ayant trouvé moyon, à la favcur 


\section{0}

\section{$\mathrm{V} O \mathrm{Y} \mathrm{A} \mathrm{GE}$}

de certaines roches, d'approcher assez près de lui, sans bruit et sans être découvert; je vis que c'en étoit un, qui se battoit avec un seipent.

Le combat étoit très-vif des deux côtés, et la ruse ćgale de part et d'autre. Mais ic serpent, qui sentoit l'inégalité de ses forces, employoit, pour fuir et regagner son trou, cette prudence adroite qu"on lui attribue; tandis que l'oiseau, devinant son intention, l'arrêtoit tout-d̀-coup, et par un saut, se jettant au-devant de lui, coupoit sa marche. De quelque côté que le reptile essiyât de s'échapper, il retrouvoir toujours son ennemi. Alors, unissant à la fois la ruse au courage, il se dressoit fiérement pour l'intimider; et avec un sifflement affreux lui présencoit une gueule ménaçante, des ycux cillammés ct une tête gonflée de rage et de veniit.

Quelquefois certe résistance offensive suspendoir pour un instant les hostilités; mais bientôt l'oiseau revenoit à lia charge; ct se couvrant le corps avec une de ses ailes comme avec un bouclicr, de l'autre il frappoit son cnnemi avec ces procubérances osseuses dont j'ai parlé, et qui, comme de petites massues; l'accabloient d'autant plus sûrement; que lui-même il se présentoit aux coups. Ifffectivement, je le vis chanceler et tomber étendu; et alors le vainqueur se jetta sur lui pour l'achever; et d'un coup de bec il lui ouvrit le crânc.

Dans ce moment, n'ayant plus d'observations à faire, je le tuai. je trouvai dans son jubot (car il en a un, ce que personne n'a dit), en le dissequant, onze lésards assez grands, trois serpens de la longueur du bras, onze petites cortues bien entieres, dont plusieurs avoient deux poices de dia- 
mêtre environ, enfin une quantité de sauterclles et d'inscetes, dont la plupart étoicnt assez entiers pour mériter d'être recueillis et de faire suite avec les miens. Les lésards, les serpens et les tortues avoient tous reçu le coup de bec sur la tête.

J'observerai de plus, qu'indépendamment de cette masse d'alimens, la poche de l'animal contenoit encore une espèce de pelotte, grosse comme un ouf d'oic, ct forméc des vertèbres des serpens ce des lésards qu'il avoit dévorés auparavant, d'é. cailles de petites tortues, et d'aîles; de pattes et de corselets de différens scarabées. Sans doutc, quand cette masse incigeste est devenue trop considérable, le secrétaire, ainsi que les autres oiseaux de proie, la vonit et s'en débarrassc. $\Lambda u$ reste, il résulte de la quantiré surabondante de nourriture cu'aroit cclui-ci, çu'en attaquant le serpent de la fondric̀re, ce n'étoit point la fain qui l'avoit déterminé au combat, mais la haine ce l'antipathie qu'il porte à ces reptiles.

Uie parcille aversion est d'un avantage inappréciable dans une contréc où la temptrature favorise ćtonnamment la inultiplicarion d'une infinité d'animaux muisibles et vénimeux. Sous ce point de vue, le secrétairc est un véritable bienfait de la nature. Aussi l'utilitć dont il est, et les scrvices qu'il rend, sont si reconnus au Cap et aux environs, que les colons et les Hottentots le respectent et ne le tuent point, comme les Hollandois ne tuent point la cigogne, et les Egypticns l'ibis.

On apprivoise facilement le secretaire, et qund $j 1$ est devenu domestique, toute nourriture, cuite ou crue, lui convient également. Si on a soin de le bien nourrir, non-sculement il vit amiealement $\mathrm{ct}^{\mathrm{t}}$ en paix avec la volaille; mais guand il voit quel- 
que dispute, il accourt pour séparer les combattans et ramener l'ordre. Il est vrai que, si on le laisse souffrir de la fiim, il prend son parti, et qu'alors, se faisant sa part sans scrupule, il tombe sur les petits canards ou les petits poulets. Mais cet abus de confiance, si l'on peut parler ainsi, n'est en lui que l'effet impérieux du besoin et l'exercice pur et simple de ectre nécessité, qui voue impérieusement la moitié de tout ce qui respire à l'appétit de l'autre moitić.

J'ai vu dans beaucoup d'habitacions de ces secrétaires privés. Leur ponte est ordinairement de deux à trois-œufs; $c$ ces cufs sont grbs à-peu-près comme ceux dé l'oie, et sont blancs comme ceux de la poule. Les petits sont long-tems à sortir du nid, parce que leurs jambes étant longues et grêles, ils ont beaucoup de peine à se soutenir. On les voir mêne, jusqu'à l'âtre de quatre mois, ne pouvoir marcher qu'en s'appuyane sur le talon; ce qui leur donne un air gantiche ct une mauvaise grâce assez visibles. Cependant, comme ils n'ont pas les doiges si longs, ni les ongles si recourbés que les autres oiseaux de proie, ils ont beaucoup plus de facilité que ccux-ci à marcher. Aussi, quand ils ont aztcint l'aige de scpt mois, et acquis toute la grandeur ce tout l'aceroissement que comporte leur espèce, les voit-on développer des mouvenens aisés et gracieux, qui accompagnent nterveilleusenent bien la noblesse de leurs formes. Vosmaer a pendant quelque tems nourri, à la Haye, un secrétaire; et c'est d'après les observations que lui a donné licu de faire cee individu vivant, qu’il a écrit sur l'oiscau. Buffon, en citant le ntaturaliste hollandois, dir, d'après lui : "Que, tandis qu"il dessinoit ss son secrétnire, l'oisenu curieus vint pour re. 


\section{E N A F R I Q U E. I73}

9, garder sur le papier, le col tendu, et redressant "les plumes de sa tête, comme s'il cut admiré sa "figure, etc. "

Certes, le secrétaire est assez intéressant, par son instinct et par ses qualités naturelles, pour n'avoir pas besoin que son historien lui prête un goût d'admimtion pour le dessin, et une sorte d'orgueil de se voir représenté. Si celui de Vosmacr s'approchoir de lui, en tendant le cou et en redressant son aigretre, ce n'étoit, sclon moi, ni par curiosité, ni par ravissemcht, mais uniquement par une sorte d'habitude qui est propre ì bcaucoup d’autres oiseaux. On sait que la plupart, lorsqu'ils sont familiers ẹt domestiques, aiment à se faire gratter sur la tête; que ce chatouillement semble leur procurer quelque plaisir; ct qu'ils vientent se présenter au premier venu, et allonger le cou pour lui demander ce service.

C'est ce qu'on peut voir en Europe, par rapport au paon, au perroquet. Le secrétaire se trouve dans toutes les plaines arides des environs du Cap. Jc l'ai trouré à l'est, sur route la longucur de la côte, dans la Caffreric, et même fort avant daṇs les terres. Miais à l"ouest, quoique cette partie de l'A frique ait des déserts plus arides cncore que la partic orientale, et que, par conséquent, elle offrc à l'oisenu les diférentes sortes de nourritures qui pourroient lui convenir, je ne l'ai rencontré nulle part au-delà du pays des Grands Namaquois. Je ne dirai plus qu'un mot sur ect intéressant animal; c'est qu'il n'a point un bec de gnlinacé, comme le dit Vosmacr, mais bien un vrai bec d'oiscau de proic. Il n'a pas non plus, comme l'avance Buffon, la jambe dégarnic de plumes comne les oiseaux de rivage. Du reste, je renvoie à mon Ornithologie, 
où j'cntrerai dans de plus grands détails au sujet du secrítairc.

Ces détails sur un oiscau très-intéressant justifieront suffisamment, je pense, les motifs qui me détcrminèrent à donner son nom à la source près de laquelle nous étions venus camper. Nous y passâmes la nuit. Le lendemain, quatre Sauvares s'en étant approchés pour boirc, et ayant reconnu mes guides qui ćtoicnt de lcur connoissance, ils m"invitèrent à venir ì leur horde, distante au plus, disoicnt-ils, d'une demi-journce de marche. Je l'acceptai; et après avoir envoyć en avant deux d'cntre cux avec Klaas Baster, pour prévenir de mon arrivée, je me mis en chemin; mais la plaine étoir si pénible, que nous ne pûmes nous y rendre qu'en huit heures de marche.

A mon approche, le chcf, vicillard respectable, vint au-devant de moi, accompagné, selon la coutume, d'une partic de sa horde. Après le compliment d'étiquette, il me fit présent de deux moutons pour ma troupc; et tandis qu'elle les apprêtoit, j'allai visiter le krmal. A chaque hutte où je me présentois, j'entendois dire, tabacana maté (donnč-moi du tabac). Moi, je respondois, Deip maté (donncz-moi du lait); ct cn effet, j'ćtois si alréré de la route, qu’en ce moment j’eusse préféré une jatte de lait à un présent de dix bouts. Ma demande fut accueillic avec empressement. On conduisit à ma tonte plusieurs vaches, que je fis traire en ma présence, et je m'abreuvois délicieusement d'une liqueur saine et douce, qui souvent me ticndroit licu de toute autre nourriture.

Le vicillard ne m'avoit pas quitté un seul instant, ct j'avois mis sa présence à profit, le faisant interroger sur tout ce qu'il m"intéressoit de savoir 


\section{E N A F R I Q UE. I 75}

sur la contréc. Lrui, profitant également de l'occasion, me parla d'un chagrin qu'il avoit. Il étoit peu éloigné de la rivière. Les hippopotames y fourmilloient; et ses compagnons et lui cussent bien voulu s'en procurer de tems en tem. quelques-uns pour leur nourriture; mais, quoiqu'ils eussent creusé des fosses et tendu des pièges le long du rivage; cependant, depuis deux ans qu'ils habitoicnt le canton, ils n'avoicnt pu encore en prendre que trois. Ces animax, disoit-il, étoient trop fins pour cux; et il ne doutoit pas qu'avec mes fusils, dont il avoit entendu raconter les effets, je n'en eusse autant qu'il me plairoit.

Une pareille remarque étoit une prière indirecte de rendre service à la horde. C'étoit pour moi une occasion de me faire des amis; er cutuand la détresse où je me trouvois ne m'en eût pas imposé la loi, je l'eusse fnit encore pour obliger ces pauvres gens.

Mion plan fut de purtir dans l'après-diner du joul suivant, d'aller passer la nuit pres de lit rivière, et le lendemain, de commencer la chasse dès le crépusculc. J'enmeni avec moi tous mes chasseurs. Un détachement de la horde me suivit, avec quelques boufs de charge pour porter le produit de notre chasse, et au point du jour je mis tout mon. monde en activité.

La moitié de la double troupe passa le fleuve à la mage, tandis que l'autre moitié resta de mon côté. Quand les nageurs furent arrivés à l'autre bord, ils se partagèrent en deux bandes, dont l'une remonta la rivière à une certaine distance, et l'autre la descendit. La même chose se fit sur mon rivage. Les quatre bandes embrassèrent ainsi trois quarts de lieue de rivière; moi seul, je reșcai en place et au centre des traqueurs. 


\section{I76 6 O}

A un signal donné, tous avoient ordre de partir de lcui poste, à pas lents, et de se rendre vers moi; les uns en poussant de grands cris, les autres en tirant de tems en tems des coups de fusil, pour rabattre et conduire à 1112 portéc les hippopotames qui se trouveroient dans cet espace dut fleuve. Il s'en rencontra huit. Toutes les bandes de chasseurs étant rémies au centre commun, nous n’cûmes plus besoin que de pacience et d'adresse.

En peu de tems nous en blessâmes plusicurs. Déja même deux étoient mis à mort; et les gens de la horde étoient ravis de joic. Mais quelquesuns d'entre cux s'écant mis à la nage, pour faire échoucr à la rive les deux bêtes mortes, un des nageurs reçut, des hippopotames blessés, un coup de boutoir, et un antre eut la cuisse fendue d'un coup de dent. Ce double accident m'en fit craindre quelque autre plus ficheux encorc. Je rappellai tout mon monde; et an grand legret des Numaquois; je terminai une chasse, que tout annonçoit devoir être plus abondante, mais qui ne pouvoit plus se continuer sans de très-grands périls.

Le reste de la journéc et une partic de la matinéc du lendemain furent comployés à dépecer et à charger sul nos beufs les deux animaux tués. L'odeur qu'ils exhaloient, portée au loin par les vents, attira, dans le lieu, des nuées de vautours et de milans, qui nous suivircnt même pendant longtems, en planant sur nos têtes.

Les vautours me paroissoient d'une espèce noutvelle et inconnuc. Mais vainement j'essayai d'cn tirer quelques-uns; ils se tinrent toujours hors de portéc, et le bruit du fusil ne fit que les éloigner sans retour.

Ce fut avec une grande allégresse qu'on nous vît 
vît arriver dans la hordc. Mais la joie neeut plus de bornes, quand on sut, qu'à l'exieption de quelques morcenux que je réservai pour mes gens, $j$ 'abandonnois aut Kraal les deux animaux en cnticr. Le chef, pour me témoigner, au nom de tous, sa reconnoissance, me pria d'accepter un bouf gras.

Je le remerciai. Mais, voyant que mon refus le mortifioit, je lc priai de mo domner en échange deux moutons; parce que, dans un moment de détresse, ils pouvoient en route nous servir de nourriture. De mon côté, avant de le quitter, je lui fis présent d'un coutcau, ct je distribuai quelques verroterics aux femmes.

Pour arriver au canton où l'on me dit que nous trouverions certainement les giraffes, il me falloit traverser unc autre horde, situce à quelques licues de la sienne. Je lui demandai de me donier des guides qui m'y conduisisscnt, ct sur-tout, de m'y faire annoncer par quelques-uns de ses hommes. Telle étoit ma coutume quand je quittois une horde. Jc me faisois rccommander à celle dans laquelle j’allois passer; et toujours je me suis applaudi de ce procédé. Lorsque, avec si peu de moyens qu'en ont les Sauvages pour se garantir de la rapacité des curicux et des méchans, il leur arrive de recevoir des visitcs scmblables à celles d'un Pinard, on ne doit guc̀re être surpris des précautions que je prenois pour m'en faire bien venir, ne voulant jamais m'en faire redouter.

A notre départ, nous repassâmes à la Fontaine du Secrétaire; ce delà, tirnnt au nord-cst, nous arrivâmes, après quatre heures ce demie dc marche, dans une plainc desséchéc qu'habitoit la horde que je cherchois. Le kraal étoit composé d'une vingtainc d'hommes, qui vinrent au-devant de moi pour Tome II. 


\section{I $78 \quad \mathrm{VO}$ Y A G E}

me recevoir; tout y annonçoit la plus profonde misc̀rc.

Cependant, je fus frappé d'une sorte de distinction que j'spperçus sur une des huttes. Elle étoit couverte, en entier, d'unc penu de girafle. Moi, qui ne connoissois ce quadrupède, le plus haut de tous ceux du globe, que d'après les descriptions et les dessins fautifs que $j$ 'cn avois vus, je n'avois garde de reconnoitre ici sa robe; et cependant c'cn étoit unc. Enfin, j'étois dans lc pays qu'il habite; jallois ch voir de vivans, et je touchois au moment d'être dédommagé, au moins en partic, des malheurs et des chivgrins de mon voyage.

Les deux mourons que je conduisois avec moi, se refusoicnt à nous suivre, et l'on avoit eu beaucoup de peine ì les faire arriver jusquau krual. Pour ćviter que cet cubartas ne se renouvellît davantage, $j$ ordonnai de les tuer, et je les distribuai dans la horde avec quelques pièces d'hippopotames. Cette largesse devenoit pour elle d'aucant plus intéressante, qu'clle n'avoit absolument, pour toute nourriture, que le lait de quelques vaches. In la quittant, j'eus le bonheur d'ajouter cncore quelques provisions à celle-ci; c'étoicht cinq gazelles spring-bock', que je tuai sur une colline, à mille pas du kraal, ct que j'y envoyai aussi-tôt.

Jc n'ai point été témoin de la joic que dut y produire ce nouveau présent; mais s'il m'est permis d'en juger par celle qu'y occasionna le premicr, er par les remereimens sans fin que me firent ceux de la horde qui m'iccompagnoient et me servoient de guides, mon passage, chez ces malheireux humains scra unc époque qu'ils n'oublicront pas de sitôt; ct les miracles du grand pourvoyeur y seront redits de génération en génération. 


\section{E N A F R I Q UE. I\%9}

Arrivé an Gamma-Rivier (Rivière des lions), je trouvai un torrent qui avoit si peu d'eau, que nous choisîmes, pour notre route, son lit même. A ln vérité, le sable mouvant dont il ćtoit couvert, nous fatiguoir bcaucoup; mais nons etions dédommagés de cette Cacigue, par l'abri que nous préscntoicnt, contrc l'ardcur du soleil, les arbres rouffus de ses borris. Aux approches de la nuit, nous nous arrêtanes sous un grand mimosa, et après avoir allumé un teu, nous nous assimes en ccicle autour du foyer.

Sur l'arbre étoit un de ees nids énormes dont j’ai parlé ci-dessus, et qui composent une république d'oiscnux. Soit que la fuméc incommodât les animaux, soit que la clarté que répandoit notre feu leur parût celle du jour, benccoup d'entre cux sagritoicne dans les branches, tandis que d'autres, gazouillant en foule, formoient un bruit confus, quoiqu'assez agoćable. L'occasion ćtoit favorable pour m'en procurer quelques-uns. Jc montai sur l'arbre, et glissai la main dans une des cellules. Mais ce mouvcment, malgré toutes mes précautions, ayant ćbranlé la ruche, tous cherchèrent ì s'cnfuir, et de tous les trous, il en sortit à la fois une quantiré prodigieusc.

Néanmoins ma main avançoit toujours. Déja même je touchois quelque chose, quand tout-itcoup je me sentis mordre eruellement; et cette pinçure m'étonna d'autant plus, que les oiseaux constructeurs, étant du même genenre que les moinenux du Cap, ils ne pouvoient faire tant de mal. Il y avoit done dans le nid une espèce étrongère quil étoit curicux de connoître. La morsure étoit faite; je ne lâchai point prise, ct bientôt, en cffet, je retirni du nid, avec autant de surprise que de 


\section{I $80 \quad V O Y \wedge G E$}

joic, deux petits perroquets charmans, mâle ct femelle.

La présenec de ces intrus dans une république étrangère, me paroissoir un fait incxplicable. Les Namaquois sculs n'en étoient point étonnés. Ils le connoissoient pur cxpéricnce, et m'apprirent, que quand les républicains ont fini leur habitation, quelquefois des oiscaux d'une autre espice, et plus forts qu'eux, viennenc les cn chasser et s'y établir, et qu'en se multiplinn, ils y vivent de même en association. Ainsi done, ce n'ast pas chez les humains sculcment, que le foible est opprimé, dćpouillé, chnssé; chez les oiscaux aussi des tyrins s'approprient le fruir du travail des autres, er nc maniucnt pas non plus d"une logique, pour prouver qu'ils l'ont fait à bon droit.

Le jour, qui force les bêtes féroces de rezourner dans leurs repaires, et qui rend le coumegre à ceux dont la vie est innocente et les mours paisibles, ramena sur l'arbre la foule des petirs perroquets, que la fraycur de l'aventure de la nuic avoit épapillés au loin. Ils arrivoient tous par paire; et avint de rentrer dans l'habitation commune, ils s'arrêtoicnt sul les branches, pour cxaminer le dégât qu'elle avoit souffert. Mais je remarquai qu'il ne revint que des perroquers, et pas un scul des ancicns constructeurs. Ceux-ci avoicnt été bannis juscu"au dernier.

Taudis que je réféchissois sur cette transmutation de colonie, un des Namaquois, mes guides, vint aree cmpressement me donner un avis qu'il avoit cru devoir m'être agréable.

Cet homme m'avoit vil, dans sa horde, transporté de plaisir, à la vue d'une peau de giraffe, ct il étoit accouru pour me dire, qu'il venoit d'ap- 


\section{E N A F R I U E. I $8 \mathrm{I}$}

percevoir, dans les environs, un de ces animaux, sous un mimosa, dont il broutoit les feuilles.

A l'instant, ravi de joie, je sautai sur un de mes chevaux; $j$ 'en fis monter tm autre ì Bernlry, et suivi de mes chiens, je volai vers le mimosa indiqué. La girafíc n'y étoit plus. Nous la vîmes raverser la plaine du côté de l'ouest, et nous piquâmes pour la joindre. Elle prit un trot fort lćger, sans véanmoins forcer sa marche. Nous galopâmes après elle, et de tens en tems lui tirâmes quelques coups de fusil; mais insensiblement elle gagna tellement sur nous, qu'après l'avoir poursuivie pendant trois heures, forcés d'arrêter, parce que nos chevaux étoient hors d'haleine, nous la perdìmes de vlie.

Ce début me parut d'um manvais augure. Mes gens ne m’avoient annoncé que du plaisir dans la chasse aux girafies. A les cnecndie, ce ne seroit qu'un jeu pour moi; et cependint $j^{3} y$ voyois des difficultés très-considérables. Mais, pour le moment, ce n'éroir point là l'idéc la plus lầcheuse qui móocupât.

Notre course nous avoit fort éloignés les uns des autres et du camp. Selon mon estime, j'en étois su moins à cinq grandes lieues; et ce qui ćtoit bien plus inquictant cncore, c'est que la giralfe, ayant fait, dans sa fuice, différens détours et circuits, je ne pouvois plus m'orienter pour le rejoindre. II étoit midi. Déja je commençois à sentir les besoins de la faim et de la soif; et je me trouvois seul dans un licu très-aride, exposé à un solcil dévorane, et sans le moindre abri contre la chaleur, sinsi que sans provisions contre la faim.

En vain aurai-je essayé de me servir de mon cheval; haletant ct forcé, il ctoit hors d'état de me 


\section{I82 $\quad \mathrm{O}$ O Y A G E}

servir. Le seul parti qui me restoit à prendre, étoic done de demeurer en place, et d'attendre que mes gens, inquiets sur mon abscnce, se missent en quête pour mé chercher. Mais, à cetre distanee, sans moyens de recomnoissance et de renscignemens, commcnt cspérer qu'ils parvinsent jusqu’à moi? Je tirai quelques comps de fusil pour me faire entendre de Bernfry, qui ne pouvoit être loin de moi, et qui, pcut-être, s'étoit ćgaré lui-même.

De tems en tems je voyois passer en l'air, audessus de moi, quelques gélinottes. Pour tromper l'ennui, autant que pour soulager la faim, j'en tuai quclques-unes. Puis, avec lc bassince de mon fusil, et aux dépens d'ute de mes manchertes qui me servit d'amadoue, ćtant parvenu à allumer quelques broussailles, je les y fis griller.

Quoiquc cette oceupation m'eût employć deux heures, elle ne m'envêchr pas de faire des réflcxions bien amères. Que les momens sont longs dans de parcilles circonstances! Enfin cependant, quand je ris cinq beures à ma montre, et que jc me trouvai réduit à passer là la nuit, exposé aux attaques des bêtes fóroees, j'employai ce qui me restoit de jour à ramasser tout ce que je trouvai de broussailles dans les environs, pour entretenir et alimenter mon feu pendant les ténèbres.

Cettc précaution ne fut point nécessaire. Dans le moment oì je désespćrois le plus de seeours, je crus entendie, au loin, quelques décharges, ct je n'ai pas besoin de dirc tout ce que ce signal me causa de joic. J'y répondis par mes deux coups. Effectivement, c'étoient quelques hommes de ma troupe, du nombre desquels étoit Bernfry, qui me cherchoicnt. Bientôt j'cntendis lcurs cris; eux-mêmes ne tardèrent pas à me rejoindre, et je partis avce eux pour me rupprocher du camp. 


\section{E N A F R I Q U E. I 183}

Nous eûmes encore le tems de faire deux lieues avant la nuit. A la chitte du jour, nous eampâmes sous quelques aloès qui se trouvèrent sur notre route. Mais, à peine cut-on allumé les feux, que nous en appercûmes d'autres dans la montagne. Mes gens attribuoient ceux-ci aux Boschjesman, et ils craignoient que les nôtres, en nous trahissant, ne nous attirassent quelques atraques de ces rédoutables voisins. Mais nous étions assez en force pour n'ivoir rien à craindre, ct nous nous reposâmes tranq̨uillement.

Le lendenain, ma caravane entière me rejoignit. Je vis cinq autres girafies auxquelles nous donnâmes la chasse, mais qui cmployèrent tant de ruses, qu'après avoir été çourues pendant tout le jour, clles nous ćchappèrent à la faveur de la nuit.

J'étois désolé de ce mauvais succès. Mais ce qui me désespéroit sur-tout, c'est, qu'ayant vingt-six bouches à nourric, les provisions alloient me manquer tout-in-fait. Il me ne.restoit plus que quelques livres d'hippopotame; je venois de perdre deux journées en tentatives inutiles pour me procurer des vivres, et javois lieu de craindre que les autres ne fussent pas pius heurcuses. Ce fut alors que je regrettai de n'avoir pas acecpté le bouf que m'offrit le chef namaquois. Si la fortune continuoit de m'être contraire dans ma chasse du lendemain, j’allois ctre réduit ì faire tuer un des nôtres. Heureusement elle me favorisa; et le lendemain, qui étoit le dix novembre, fut pour moi un des plus heurcux de ma vie; comme il est l'époque la plus précieuse de mes voyages, ct que je me rappelle avec le plus de satisfaction.

Je m'étois mis en chasse au lever du solcil, dans l'espoir de trouver quelque gibier pour mes proII 4 


\section{$184 \quad \mathrm{VO} \mathrm{Y} \mathrm{A} \mathrm{G} \mathrm{E}$}

visions. Après quelques heures de marche, nous apperçûmes, au détoul d'une colline, sept giraffes, qu'à l'instant ma meute attaqua. Six d'entre clles prirent la fuite ensemble; la septième, coupéc par mes chicns, s'ćcarta d'un autre côté.

Bernfry, dans ce moment, marchoit à picd, et tenoit son cheval par la bride. En moins d'un elind'œil il fut en sclle, et se mit à poursuivre les six premières. Moi, je suivis l'autre à toute bride; mais, malgré les efforts de mon cheval, clle gagna bientôt tellement sur moi, qu"en touriant un monticule, cllc disparut à ma vue, ct je renonçai à la poursuivre.

Cependant mes chiens ne tardèrent pas à l'atteindre. Bientôt même ils la joignirent de si près, qu'elle fût obligée de s'arrêter pour se défendre. Du lieu où jétois, je les entendois donner de la voix de toutes leurs forces; mais ecs voix me paroissant tonjours venir du même endroit, j'en conjecturai, que l'animal étoit quelque part acculć par eux, ct aussi-tôt je piq̣uai vers lui.

En effet, j'eus a peine tourné la butte, que je l'apperçus, entouré des chiens, et tachant, par de fortes ruades, de les écarter. Il ne $m^{\prime}$ en coûta que de mettre pied à terre : d'un coup de carabine je le renversai.

Enchanté de ma victoire, je revins sur mes pas, pour appeller mes gens auprés de moi, et leur faire dépouiller et dépecer la bête. Tandis que je les cherchois des yeux, je vis Klans Baster, qui, d'un air très-empressé, me fiisoir des signes auxcuels d'abord je ne compris rien. Mais, ayant porté la vue du côté que me désignnoit sa main, j’apperçus, avec surprise, une giraffe arrêtéc sous un grand ébenier, et assaillic par mes chiens. Je crus que 


\section{E N A F R I Q UE. 185}

c'en étoit une autre, et courus vers elle. C'étoit la mienne qui s'étoit relevéc, et qui, al moment où j'allai lui tirer mon second eoup, tomba mortc.

Qui croiroit qu'une conquête pareille excita dans mon ame des transports voisins de la folic. Peines, fatigues, besoins cruels, incertitude de l'avenir, dégout quelquefois du passé, tout disparut, tout s'envola ì l'aspect de cette proic nouvelle : Je ne pouvois me rassassier de la contempler; $j$ 'cn mesurois l'énorme hauteur. Je reportois avec étonnement mes regards, de l'animal détruit à l'instrument destructeur. J'appclois, je rappelois tour at tour mes gens; er quoique chacun d'eux en eût pu faire autane, quoique nous eussions abattu de plus pesans et de plus dangereux animaux encore, je venois le premier, de tuer cchi-ci; $j$ 'en allois enrichir l'histoire naturelle; j'allois détruire des romans, et fonder, à mon tour, une vérité.

Tous mes gens accoururent et me félicitèrent sur mon triomphe. Bernfiry scul restoit en arrière. En vain je le pressuis du geste et de la voix. Tombé de cheval, il avoit cu l'épanle froissćc, et murchoit à pas lents, tirant sa monture par la bridc. Arrivé à ma portéc, il me parla de sa chutte. Moi, sans entendre ce qu'il me disoit, sans songer qu'il pouvoit avoir besoin de sceours, je lui parlois de ma victoirc. $11 \mathrm{me}$ montroit son épaule, je lui montrois ma giraffe; j’étois ivre, et n'aurois guère songé à mes propres blessures.

J'ai donné quelques notices sur les mœurs et l'instinet de la giraffe, et j'en dirai quelque chose encore. J'en ai rapporté une peau en Europe; et si les appartemens que pent occuper un particulier, n'étoient point beaucoup trop bas pour la hateur 


\section{$186 \quad \mathrm{~V} O \mathrm{Y} \mathrm{A} \mathrm{G} \mathrm{E}$}

d'un pareil animal, j'eusse dressé cette ponu, afin d'ofirir aux amateurs un modilc vrai de ce qu'il est dans li naturc.

Il me reste à détailler les précautions et les soins que j'ai pris, en le dépouillant, pour conserver sa robe aussi entière, aussi intacte qu'il étoit possible. Cette instruction peut devenir utile à ceux des voyageurs, qui, se proposant de parcourir, comme moi, la contrée des giraffes, voudroient, comme moi, en rapporter la dépouille. Des curieux, en voymt celle dont je suis possesseur, et qui, quoique suspendue sans précautions dans mon cabinet, depuis sept ans, les a surpris par sa fraicheur et son intćgrité, m’ont fait, à ce.sujet, plusicurs questions. Les détails dans lesquels je vais entrer, répondront à tout; et les procédés que j’ai ì décrire, seront peut-être accucillis avec d'autant plus de faveur qu'ils peuvent s'appliquer à tout autre animal qu'z̀ une girnffe.

Mon premicr soin, quand j'eus tué la mienne, fut d'en prendre très-cxactement toutes les proportions; puis de la dessiner, en réduisant mon dessin d'après l'échelle de mes mesures. Pendant ce tems tous mes gens étoient employés à soutenir les différentes parties que je dessinois.

A dire le vrai, ccte opération leur parut longue. Mournns de faim, n'ayant point mangé non plus que moi, depuis trente-six houres, ils aspiroicnt au monent où elle seroit finie, pour se repaîte de l'animal. Déja même, afin de travailler plus vite à sa dissection, plusicurs d'entre eux aiguisoicnt leur couteau sur des cailloux. Mais mon intention étant de conserver sa peau et de le dépouiller moi-même, je n'avois gardc de le leur lnisser déchiqueter et inettre en pièces. Vainement 


\section{E N A F R I Q U E. I8?}

ils m’invitoient à l'abandomer et m'assuroient que jallois désormais en trouver assez d'autres, je ne me laissai point prendre à ce langage d'affamés, et me mis incontinent à l'ouvrage.

D'abord je fendis la peau par-dessous le corps, depuis l'anus jusqu'à la lèvice inféricure. Cependant je n'cntamai point la livvre, parce que cette partic, ćtant d'une texture plus mollasse que le reste, elle se recircroit davantage par le dessechement, si clle étoit fenduc : ce qui défigureroit l'animal, quand on voudroit lui rendre sa forme. Après cette première incision, $j$ 'cn fis quatre autres, une cn dedans de chaque jambe. Celles-ci montoient du sibot au ventre, et aboutissoient à la première.

Cetre opération préliminairc finie, il ne s'agissoir plus que d'écorcher et de dépouiller le quadrupcde, et c'est ì quoi j'employai quelques-uns de mes gens avec leurs coutenux affilés. J'eus soin pourtant que les sabots et la tête restassent adhérens à la peru. Ce fut moi qui me chargeai encore de ce travail; et c'est ce que j'opérai en coupant la tête à la dernière vertèbre du cou, et détachant les sabots du tibia. Pendant mon travail, mes Namaquois alloient dans les environs couper du bois, et ils allumoient du feu pour notre cuisine. En parcourant le terrain, ils venoient de découvrir une source. J'y fis porter la peau afin de li nettoyer du sing et des autres ordures qui pouvoient la souiller; puis jabandonnai le corps de l'animal à mes affamés.

Klaas, toujours attentif, toujours occupé de moi, avoit, avant eux, prélevé quelques morcciux, qu’il m'apporta grillés et que je trouvai excellens. Il mit aussi sur le brasier les tibia. Leur moëlle, blan- 
che et ferme comme la graisse de mouton, étoit viaiment appétissante. Jamais je n'en avois vu d'aussi belle, et je regretrois benucoup de n'avoir pas de pain pour en faire des rôties. J'en fis fondre au moins une certaine quantité, dont je remplis la vessie de la giraffe; et par la suite cette provision me servit pendant assez long-tems à cuire des tranches de l'animal même.

Après le diner, je me remis à l'ouvrage. Klaas avoit nettoyé et applani un espace de terrain d'environ vingt pieds currés. J'y fis étendre la peau, le poil en dessous; et, dans cet état, on l'assujettit sur ses bords avee de grosses pierres.

En pareil cas, les colons se servent de chevilles de bois dont ils percent la penu pour la tendre fortement; mis cette méthode est vicicuse, car la peau se festonine, et par la suite, quand on veut l'employer, ces appendices subsistent, mème après qu'clic a été humectéc dans l'cau, parce que ce qui a ćté rrop distendu ne se rappétisse jamais. Quel que soit l'adresse du naturaliste, il ne peut plus, quend il la inonte, remédicr à ces difficultés insurmontubles; ct la peau bourée qu'il place ainsi dans son cabinct, n'est plus qu'une peau informe, qui ressemble toujours peu à l'aninal qu'elle représente.

Il me restoit à dessécher la peau de ma giraffe, à consumer sa graisse et à détruire enfin toutes les causes de fermentation qui cussent pu la pourrir ou l'endommager. Dans ce dessein j'avois ordonné de grands feux afin d'avoir beaucoup de cendres. J'y épandis ces cendres; ayant soin qu'elle en fût. couverte encièrement et d’une manic̀re égale. Elle resta dams cet ćtat pendant toute la nuit; ct de peur que quelque hicme ne vint, à la faveur des ténc̀- 


\section{E N $\triangle$ FRIQU E. I 89}

bres, en dévorer des lambeaux, je dressai ma tente tout auprès de mon trésor.

La dissection de la tête et des sabots me prit toute la journée du lendemain, parce que je ne pus et ne voulus m'y associer que Klaas. Les sabots me coûtirent peu de peine, mais il n'en fut pas ainsi de la tête. Pour ce qui reģarde celle-ci, d'abord nous commençâmes par soulever la peau des mâchoires et des joutes, et par enlever les chairs qui étoient en-dessous, en y substituant des étoupes pour restituer et conserver les formes. Les yeux furent traités ì-peu-près de même. Après avoir arraché le globe de l'œil et desséché son orbite avec des cendres ehaudes, je remplis également d'étoupes cette cavité, afin de soutenir les paupières.

L'opération la plus difficile fut l'extraction de la cervelle (la giruffe en a beancoup), et je fus même d'autant pliss cmbarrassé que je n'y voulois ni incision ni fracture. Enfin, j'imaginai de l'imbiber et de l'éponger, pour ainsi dire, peu à peu. C'est ce que nous exćcutâmes à l'aide d'un fil de fèr, que je garnis, à son cxtrémité, de poils tiré du kros de mes IIottentots; et qui, changé ainsi en pincenu, fut introduit dans la boëcc osseusc du crâne. Le cràne vidé, je le remplis de cendres chaudes. Quant à la partic antéricure de la tête, depuis les narines jusqu'aux appendices osseux dont j’a parlé ailleurs, et qui forment à l'animal des espèces de cornes, je n'eus rien ì y faire, parce qus n'étant pas charnue, je n’avois qu'à la dessécher.

De tems en tems je renouvellai les cendres sur la peau. J'entretins même, pendant plusieurs jours de suite, de très-grands feux, uniquement pour avoir des cendres. Elles opéroient à la fois par l'action combince de lcur vertu dessicative ce alka- 
line, et ce moyen m'a réussi purfaitement, comme on peut le voir dins mon cabinet.

Je n'cn dirai pö̈nt autant ciu scl marin qu'cmploient, en pareilles circonstances, les colons. SeIon moi, saler une penu, c'est la détruire; et j'ai vu constanment che\% cux ce fait confirmé par l'cxpéricuce. Outre que le sel n'empêche pas certains insectes de venir y déposer leurs cufs et en attaquer les poils, il y entretient une certaine humidité, er par conséquent un commencentent de destruction qui bientôt s'achève pendant le trajet de la mer, et par un long séjour dans le vaisscau.

Avant que j'apportasse en Europe la dépouille de la girafic, il y en étoit arrivéc une en Ilollande; mais ayant ćté misc dans le sel, elle fut gâtée : clle l'étoit mêne déja avant de partir du Cap.

Quant au squelette de cet animal, qui fait partie du cabinet de la Haye, un écrivain qui n'est nullement naturaliste, a écrit, dans le journal de Paris, 26 mai 1788 , qu'il y a vu une peau entic̀re avec le squeleite du benu quadrupede auquel elle a appartenu. Le squelettc existe cn effet. Mais pour la robe, comme clle est gâtéc, on n'en montrc ordinairement aux curieux qu'un échantillon. Je ne doute nullement que cet auteur, en la voyant ainsi, n'ait jugé du tout par la partic qu'on lui en a montréc.

Pour moi, j'ai, à mon retour d'Afrique, examinć plusicurs fois ce beau squelette, ainsi que les débris d'une peau, j'ose donc avancer qu'clle est composéc de différentes parties, dont la plupart sont même tellement dégradées que si on entreprenoit de r'habiller l'animal en enticr, on n'y parviendroir pas. Si Vosmaer, directeur du cabinet, a écrit sur la giraffe, certes, ce n'est point d'après 


\section{Tonez Pl. VIIL.}

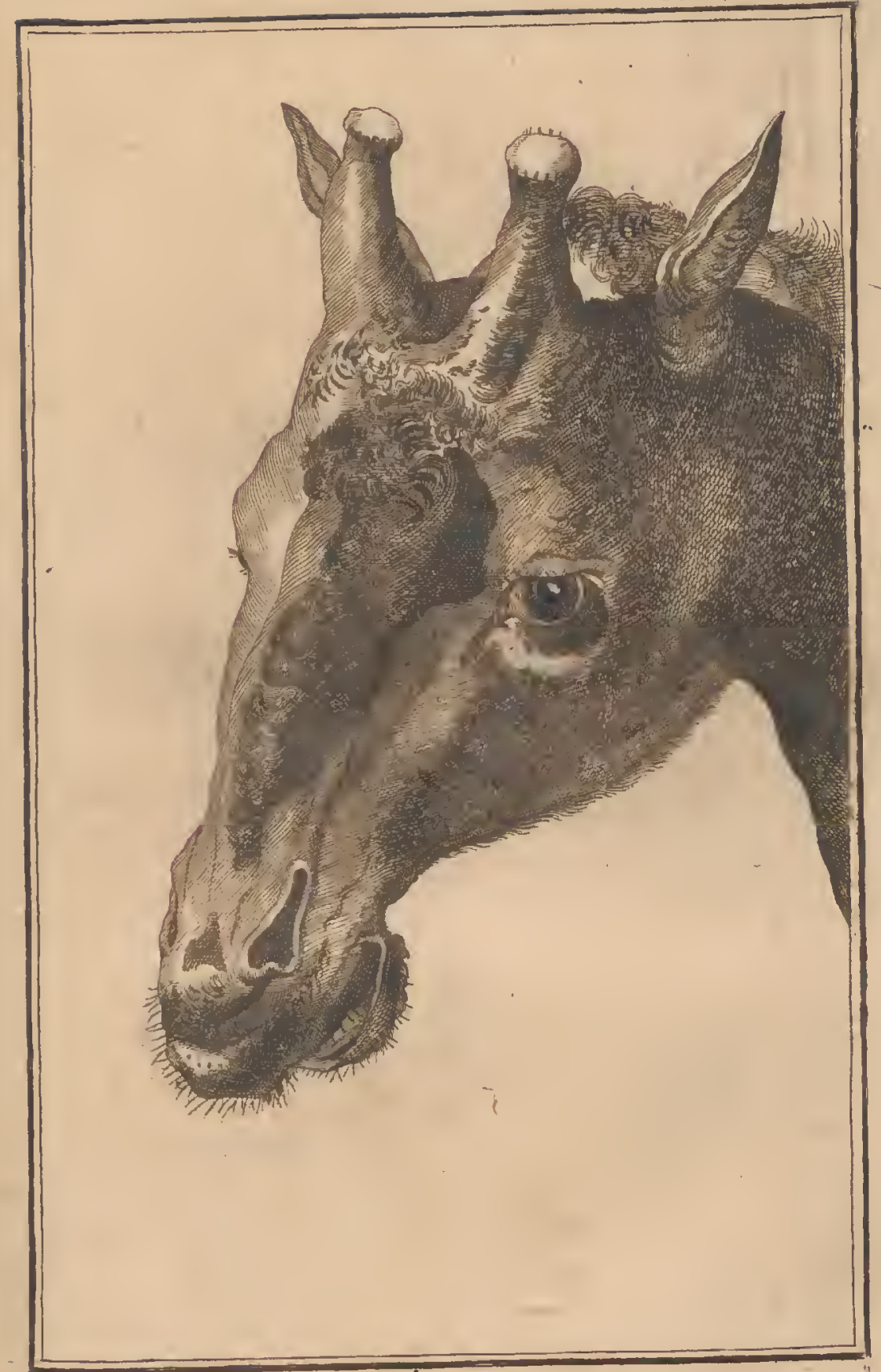

TETE DE GIRAFFE. 



\section{E N A F I Q U E. IOI}

les connoissnnces qu'a pu lui procurer eette dépouille informe, mais d'après ses lectures ou des conversations particulicres avee des gens instruits. La preuve de nion assertion est dans la premiere gravure qu'il a donnéc de ce quadrupède, et qu'il rectifia cnsuite d'après ce que je lui ai dit à mon retour, et d'après mes dessins qu'il a rus.

La giraffe rumine; ainsi qu'en général toutes les bêtes à cornes et à pied bifourchu. Wile broute aussi comme clles; mais mrement, parec que le pâturage manque dans la contréce qu'elle habite. Sa nourriture ordinaire est lit feuille d'unc sorte de minosa, nom:ace par les naturels du pays kmaap, et par les colons kameel-doorn. L'arbre étant particulier a canton, et ne croissant que là, il se pourroit que ce fitt la raison qui l'y fixe, et qui cmpêche qu'on n'en voic dans les régions de l'Afrique méridionale on il ne croit pas; ce qui n'est au reste qu'unc assertion hasardéc, ct que l'antiquité même scmble contrarier:

Sans contredii, la plus belle partic de son corps est la tête. Sa bouche est petitc, et ses ycux sont vifs et bien ouverts. Entre les dcux ycux et audessus du nez il a une tubcrcule tress-saillante et bien prononcéc. Cette éminence n'cst point une excroissance charnue, mais un renflement de la partic osscuse; et il en est de même des deux petites bosses, ou protulsérnnes, dont son occiput est armé; ct qui, grosses comme un neuf de poule, s"élèvent, de chaque côté de la naissanec de sa crinière. Sa langue est rapeusc ct se termine en pointe. Ses deux mấchoires ont, de chaque côté, six machclic̀res; mais l'inféricurc porte on outre, sur le devant, huit dents incisives, tandis que la supéricure n'en a point. 
Les sabots sont fendus, ils manquent de talon et ressemblent asse\% à ceux du bouf. Cependant on remarque, au premicr coup-l'ceil, que ccux de l'avant portent plus de grosseur que ceux de l'arrière. La jambe est très-fine; mais les genoux sont couronnés, parce que l'animal s'agenouille pour se concher. Il a aussi an milien du sternum une grande callosite; ce qui prouve qu'il repose ordinairement sur la poitrine.

Si je n'avois point tué de girafes, je croirois, ainsi que beaucoup de naturalistes, que ses jambes de devant sont berucoup plus hautes que celles de derrière. C'est-ì̀ une erreur; cllus's ont entre elles à-peu-près la proportion ordinaire les autres quadrupèdes. Ic dis la proportion ordinaire, parec qu'en ce genre il y a des variérés, même dans les animatux de même espèce. $\Lambda$ insi, par exemple, personne n'ignore, qu'à hauteur érale, les jumens sont plus basses du devant que les chevaux entiers. $\mathrm{Ce}$ qui trompe dans la girafie, sur cette différence apparente entre les jambes, c'est la hauteur du garot qui, suivant l'âge qu'clle a, peut excéder celle de la croupe de scize à vingt pouces, et qui, quand on la voit courir de loin, paroit domer plus de longucur aux jambes de devant.

Si la giraffe est arrêtéc, et que vous l'apperæcviez en face, l'effer est tout différent. Comme la partie antéricure de son corps est benucoup plus large que la postéricure, elle couvre celle-ci en enticr; l'animal ressemble alors à un tronc d'arbre mort sur pied.

Son allure, lorsqu'il marche, n'est ni gauche ni désagrúable. Mais, s'il trottc, elle devient ridicule; et l'on croiroit que c'est un animal qui boite, en voyant sa tête, perchéc à l'extrémité d'un long cou 


\section{E N A F I Q UE. I93}

qui ne plic janais, se balancer de l'avant à l'arrièrc, - et joucr, d"unc seule pièce, entre deux épaules qui lui scrvent de charnièrc. Au reste, Ia longucur du cou, dépassant au moins de quatre pouces celle des jambes, il est évident, qu'ajoutée à la longueur de la tête, clle lui suflit pour brouter sans peine; et que par conséquent il n'est pas obligé, ou de s'ag'enotiller, ou d'écartet les pieds, ainsi que l'ont écric quclques auteurs.

Sa défense, comme celle du cheval ce des autres solipides, consiste en ruades. Mais son arric̀re-train est si léger et ses ruades si vives que l'ceil ne peut les suivre. Elles suffisent même pour le défendre contre le lion, quoiqu'elles soient insullisantes contre l'attnque impétueusc du tigre.

Pour ses cornes, il ne les emploie nullement dans ses combars. Je ne l'ai pas même vu s'en servir contre mes chiens, et cette arme foible et inutile ne scmblcroit qu'unc cricur de la nature, si dans scs ouvriges la nature pouvoit manquer son but et se tromper.

En général, c'est une règle assez constante chez les animaux, que dans leur jeunc âge les mâles resscmblent aux femclles, ct n'ont rien qui les distingue. Cette ressemblance de jeuncsse est un caractère propre, non-sculement à plusieur's espèces de quadrupedes, comme je lc prouverai dans la suite, mais encore à nombre d'oiseaux, tant de ccux chez qui les deux sexes difièrent le plus dans leur état parfait, que de ceux très-nombreux encore qui changent de couleurs dans les diverses saisons de l'année. Il est, pour ceux-ci, une époque fixe à laquclle le mâle quitte sa robe brillante, pour prendre la livréc simple de sa fenelle; ct dela ces erreurs fréquentes de certains naturalistes qui, dans

Tome II. 
leurs cabinets réunissant des animaux d'espèce différente, ou cn séparant d'autres de même espèce, contrediscnt la nature qu'ils connoissent mal.

Les giraffes, mâles et femelles, sc ressemblent h̀ l'extérieur pendant leur jeuncsse. Leurs cornes obtuses se terminent par un faisceau de longs poils, que la femelle conscrve plus long-tems, que le mâle, qui les perd lorsqu'il ese parvenu à lâge de trois ans.

Il cn est de mếme de la robe, qui d'abord d'une couleur roux-clair, se fonce peu à $\mathrm{peu}$, à mesure que l'animal grandit, et qui finit par être brun-fauve chez la femelle, et d'un brun presque noir chez le mâle. On peut voir la preuve de ce que je dis ici, dans le cabinet d'histoire naturelle de I_cyde, où il cxistc une jeune giraffe d'environ sept picds de haut, laquelle a éré enroyéc par le gouverneur Tulbach au professeur $\Lambda$ llamant, et que cclui-ci a faic monter avec soin.

C'est ì cette différence de couleur dans les giraffes d'un certain âge, qu'on pcut, à quclque distance, distinguer les mâles des fenuelles. Au reste, la robe chez tous les deux varie éçalement pour la distribution et pour la forme des taches; jobserverai encore que, quand la femelle devient trèsvicille, elle prend la teinte foncéc du mâlc.

De près, la femelle se distingue en outre par sa taille moins haute ct par la bosse de son avant-tête, moins saillante et moins prononcéc. Elle a, comme la vache, quatre pis ou mamelons; et, si je puis citer ici le rémoignage des Sauvages, clle porte pendant douze mois, ct n'a jamais qu'un petit à chạue portéc. I a gravure de mon premicr voyage qui représente la giraffe mâlc étant défcctucuse en ce que la tête de l'animal est mal rendue; on ne 


\section{E N A F R Q UE. 195}

sera pas fàché de trouver ici une représentation plus exacte de cette partic, et sur une plus grande échelle.

$\Lambda$ cinq lieucs de' nous, du côté de l'est, nous avions une horde die Caminouquois qui, sans doute avertis de ma présence par nos feux, vinrent me rendre visite et domer à ma troupe des leçons d'économie. Ils se jettìrent en affamés sur ce qui restoit de ma giraffe, et mmassèrent soigmeusement les os; même jusqu'̉̀ ccux que mes grens avoient jettés après cn avoir mangé la moëlle, furent mis par cux à profit. Ils les brisèrent en morcenux, mempruntcrent ma chaudière pour les faire bouillir, et en tirèrent une quantité incroyable de graisse qu'ils recucillirent avec une grande joie.

Pendant les neuf jours que je restai là, ce furent des voyages continuels du Kraal à mon camp. C'étoient des fourmis prévoyantes qui, allant et revenant sans cesse, emportoient toujours quelques provision̂s.

D'ailleurs, sans me donner aucune peine, je leur fournissois abondamment plusieurs espèces de gazelles. Chaque jour rígulièrement elles venoient cn troupe vers les quntre heures du soir, boire à la source; et me mettant en cmbuscade, j'en abattois autant qu'il me plaisoit. Plus loin, à trois quarts de licue, étoit une colline que j'avois appellée mon garde-manger. Tous les matins, au lever du soleil, clle étoit tellement couverte de gélinottes, que d'un seul coup chargé à mitraille j'en tuois plus qu'il ne nous en falloit pour notre consommation. Ainsi, après avoir éprouvé pendant long-tems les hor" reups de la fanine, nous nous trouvions tout-àcoup dans une abondance excessive; et je pouvois, avec notre stperflt, nourrir sans peine mes voisins. 


\section{$1.96 \quad$ VO Y A G E}

Je prolongeois quelquefois jusques ehez cux mes promenades et mes chasses, dins le desscin de les ćtudier et de les connoître. Mlais ils n'ont rien absolument qui les distingue des Grands Namaquois. Armes, mours, usages, habillemens, langage, construction de huttes, tout che\% les uns et che\% les autres est entièrement semblable.

Outre les gazelles spring-bock et les gélinottes, je trouvois souvent encore à chasser des bulfles. Pendant les premiers jours les giraffes continuc̀ent de se montrer en petites troupes de sept à huit bêtes. Mais bientôt ces animuux timides s'effarouchèrent de nos fusillades continuelles; ils désertèrent le canton, et ne reparurent plus; et ce fitt alors que je m'applaudis de n'avoir pas cédé aux instances de mes gens, quand, pressés par la faim, ils me demandèrent de leur abandonner la girafle que j'avois tuéc. Les zèbres abondoient en troupes; je me vengeai sur eux et leur fis porter la peine de la fuite des giraftes. J'cusse voulu faire éprouver le même traitement à deux rhinocéros, mâlc et femelle, que j'cus occasion d'appercevoir un jour; mais ils passerent trop loin, et nous ne pûmes les joindre.

Pour une autre raison, je m'abstins d'attaquer les élćphnns, quoique l'occnsion s'en présentàt souvent. L'appât de leurs défenses m'eût bien tenté; mais dénué de voitures et n'ayant que des bœufs de charge, je craignois d'ajouter un trop grand poids à cclui de la giraffe. Je me dédommageai par une autre collection non moins précicusc et bien plus aiséc à transporter. J'amassois des plumes d'autruches, en même tems que je me nourrissois de leurs oufs dont $j \mathfrak{a}$ ai souvent fait des soupers déliciemx. 


\section{EN A F R I Q UE. I97}

Le canton érant neuf pour moi, je ne pouvois manchuer d'y trouver quelques nouvenutés pour mes. collections. J'y vis commencer le passage des grands et des petits guépicts. La premicre espèce de ces giscaux est communc an Cap, ct même dans les provinces méridionales de la France. La scconde a un caractère distinctif particulier; c'cse unc queue presque aussi fourchue que celle de l'hirondelle, tandis qu'en général tous les autres guépiers connus l'ont en fer de lance, par l'effet des deux plumes du milicu, lesquelles dépassent de beaucoup les autres.

Les Namaquois donnent à ce charmant oiseaù le nom de tawa (ficl), ä raison du beau verd qui fait sa couleur principale. Ce fond agrćable cst rclevé par une gorge jaune terminée d'un collier outremcr.

J'acherai chez mes voisins, les Caminouquois, la peau d'un chat sauvage qui a tous les caractères du lynx. Par la suite, jai cu necasion d'en tuer plusieurs. Cet animal est d'un roux très-foncé; mais il a les oreilles noires, et elles sont surmontées d'un faisceau de poils de la même coulcur. C'ese une espèce nouvelle, qui n'a pas cncore été décrite que je sache.

Mes absences étoient fréquentes; mais elles étoient courtes, et chaque jour je revenois, à une heurc régléc, pour assister au renouvellement des cendres sur la peau de ma giraffe : cette conquête étoit une grande affaire, et jc ne voulois point que cette općration se fît sans moi. Enfini, après ncuf jours de cette tanneric incalescente, voyant que lc cuir, quoiqu'il n'cût pas chcore le degré de dessication qui étoit nécessaire pour le conserver, en avoit ccpendant acquis une, tellc que, poussée plus 
loin, il ne seroit plus possible de le manier, je le fis plicr en quatre et assujettir avec des courroies, les pieds ct la tête en dessus. Dans cet état il formoit un paquet de six pieds carrés stir trois pieds et denil d'épaisseur.

I, "cmbarras de traincr avce moi un parcil fardeau pendant toute ma route, me fournit d'abord l'idée de le laisser en dépôt chez mes bons voisins les Caminouquois, pour le reprendre à mon retour. IVais dans l'hypothèse où je réussirois à traverser l'Afrique, il n'y avoit point de retour pour moi; et dans eclle où les événemens me forcêroient de revenir sur mes pas, pouvois-je espérer qu'ils me permettroient de repasser par la horde; ct puis j'illrois voulu le confier, et en même tems le couver de mes yeux. Je portois un trop vif attachement à ce tréso: précicux pour l'abandoriner.

D'un autre côtć, j’avois à craindre que la peau ne se gâtât faute de soins, pendant mon abscnce; et je sentois combicn il me seroit difficile d'en avoir une autre, si je perdois celle qu'un si heureux hasard m'avoit procurée. Tout, jusqu'aux soins que je venois de prendre pour la préparer, me la rendoit précieuse. Ainsi done je ne songreni plus qu’à la conserver, et voici le parti que je pris.

En réfléchissant sur ma route et en morientant, il me scmbla que je ne devois pas être ćloigné de plus de dix-huit ou vingt licues de mon cump sur la rivic̀re d'Orange, et que par consćquent il ne mic falloit que quatre jours pour m'y rendre c1z ligne droitc.

A la vérité, des deux motifs qui m’avoient déterminé à ma petite excursion, je n'en vbyois qu'un de rempli; et ce n'étoit point assez d'avoir connu la giraffe, il me restoit cneore à acheter des boufs 


\section{E N A F R I Q UE. . I99}

potir mes voitures; mais le pays étoir trop stérile et les Caminouquois trop misćrables pour fournir à de pareilles emplettes. Je me proposois de tenter, dans d'autres contrécs voisines, quelque autre coursc execntrique du même genre, qui peut-être seroit plus heureuse; cn attendant, je ne m'oceupai qu'à mettre en sîreté ma giruffe.

Mon plus grand embarras étoir de savoir comment je l'emporterois. Sans voiture et même sans possibilité d'cn faire arriver une jusqu'à nous, je n'avois pour cette expédition que mes beufs. Mais indépendamment des retards et des incommodités que devoit nous oceasionner en route un paquet aussi volumineux, son poids énorme étoir au-dessus des forces d'mn bœuf ordinaire; l'animnal en cût été écrasé. J'imaginai done de louer les deux plus forts boufs qui fussent dans la horde, et de construire un brancard, qui, s'adaptant sur leurs ćpaules et les obligeant ì marcher de front, partageroit lc fardenu cntre eux deux. La machine achevéc, je l'essayai; er son succès étonna tellement les Caminouquois, pour qui clle étoii nouvelle, qqu’à mon départ toute la horde accourut pour la voir et l'admirer. Aux yeux d'un Sauvage les choses les. plus simples sont une invention qui tient du prodige. Quclle supériorité nous donnent sur lui les avantages de l'industric exerée; mais en revanche quelle supériorité lui*donne sur nous le pouvoir de s'en passcr.

Le second jour', j’arrivai à la Rivière des Lions, que nous triversâmes au même endroit où nous l'avions passée précédemment; et lc quntriène, eomme je l'avois conjecturé, je fus, vers le soir, à la vue de mon camp, sur l'autre bord de l'Orange.

Au bruit d'une décharge que nous fìmes pour $\mathrm{N}_{4}$ 


\section{$200 \quad \mathrm{VO}$ X G E}

avertir de notre arrivée, tous mes gons passèrent hat rivière à la nage et vinrent à moi. Swancpoel resta scul au camp, fort intriguté de cc brancard ct de cet attelige de deux bœut's sans voitures qu'il voyoit ì ma suitc. Nénnmoins l'obscurité qui croissoit $\mathrm{m}$ 'cmpêcha de risquer ma traverse sur le radcau. Jc passai la nuit où je me trouvois, et ne revins au camp que le lendemain.

La première de mes occupations, en y arrivant, fut de metre ma girafle à l"eau pour la ramollir et de la nettoyer des cendres qui l'encroutoient; puis je l'érallai, je l'écharnai; cn un mot, j'y fis ce qu'auroit fait un tamncur.

Pour la mettre en état de se conserver, il ne s'agissoit plus que de l'imbiber de quelques sucs stiptiques ou astringens, et c'cst cc que j'opérai, en employant, au défatut de tan, une forte lessive de cendres et de tabac, dans laquelle ćtoient dissous un peu d'alun, quatre onces de camphre et une livre de savon.

Ma lessive ne pouvant s'appliqutucr d'une manière utilc qu'autant que la peau seroit dans une situation horisontale, j'élevai à cet effet unc fortc claic en forme d'échaffiud, posće sur des fourches et composéc de traverses à grandes mailles. On y étendit Ic cuir, le poil cn dessus; ct dans cette situation, on l'arrosa de la lessive, tandis qu'cn dessous on J'humectoit atce des linges imbibćs" de la liqucur. Après quoi, l'ayant couvert de nattes afin d'empêcher que les rayons du solcil n'altérassent les coutJeurs du poil, je le laissai sécher en cet ćtat. On verra, par la suite de ma relation, qu'il y est resté bien long-tems.

Mon retour fut unc fête pour mes Hottentots; mais le motif de leur joic devint pour moi un cha? 

Simn. II.

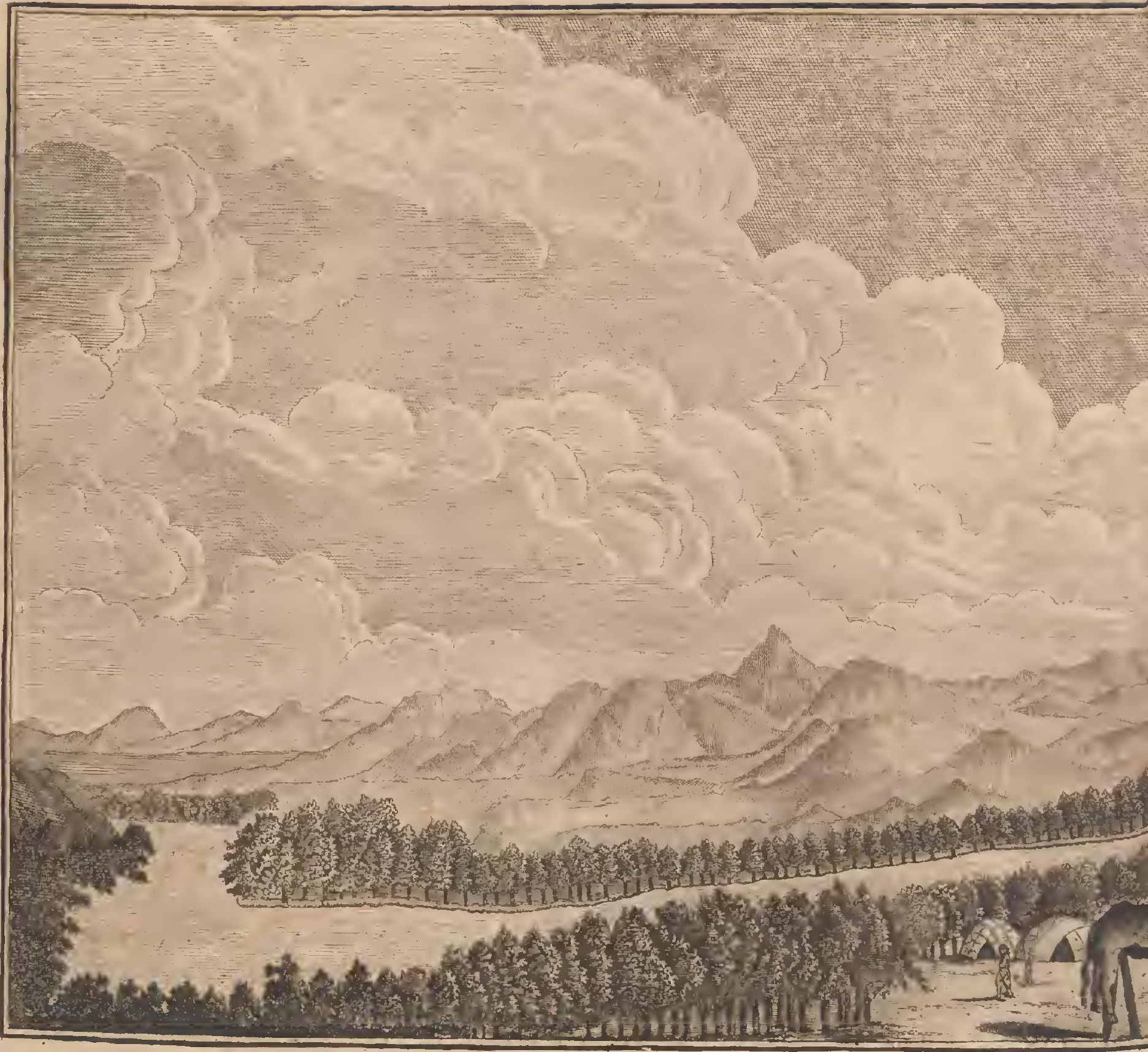

CAMP DE I,A GIRAFFE, SUR LE BORD 



\section{E N A F R Q UE. 2OI}

grin rćcl. Il m'apprit à connoître lc vrai caractère de cette nation casanic̀re et indolente des Hottentots colons dont j'avois jusques-là trop bien auguré, et qui utile peut-être tant qu'on ne voudra point sortir des colonies, devient incommode et iz charge quand on la conduit dans des récyions lointaines, semées de hasards et de dangers.

Ils se flattoient que, ne ponvant avancer plus avant avec mes charriots, j’allois être obligé de retourner au Cap et les rendre à leur paresse naturclle, avec des profits obtenus sans fatigues. Assurénient il s'en falloit de beaucoup que je songeassc à mon retour; ct quand ic l'aurois voulu, j'étois bicn loin de le pouvoir. Pendane les vingtsix jours de mon absence, non-sculement j'avois perdu tous mes boufs, à l'exception de onze; mais ces onze ćtoient eux-mêmes dans un état de dépćrissement qui m’n faisoit désespérer. Je déclarai done tout haut que si j'étois revenu au camp, c'étoit uniquement pour me débarmsser de ma giraffe, ct que j'avois l'intention dé repartir au plutôt et d'aller, ou chez les Grands Nannquois, ou chez quclque autre peuple voisin, acheter de quoi remonter mes voitures.

A cette impaticnce de mes gens pour leur retour, sc joignoit un autre sujet d'inquiétude, bicn plus alarmant encore. En arrivant au camp j'avois étć salué par un personnage inconnu, qui n"ćtoit. venu, disoit-il, que pour me voir et me faire visite. Son visagre ammonçoit vingt-quatre ans; mais scs traits portoient un tel caractère de scélératesse qu'on n'avoit pas hesoin de savoir son nom pour concevoir de lui l'opinion qu'il méritoit. C'étoit Matthys Moodel, l'ami intime de Bernfry, et l'un de ces fugitifs proscrits de la Colonie pour lcur 
conduite, et par les colons pour la noirceur de leurs forfaits.

- La réunion de cos deux hommes ne pouvoit que m'inquiéter benucoup, et je la regardois comme un mal cent fois pire pour moi que ne l'eût été le voisinage des lions, des tigres et de tous les monstres d’Afriquc. Après tout, n'étoit-il pas possible que de pareils hommes se fussent ligués ensenble pour venir m'assassiner er s'emparer de mes armes et de mes munitions. Un tel projer étoit digne d'eux; et l'éloignement des déserts où ils vivoient leur en assuroit l'impunité.

Quelles cussent donc été mes craintes, si j’avois su alors, comme je l'ai appris depuis, que tel étoit en effet leur méticr, et que tous deux étoient liés avec les Boschjesman; qu'jls leur donnoient des renseignemens pour venir piller les Namaquois, et partageoient ensulite le butin avec eux.

Swanepoel, il est vrai, m'avoit averti que pendant mon absence quelques Boschjesman étoient venus au canpo, sous prétexte de lui demander du tabac. Cette sorte d'espionage eût dû sufire scul pour 117ouvrir les yeux. Mais quoique les deux coquins me parussent capables de tous les crimes, soit distraction, soit confiance dans ma petite armée, il ne me vint point à l'esprit de les soupçonner de celui-ci. Er quant à la visite des Boschjesman, elle ne me parut pas alarmante, parce que ces voleurs n'attaquent jamais qu’à coup sûr, et qu'ils ne craignent rien tant au monde que les armes ì feu.

Outre Moodel, j’avoîs trouvé, à mon arrivée, baaucoup d'autres visages inconnus. C'étoient des fenmes que mes Hottentots avoient appellées près d'cux et qu'il me falloit nourrir, pour le plaisir de 


\section{E N A F R Q UE. 203}

ces messicurs. Chacun avoit la sienne, ou plutôt il y en avoit de quoi suffire à leur rechange; et plusicurs même, à l'excmiple de Bernfry, s'cn étoient approprié jusqu'à trois. Ce désordre cn avoit produit nécessairement d'autres. Le service ne se faisoit plus qu'avec une néçliggence cxtrême. On se relìchoit sur tour, et l'insubordination étoit même devcnue si générale, que pour couper court au mal, je me mis en devoir de prononcer autant de divorces qu'il y avoir eu de mariages, et de renvoyer impitoyablement toutes ces dames hotrentotés.

Une injonction aussi sévc̀re ne pouvoit manquer de déplaire à des fainéans qui n’avoient plus d'autre occupation que de se divertir, ct auxquels j'annonçois les farigues d'un nouveau voyage. La plupart murmurèrent hautenent, et ils sc plaignirent qu'après les avoir conduits depuis trois mois dans des pays horribles, je voulois les mener dans d'autres plus affreux peut-être et plus périlleux encore. La vue des femmes qu'il filloit quitter ajoutoit au mécontentement. Enfin, il devint tel que Klaas, cntrant dans ma tente, m’annonça que si je ne prévenois l'insurrection en révoquant nion ordie, je courois risque de me trouver seul le lendemain avec lui et Swancpoel, parce que tous les autres s'arrangeoient déja pour partir avec leurs maitresses.

En toutc autre circonstance, un parcil avis cût peut-ĉtre produit en moi beaucoup de réflexions. Dans celle-ci, il ne fit que m'irriter. Je ne vis plus dans mes gens que des serviteurs rebelles; et ma têtc ćtoit même si échaufféc des murmurcs, que, sortant précipitamment de ma tente, je renouvellai tout haut l'ordre du départ des femmes; en ajoutant que ceux qui les préféroient à moi, pouvoient 
204

partir avec elles; que je ne voulois plus de leur service, et qu'un jour, quand je le voudrois, je saurois les recrouver et les haire punir.

Le con ferme avec lequel fut prononcéc ma mcnace aymut fint taire les murmures et produit un grand silence, je tentai de metere à profit cette impression momentanéc, en essayant mon autorité par un ordre d'un autre genre. Deux de mes chèvres et un mouton s'étoient égarés la veille, et les gens que Swanepoel avoit cnvoyés à leur recherche ćtoient revenus, sans les ramener. Je commandai qu'on allat de nouvcau les chercher. Mais persome ne se meetant en devoir d'obéir, j'en dommai spécialement l'ordle à celui qui sc trouvoit le plus près de moi. C'étoit un nommé Adam, Hottentot, qui m'avoit accompagné pendant mon premier voynge, et qui depuis, et avant que je commençasse mons second, avoit continuć d'être à ma solde pour la garde de mes boeufs.

En ce moment, Adam ćtoit assis sur son paquet, et prêt à partir. Sans se lever, il me répondit impertinemment que, n’étant pas plus sorcier que ses camaracies, et n'ayant pas plus qu'cux le talent de retrouver ce qui étoit perdu, je pouvois me dispenser de l'envoyer à la recherche des bêtes, et qu'il ne vouloit pas y aller. Cette résistance in'enflamina de colère. Je le frappai dans l'estomac d'un coup de pied qui le renversa par terre; puis armant un des pistolets de ma ceinture, je lui criai de se sauver, s'il ne vouloit pas que je lui fisse sauter la cervelle.

En effet, il ramassa son paquet et se sauva au plus vìtc. Mais à peine fut-il à trente pas et hors de la portéc de mon pistolet, qu'il s'arrêta tout court et se mit à proférer quelques phrases que je 


\section{E N A F R I Q E. 205}

ne pus, à la vérité, distinguer, et qui probablement étoient des menaces, au moins à en juger par son attitude er son geste. Alors je siisis mon fusil, et lui envoyai successivement mes deux balles, non dans l'intention de l'atteindre, mais pour-intimider ceux qui, à son. exemple, cherchervit à se soulever; la terreur en un instant se répandit dans tout mon camp, ct le coupable s'enfuit à toutes jambes; il couroit comme si le vent l'eût emporté; de sorte qu'cn un instant il fut hors de notre vuc.

Ce coup de parti hâtoit le moment d'une révolution qui pouvoit devenir générale, et j’eus lieu de le craindre, inmédiatement après, en voyant chacun partir de son côté et se répandre dans la campazne. Je ne trompois. L'exemple de séverité dont ils venoient d'être témoins, leur en avoit imposé. Klaas m'assuria qu'ils alloient chercher les bêtes perdues; et en effet, lorsqu'ils revinrent le soir sans les avoir retrouvées, il vint m’avertir que tous éroient fort inquiets sur les suites de ma colère, et qu'ils craignoient que je n'attribuasse à négligence et à mauvaise volonté l'inutilité de leurs recherches.

Ce retour m'affecta peu, et j'eusse vu d'un œil tranquille leur éloignement. Sûr que Klaas et Swanepoel ne me quitteroient jamais; sûr de m'être fait des amis parmi les Sauvages que je venois de visiter; tout m'annonçoit que je pourrois continuer mon voyage, et que j"allois trouver, soit chez les Namaquois, soit dans la horde Caminouquoise, de nouveaux associés qui se feroient un plaisir de se mettre à mon service, et qui au moins m'aideroicnt à trouver une escorte de horde en horde.

Certainement ces nouveaux compagnons m'eussent été, et plus utiles, et à coup' sûr moins coûn 


\section{V O Y A G E}

teux que cette race indolente de Hottentots, quí, comme je l'ai dit plus haut, ne sont bons que dans les colonies, et qui ne savent servir qu'autant qu'on ne les laisse manquer ni de tabac, ni d'cau-de-vic, ni de graissc. Dans ma colìre, j’avois permis à ceuxci de me quitter; ct je les aurois chassćs sans retour, comlne ils le méritoicnt, si j'avois pu prévoir qu'cn continuant ma routc je rencontrcrois une nation gucrictre, infatigahle, active, industricuse et sobrc, composéc enfin d'hommes tels qu'il m'en falloit pour me seconder dans l'entreprise hardie que j'avois formée er pour m'aider à surmonter les obstacles de tout genie qui m'attendoient.

J'ai connu, trop tard pour moi, cette race d'ètres privilégiés, dignes de concourir au succès d'un voja je en Afrique. A la vérité, la fortume parut quelquefois favoriser mon audace; nais bien plus souvent cncore cllc m'a contrarió, et les fausses combinaisons d'unc première tentative n'ont que trop sccondé sa marche en ruinant les espérances que de loin en loin clle sembloit m'offrir comme à travers d'ćpais nunges.

Il en fut du soulevement de mes gens comme de toutes les émeutes poptlaires. Violent, mais court, la nuit le calma entic̀rement. A mon reveil, je trouvai tout le monde soumis et tranquillc; ct mon confident m'apprit que l'on se proposoit de venir me demander l'oubli de ce qui s'étoit passé, ct la grace des femmes.

Depuis long-tems l'expérience m'avoit appris combien il est hasardeux d'attaquer trop brusquement certains abus; et cclui-ci ćtoit de ce nombre. Ma faute étoit de ne m'y ĉtre point opposé dès sa naissance, au moment où Klaas Baster ct quelquesuns de ses camarades avoient loué des femmes à 


\section{E N A FRIQUE. 207}

Bernfry. Ill m'cût été facilc alors d'arrêter un mal qui n'étoit encore que cclui d'un très-petit nombre de coupables. Mais à présent que le désordre étoit la faute de tous, jc crus plus prudent dic lc tolćrer; et en conséquence je consentis à ce que les femmes restassent; mais $j$ 'cus soin d'ajouter que si quelqu'un manquoit en la moindre chose à son devoir le plus rigourcux, à l'instant même je chasserois la sienne.

Ces réflexions afligreantes m'ayant donné quelquc. mélancolie, jallai chercher à me distraire sur les bords de la rivière, et j’y trouvai fort près de nous, ce qu'on avoit cherché bien loin, mes trois bêtes égarécs. Le mouton avoit été dévoré par un tigre; il n'cn restoit plus que quelques lambenux. En suivant les traces du carnivore, j'apperçus, à quelque distance plus loin, un buisson dont les branches étoient agitées intéricurement, comme si un animal y étoit caché. Je soupçotnai que ce mouvement pouvoit êtuc l'effet du tigre qui s'ćtoit retiré là, pour revenir pendant la nuit achever sa proie.

Dans cette idéc j'armai mon fusil de deux ballcs, et après avoir tiré mon promicr coup à traver's lc buisson, je n'avançai arec précaution, en tenant mon second tout prêt. Mais quelle fut ma pcine, quand, au lieu d'un tigre, je trouvai l'une de mes chc̀vres blessée à mort et rendant les derniers soupirs.

Heureusement cctte méprisc douleurcuse fut compensée, à l'instant même, par une découvertc agréable. Tandis que j'entr'ouvrois le buisson pour cn tirer la chèvre blessée, $j$ 'en vis sortir l'autre, avec dcux petits chcvrcaux qu'clle étoit venue, la vcille, y mettre bas. Sans moi, dès le soir même, ils cus- 


\section{8}

\section{O Y A G E}

sentété, à leur tour, dêrorés tous trois; cr cette idée me les rendoit plus chers encore. Je pris sous chacun de mes bras un des nouveaux-nés; et suivi de la mère qui marchoit sur mes pas en bêlant; je vins les déposer au camp et les joindre au troupeau.

Lc soir, ccux de mes Hottentots qui pendant le jour avoient été de faction dans la campagne pour la garde de mes bestiaux; étant revenus, après avoir été relevés pour la nuit, ils m'apprirent qu'Adam, au moment de sa fuite, étoit venu se réfugier auprès d'cux dans leurs huttes; qu'il étoir bien affligé de sa sottise; mais, que, n'osant ni se rapprochcr du camp ni demander grace, parce qu'il étoir convaincu que j'avois voulu le tuer, il les avoit priés d'engager Klaas à aller le voir.

Ce désir de parler à un homme qui avoit et qui méritoit toute ma confiance, annonçoit que le fugitif cherchoit à se procurer auprès de moi un intercesseur. Mais, pour l'exemple, je n'awois garde de lui accorder sitôt et si facilement son pardon ; et en permettant à Klaas d'aller lc voir le lendemain matin, j'endoctrinai celui-ci sur ce qu'il avoit à dire, tant pendant son message qu'après.

Tous mes gens attendirent son retour avec impatience. Dès qu'il parut, ils coururent au-devant de lui, pour le prier d'interposer auprès de moi ses bons offices en faveur de lemr camarade; et quand il entra dans ma tente, ils s'ei approchèrent, afin d'entendre ce que j'allois répondre. Klaas me parla benucoup du repentir d'Adam. Il m'issura l'avoir laissé dans la désolation et les larmes. "Mais, maitre, vous , oubliercz sa faute, ajouta-t-il; et moi-même, comme vous allez partir, je lui ai fait espćrer qu’à ma sollicitation vous lui ferez grace et que vous 


\section{E N A F R I Q U E.}

Ala réponse étoit eoncertée d'avance avec Klaas. J'affectai un ton de fierté qu'cn ce moment rendoir néeessaire la préscnce de ceux qui m'éeoutoient; et blàmant Klaas d'avoir exećdé ses pouvoirs en promettant ee que je ne voulois point lui aecorder : „Non, lui dis-je, Adim ne m'nceompagnera "plus, il a manqué ì tous ses devoirs; je ne veux " plus entendre parler de lui; je déelare même " que si parmi eeux que j'cstimerai assez pour les " adlunetre is me suivre, quelqu'un s'ivisoit ja"mais de prononcer son nom, à l'instant je le " chasse irrémissiblement, en quelque licu que ee " puisse être. Cependant je ne veux point aban" domner ee malheureux au milieu des déserts; " qu'il revienne d:ms mon camp auprès de Swa" nepoel “. Je lui permets d’y rester juscqu’ ì mon retour.

Ce diseours fit, sur ceux qui l'entendoient, tout l'effet que je m'en ćtois promis. Ces mêmes gens qui la veille vouloient tous me quitter, paree que je leur amnonçois un voyage nouvenu, en ce moment n'ambitionnèrent plus qu'à l'honnetir d'être de ce voyagc. Tous me demanderent à me suivre; c'écoit à qui obtiendroit la préférenee, et on la sollieitoit avec cmpressement, comme une grace.

Pour ne point laisser refroidir ce zèle si ardent, je fixai mon départ au surlendemain, I 4 déeembre. Mais en mêtne temns, pour donner à Klaas une certaine eonsidération parmi ses camarades et le récompenser de la fidélité constante qu'il ṃ'avoit toujours montrée, je le laissai maître din ehoix, et annonçai que je prendrois eeux dont lui-mềme il me répondroit.

Cependant, ne voulant point m'embarrasser de trop de monde, je résolus de ne prendre que la moiToine II: 


\section{$210 \quad$ V O Y A r. F,}

tié de ma trotipe, et crus que l'autro moitié suffroit pendant mon absence, pour garder mon camp.

Quoique Bemfiy cht dû m"inspirer de la défiance par ce tiain $c^{\prime} c$ jolies filles de Boschjesman, qu'il avoit chns le nombre de ses maitresses, je ne soupçnnois point alcrs, anisi que je l'ai dépa dit scs liaisons arec ces brigands. Jignorois, qu'associé avec eux, il leur donioit avis dii butin qu'ils pouvoient firire, et que par conséquent i] étoit possible cu'il les prénint de non départ. Mais jusqu'nlors ils n'avoicut fate aucunes tentatives, et avec nos armes à feu je ne les craignois point. D'ailleurs, bernfry me demandoit à macconpngner dins ma seconde course, comme il mavoit accompagné dans ma promic̀re; et le niĉme motif par lequel je m'étois déteminé, li première fois, à y consentir, venoit de me déterminer encore pour.celle-ci. J'avois dons mon camp un certain nombre de Caminouquois, qui d'amitić m'y avoient suivị avec leurs femmes. Quand ces brives gens surent que jallois partir pour une nourclle excursion, tous, ainsi que les femmes, s'offrirent à maccompanner: ne demandant pour tout traitement extraordinaire qu'une ration de tabac par lune. J'acceptai leur offre avec une grande joic.

$\Lambda$ dire le vrai, cette troupe de Hottentots que j'arois à mon service me paroissoit désormais une charge plutôt qu'un secours. Depuis leur rebcllion j'ćtois changé à leur égard, ct ne les voyois plus dir même oil. Dans ma petite excursion, je renois d"ćprotrer combien il est ficile de se faire des amis chez des Souvages; et j'avois senti sur-tout, quel arantage prodigieux auroit un voyagcur, qui, pour connoitre et parcourir un pays, ne prendroit suc- 


\section{E N $\triangle$ F R I Q U E. 2 II}

cessivement d'autres compagnons et d'autres guides que ses propres habitans.

Mes Caminouquois avoient neuf beufs. Je les leur louai. J'en fis acheter sept autres, et je ne songeai plus qu'ì faire cmballei cans des sacs de peau de mouton, les pacotilies et provisions que j'allois emporter.

Pour mettre de lordie chns mes effets et pour pouvoir les retrouver en ronte suns peine et sans confusion, quand jen aurois besoin, jériquetai svec des colileurs différentes chacun des différens pnonets cui devoient composer une charge de bouf. Chaque breuf avoit la sienne, lnqueile ne devoit jamais être changéc en voyage. li avoit ses hommes destinés à son service; ct moi je métois fait un petit bordereau, sur lequel se trouvoit le nom de chaque bouf, ceux de ses conducteurs, et le contenu de sa cliarge : de sorte que si je voulois tel ou tel objet, je n'avois qu' ì jetter les yeux sur mon mémorial, et appeller tel ou tel homme ou demander tel bœuf.

Cependant parmi les scize, je n'en destinni que sept it mon scrvice personnel. Ceux-ci portoient, outre mes deux tentes, tout ce qui mappartenoit; comme munitions de chasse, objets de commere, batteric de cuisinc, toilertes, tabac et de l'cau-devie pour les besoins particulicrs.

Scpt autres deroient être chargés de nattes, peaux, armes, ustensiles de la troupe et des cercles destinés à ln construction de ses huttes. Enfin, les deux derniers étoient réservés pour ciss d'accident, les malades ou blessés, et pour le soulagement des femmes qui pourroient cn route se trouver fariguées de lin marche.

Je dois dirc, ì l'honneur de celles-ci, que pen$\mathrm{O}_{2}$ 


\section{VOYA G E}

dant tout le voyage pas une seule d'entre elles n'usa de la monture; que toujours chantant, sautaunt, folâtrant, elles mirent dans la caravane une gaieté continuclle; et qu'aux jours de souffrance ct de détresse elles donnèrent aux hommes des leçons de courage.

11 est vrai que, voyageant avec des ressources et des commodités quiclles n'avoient jamais connues, la marche étoit pour elles une partie de plaisir et une sorte de fête. Leul curiosité d’aillcurs s'applatidissoit d'avoir à parcourir un pays nouveau, où d'ailleurs elles ne manqueroient de rien.

Eilles écoicne onzc, femmes ou filles, sans compter Rachel, femme de Klas, que jemmenois pour soigner un petit troupcau de trois vaches, six chèves et scize moutons, qui devoient me suivre en cas de disctte. J'avois en outre Kees, quatre chiens et trois chevaux; car Bernfry joignit son . cheval aux deux miens; cnfin, soixante personnes ct quarante-sept animaux; telle étoit ma caravane, qui partit en bon ćtat ct ne revint point de même. C'est ainsi qu'on marche à une bataille.

Dans laprès-dinéc du jour indiqué pour lc départ, je commençai par faire défiler les beufs avec lcurs conducteurs. Tous traversèrent la rivière à la nage; et pendant ec tems les ballots et les paquets passoicnt sur le radeau. Quand tout fut arrivé sur la rive, on mit les effets à terre; et les conducteurs, reconnoissant, ì la coulcur des étiquettes, ccux qui alloient lcur être confiés, les rangeoientà part ct en formoient un tas, en attendant le moment de charger.

Pour moi, je résolus de ne partir que le lendemain matin et de passer encore la nuit dans mon camp, afin de tout régler et de donner mes derniè- 


\section{E N A FRI Q UE. 213}

res instructions à Swancpocl. Avec la moitić de mes gens, je lui laissois, pour sa garde et sa défense, la moirjé de mes armes. Je laissois également au camp Klaas Baster, qui, pendant mon absence, pouvoit me servir, en allant dans les hordes namaquoises macheter des boufs d'attelage; tandis que, de mon côté, je travaillerois à m’en procurer d'autres dans les contreces que je devois traverser.

En supposant que j'cn trouvasse, quallois-je faire? quallois-je devenir? sans plan et niême sans possibilité de an'en faire un, puisque les pays que je devois parcourir m'étoient totalement inconnus; j'étois combattu par mille idées confuses et contradictoires qui me troublèrent pendant toute la nuit.

Mon premicr projet, il est vmi, avoit été de trnverser l'Afrique d'une extrémité à l'autrc. Tous mes préparatifs à l'époque de mon départ du Cap, toutes mes démarches et mes précautions depuis ce jour n'avoient tendu qu'à ce but unique; er je me le proposois encore cxclusirement, nilgéé les obstacles toujours renaissans quue mopposoient les snisons.

Jusques-là, mon courage s'étoit roidi contre les contrariétés, et je me sentois celui de les braver encorc. Mais je me croyois arrêté par une difficulté insurmontable; celle de me faire suivre désormais par mes charriots et de les conduire avec moi : et ce qui mícoit bien plus douloureux cncore, c'est quen laissant mes voitures sur les bords de lOranğe, jabandonnois en même tems ces oiscaux, ces quadrupc̀des, ces insectes que je n'ćtois procurés depuis mon départ du Cap, cette girafic dont la conquête m’avoit causć tant de joje, enfin cette collection précicuse et chéric, achetće par tant de

O 3 
farigues, de sucurs et de dangers. Ainsi falloit-il en revenir toujours à cecte réflexion, que la traversćc de l"Afrique, si clle est possible, ne comporte tout au plus avec elle que des observations rapides, et que vouloir cnsemble marcher toujours, et toujours recucillir, est un projet fon, auquel ne pourroient suftire des amées de bneufs attelés à des charriots. Miais je n'cn assemblois pas moins toutes cer idées dans ma têtc.

Dans ces incxiricables perplexités, mon parti le plus sage ćtoit d'achever l'excursion préparatoire que j'sllois commencer, ex de remetre à prendre, ¿̀ ce sujet, unc demière résolution, sclon les circonstances qui mattendoient. Jusqu'au moment de cette détermination fixe, je me proposai de travailler dans la routo à augmenter mes collections d'histoire naturelle; de me faire sur mon passage autane d'anis qu'il me seroir possible; enfin de percer, si je le pouvois, vers l'cst, jusquu’'̀ cette partic du centre de l'Afrique qui n'a guc̀re que trois cents quarance licues de large, pour y découvrir cuclque passige plus favorable que coux oì je ne trouvois engagé, er massurer au moins, dans le cas où quelque malheur inattendu 111 "enpêchroit d'avinncè plus avant, la ressource de recommencer mon voyage sous de meilleurs auspices et avec des espérances plus fondées. Voilà ce qu'il y avoit en demier résultat de plus misomnable. La suite montrera si, même en cela, mes désirs étoient fondés sur des possibilités.

D'après ce plan provisoire, je dis à Swanepoel de m'attendre sur l'Orange pendant quatre ou cinq mois. Mlais ce terme une fois écoulé, je lui permis, s'il trouvoit des attelages, de retoumer au Namero mattendre chez Van der Westchuysen pen- 


\section{E N-A F I Q U E. 2I 5}

dant quelcue tens cacore; après quoi il devoit retoimer au Cap. Je lui livtai mes notes, avec des instructions pour les faire passer à ma fanille, dans le cas où il n'entendroit plus parler de moi. Enfin, après l'avoir charié de deux leteres, l'une pour Gordon, l'nutre pour Serturier; après avoir conscnti qu'il rappellitr Adam, jo montai sur le ridzau, ce rejoignit nila caravane.

Nous étions aux jours les plus longs er les plus chauds de l'annéc; ct chacun d"cux ćtoit narqué par un orage. Mais nous n'avions que les incommodités de ce métćore, sans en éprouver les avantages. Les nuages alloient se porter au loin vers les hautes montagnes. Rarement ils laissoient échapper quelques pluies autour de nous; ; et par-tour lin séchóresse étoit génémlement la mêne.

Cependant ce léger arrosement avoit sufi, en quelques endroits, pour faire germer et pointillex déjal'herbe des buschjesman. Ce gramen n'est point vivace. Anmuellement il se desseche sur ses racines, cr se reproduit par ses semenes. Mais il ticne si peu a la teric, que les boufs qui le broutent, arrachent la plante toute cntiere, er que le vent même suftir seul pour la déracinct et l'enlever.

Afin que mes animaux pussent proficer, dans leur route de ec peu d'herbe nouvelle, je les fesois marcher de front autane que le local le permettoit. Par ce moyen ils pouvoient brouter tous également à la fois; ce qu'ils n'eussent pu faire, s'ils avoient marché à la suite les uns des autres. Souvent d'une extrémitć de la ligne ì l'autre, il y avoit une demilicue de distanec; et nous ne nous ressertions que quand la mprochement des monagnes nous y forçoit.

Dans des pays où l'herbe est anssi clair-scméc, 04 
cette méthode a de grands avantages. Diailleurs, c1 nous faisant cmbrasser in terrail plus vaste, clle nous mettoit ì portéc de rencontrer des sources, qu'autrement nous cussions long-tems cherchécs en vain. C'est ainsi que, dès le même jour, vers midi, après einq heures de marche, nous en découvrîmes une themalc. J'y fis halte, pour laisser respirer nos boeufs; et pendant ec tems, prenant hauteur, je trouvai vingt-sept degrés cinq minutes de latitude. $\Lambda$ près quoi, tirant à l'ouest, afin de gagner la Rivière des Lions, nous y arrivâmes en trois heures et demic de marche.

Avant de quitter mon camp sur l'Orange, j'avois remarqué que les erues de la rivière devenoient plus fortes et plus fréquentes qu'auparavant; que quelquefois elles s'élevoient jusqu'ì six pieds, et restoicnt dans cet ćtat pendant plusicurs jours. Cet accroissement annonçoit la saison pluvicusc dans les montagnes du nord-est, où cette rivì̀re, ainsi que presque toutes eelles de l'ouest, prend si sourec.

L_a même cause devant produire le même cfíct sur 1a Rivière des Lions, j'avois ̀̀ eraindre, si j'attendois plus long-tems, de me trouver embarrassé pour la passer. Déja même elle avoit plus d'enu qu'à ma dernière traversée. Ainsi, voulant la mettre derric̀re moi, j’allai camper sur sa rive droite : après quoi nous İ côtoyâmes pendant trois jours, sans nous arrêter que pour le campement du sojr, et dans le jour, que pour donner la chasse à quelques giraffes que nous appercevions de tems cn tems, mais qui finissoicnt toujours par nous gagner de vitesse et par disparoître.

Le quatrième jour, nous arrivâmes dans un licu ombragé par de beaux arbres, et d'une fraîcheur si agréable à l'œjl, et si séduisante au milieu des cha- 


\section{E N A F R Q U E.}

leurs intolérables qui nous dévoroient, que je résolus d'y passer non-sculement la nuit, mais encore la journće suivante. Autour de moi étoient des herbages verds et des caux claires; et plus loin, dans le lointain, j'appercevois des giraffes, des gazclles, des gnoux et sur-tout des cspèces d'oiscaux que je ne connoissois pas encore.

En un instant, mes tentes furent dressécs et le bois ramassé, graces aux femmes, qui, après avoir supporté les farigucs et la chaleur de ces quatre jours avec plus de courage que les hommes, se mirent sans délai à l'ouvrage. Elles s'étoient emparé exclusivement de celui-ci, et ne vouloient point qu'ils 's'cn occupassent.

Il cn ćroit de même de ce qui regardoit mon ménage. Chacune d'elles disputoir à qui se montreroit plus utile. Elles sembloient craindre que je ne me repentisse de les avoir emmenées avec moi; ct, pour prévenir jusqu'au germe du regret, elles cherchoient, par mille prévennnces, à se rendre nécessaires. C'ćtoir pour elles une jouissance d'avoir à exécuter quelque ordre nouveau de ma part, olt quelque détail qui me regardât; et c'ćtoit aussi un intéressnnt tableau que ces groupes d'êtres mouvans ou pressés autour de moi, et devenus si dociles depuis la dernic̀re émeute du serrail.

Pendant qu'elles apprêtoient mon souper, j’allai me promener sur les bords de la rivière; ct là, presque dans son lit, j’apperçus un phénomène, qui est asscz rare en géologie, pour qu'un naturaliste, quand il le rencontre, l'observe avec attention. C'étoit unc source si prodigieusement saléc, qu'il étoit impossible d'en boire une goutte.

J'ai vu les puits salins de la J.orraine allemande et du comté de Nassau; et jamais, quoique j'aic 
gututé leurs eaux, je n"ai éprouvé une salure parcille. Celle-ci, dins son cour's souterrain, passe sins doute sur quelque lit de sel gemme yu'vlle runge; et à raison de l'extrême chrleur du clinat, clie en dissout probablemene benucoup; au moins à ch juger par la saveur, elle contient beaucoup de scl. Cependant je no oserois assirrer que ee sel fut celuiqui dans nos cuisines cst connu sous ce nom; et d'après son cxtrême causticité, je scrois même fort porté à en douter. Mais n'ayant à ma disposition aucun. moyen chymique de l'analiser, je ne pouvois juger de sa nature que par la décrustation; moyen peusûr, et quclquefois d'sutane plus trompcur que toujours' comparant une sensation nouvelle avec des sensations anciennes ex déja connues, il est facile en les confondzun de les croire toujours la même.

Outre ses sources salées, l'Afriquoa encore beaucoup de lacs, pius ou moins grinds, qui le sone nussi, ou qui sont samâtres. Ceux-ci n’étant alimentés que par des caux pluvinles, il est probabic qu'ils ne doivent letr salure qu'aux terios sulsugineuses que lavent ces caux.

Koibe, aussi décisif qu'ignorant, n'a garde d'admettre cette calise simple er naturclle. Raisumant ì sa minic̀re, il mnonce, sur le fait dont je parle, un systeme absolument neuf, ex dont personneavant lui, dit-il, n'en cut connoissance.

Pour établir son hyporhese, oui vrament esi neuve et qui le scra long-tens, il cmploic la succession de la saison sèche et de la saison humide, du vent de nord du vent de sud, de la glace er du tommerre. Avec ees noycins il n'a plus besoin de ricn; c'est une baguette qu'une page de scn livre. Selon lui, les combars des saisons forment dans l'air

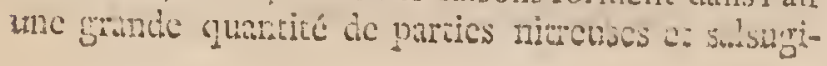




\section{E N A R I U E. 219}

neuses; l'atmosphère en est chargéc; et comme le vent de sud-est souffle alors violemmene ec cu'il agite l'cau des bassins, il les y précipite et les y dépose. En Europe, c'est un bien grand homme que ce Kolbe.

On est tenté de rire, quand on voit un autcur proposer sérieusement de pareilles explications; et cependant celui-cicmploic à li sienne plusieurs paragraphes. Ii traite même avec une sorte de mépris l'opinion de ceux qui eroicnt que ectte salure est due à des sources d"cau saléc, soir qu'clles somident dans le bussin même, soir qu'clles y arrivent de dehors.

"Si cela étoit, ajoute notre physicicn, la quan"tité de scl que formeroicnt ces sources constan"tes, ne varicroir pas autanc qu'clle varic. D"ail"leurs, l'eall seroit toujours et en tout tems sau"mache, au lieu qu'clle cst constamment douce "et très-bonne jusqua’au commencement de l'ćté; en sorte que les troupenux dialcntour n'c1 boi-

2. toicnt, sins doutc les colons cn auroicnt du moins ", decouvere quelqu'une; ce qui n'est point encore "arrivé "6.

Je ne perdrai point mon tems ì combattre une opinion qui ne mérite point d'être combatue. Selteinent je me permettrai de donner une explication de ce fait des eaux, alternativement douces et salćes.

On ne connoît au Cap que deux saisons : celle des sćcheresses, qui forment l'étć; ct celle des pluies, qu'on nomme hiver. Si, pendant cette dernière, les eaux dont il s'agit deviement potables, c'est qu'elles sont adoucies par la quantité de cel- 
les que les pluies y cuvoient continuellement. Dans l'été, au contraire, elles s'évaporcnt, en grande partic, par l'extrêne chaleur; ce le peu qui reste, étant concentré, reprend toute sa salure.

J'ignore si, au tems de Kolbe, les Colons ne connoissoient point de sourees salcees. Cependant ils devoient présumer que dans un pays où il y en avoit tant de saumâtícs, il falloit nćcessairement qu'il s'en trouvât aussi beaucoup dautres du genre des premières. Moi, qui ne les cherchois point, j'en ai pourtant trouvé deux en quarante-huit heures: car la veille du jout où s'offrit à moi celle du lic de la Rivic̀re des Lions, j'avois campć auprès d'une autre, moins styptique à la vérité, mais pourtant dc même nature.

J'ajouterai ici, cn passant, que jen ai rencontré plusicurs martiales, et d'autres qui, à la dégustation, mont paru ou cuivreuses ou vitrioliques; ct si ee genre de recherehes eut eu quelque attrait pour moi, j'cusse probablement trouvé toutc autre chose encore, parce que j'étois aux lieux où l'on trouve véritablement; et Kolbe, comme je l'ai déja dit, n'a jamais quitté ccux où tout est trouvé.

Tout le pays qui avoisine la rive droite de la $\mathrm{Ri}$ vière des Jions cst une roche quartzcusc, qui, cn quelques endroits, renferme du fer, du cuivire et même des crystaux d'une très-belle eau; et qui dans d'autres, se rapprochant de la nature du granit, contient du mica jaune et du mica blane.

Pendant les quatre jours de route, je m'étois amusé à ramasser ces productions diverses, que j'ajourois avec soin à mes collections. Mes Hotrentots qui ne me voyoient gucre oceupé que dobjets du rc̀gne animal, étoicnt surpris du soin que je mettois à ceux-ci. Ils imaginoient que je me formois un 


\section{E N A F R I U E. 221}

trésor; et en conséquence, ils fouilloient la terre à mon exemple et amassoient, de lcur côté, avec un empressement qui me faisoit beaucoup rire. C'étoit sur-tour pour les deux micas quils montroient le plus d'ardeur. Mais abusés par la coulcur, ils les croyoient de l'arçent et de l'or' nation se repaissoit de la fortunc quils alloient faire ̀̀ leur retour au Cap*

Au point du jour, je partis avec Klaas, dans le dessein de me procurer quelques oiseaux nouveaux; et pendant ce tems mes chasseurs et quelques - uns des Caminouquois qui me suivoient, se répandirent de côté et d'autre, pour chissser à la gorunde bête et foumir à notre cuisine. Jeus le bonheur de rencontrer deux oiseaux, mâle et femelle, du genre de celui que javois vu dans les forêts de Bruintjeshoogte, et qui fut nommé par mes gens uytlacher (le moqueur). Ceux-ci étoient encore une espèce nouvelle du même ugenre, et qui devenoit pour moi une vraic jouissance.

Je vis aussi des barbus et quelques autres espèces d'oiseaux que j’avois rencontrés à la côté de l'est; mais ils y étoient bien moins nombreux.

- Les plus multipliés étoient les républicains et les petits perroquets dont j’ai parlé, en traitant de ceux-ci. Les premiers s'y trouvoient par troupes nombreuses.

Il paroît que quand ils s'établissent dans les plaines et qu'ils construisent leurs énormes nids sur des aloës, arbres qui dans les tempêtes sont sujets à être renversés par les vents, c'est au défaut d'un asyle meilleur. Aussi choisissent-ils de préférence les revers de montagnes, les gorges, détours et autres licux de cette nature, bien abrités. Là ils se multiplient al l'infini, et l'on rencontre ì chaque 
instant ceces nids. Nisis par-tout où ils vicunent s'établir, les petits perroguets les stivent pour s'emparer de leurs conscrtetions. His les en chassent à force ouverte; et l'expulsion se fait mème si lestement, que plusicurs fois j'a va en moine de deux heures l'habitation changer de propriétaires et se rempiri dic nouveaux hòtes.

Dins l'urres-dince, une partic de snes chasseurs revint avec deux gnoux et plusicurs gazelles springbock, quilis avoicnt tucs. Leur chasse avoit même été si heurctse, qu'ils s'étoient vus obligés d'envoyer chercher au camp deux boufs pour rapporter leur gibier. 11 étoit déja nuit close, quand icurs autres camarades et les Caminouquois, qui ies accompagnoient, revinrent. Ceux-ciavoientles mains vides; mais is mapportoientune nouvcilc agréable.

En battant le pays, ils avoicnt rencontré quclques Grands Namaquois, dont la horde n'étoitquà quatre licues de mon camp; et ecrtains que, me procurer l'oceasion de la voir, étoit m'obliger, ils $s^{2} y$ ćtoicnt rendus, pour demander l'agrément du chef ec le prévenir cie ma visite. Celui-ci les avoit assurés du plaisir qu'il auroit à me voir, et il m'y invitoit en m'envoyant six de ses gens. Je reçus ct. traitai anicalement ecs députés, et je répondis à lcurs instancesque le lendemain, à la pointe du jour, je Ics suivrois à leur hordc.

Les émanations de notre gibicr et l'odeur de notre cuisine, avoient éveillé au loin l'odorat des hiennes et des jackals. Pendant la nuit ees animaux rodèrent autour de mon camp. Les hicnnes sur-tout, plus hardics ou plus pressécs par la faim, s'cn approchoient si près qu'on suivoit leurs mouvemens à l'ćclat de nos feux, et j'en tuai une au moment où clle se jettoit sur un dic nos moutons. Cet ani- 
Tom II.

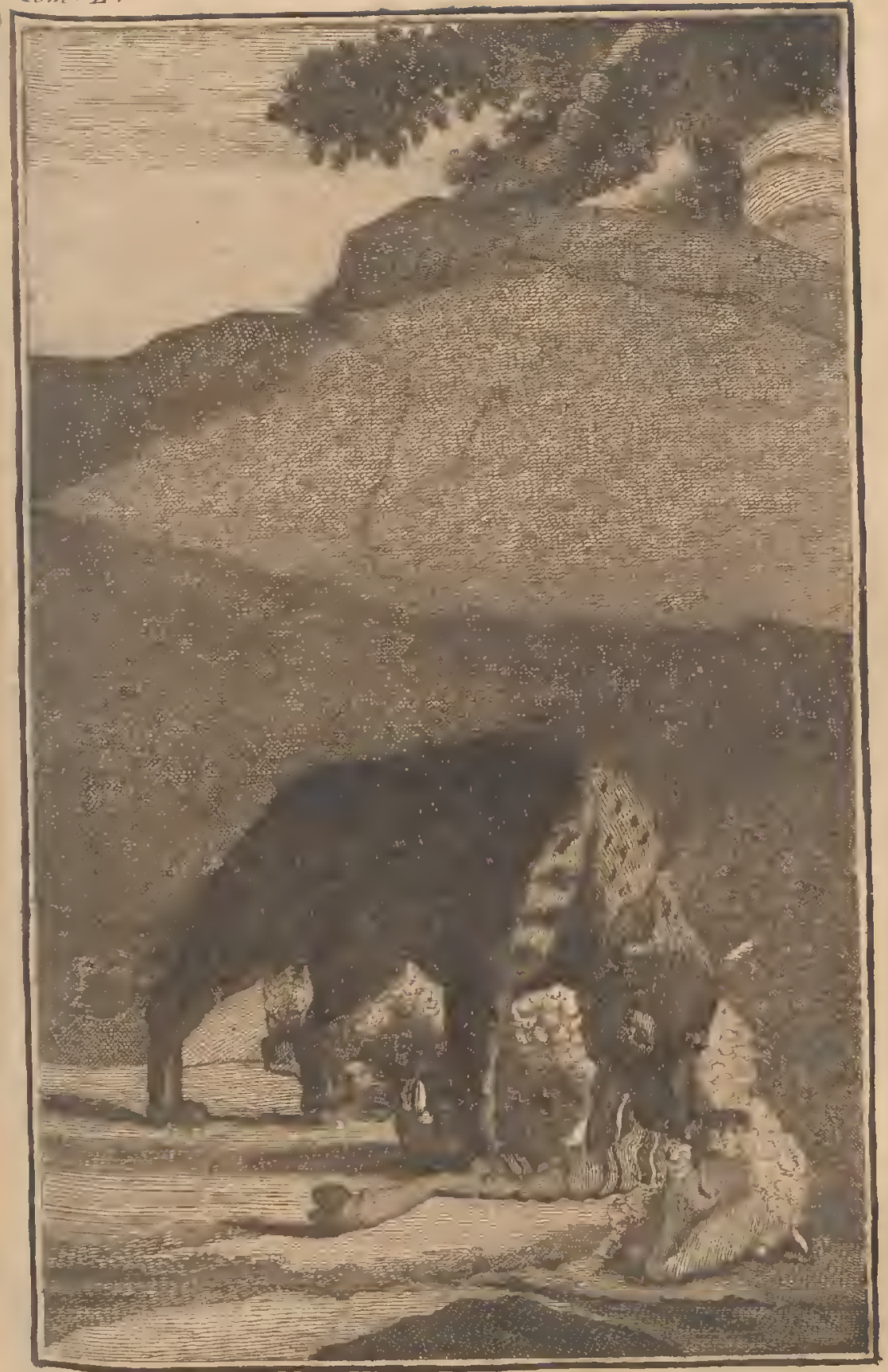

LOUP 'I'A CHETE'. 



\section{E N $A F R I Q U F . \quad 223$}

mal ettoit absolument de la même espècc que eenx que nous avions déja tués à la rivière Gamntoos. Les Colons le nomment loup tacheté; il est de la taille de nos loups d'Purope; son pelage est d'un fauve foneć, parsemé de taches d'un błun noir. Je place iei la figure de cet animal, dont je purierai plus au long dans mes descriptions des quadrupèdes d'Afrique. En vain ehorchions-nous à éloigner les autres par notre mousquetrerie, les hurlenens douloureux de celle que je venois d'aluatre, sembloit les avoir animés darantage ì la curée, et elles ne devinrent que plus âpres à l'attaque; elles ne quittoient un endroit que pour revenir dans un autre. Nos bêtes, qui les appereevoient ainsi que nous, et qui. entendoicnt lcurs cris, s'agitoient violemment, et rémoignoient une grande fraycur. Enfin, pour notre sûreré et pour lạ défense du troupcun, nous fûmes obligés d'être sous les armes pendant tonte ln nuit.

Outre ees hiennes et les jnckals, animaux qu'il nous étoit aisé de distinguer à lcur vốtx, javois remarqué encore le eri partieulicr d'un autreanimal. Mes gens le désignoient sous le nom de loup de terre. Je ne le connois point, et n'ai jamais vu de lui qu'un morceau de sa penu que je trouvai, comme je l'ai dit ci-dessus, daus une horcie, et qu'ì l"inspection je jugeai avoir ppartenue a un isatis. Quoiqu'il en soit de l'animal, il paroît, qu'aynnt les mêmes habitudes et le même instinct de ehasse que les deux autres, il se joint er s"assoeie à eux pour la quête et pour l'attaque.

Dans notre fusillade de la nuit, ef pami tous 'es coups tirés au hazard, un jnekal avoit été atteint ct blessé d'une balle. Nous le trourâmes le lendemain sur notre route, en sortant du camp; ct ce fut pour ma troupe un sujet cic dispute : chaeun prém 
tendant l'avoir tué, et tous alléguant, en preuve de ce fait, des raisonnemens si plaisamment bizarres, qu'ils me faisoient rire aux éclats.

Leurs altercations durèrent toute la route, et ne cessèrent qu'aux approches du kraal, quand je fis halte pour attendre et recevoir le ehef.

Il vint au devant de moi, aecompagné de quelques femmes et d'une grande partic des hommes de sa horde. Ils étoient tous grands, hauts de cinq pieds et demi à peu près; ayant une figure donee, mais froide et phlegmatique. La physionomie des hommes annonçoir le mêne phleg̣me : mouvemens, gestes, regards, tour chcz eux étoir triste et glacial; et je ne tardai point à m'appercevoir dans la conversation que eette froide lenteur étoit dans leurs affections et dans leurs pensées, ainsi que dans leur extérieur. Leur fait-on une proposition, agrćable ou non, jamais ils n'y repondent sur-le-champ. On les voit garder pendant quelque tems le silence, réfléchir gravenent, et parler avec poids et mesure.

Ce caractère tranquille et inaltérable est, en général, fort éloigné de eelui des Sauvages. Il n’est nullement le caraetère des Gonaquois et des Caffrés; mais il contrastoit singulièrement avec celui des femmes de la horde, dont l'air enjoué annonçoit une vivacité extrême, et qui sur-tout se montroient de grandes rieuses. J'ignore quelle cause loeale a pu modifier aussi tristement l'ame des Grands Namaquois; mais si leur sćrieuse mélancolie est chez eux une qualité physique, je demande, comment ces femmes, qui sont leurs mères ou leurs filles, diffèrent d'cux aussi étrangement.

En route, j'avois apperçu d'immenses troupeaux de bœufs qqu'on m'avoit dit appartenic it la horde; 


\section{E N A F R I U E. 225}

et cotte découverte m'étoit d'autant plus agréable, qu'elle me donnoit l'espoir d'acheter sans peine tous ceux dont j'avois besoin. Arrivé au kraal, je demandai au chef s'il pourroit m'en vendre ou m'en faire vendre quelques-uns; et je promis de les payer sur-lc-champ on verroteries et sur-tout en tabac. Il garda quelque tems le silence, se tourna vers ses gens, leur dit deux ou trois mots; puis, après une nouvelle pause, me répondit tranquullement qu'ils avoient peu de bœufs.

Cette réponse ambigue et pas mal normanáe, ne s'accordoit guère avec la bonhommie du caractère sauvage, Quoiqu'clle n'annonçât point un refus formel, elle me déconcerta. Maís les Caminouquois, mes bons amis, qui connoissoicnt leurs voisins, m'avertirent tout bas de n'être point inquiet, et. ils m'assurèrent que, si je voulois cacher les pacotilles que j’avois annoncées, et sur-tout ne point prodiguer mon tabac, jobtiendrois bientôt tout ce que je désirois.

L'avis étoit très-sensé, et je ne pouvois que gagner à lc suivre. En conséquence, pour inspirer au chef le goutt de mes échanges, je lui fis un cadcau de très-bon tabac de Hollande; mais, au licu d'en donner, sclon ma colitume, une certainc quantité, je réduisis mon présent à la charge de deux pipes, quoique la sienne fût démesurément grande. Il le fuma tout aussi-tôt, se récria sur sa bonté; ct pour faire participer les principaux de sa horde à son bonheur, il leur fit passer suceessivement la pipe.

Ceux qui ne furent point admis à cette félicité . paroissoient très-chagrins. Ils aspiroient de toutes leurs narines la fumée que laissoient échapper leurs camarades, et venoient, d'un air stippliant, me Tome II. 
présenter leurs pipes vuides. Moi, décidé, d'après mon systême, à ne point céder, je demendois des boufs; mais ils m'offroient des inoutons; enfin, pour ne pas montrer trop d'empressement à l'échange, er les dépayscr, j’affectai de u'en plus parler, et résolus de prendre patience et de les voir venir.

Cependant, comme dans le nombre des femmes j'en voyois qui avoient l'air de gronder leurs maris, et de trouver mauvais qu'ils ne s'arrangeassent pas avec moi, je crus que, si je rangeois celles-ci de mon côté, je viendrois plus promptement à bout de mon marché. Ainsi donc, j’annonçai que sil'on vouloit mapporter du lait dans mon camp, jc payelois chaque terrine avec un rang de verroterieslong d'un picd.

Assurément c'étoit-là un prétexte. Je u’avois nul besoin de lait, et mes trois vaches m'en fournissoient plus qu'il ne men falloit pour ma consommation. Nénnmoins la journée se passa, sans que je fisse affaire. Je crus même pendant quelque tcms que ma proposition n'auroit aucun succès; mais sur le soir, toutes les femmes arrivèrent avec des terrines, et mon camp fut rempli de lait. Je payai très-exactement. Elles auroient bien voulu, qu'au lieu de vertoteries, je leur cusse donné de mon bon tabac. Mais je tins ferme, et mes refus constans opérètent même si bien, que l'une d'clles, qui avoir apparemment plus d'empire sur son mari que les autres, m'assura que le lendemain dans la journće ellc m'ameneroit dcux beaux bœufs.

Il y eut bal, sclon l'usage; et l'on dansa toute la muit. L.es filles namaquoises sont très-bien faites, d'unc jolie figure, et sur-tout fort galantes. Mes gens profitèrent de la danse, pour obtenir d'elles des têtes-ì-têtes. N'ayant point, comme moi, des 
bœufs à aeheter, ils employèrent, à négocicr ec marché, leur ration de tabac; ct faute de mieux, on acecptoit l'offir.

Comme chef de la caravane, comme blanc, enfin, commic possesseur d'un tabac bicn supéricur, j'cssuyai aussi beaucoup d'agaceries. Ic suis persuadé, que pour la charge de quelques pipes, j’aurois pu contracter alliance avec toutes les familles. On me pressa même assez vivemente, pour me voir obligé d'cmployer quelque résistance. Mais j'avoucrai en même tems que mes refus n'offensèrent point, et que les personnes qui en avoient éré pour leurs avanees, ayant bientôt trouvé à fairc d'autres arrangemens, ne m'cn témoignèrent pas moins d'amitić. Moi, de mon côté, quoique je me fusse imposé par prudence cerraines bornes que je ne voulois point franchir, cependant je me permettois par fois de la gaicté en paroles. Bernfry m'avoit appris à dire en namaquois, meuycé neuyp maté; et chaque fois que je répétois ectrc phrase, aux jeunes fillcs, elles rioient aux éclats.

Au resté, j'ajouterai ici que les filles scules m'ont paru si libres, mais que les femmes étoient, au contraire, réservées et modestes; et c’est là une
différence earactéristique qui distingue les Grands Namaquois d'avec la nation hottentote en général; comme ils sont distingués eneore par l'air bas et rampant qu'ils cmploient quand ils ont quelque ehose à demander.

Le lendemain, dìs le matin, la femme qui m'nvoit annoncé deux bøufs, m'en amena trois. Pour engager les autres à suivre son exeniple, je la payai magnifiquement, et lui donnai trois bracelets en fil de laiton, trois ceintures de verroteries, une portion de tabac, un coutent, enfin un bri- 


\section{8}

\section{O Y A G E}

quet avec une boëte en enivre remplic d'amadoue.

Mes gens se réerièrent beaucoup sur ma prodigalité. A les entendre, je faisois un vrai marché de dupe; mais j'avois mes raisons pour agir ainsi; et la femme elle-nıêne les devina si bicn, qu'elle me demanda, avant de s'en aller, d'ajouter au marehé un gobelet d'cau-de-vie. Je le lui fis donner. Tout ici bas est relatif. Elle se retira, en croyant m'avoir dupé; et moi je m'applaudissois d’avoir eu d'elle trois bocufs magnifiques, dont chaeun me coutoit cuviron quarante-cinq sous de France.

A peine eut-on eonnu dans la horde les trésols qu'clle venoir d'aequćrir, qu'on s'empressa de venir négocier avec moi. Avant le soir, j’eus onze boufs ct un superbe taureau noir. Ce n'étoit point pour moi que j'aequérois ce taurẹu, mais pour mon digne ami Slnber. Plusieurs fois il m'avoit prié, si jallois ehez les Namaquois, de lui faire emplette d'un de ces animaux, renommés ehez les eolons pour leur foree et leur beauté. Il est vrai que celuiçi me coûta le prix de quatre bœufs; mais, eut-on exigé davantage, je l'eusse donnć avee plaisir pour mon respeetable et tendre ami.

J'avois à craindre, que les bêtes qui étoient le fruit de mes achats, ne retournassent au troupeau, et qu'en s'y coufondant avee les autres, elles ne fussent perdues pour moi. Afin de parer à eet inconvénịent, et de les reconnoitre, je le fis marquer ì la cuissc avec un fer chaud. D'un antre côté, il devenoit embarrassant pour moi de m'en faire suivre dans ma route; et avant de regagner mon camp de l'Orange, jeusse bien voulu les envoyer direetement à Swancpocl.

A la vérité, le chef de la horde moffrit de les 


\section{E N A F R I Q E. 229}

y faire conduire par quelques-uns de ses gens, de la fidélité desquels il répondoit. Mais cetre proposition pouvoir être un piège er un moyen sûr de reprendre ce que j'avois acquis. Néanmoins mes Caminouquois m'ayant assuré que je n'avois rien à craindre, et qu'un marché conclu étoit dans toutes les hordes une chose sacréc, j'acceprai l'offre; et après avoir fait indiquer aux conducteurs le chemin qu'ils devoient tenir, après les avoir payés d'avance, je les fis partir; et moi-même, de mon côté, je repris ma route, marchant nord-quart-nord-est.

Avant de me quitter, le chef me fit apporter un mouton gras, quavec son ton froid il me pria d'accepter, en m'assurant que c'ítoit un pur don. Je le reçus, quoique ce fut pour moi un cadeau fort inutile, et quoique je fusse convaincu que sa libéralité n’étoir pas aussi désintéresséc qu’il le prétendoit. Aussi ne refusa-t-il ricn de ce g̣ue je lui donnai en retour.

A quelque distance de la horde, je trouvai un dépôt d'eau salée, dans lequel la chaleur avoit cristallisé plusicurs blocs de sel. Je les recueillis avec soin : c'étoit une provision que la nature ajoutoit à la mienne.

Là, je me vis placé entre deux directions différentes, et embarrassé du choix. Droit à l'ouest, c'éroir une plaine aride, couverte de mimosas et d'ébéniers, et qui, à une distance de cinq ou six licues, se terninoit par une chaine de montagnes. Vers l'est, se présentoit une plaine, plus découverte, il est vrai; mais au luin j'appercevois de grands arbres qui paroissoient border une rivière. Les naturels m’assturoient que c'étoit celle des lions que je retrouverois encore.

La nécessité d'une aiguade pour mes gens et P 3 


\section{$230 \quad \forall O Y A G E$}

pour mes animaux me fit tourncr de ce côté; mais je fus trompé dans mon attente. La rivièrc n'ivoit pas d'eau, et il fallut passer une nuit à sec. Pour comble de chagrin, le lieu étoit rempli de pintides, oisenux de mauvais augure, dont la présence annonce toujours un pays misérable. Leurs cris nous empêchęrent de fermer l'œil. Jc donnai au campement le nom de Cramp des pintades; et dès le poine du jour je me hâtai de le quițter, dans l'espoir d'en trouver un mcilleur.

La fortune, ce jour-là, nous servic bien; et en effet, nous étant oricntés nord-est, nous trouvâmes, après trois heures de marche, unc source d'enu excellentc, à qui je donnai le nom de Fontuine des tortues, parce que près de son lit je trouvai une tortue, tclle que jusqu'alors je n'cn avois point encore vue de pareille. Ellc pesoit plus de douze livres, et contenoit une quantité considérable d'œufs de toutes yrandeurs, dans le nombre desquels il y avoit une vingtaine de jauncs, gros comme ceux des auls de poule. Jc la fis rôtir sur le hrasier; et sa chair blanche, aussi tendre que celle du poulet, me domn un soupcr exccllent.

Les pintades continuèrent de nous assourdir par leur bruyant caquetage; mais nous avions en mênie tems plusieurs espèces de jolis oiseaux; celui quc Buffon a décrit sous le nom de grenadin de la côte d'Afrique, et spécialement ces charmans guépicrs dont j’ai parlé ailleurs.

De leur côté, mes chasseurs m'apportèrent un animal fort curieux, et quc jc n'avois pu encorc me procurer : c'étoit la grande gerboisc du Cap. Elle est fortc comme nos plus grands lièvres; elle a le poil roux ct foncé, la queue fort longuc, ct cerminéc, comme celle de l'hermine, par un bou- 


\section{E N $A F R I Q U E . \quad 23 I$}

quet de poils noirs. On le nomme dans les colonies spring-haas (lièvre-sauteur); parce que ses jambes de derrière étant disproportionnément beaucoup plus longues que eelles de devant, elles lui permettent de faire des élans et des sauts prodigieux. Sa chair est un cxcellent manger. Ce singulier quadrupède, quoiqu'abondant dans certains cantons de l'Alirique, est copendant très-difficile à trouver, parce qu'il se retire pendant le jour dans des terriers profonds qu'il sc creuse lui-même, et n'en sort qu'au solcil couchant pour aller brouter l'herbe qui est sa principale nourriture.

Bernfiry, de son cổté, eut le bonheur de tuer une girafie nâlle. Elle avoit quinze pieds un pouce de hautcur; et j'eusse bien désiré avoir sa dépouille comme celle de la premièrc. Mais, loin de mon camp, où je ne comptois pas revenir, au moins de sitôt, et manquant absolument de toutes les commodités nécessaires, qu'en pouvois-je faire? Ce fut alors que je sentis combien je devois m'applaudir d'avoil la mienne en sûreté dans mon eamp de l'Orange. Celle-ci étant apprêtéc et saléc, servit de nourriture à ma caravane pendant quelques jours.

Le lendemain je me dirigeai au nord-quart-nordouest, pour gagner un torrent nommé le Draay (Rivic̀re-Torteuse). Son lit, au lieu où nous le joignìmes, étoit peu prolond, et nous ne l'apperçûmes qu'su moment d'y descendre. En cet instant, un troupeau de buflles y étoir couché. Nous nous trouvâmes en présence; mais, à notre vue, se levant tous ensemble, ils s'enfuirent avce une précipitation, un bruit et un effioi que je ne puis pcindre; tandis que nous, aussi ćtourdis qu'cux de la rencontre, et nullement préparés à l'aventure, nous les laissâmes fuir, sıns songer sculement à leur tirer une balle. 
Quoique le Draay fut à sec, il avoit pourtant quelques lagunes dans certains bas-fonds, er il étoic garni de beaux arbres. J'y cherchai un campenent, tant pour nous reposer, que pour nous garantir d'un violent vent de nord, qui, en nous aveuglant par une pluie de sable, nous étouffoit par une chaleur brûlante. $A$ midi, lc thermomètre de Farenheit marquoit cent dix degrés; et le soir, au coucher du soleil, il étoit encore à quatre-vingt-dix.

Malgré le vent et la chalcur, j'allai chereher fortune dans les arbres du rivage, et j'y trouvai effectivement un magnifique et superbe aigle, d'espèce nouvelle, dont j'eus le bonheur de cuer lc mâle et la femelle, de mes deux coups de fusil.

Déja, sur les bords de l'Orange, j'en avois vu de pareils; mais ils ne s'étoient point laissés approcher.

J'ai nommé eet aigle griffard, parce qu'il a les serres plus fortes et plus acérécs que tous les autres aigles connus. Aussi fort que l'airle royal, il a, pour caractère distinctif, une espèce de huppe pendante sur l'occiput; le carse est couvert din fin duvet dans toute sa longueur, et ses jambes sont dépourvues de ces longues plumes, que, chez tous les oiscaux de proic, on nomme culcte; toute la partie antéricure de son corps est d'un beau blanc, et lc manteau d'un brun clair. J'étois à près de trois lieues de mon camp, quand je tuai ces deux charmans oiseaux, et j'y arrivai excédé de fatigue de les avoir portés; car ils ne pesoient ensenble guère moins de trente livres.

Dans l'après-dìnéc, pendant que j'étois occupé à écorcher et préparer mes deux aigles, on vint m'apprendre que nos chevaux étoient perdus. Un vieux Caminouquois, âgé de soixante ans, s'étoit 


\section{E N A R I Q E. 233}

chargé de les garder; mais le vieillard, accablé par l'extrême chaleur, et plus encorc peut-être par les fatigues d'un voyage au-dessus de ses forces, s'étoit endormi; et à son reveil ne les ayant plus retrouvés, il avoit craint d'être puni, ct étoit allé se cacher.

Le scul parti à prendre dans cette circonstance, étoit d'aller à la recherche; et c'est ce que je fis avec tout mon monde. Bernfry aroit son cheval égaré comme les deux miens. Au licu de suivre mon excmple, cet homme violent, qui jusqu'alors s'étoit montré assez bien, parce que son naturel colérique n'avoit pas cu occasion d'éclater, s'emporta tout-à-coup en imprécations contre le gardien imprudent; et avec des sermens horribles, il jura de l'assommer', s'il le rencontroit.

Effecrivement, à force de le chercher, il le trouva; er sans pirié pour son âge, sans compassion pour les regrets qu'il témoignoit, d'une faute bien pardonnable, il le renversa sous ses picds, et se mit à le frapper avec fureur. Cet emportement coupable étoit d'autant plus répréhensible, qu'en ce moment on venoit de retrouver les chévaux et qu'on les ramenoit.

Par bonheur pour le malheureux, je n'étois pas loin de lui. A ses cris j'accourus, ct le trouvai baigné dans son sang. Ce spectacle, je l'avoue, me mit hors de moi-même. Saisi de colèrc, autant que d'indignation, j'arrachai le bourreau de dessus sa victime; et le poussant de coutes mes forces loin du vicillard, je le menaçai de ma vengeance, s'il osoir sculement approcher de lui. "Apprencz, "ajoutai-je, que tous ccux qui composent mon "camp, étant à ma solde et à mon service, vous „n'avez aucun droit sur eux : et que c'cst m'insulter noi-même que de les frappcr."6 
Ce discours acheva d'irriter sa fureur. Il ceumoit de rage; et me demandant avec arrogance, si j'étois venu dans le pays pour soutenir les Sauvages contre les blanes, il menaça de me quitter; je le pris au mot, et l'en priai même d'un ton à lui faire comprendre que je l'exigeois; et comme il y avoit dans mon camp quelques hommes ct quelques femmes de sa horde qui l'avoient suivi, je donnai ordre à ces gens-là de s'éloigner à l'instant même. Ils allèrent le rejoindre; pendant que j'emmenai le vicillard dans ma tente pour y panser ses plaics et lui donner des soins. Je vis le brutal se retirer avec son monde à quatre ou cinq cons pas de nous, et s'y établir pour y passer la nuit.

Le voisinage d'un pareil homme étoit une chose alarmante; ct je ne vis pas sans inquiétude son affectation à rester si près de moi. Tout moyen est bon à un scélérat, pourvu qu'il sc venge. Celui-ci emportoit une corne de buffle remplic de poudre, que je lui avois domée pour la chasse; ct j'avois à craindre qu'il ne s'en servit pour nous nuire. Mes gens, quoiqu'enchantés d'être débarrassés de lui, quoiqu'applaudissant à ma sévérité qu’ils regardoient conme un acte de bonté en leur faveur; craignoient, ainsi que moi, quelque trabison nocturne de sa part. D'une voix unanime, ils prirent cous le parti de veiller et de rester sous les armes jusqu'au jour, et je vcillai comme cux.

On se doute bien que la nuit se passa toute entière à parler de Bernfry. Les uns racontoient les actions de sa vie dont ils avoient été témoins; les autres celles qu'ils avoient cntendu conter; et tous ne citoient que des horreurs abominables. Ces récits me domoiont beaucoup à penser. Je me reprochois l'indulgence avec laquelle j’avois excusé pré- 


\section{E N A F R I Q U E. $\quad 235$}

cćdemment et atténué scs torts; ct je m’applaudissois de ne l'avoir plus dans ma société. Outre qu'il me devenoit inutile, puisque jallai me trouver dans des contrécs où jamais nul blane n'avoit pénétré, et où lui-même n'étoit pas plus connu que moi, son humeur brutale et cmportéc, son brigandinge et ses vices, pouvoient me devenir dangereux, en me suscitant des querelles ct me faisant mass?crer avec lui par les naturels du pays. C'étoit ce danger d'une compagnie étrangère qui m’avoit décidé à refuser plusieurs honnêtes gens du Cap, lorsqu'ils s'ćtoient offerts à m'accompagnel dans mon voyage.

D’après ce motif, n'cût-ce donc pas été une imprudence à moi de m'associcr un tel homme, dont je ne devois attendre que des chagrins; tandis que je renonçois volontaircment à des sociétés agréables, qui après tout 11'avoient à me faire craindre que l'incertitude d'un périí.

Il est viai, que je ne l'avois pris avec moi que pour l'éloigner de mon camp, parce que jele croyois moins redoutable lorsqu'il seroit sous mes yeux. Mais on n'échappe point à sa destinéc. Ce méchant homme paroissoit m'avoir été cnvoyé par le sort, pour déconcerter mes projets. On verra jusqu’où sa vengennce a pul se porter envers moi, qui pouvois et ne voulus pas y mettre fin d'un seul coup.

11 étoit à croire, que le traitement barbare qu'avoit essuyé le vieux Caminouquois, devoit avoir révolté ses camarades, ct que dans la crainte d'en essuyer de scmblables, ils se recireroient chex eux. En conséquence je m'attendois à les voir arriver, au lever du soleil, pour m'annoncer leur départ; mais je m'apperçus avec plaisir que, loin de montrer du resscutiment, ils vinrent me remercier d'avoir défendu et siuvé la vie à l'un de leurs firères, 


\section{$236 \quad V$ Y A G E}

et m'assurèrent qu'ils étoient prêts à me suivre par tout où je les conduirois.

Ces protestations d'attachement me firent dans la circonstance un grand plaisir. Je repris ma route aussi-tôt; et me dirigeant nord-est, pour n'avoir pas à suivre les sinuosités du Diray, nous arrivâmes quatre lieues plus loin, à une coude de cette rivière, où nous fìmes halte au milieu des éléphans et des buffles. Je dis au milicu; car ces animaux y etoient si nombreux et si peu farouches, que de toutes parts nous cn étions entourés.

L'après-dìnéc, nous fimes encore quatre lieues, dans la direction nord-oucst, afin de m'éloigner tout-à-fait de la rivière, et nous vinmes camper près d'un ruisseau qui, comme clle, étoit à sec, mais qui, comme clle, avoit encore quelques amas d'cau dans certains bas-fonds.

Ces réservoirs au milieu d'un désert aride avoient, je crois, atciré là tous les monstres de l'Afrique; aussi ai-je eu, dans tous mes voyages, peu de nuits aussi orageuses que celle-ci. De tous côtés nous entendions les bêtes fúroces, et sur-tout les lions, crier et rugir d'une minière épouvantable. Il y eut particulièrement plusieurs de ces derniers qui, pendant toute la nuit, vinrent roder autour de mon camp et remplir d'effroi mes gens et mes animaux : ni nos lcux, ni nos mousqueteries ne purent les éloigner; ils répondoient avec une sorte de fureur aux rugissemens de ceux des environs, et sembloient les appeller au carnage et à une attaque faite en force. Enfin cependaut, le jour nous en délivra; et comme j'avois remarqué que c'étoit principalement du nord-ouest que venoit le bruit des animaux, je voulus les eviter; et, changeant de route, je tirai vers le nord-est. 


\section{E N A F R I Q U E. 237}

An débouquement d'une gorge, nous entrâmes dans un canton qui étoit éouvert de plusieurs troupcaux; mais à notre aspect les gardiens, rassemblant leurs bêtes, s'enfuirent avce elles à toutés jambes. En vain nous cherchions à les rassurer par des signes d'anicié; enveloppés dans les nuages de poussière qu'élevoit leur fuite, ils ne pouvoient nous appercevoir; et j’avois à craindre qu'ils n'allassent jetter l'alarme dans leur Kral, et y causer le même effroi.

Pour prévenir cet effet funeste, je fis monter Klaas à cheval, et l'cnvoyai après cux, suivi de ces Namaquois qui, depuis la demière horde que j'avois visitée m'accompagnoient fidellement, et qui étant leurs voisins et parlant la même langue, pouvoient plus que personne les rassurer. Ceux-ci prétendoient que cette démarche n'étoit point nécessaire; mais j'avois pour systême que jamais je ne pourrois prendre trop de précautions, et ne voulois me présenter nulle part qu'cn ami.

Klaas, après avoir, par le moyen des Namaquois, rassuré les fuyards, écoit allé avec eux jusqu’à leur Kraal prévenir de mon arrivéc la horde; et bientôt je le vis paroître enviromé d'une cinquantainc de sauvages, tous sans armes, en signe de confiance et d'amitic. Als avoient parmi cux leur chef qui, à son visage me parût malade, et qui me fit comprendre effectivement, qu'il languissoit depuis long-tems d'une dissenterie.

Sa maladic ne l'empêcha point d'accepter, avec de grands signes de joie, un verre d'cau-de-vic que je lui présentai pour le ragaillardir. Mais après en avoir avalé les deux tiers, il donna le reste à une femme qui l'accompagnoit. C'étoit l'une des siennes, car il en avoit deux. 
Celle-ci étoit grosse à pleine ccinture, et avoít voulu le suivre pour voir un honme extraordinaire. Depuis long-tcms cette femme à qui on avoit parlé de moi, mais qui n'ivoit jumais pu croire tout ce qu'clle en avoit entendu raconter de merveilleux, venoit pour s'en assurce par ses yeux. Elle m'cxaminina très-attentivement, me regarda dans tous les scns, et finit par me faire bcancoup d'anitićs. Jc les lui rendis avec usurc, et lui fis plusicurs cadcaux qui lui plurent infiniment.

Cette horde étoit une des plus nombreuses de la nation Namaquoise. Je traversai le Kraal avec toure ma troupe, et jallai dresser mon camp à quelques milliers de pas plus loin, près d'une source dont l'eau étoit excellente, quoi qu'elle cût un coupd'œil laiteux, qui ne lui laissoit qu'une demi-transparence. Résolı de m'arrêter quelques jours dans ce licu, pour étudier les nocurs de la nation; je notifiai mon projet à mes gens : c'écoit pour cux une nouvelle agréable. En un instant ils curent dressé mes tentes, construits lcurs huttes, et formé cette enceinte de piquets, qui sclon notre coutumc, quind je voulois sćjoumer, scrvoient à attacher et ì renfermer nos boufs et nos chevaux.

Pendant que les femmes et les hommes travailloient chacun de leur côté, un joli gutépicr, d'espèce nouvelle, vint effrontément sc poser sur une de nos palissades. C'étoit venir de lui-même s'offrir à ma collection, aussi l'y fis-je entrer, en l'abattant d'un coup de fusil. En ce moment, j'avois près de moi plusicurs des Sauvages de la horde, qui, attirés par la curiosité, s'amusoicnt ì regarder les travaux du camp.

Ces.gens, dont la plupart n'avoicnt pas la moindrc idéc d'une arme-à-feu, furcnt étrangement sur- 


\section{E N A F R I U E. 239}

pris, et l'on peut juger de l'étonnement que produisit sur cux l'cxplosion bruyante de la micnnc et - cette mort subite de l'oiscan. Stupélaits d’admiration, ils coururcnt aussi-tôi au kraal, raconter le double prodige dont ils venoicnt d'être témoins. On y avoit cntendu le coup; mais quand on sut que c'étoit l'homme blane qui avoit produit ce tonnerre, et tué à la fois un oiscau, presque toute la horde accourut au licu du miracle.

Le Iendemain quand ces bons Sauvages vinrent visiter mon camp, j'ćtois occupé à prendre hautcur. Ccux d'entre cux, qui, la veille m avoient vu viser le guépier avant de l'abattre, me voyant mirer de même le soleil avec mon quart de cercle quils prenoient pour un sccond fusil, portoicnt attentivencnt la vue et sur l'instrumente et sur l'astre. Immobiles et en silence, ils attendoicne impatiomment que le coup partît, et ils furent tiès-déconcertés quand ils virent mon opération finir sans bruit.

Le reste de la troupe qui, daprès leur récit s'attendoit à un prodige, ne savoit trop que penser de tout ceci. Enfin ecpendant, voulant lcs satisfaire d'une manic̀re ou d'autre, et cn même tcins m'amuset de leur simplicité, je fis apporter ma lunette, (c'étoir pour eux un troisième fusil), je lc plaçai sur le pied qui servoit de pivôt à ma grosse carnbine, et après l'avoir pointée sur le kraal, j’appliquai à l'occulaire l'œil du Namaquois que je juycrai le plus hardi de la bande.

Personne n'ignore l'histoire de ce jeune homme qui, né aveugle par l'effect d'une cataracte, vit toutà-coup la lumiere par l'opération de Cheselden. On sait que pendant quelque tems tous les objets qu'il appercevoit ne furent pour lui que des illusions. On sait qu'il les croyoir tout près de son wil; quil se 


\section{0}

trompoit sur leurs formes comme sur leur éloignement, er que ce ne fût que par l'expérience et le tact, quil apprit enfin a juger des distances.

Ce qu'étoir l'aveugle de Cheselien, l'homme clairvoyant peut l'être, s'il a une intelligence bornéc, er si l'objet d'oprique qu'il apperçoit est nouvenu pour lui. Croire que le Namaquois qui ćtoit à ma lunetre pouvoit deviner la magie de l'instrument, ce seroit l'élever à notre hauteur; ce seroit lui prêter notre expérience, nos connoissances physiques, enfin, une masse d’idées et de réflexions qui jamais ne peut approcher de son entendement obtus.

Oublions, pour un moment, les lumières de notre éducation; supposons nous, conme lui, profondément ignorans, n’ayant pas la moindre idéc dine lunette, et alors nous comprendrons quelle dût ĉtre son admiration quand il apperçût si près de lui une hutte, à l'entréc de laquelle jouoient deux petits enfans. Son étonnement fùt tel qu'il tressaillir de joie et que tous ses muscles se contractèrene à la fois. Sans déplacer son wil de l'occulaire, il allongeoir la main vers le bout du tube, comme pour toucher ce qu’il voyoit. Enfin, malgré tous ces tâtonnemens, ne les trouvant point, il quitta l'instrument et fût bien surpris de ne plus les voir où il les croyoit : il demande à ses camarades s'ils sont retournés à lcur place. En vain, ils lui répondent qu'on ne les a point vus; il ne veut pas les croire; il montre du doigt la place où ils ćtoient: c'cst là, là, dit-il. Plus on s'obstine à le désabuser, plus on le dépite, er la scène finit presque par une dispute.

Parmi les créatures humaines que la nature a graŁifiées d'unc dose plus ou moins forte d'intelligence, 


\section{E N A F R I Q UE. 24 r}

In nation hottentote, considúréc dans ses différentes peuplades, cst une des plus mal partagées. C'est avec cette foible portion de lumières que raisonnoit le Namaquois. Et sans y ricn comprendre, quelques efforts que j'eusse faits pour rendre sensible à sa raison mon expéricnce, il donnoit à ma lunette le pouvoir d'attirer à ellc tous les objets.

Au reste, son explication, son cnthousiasme, sa colère mênic, avoicnt cxcité la curiosité de ses camarndes : tous vouloient venir à ma lunette, et je me prêtois à leur empressement; mais en changeant de tems cn tems, sans qu'ils s'en doutassent, la direction du tubc. Ce qu'ils voyoient les ravissoit de plaisir; c'étoit un enchantement général. Mais les uns, voyaut s'approcher des arbies, les autres une montagne, ccux-ci des oiseaux volans, ceux-là des troupeaux tout entiers, etc., on imagine quelle confusion devoit résulter de lcurs transports, comme ils se disputoient sur les objets qu'ils avoient apperçus si près d'eux, et combien toute cette discordance m'amusoit.

Cette comédic durn jusqu'au soir; mais ce fue pour moi un divertissement instructif, et il me montra ce que les charlatans les moins habiles ont pu établir d'iscendant sur des pcuples aussi neufs que cclui-ci, lorsqu'ils en ont faic la découverte.

Tout ceci m'attira dans la matince du lendemain, d'autres visites cncorc, de la part de ceux qui n'avoient pu venir la veille. Dc ce nombre étoit le chef, avec ses deux femmes. J'étois déja pour l'une des deux une ancienne connoissance, aussi me fitelle bcaucoup de caresses. Elle étoit accompagnée de deux de ses enfans, garçon et fille, âgés de quatre ans et jumcaux. Dans une couche précédente, ellc avoit eu deux jumcaux encore, qui vivoient Tome 11 : 
ainsi que ceur-ci, et clle se flattoit d'en aroir der.s autres à la troisieme couche.

Je fis servir au chef et à ses épouses un déjcûné hollandois à la manière du Cap, c'est-à-dire , du bon tabac et de l'eau-de-vie : après quoi il me demandèrent de voir ma lunette et d'admirer les merveilles qu'ils en avoient oui raconter. Ic la plaçai comme la veille sur son pivot; mais à peine avoientils vu un objet qu'ils me prioicnt d'cn amener un autre; ne doutant pas, comnie je l'ai dit plus haut, qu'clle n'eût la vertu de les faire arriver à ma volonté.

Après leur départ, les gens de la horde se présentèrent à leur tour ct me firent les mêmes pric̀res; mais ce jeu étoit bon pour quclques instans : à force d'être répété, il cût fini par m'ennuyer, ct ce fut pour éviter ce dénouement que j'y renonçai. Cependant, afin de satisfaire les curicux, je laissai pendant tout le jour la lunette en place, mais j'cus soin d'en confier la garde à l'un de mes Hottentots, avec la charge d'empêcher qu'on y touchât, ct qu'on la déraingeât on rien.

En entrant dans la contrée des Namaquois, mon intention ćroit sur-tout de vérificr tout ce qu'on cn dit au Cap. Que de contes n'avois-je pas entendus faire sur cette nation! Que de choses merveillcuses sur scs mours, scs arts, scs trésors, ctc.! Déja mon lecteur sait à q̨uoi s'en tenir sur ses prétendues mines d'or et d'argent. Eh bien, il en est de ses arts et de ses loix comme de ses mines.

L'homme par qui se sont accréditécs toutes ces fables, est Kolbe. Moi-mêtnc, sans aucune notion sur ces peuplades éloignćes ct inconnucs, j’avois ajouté quelque foi aux rêverics de cet ćcrivain. En consćquence, et à mesure que je pénétrois dans 


\section{E N A F R I Q UE. 243}

lintérieur de l'Afrique et que je visitois les $\mathrm{Hot}$ teintots, je cherchois par-tout les vestiges de cette florissante agriculture qu'ils entendent incompcrablemeni mieux que les Européens du Cap, qui s'adressent très-souvent it eux pour avoir leur avis lì-dessus. Je désirots voir quelqu'un de ces mariages solemnels qqu'un prêtre forme et légitime en inondant de son urine les deux conjoints. Je voulois visiter les prisons publiques de ce peuple, as sister aux audiences de ses tribunaux et aux sentences de son conseil suprême. Peut-être avois-je détruit en $\Lambda$ frique assez de monstres, pour aspirer à l'honneur d'être admis dans cet ordre de chev'a. lerie dont l'historien nous décrit la marche et les cćrémonies, avec autant de pompe que d'exactitude.

Hélas! toutes ces brillantes chimères se sont évanouies devant moi. Religion, police, loix, tactique des armées, ordre de bataille, traité de paix, cxpérience militaire, prisonniers, vainqueurs ct vaincus, toutes ces hableries n'ont jamais existé que dans le cerveau de l'auteur, et dans les cabarets, où, en se moquant de lui, on les lui a débitées.

Trente ou quarante ans après la publication de ce voyage, l'abbé de la Caille fut aussi séjourner au Cap, et par-là fut à portée de prononcer sur cer ouvrage, au moins en quelques matières; il en a parlé comme il dcvoit. Depuis la Caille, d'autres voyageurs ont aussi porté sur Kolbe leur jugement, et aujourd'hui nous savons à quoi nous en tenir sur le récit de ce voyageur.

A l'en croire, dans toutes les peuplades hottentotes, sans exception, les mères ont l'horrible préjugé de ne pas vouloir deux jumenux, et l'abominable coutume d'en ćtouffer ou d'en égorger un deg 
$244 \quad V$ O Y A GE

deux. Si ce sont deux filles ou deux garçons, c'est le plus foible qu'elles sacrifient; si c'est garçon et fille, c'est la fille, dit-il, qui est la victime : et ces crimes, il ne rougit point d'attester qu'il en a été le témoin.

Et moi, j'atteste que cette imputation est la plus noire calomnie contre la nature dont jamais écrivain sans pudeur ait souillé sa plume. Pour m'en convaincre, il me suffisoit d'avoir vu les deux jumeaux d'une des femmes du chef. Mais cependant, comme ces enfans auroient pa, par quelque raison particulière, être une exception à la loi générale, je voulus interroger leur père sur ce prétendu massacre.

Tous les matins, avant mon départ pour la chasse, il venoit me voir avec ses deux femmes, et se régaler en fumant une pipe et avalant un sopje (petic verre d'eau-de-vie ). Quoique son langage fut différent de celui des Hottentots de la côte de l'ouest, nénmmoins, depuis près de deux mois que je parcourois le pays, j'avois appris a le comprendie un peu et à me faire entendre.

Un jour qu’avec lui et ses deux femmes jeétois assis sur l'herbe près de ma tente, je mis la conversation sur l'objet des jumeaux, et fit demander à la femme si, dans le cas où elle auroit deux enfans, elle n'en étoufferoit pas un? Cette question parût la fâcher; elle garda le silence et tomba dans une rêverie stupide. Mais le mari, se toumant vers moi et me rappellant que déja je lui avois fais plusieurs questions pareilles, mattesta avec violence que ce sacrifice étoit impossible.

Ainsi donc, voilà les blancs qui, d'après Kolbe, accusent les Namaquois d'un crime abominable, et qui outrage la mère commune de tous les êtres. 


\section{E N A F R I Q E E. $\quad 245$}

J'ajouterai ici que les Namaquois, non-sculement ne se défont pas d'un de leurs jumeaux quand ils en ont, mais qu'ils conservent et élèvent tqus leurs enfans; ce slevoir est si naturel, que je n'aurois pu parvenir à faire comprendre une idée contraire.

Outre la grande inculpation révoltante dont je viens de parler, on m'avoit débité sur les Grands Namaquois, une fąble absurde dont je vérifiai égalcment la fausseté. Ce n'étoit point au Cap que celle-ci m'avoit été racontée, ainsi que l'autre. Je la tenois de Klaas Baster, qui, né dans les environs de l'Orange, pouvoit avoir sur ce peuple quelques connoissances certaines.

Selon lui, les pères, pour montrer quelle affection ils portent à leurs enfans, nourrissent d'une manière particulière leur aîné, comme devant êtree le premicr objet de la tendresse paternelle. Pour cela, ils le mettent, pour ainsi dire, en mue; ils l'enferment dans une fosse, faite sous leur hutte, où, privé de mouvement , il perd peu par la transpiration; ct là, ils le nourrissent et l'empâtent, en quelque façon, avec de la graisse et du lait. Peu à peu l'enfant s'engraisse; il enfle comme un tonneau; enfin, quand il en est venu au poine de ne pouvoir plus marcher et de plier sous son propre poids, les parens l'exposent à l'admiration de la horde, quị, dès ce moment, conçoir plus ou moins d'estime et de consideration pour la famille, selọ que le monstre a plus ou moins de rotondité.

Tel étoit le récit que m’avoit fait Klaas Baster; et quoique tout me parût invraisemblable, cependant le narrateur y ajoutoit tant de circonstances ct de détails, dont il prétendoit avoir été le témoin oculaire; il avoit si peu d'intérết à me tromper ; 
enfin l'esprit humain, chez des nations grossicres et ignorantes, montre quelquefois des préventions et des courumes si insensées, que, malgrć ma répugnance, jc m'ćtois vu forcé de croire à celle-ci.

Bicntôt je fus désabusé; par-tout où je fis des questions à ce sujer, je vis qu'on étoit prêt de me rire au nez. Cependant, comme il me paroissoit incroyable qu'un homme qui disoit avoir vu, n'ent pas vu récllement; comme il étoit possible que, sans cetre vraic dans tons ses détails, la fable néanmoins êt quelque fondement, je voulus me convaincre par moi-même de ce qui pouvoit y avoir donné lieu, et chaque fois que je visitois une horde, j’avois soin, sous différens prétextes, d'cxaminer, l'une après l'autre, toutes les huttes du kraal, et de demander quel étoit l'ainné de la famille; mais nulle part je ne vis rien qui annonçât, ni cette prétenduc nlue, ni cc prétendu cmpâtement, dont on mavoit parlé.

Il est probable qu'un parcil conte avoit pris naissance chez les colons sirués dains le Namero et dans le voisinage du pays des Namaquois; que c'ćroit une plaisanteric faite par quclque bel esprit du licu, sur la maigreur de ces peuples, qui en effet est excessive; ct que Klaas Baster, fils d'tne Hottentote et d'un colon, en ayant été imbu dès son enfance, avoir fini, comme tous les menteurs, par assurer avoir vu ce qu'il ne faisoit que répéter. C'est ainsi que, dans toute la colonie du Cap, les colons et même les Hottentots, vous assurent que dans les hordes sauvages, on pratique l'aspersion d'urine dans les cérémonies de mariage.

Je donne iei la figure de deux Grands Namaquois, homme et femme. La première est celle du chef, dessiné d’après nature, dans une de ses sén. 
Tom $\Delta$.

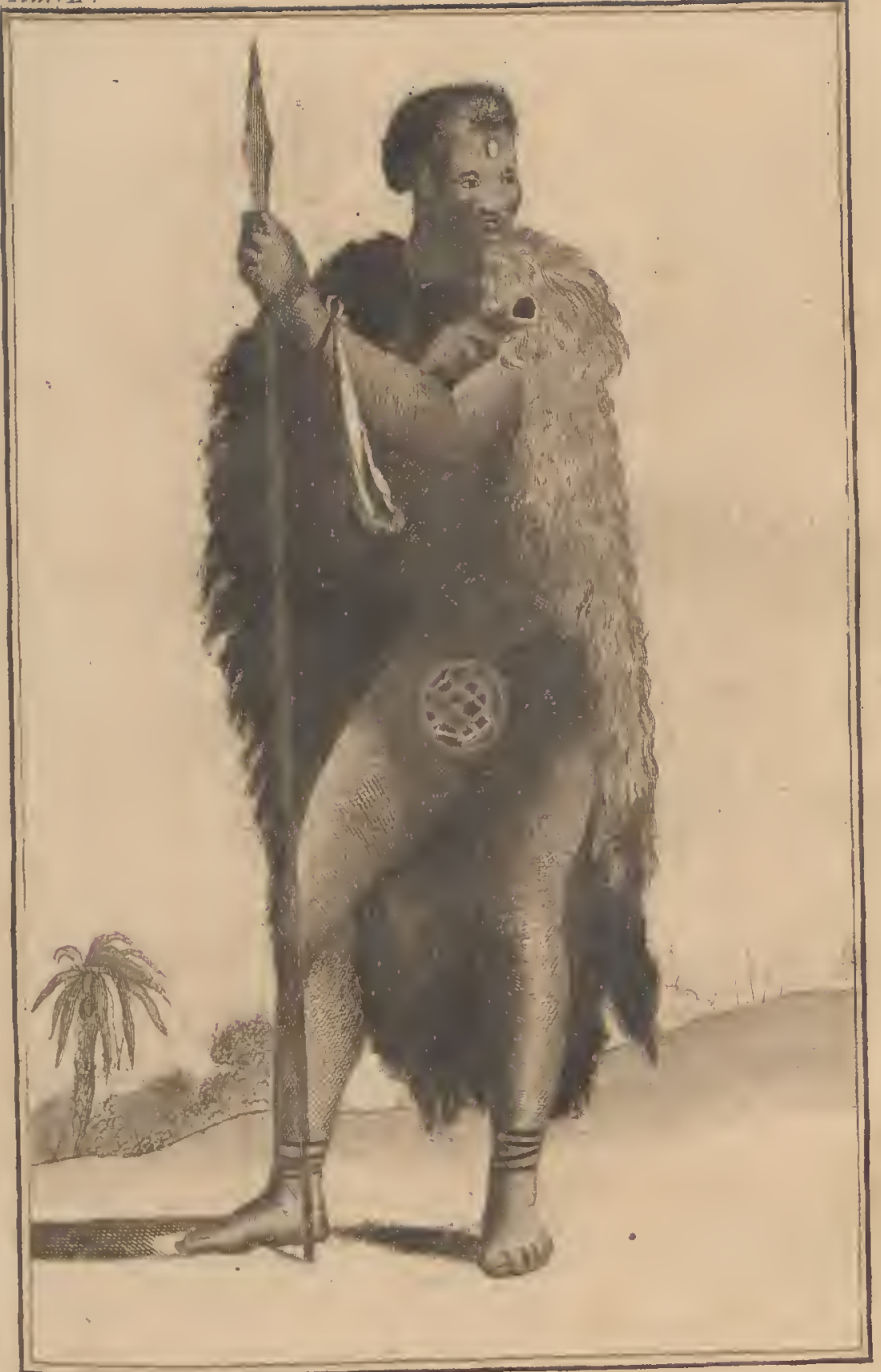

GRIND NAMAQTOIS. 


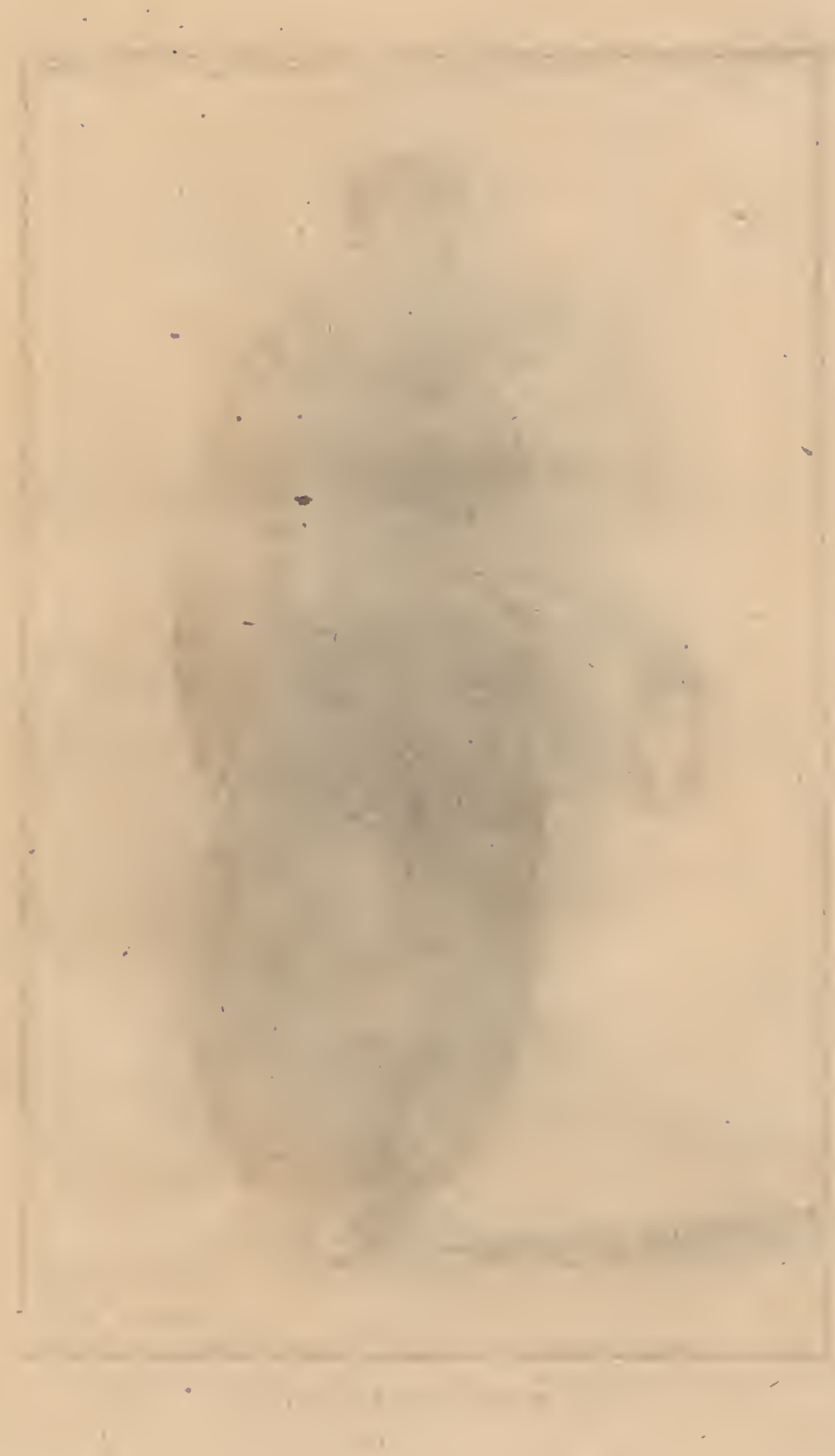




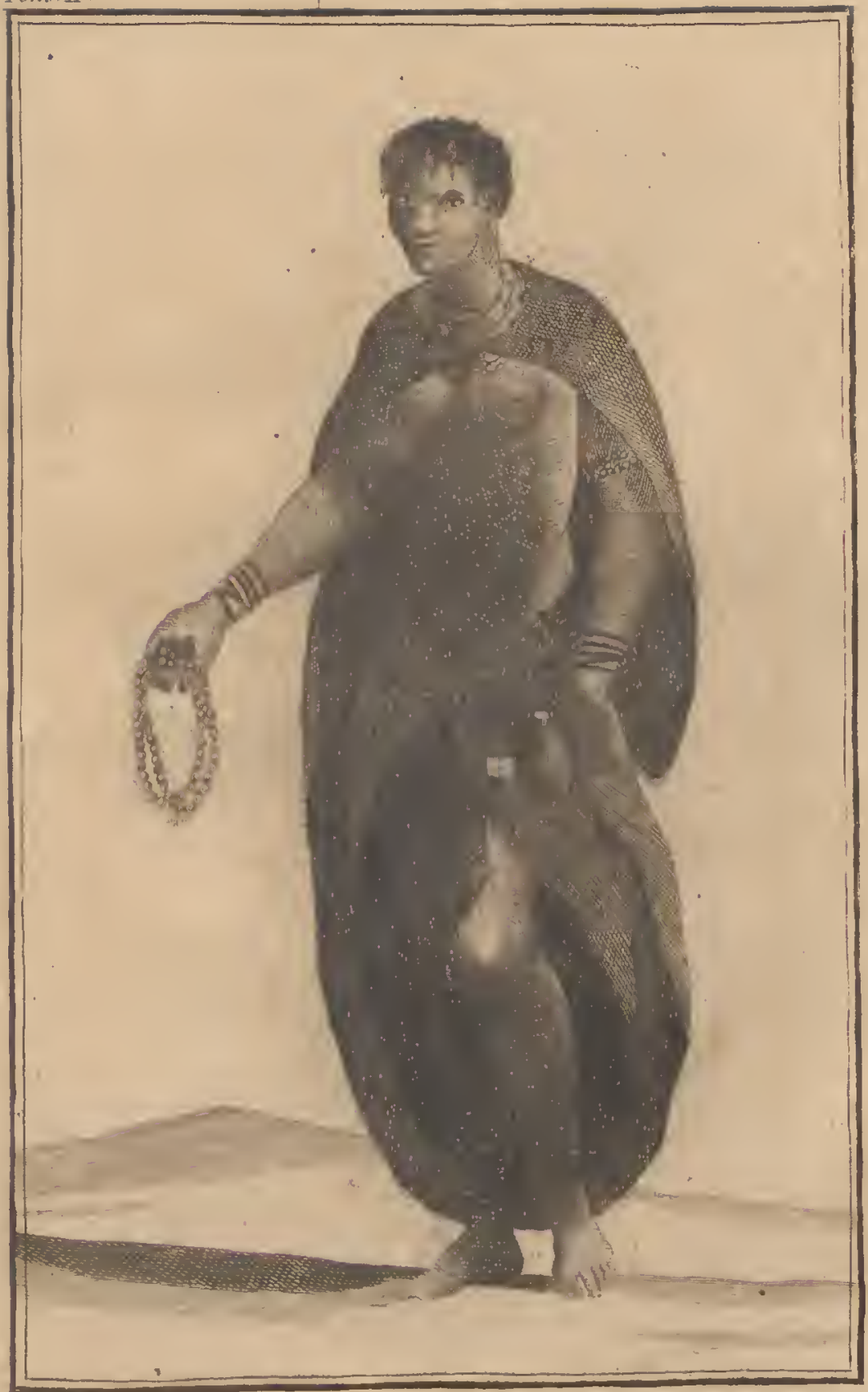

GRANDH NAMAQTOISE. 



\section{E N A F I Q U E.}

ces qu'il venoit passer precs de moi pour fumer une pipe. J'y avois joint lc portrait de l'unc de ses femmes; mais ee portrait s'est perdu, je ne sais commene, dans mon retour en Europe.

A son dićfaut, j'en substitue un autre; cclui d'une femme, qui, depuis long-tens m'avoit tourmenté pour que je lui fisse aussi son portrnit, et qu'cficetivement je dessinai pour m'amuser. Jc crois devoir en prévenir mes lecteur's, afin qu’ils ne jugene pas des Namaquoises par les traits de celle que je leur présente. C'est une des plus laides de li horde; et clles sont généralement micux que celle-ci, on ponrroit même dire jolies quund elles sont jeuncs.

La taille des Grands Namaquois, est plus haute que eclle des autres peuplades hottentotes; ils paroissent même plus grands que les Gonaquois, quoique peut-čtre ils ne le soient pas récllement. Mais leurs os plus petits, leur nir fluct, leur taille eflanquéc, leurs jambes minecs et grôles; tomi enfin, jusqu’a leurs longs manteaux peu ćpais, qui, des épaules descendent jusqu'ì terre, contribuent à l'illusion. A voir ces corps effilés comme des tiges d'arbres, on diroit des hommes pussés à la filiere.

Moins foncés en coulcur que les Caffres, ils ont un visage plus agréable que İcs autes Hottentots, prarce que le nez est moins écrasé, et la pomette des joucs moins proćminente. Mais leur physionomic froide et sans traits, leur air phlegmatique ct impassible, leur donne un caractere particulier auquel on les distingue. Toutes les fois que je les regardois, jc croyois voir une de ces figures gothiques, ì la minc oblongue, au corps alongé, qui, dans certains pays catholiques romains, semblent servir de sentinclles au portail des églises.

J'ai déja dit ailleurs que les femmes ne tiannent Q 4 


\section{V O Y A G E}

rien de cette tranquille apathie. Gaies, vives, sémillantes, aimant beaucoup à rire, on croiroit qu'elles sont d'une pâte différente. Il est aisé de concevoir que, malgré des humeurs si diverses, un ménage peut néanmoins vivre en paix. Mais ce qu'on a plus de peine à concevoir et à expliquer, je le répète', c'est comment ces tristes pères font des filles si gaics, et ces femmes si gaies des garçons si tristes.

Le kros ne differe en rien, pour la forme, du manteau hottentot. Sculement, comme je l'ai déja remarqué, il est plus long; beaucoup d'entre eux se servent de penux d'hicnne, de jackal ou d'isatis, quand ils sont assez heureux pour s'en procurer suffisamment pour faire un kros.

Quant aux ornemens qu'ils y ajoutent, ce sont des verroteries et des plaques de cuivre qu'ils tirent des Hottentots de la colonie; j’ai trouvé chez eux une espèce particulière de ces verroterics en petits tubes alongés, de diverses coulentrs, et transparens. Cetce sorte de verroteric étant inconnue au Cap, j'ai voulu savoir d'où les Sauvages la tiroient; ils m'ont répondu qu'ils se la procuroient par des échanģes avec d'autres nations voisines, que celles-ci ne l'avoient elles-mêmes que de la seconde main, et qu'originairement elle venoit des noirs qui habicent les côtes de la mer des Indes, ̀̀ l'est de l'Afrique, et qui la fabriquent eux-mêmes.

Si les objets dont je parle étoient des pierres et des gemmes colorés par la nature, on pourroit croire que les noirs de l'ouest, après les avoir réduits cn pecits frigmens, savent les forer et les façonner; comme font, pour la pierre de l'amazone, les Sauvages de la Guyane. J'ai trouvé de ces substances colorées dans plusieurs roches de l'Afrique occi- 


\section{E N A F R I Q U E. 249}

dentale; et l'orientale peut en avoir de même. Mais ceux-ci sont des émaux, c'est-à-dire, un veric coulé et soufflé. Or, un parcil travail, supposant nonseulement pour la fonte, mais encore pour la composition des couleur's, beaucoup d'habileté, des instrumens, des connoissances chyruiques, etc.; on peut, je crois, assurer, sans beaucoup de témérité, que jamais les Nègres de l'cst ne connurent un pareil art; et que les émaux qu'ils vendent à leurs voisins leur viennent probablement des colonics portugaises du Mozanbique. J'ai dans mon cabinet unc de ces ccintures de verroteric; ct je certifie qu'ellc n'est ni de fabrique françoise, ni de fabrique hollandoise.

Outre l'espèce de décoration que je viens de décrire, les Grands Namnquois en emploient une autre, celle de s'enduire les cheveux avec une couche trìs-épaisse de graisse mêlée de différentes pondres de bois odoriférnut. Plusieurs d'entre cux se tâtouent le visage, les bras et même le corps. Tlais le dernier usage n'est pas si usité chez eux que chez d'autres peuples plus au nord. Au reste, il se pourroit aussi que ce fût un usage indigène, ct que le même esprit de coquetteric qui l'a faic imaginer che\% les autres, l'eût également fait inventer chez les Namaquois.

Pour ce qui est de la religion, du culte, des prêtres, des temples, de l'idée d'unc ame immortelle, tout cela cst nul pour eux : ils sont sur cet objet, ce que sont tous les autres Sauvages, leurs voisins; c'est-à-dire, qu'ils n'cn ont pas la plus légère notion.

La nature leur dit assez de ne pas faire à autrui ce qu'ils ne voudroicnt pas qu'on leur fit; mais les petires réunions qui sont un commencement de ci- 


\section{$=50^{\circ} \quad \mathrm{VO}$ Y A G E}

vilisation les mènent, à eet égard, plus loin que bien des peuples cultivés, en leur preserivant de taire à autrui ce qu'ils voudroient qu'on leur fit.

Je ne sais si je dois rapporter ici, un usage absurde qui est pratiqué chez les Namaquois, ct qui, comme beaucoup d'autres, n'a de fondement que leur ignorance : e'est de se lier le prépuce lorsqu'ils ont une rivière à traverser. Cette opéracion se fair avec un fil de boyau; et même, comme leurs idćes de pudcur sont, sur certains points, différentes des nôtres, ils la font, sans aucune précaution, vis-ìlvis de leurs filles.

Quand je leur ai demandé le motif d'une parcille coutume, ils mont répondu, en vrais Sauvages, que c'étoit pour fermer une ouverture à l'enti qui pourroit entrer dans leur corps. Li ce qui prouve combien les préventions de l'ignorance sont cxtravağuntes et même contradictoires, e'est que les femmes, en pareils cas, ne se lient ni se bouchent aucunc partic du corps, quelqu'accès qu'clles paroissent offrir à l'élément liquide.

D'après ce que j’ai dit du caractère flegmatique du Namaquois, on se doute bien que ce peuple n'est mullement gucrier. Cependant il a, ainsi que les nations qui l'entourent, un sagaic et des flêches empoisonnées; ct, comme elles, il sait trc̀s-bien manicr ces armes. Il possc̀de des bocufs de guerre, si redourables dans les combats et si favorables à la Jâcheté ou à l'inaction du combattant. 11 s'cst même fait une arme particulic̀re que n'ont point ses voisins : c'est un grand bouclicr de sa hauteur, et derrière lequel il peut se cacher cout entier. Mais, outre que son aparhic naturelle l'empêche d'offensel' et de se croire ofiensé, il est récllement, par li froideur de son caractere, pusillanime et poltron. 


\section{E N A F R I Q E. $25 \mathrm{I}$}

Pour le faire trembler, ilsuffit de prononcer devant lui le scul nom d'Houzonana. Ce nonin est celui d'un peuple voisin, né brave et guerrier, et distingué des autres nations africaines, par des traits purticulicrs. J'aurai lieu d'en parler bientôt.

Malgré sa froideur, le Nammquois n'est pourtant pas insensible aux plaisirs. Il cherche même avec quelque empressement ceux qui, sans lui donner beaucoup de peine, peuvent le seconer et lui procurer des sensations agréables. Tous les soirs, dès qu'on avoit allumé le feu de mon camp, je voyois arriver trente ou quarante persomes, hommes et femmes, qui se mêlant avec mes gens s'asseyoient en cercle autour du feu. Lì, pendant quelque tems, on gatdoit un profond silence : enfin, quelqu'un prenoir la parole; il racontoit une histoire, et parloic pendant des heures entières.

Je ne savois pas asse\% bien la langue pour suivre en entier ce récit; cependant je voyois qu'il s'agissoit ordinairement d'un événement à l'honneul de la nation, et que le héros malheureux de l'aventure étoit presque toujours une hienne, mn lion, olt même un Houzoutna. De tems en tems l'ornteur étoit interrompu par les éclats immodérés des femmes, qui rioient à gorge déployćc. Les hommes, sans participer en rien à cette gaicté folle, raisonnoient gravement et avec lapparence de la profondeur sur les détails qu'ils venoient d'entendre. Pour moi, au milieu de ces tablenux disparates et grotesques, je m'amusois de la morgue des raisomeurs; et les femmes qui me voyoient rire et qui savoient que je ne comprenois rien à la narration, redoubloicnt d'éclats et rioient à perdre halcine.

Leurs instrumens de musique sont les mêmes que ceux des autres Hotentots, mais leur dunse est bien 
différente, et tient du naturel de la nation. Si notre visage a reçu de la nature des traits qui peuvent exprimer nos passions, notre corps a aussi des attitudes et des mouvenens qui peignent nos affections et notre caractère. La danse du Namaquois est froide comme lui. Il n'y met ni joic ni graces; et sans l'excessive gaicté des femmes, ce seroit la danse des morts.

Ces tortues, pour qui la danse est une fatigue, ne montrent gućre d'ardeur que pour les gageures, les jcux de combinaison ct de hasard, et tous les exerciccs sédentaires qui cxigent une patience tt des réflexions, dont ils sont plus capables que de mouvement.

Un de lcurs jeux favoris est celui qu'ils appellent le tigre et les agneaux. Voici à-peu-près ell quoi il consistc. Je dis à-peu-près, car je ne l'ai jamais assez compris pour pouvoir l'expliquer clairement.

On trace sur la terrc un carré long, et l'on y creuse une certaine quantité de trous, profonds de deux à trois pouces; ce qui forme une sorte d'échiquier. Les trous se font par rangées les unsà côté des autres, mais le nombre n'en est point fixé. J'en ai vu depuis vingt jusqu'à quarante.

Pour jouter le jeu, on a, selon le nombre des trous, un nombre déterminé de crottins de brebis, durcis par le desséchement, et qui représententles agneaux. Quelques-uns des trous portent le nom d'agneaux également, et l'on y met les boules. Ceux qui restent vides sont appellés tigres. Peut-être mòne ne représentent-ils que différens repaires du même animal, et des retraites ou embuscades qu'il occupe successivement l'une après l'autre. Le joucur commence par tirer quelques agneaux de leur trou 


\section{E N $A F R I Q U E . ~ 253$}

et par les mettre dans d'autres trous du tigre. Probablement celui-ci a une marche réglée, comme certaines pièces de nos échecs; et la finesse du joueur consiste à éviter cette marche, pour sauver ses agneaux et les empêcher d'être dévorés. Au moins, quand il lui falloit les placer ailleurs, je le voyois redoubler d'attention. Mais quelquefois il les approchoir ou les éloignoit si confusément, que , ne pouvant plus suivre la partic, je me perdois dans ses combinaisons, et n'y comprenois plus rien, jusqu'au moment où l'on ramassoit les enjeux.

Il y a un autre jeu qui, bcaucoup plus facile, parce qu'il est uniquement de hasard, est par-lì même d'autant plus dangereux que le Namaquois, l'aimant avec fureur, il y risque souvent ses troupeaux et tout ce qu'il possède. Celui-ei ressemble à ce jeu de croix ou pile, que jouent en France les gens du peuple. Le mimosa du pays porte pour graine une espèce de fève qui fait la principale nourriture des giraffes. On prend une certaine quantité de ces semenees; on grave sur un de leurs côtés quelque signe, qui devient pour les joueurs ce que sont pour les nôtres le croix ou pile; et après les avoir agitées pendant quelque tems entre les deux mains, on les jette à terre, où il ne s'agit plus que d'examinersi les fèves qui présentent leur marque l'emportent en nombre sur celles qui n'en présentent point.

Ce jeu, fait pour réussir également et auprès des esprits indolens, parce qu'il ne les fatigue point, et auprès des esprits bornés, parce qu’il n'exige d'cux aucune combinaison, avoit singulièrement plù à mes Hottentots. Bientôt même ils s'y livrèrent avec une telle fureur que depuis le matin jusqu'au soir ils ne faisoient autre chose, et que plusieurs 
đ'entrc cux, après avoir perdu tout ce qu'ils possé doicnt vaillant, jouoient, pour dernière ressource, la portion de tabne et d'call-de-vie qui devoit leur revenir les jours suivans.

Il ne leur restoir plus après cela que de me voler. J'avois craindre que l'envic ne leur en vint; pour couper coure à cete tentation, je récablis l'ćquilibre dans les fortuncs, ch rendant à chacun ce qu'il avoit perdu; certain que le seul espoir de regagner fait les.joucurs. Ensuite il ne fut plus besoin d"affiches pour cmpêcher ce désordre dans mon camp.

De la horde précédente, plusieurs Namnquois m'avoient accompagné dans celle-ci : ils paroissoient même se plaire bcaucoup près de moi; mais dès lc monent quil ne fut plus permis à aucun de mes gens de joucr avec cux, ils ne trouvèrent plus dans mon camp la même satisfaction, ec vinrent m'annoncer lcur départ.

Néanmoins, n'ayant qu'à se louer de mes procédés, ils me témoignèrent, en me quittant, benucoup d'attachément et d'amitić; et mêne, comme je venois d'acheter quelques bœufs pour mes attclages, ils moffrirent de les emmener avec eux ct de les remettre ì Swancpocl, dans mon camp de l'Orange. J'acceptai lcur offre. En reconnoissance, je leur distribuai quelques cadcaux; je leur confiai mes bêtes, après les avoir fait marquer; et ils partircnt satisfaits.

A peine m'avoient-ils quitté qu'un de mes Hottentots vint me demander une grace. Cet homme vouloit faire préscne d'une belle vache à un Namaquois de la horde. Déja il avoit, pour la payer, quelques gains faits au jeu; mais son aroir ne suffisoit pas, et il me supplioit de lui avancer sur ses gages un peu de quincaillerie, afin de se trouver en étar de conclure le marché. 


\section{EN $\triangle F R I Q U E . \quad 255$}

Un don d'une pareille importance supposoit quelque grand service rendu. Avant de consentir à la dcmande, je voulus savoir sur quoi clle étoit fondéc; et j’appris que ec n'étoit point d'un cadenu qu'il sagissoit, mais d'un troc; que mon Hottentot étoit amoureux de la fille du Namaqnois; que pour l'obtenir de lui, il avoit offert une vache, et que celui-ci y avoit consenti.

Ainsi se font les mariages chez tous ces peuples africains. Tels ils ont été primitivement par toute la terre, avant que l'imagination des poëtes et la politique des sociétés humaines policées cût substitué à l'amour un représentant qui, sous le nom d'hymen, s'arrogeant le droit de former seul les unions, ne contribue trop souvent qu’à les troubler et à les corrompre. Chez les Sauvages, point de contract, point de témoins, aucune cérémonic. Un homme et une femme se conviennent, ils vivent ensenble, et les voilì époux. Si la fille a des parens, cllc est lcur propriété; et en conséquence il faut ou qu'ils la cèdent ou qu'on la leur achète.

Au commencement de mon voyage, je n'avois, en femmes, avec moi que celle de Klaas, qui m'étoit nécessairc pour mon linge, pour ma euisine et pour certaincs parties de mon service; et je n'avois voulu en admettre aucune autre dans ma caravane; persuadé qu'elles n'y occasionncroient que troubles, embarras er discordes.

Ce qui m'étoit arrivé sur les bords de l'Orange, quand mes gens s'étoient faits chacun de petits sérails, m'avoit confirmé dans ectte résolution. Mais depuis qu'une troupe de Caminouquoises s' étoit mise à mon scrvice avec leurs maris et leurs pères, j’avois changé d'avis. Les services innombrables que merendoicnt ces fommes, leur prérenance toujours 


\section{$25^{6}$ \\ V O Y A G E}

en activité, ln gaieté qu'elles maintenoicnt dans non camp, me rendoient leur présence très-agréable; et $j^{j} \mathrm{en}$ avois conclu que si des maitresses passagères n'étoient propres qu'à occasionner du désordre parmi ma troupe, des épouses pouvoient y produire un grand bicn, ne futt-ce qu'en retenant les hommes auprès de moi et les empêchant de s'éclipser sans cesse pour aller de côté et d'autre acheter des rendez-vous et marchander des complaisances.

D'après ces réflexions, je ne pouvois qu'être très-aise de la requète que m'avoit présentée mon Hottentot. Je lui donnai la quincaillerie qu'il me demandoit pour acquérir sa vache; et peu après je le vis revenir avec une jeune Namaquoise, très-jolic, et âgéc de seizc à dix-sept ans.

Le lendemain, le chef de la horde étant venu déjeûner chez moi, je lui fis demander si ce mariage étoit de son goût et s'il y avoit donné son agrément. Cette déférence de ma part étoit le procédé d'un Europćen qui raisonne d'après les préjugés de son pays. J'oubliois, en ce moment, qu'un Sauvage, quoique vivant sous un chef, est un individu libre, ct que ce chef n'a sur sa proprićté aucune puissance. Aussi ne répondit-il rienà ma question, et son silence me prouva qu'il ne l'avoit point comprise.

Au reste, l'arrangement de mon Hottentot inspira à quelques-ums de ses camarades l'envic d'en faire autant. Detux d'entre eux imitèrent son exemple; et je dois dire ici que je n’eus qu'i m'applaudir de ces mariages. Les trois jeunes temmes m'accompagnèrent pendant toute ma route; et toujours je fus content d'elles, jusqu'nu moment où, de retour au Cap, elles me quittèrent pour suivre leurs maris dans la nouvelle horde dont clles alloient faire partic. 


\section{E N A F R Q U E. 257}

Le nom de Namnquois est fort célèbre dans les colonies hollandoises; mais on n'y connoît guère d'eux que leur nom. Quant à leur pays, on y suppose, je ne sais pourquoi, des mines abondantes dor et d’argent. Certes, ce n'étoit pas la soif des richesses qui m'y avoit conduit. Quoique parmi les contrées d'Afrique que j'ai parcourus, celle-eim'ait paru la plus aride et la plus désolće de toutes, je n'en ai pas moins voulu la visiter en entier, parce que je désirois connoître et les nations qui l'babitent et les produetions qu'elle contenoit.

L'enipressement avec lequel on me voyoit chercher et ramasser les insectes, très-abondans dans cette contrće, avoit intéressé à ma collection plusieurs personmes de la horde. Une femme qui s'étoit misc de la partie m'apporta un magnifique scarabée, que je crois inconnu dans tous les cabinets de l'Europe, ou qui an moins n'existe dans aucun de ceux que j'ni vu.

Pendant que j'étois occupé à examiner avec attention ce joli insecte, je me sentis tout à coup la figure inondée par une liqueur caustique d'une odeur d'alkali très-forte; cet arrosement fut accompagné d'une espèce d'explosion assez considérable pour être entendu à quelque distanee. Je reçus malheureusement de cette liqueur dans un de mes yeux, ce qui me causa une douleur si insupportable que je crus perdre mon œil ; jen souffris plusieurs jours, su point d'être obligé de le couvrir et de le baigner de tems à autre dans du lait. Dans tous les endroits de mon visage qui avoient reçu de cette liqueur alksline, je sentis la douleur d'une brûlure, et partout la peau changea de couleur et prit une teinte de brun foncé, qui ne s'effaça que peu à peu et bien longr-tems après. Ceci n'aura rien d'étonnant Come II. 
pour beaucoup de personncs qui connoissent déja İ même proprićté dans plusicurs insectes du mêne gente, et notamment à ce bupreste d'un beau verd doré que l'on trouve si communément dans nos jardins potagers d'Europe; mais comme celui dont il cst ici question est benucoup plus gros et qu'il habitc un pays très-chaud, il est naturel que l'effet qu'il produit soit plus remarquabic; cependant la liqueur que darde à son cnnemi notre bupreste doré, cause une douleur très-sensible, et son odeur est de même très-pénćtrante.

Les inturalistes Dorci ce Olvicr ont donné, dans leur antomologic, la fignre de ce bel insecte d'Afrique, que je leur ai communiqué. On peut consulter ic $N^{\circ} .5$ de la planche première des scarabécs; mais je dois observer que he firure humaine que Yon rcmarque sur son awant-corcelet n'existe point dans la nature; je suis même étonné que l'nuteur de cet ouvrage ait laissé subsister cette fausse représentation, qui est sans doute une vision du peintre ou du graveur, qui n'auroit pas dù ètre toléréc. Ic me suis cru obligé de relever certe faute, pour ne point induirc en errcur les amntcurs, qui, au reste, pourtont voir l'jnsecte lui-même, dans le cahinet de Dufiêne, nttaché au eabinct d"histoire naturelle, ¿̀ qui je l"ai donné.

Quoiquen générnl les êtres du règne animal qu'on destine ì être conservés dans les cabinets perdent tous plus on moins, par l"effet du desséchement et du racornissement, je puis certifier que le bupreste cont il est question ne portoit pas plus une figure humainc ćtant vivant qu'apris sa mort; d'ailleurs, les inscetes durs, les scarabécs enfin, ne perdent rien de leurs formes; tandis que ceux qui, par leur nature, sont moux, s'aitirent infini- 


\section{E N A F R I U E. $\quad 259$}

ment et ont besoin d'une préparation particulière pour être conservés dans leur état de nature; il en cst mêne beaucoup qu'on n'a jamais parfaits, malgré les plis grandes précautions. Qui n'avouera, par excimple, qu'un oiseau en mue uu mort de maladie ne peut être, mảlgré tous les soins et les apprêts qu'employera pour lui l'ornithologiste, aussi agréable que celui qui aura été tué dans la force de l'âge et de la santé?

Il en est ainsi de l'oiseau malade, ou qui, par quelque obstruction, est privé de cette huneur onctueuse, renfermée dans les glandes de son croupion, et qui lui sert à lustrer ses plumes. Pris dans cet écat, il n'aum ni l'éclat ni le coup-d'œil brilant qu'il peut et doit offrir, lorsqu'il a été choisi dans d'autres circonstinces. Si je me permets, en passant, ces remarcues, c'cst pour prouver qu'il est beacucoup plus difficile qu'on ne l'imagine de frire tme belle collection.

J'avois récompensé libéralement la Namaquoise de qui je tenois le bupreste; et j’avois même annoncé que je donnerois une double ration de tabac à celui ou à celle qui m'en apporteroit un autre. Cette promesse aiguillonna l'activité des fumeurs et des fumenses. Les femmes sur-tout, tant de la horde que de mon camp, se mirent en quête de tout côté. Malgrú l'ardeur et la constance de leurs recherches, elles ne purent rencontrer un second bupreste; mais clles me fournirent une quantité immense d'autres insectes et plus de deux cents espèces différentes de chrysalides : ce qui me coûta beaticoup de pipas de tabac, parce que, voulant encourage: les perquisitions, j'affectois de payer plus libéralement que ne valoient les objets.

Mon dessein étoit demporter avec moi mes chry- 
salides, afin d'attendre et d'étudicr en route leur dévcloppement et leur métamorphose. Mais, malgré tous mes soins, le voyage les fatigua tcllement quavant mon retour au Cap, plus dès trois quarts étoient mortes. Celles qui restoient paroissoient très-vivantes; mais obligé de partir pour l'Europe, il me fallut les abandonner. Je crois qu'elles étoicnt du nombre de celles à la transmutation desquelles la nature emploie une annéc entic̀re.

On sait communément en Europe que les chcnilles n'y sont point venimeuses. Au moins c'est l'assertion de tous les naturalistes qui ont écrit sur cet animal; et quoiqu'il y cn ait quolques espices velues done le contact occasionne des démangeaisons, il est prouvé, par l'expérience, que cet accident n'a point de suites. Mais l'histoire naturelle est une mine immense, qui, à mesure qu'on la foulle, présente des détails nouvcaux ct des découvertes intéressantes. Les cantharides, avalćcs intéricurement en poudre, ou appliquées à l'cxtéricur en emplâtrc, sont un poison irritant très-accif; ch! qui sait si, à mesure qu'on étudiera l'histoire des insectes, on n'en trouvern point d'autres qui ont cette faculté dangercuse.

Mon père m’a assurć qu’à Surinam, parmi les chenilles velues, il en est deux espèces, noires et blanches, qui la possèdent à un degré redoutable. Si clles touchent la peau, soit d'un noir, soit d'un blanc, à l'instant même il s'y forme des ampoules, et bientôt il s'y établit une suppuration ausisi abondante que celle d'un vessicatoire de cantharides. En moins de quatre heures, le mal augmente. Des doulcurs aigues se font sentir, accompagnéces de fière et de frissons; et si malhcureusemen: le sujet a quelque vice dans le sang ou dans lis humeurs, 


\section{EN A F R I Q UE. $\quad{ }_{2} 6_{1}$}

sa plaic devient un ulcèrc auquel il faut appliquer le bistouri, pour empêcher la gangrène. J'ai dans mon cabinet ces deux cspc̀ces de ehenilles remarquables par leur taille.

Che\% les Namaquois, on trouve unc cspèce de chenille vraiment venimeusc; clle a deux pouces et demi de long, mais elle n'est venimense qu'autant que la plante qui lui sert de nourriture l'est elle-même. Prise sur le géranium, sur lequel je l'ai trouvé souvent, elle n'a nul danger, et j'en ai fair l'expérience. Aussi les Sauvages n'ont garde d’employer celle-ci. Mais parmi leurs rochers croît en très-grande abondanee un petit arbrisseitu dont le sue cst un poison mordieant, ct qui communique Sa propriété aux chenilles qui rongent sa feuille. C'est-là qu'ils vont chereher celles qui leur sont nécessaires; ou, s'ils n'y en trouvent pas une quantité suffisante, ils y transportent celles qu'ils rencontrent sur le géranium.

Le moment de faire leur cucillette est quand l'insecte touche à l'époque qu'il devient chrysalide; c'est-à-dire, quand ses ameaux se renflent er que ses formes commencent à s'oblitérer. Alors on le ramasse; on en remplit des petits sacs de peau, ct on l'y laisse fermenter. La fermentation excite dans le sae une transudation lente; l'huneur aqueuse s'évaporc, et ce travail intestin ne eesse que quand le résidu, bien coneentré, a pris la consistance d'un vernis noir, très-épais. C'est dans cet état que le poison a aequis toute son activité et qu'on y trempe la pointe des fleches.

Probablement il faut, pour qu'il soit tour ce qu'il peut ĉtre, que la masse ait subi sa fermentation complette. Au moins l'humeur qui compose la substance de l'insecte n'a point, pendant sa vie, le 


\section{VOYA GE}

même danger que quand il a étć dissnut er décomposé dans le sac. C'est ce que m’ont prouvé quelques faits.

Il est des corps dont le natursliste, ainsi que le chymiste, se permet de vouloir connoitre la saveur. Plusieurs fois, en Europe, $\ddot{j}$ inois osé metre sur le bout de ma langue quelques gouttes de la liqueur des chenilles. Je tentai la même cxpérience pour celle des chenilles à poison, et ne lui trouvai qu'une saveur médiocrement âcre, peu différente de colle que m'avoient firit iprouver les autres.

L'insecte lui-mêne, pris intéricurement, paroît n'être pas un poison. Un jour, je vis sur un des arbrisseaux une pie-grieche qui en mangeoit. Si l'oiseau s'est empoisonné, me dis-je à moi-même, bientôt je vais le voir mourir. Il me sembloit même que l'effet du venin devoit se faire sentir plutôt sul un gésicr qui broic que sur un estomac qui ne digère que par des sucs dissolvans. Pendant plus de dcux heures, je suivis la pie-grièche, examinane avec la plus grande attention tous ses mouvemens. Elle m'échappa enfin. Mais tane qu'clle fut sous mes yeux, je n'apperçus rien cn clle qui índiquât de la souffrance, et la vis toujours également leste et gaie.

Outre le venin des chenilles, les Sauvages cmploient encore, pour cmpoisonnor leurs flèches, celui de quelques espèces de serpons; quoique ce demier soit moins actif que l'autre. Les serpens qui servent particulic̀rement pour cette opération sont lc kooper-capel, lc pof-adder et lo hoorens-manetje ou serpent cornu. Celui-ci doit son nom à quelques écailles proéminentes, placées au-dessus des yeux, et qui les débordane de plúsieurs lignes, forment mie petite aigrette sur chaque $\propto$ il. C'est à quoi se 


\section{E N AFRIQUE. 263}

réduisent es prétendues cornes de gazelle que lui prête Kolbe, qui en a donnć une figurc sous le nom de céraste. Je vois dans le voynge en Abyssinic, par Bruce, aussi un serpent cornu nommé céraste et qui paroît vraiment porter des cornes, du moins d’après cc qu'cn dit ce voyageur; mais auroit-t-il aussi mal examiné les cornes de son céraste que celles de la giraffe; car il dit positivement que ce quadrupede a les cornes comme l'antiloppe; ce cui est certaincment faux.

Quoique le scrpent cornu ou, pour mieux dire, it aigretre, nat que quinze à dix-huit pouces de Inng, et que par conséquent il soit le plus petit des trois serpens dont je viens de faire mention, il est le plus dingereux, parce qu'étant presque toujours caché dans le salyle, sa petitesse er sa couleur grise cmpêchent de l'y distingner; tandis que le kooper-capel sc faic appercevoir de loin par sa grandeur et ses conleurs vives, et que li lenteur 3u poladder permet de se garantir sans pcine de ses atraques.

On lit dans un voyage moderne, que quand les Sauvages veulent cxtraire le poison des serpens, its les pilcne tout cnticrs. Pour moi, non-seulement je u'ai rien vu de scmblable chez les Hottentots, mais jai ćté mainte fois le témoin du contrairc. Ils n'ignorent pas que le venin est dans la mâchoire; ils connoissent les vésieules qui le contionnent et savent très-bicn l'en tircr. D'ailleur's, bcaucoup dic Sauvages se nourrissent du corps des serpens, après cn avoir tranché la tête. Cet usage est très-commun chez beancoup de nations, quoique je ne l'aie jamais vu pratiquer chez les Hottentors; mais combien de fois, à Surinam, dans l'habitation de mon père, n'ai-je pas vu les nègrcs africains, lounngos 


\section{VOYAGE EN AFRIQUE.}

et pombos, quoique nourris avec abondance, chercher à se régaler de cette friandise! Ils ne rebutoient pas même le serpent à sonncttes, le plus venimeux de cetie immense fanillc. Tous ceux quibls pouvoient prendre étoient mis en ragout avec leurs autrcs alimens; et c'étoit pour eux ce qu'est pour nous l'anguille dans une marelotre.

Fin du second Volume. 

40

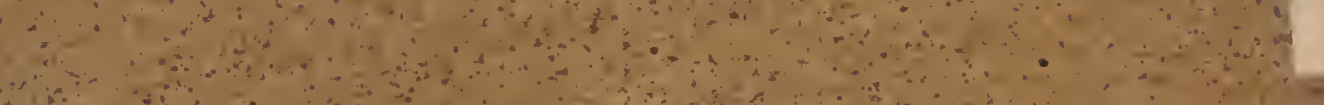

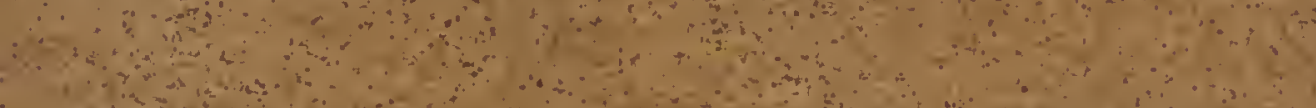
1

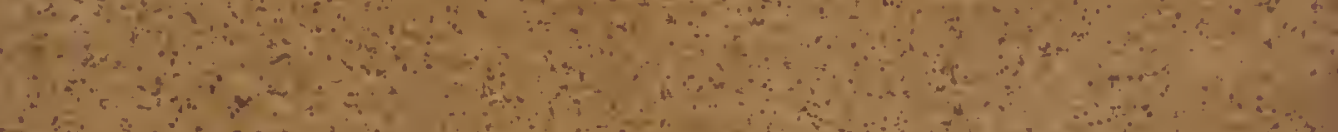

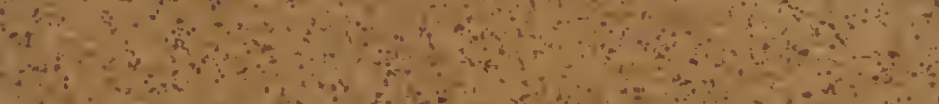

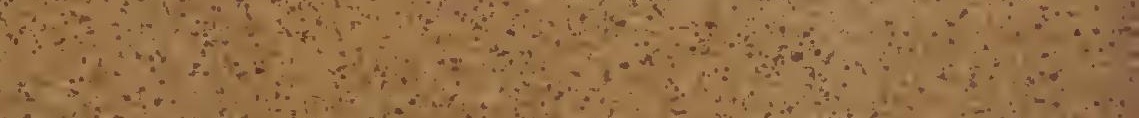

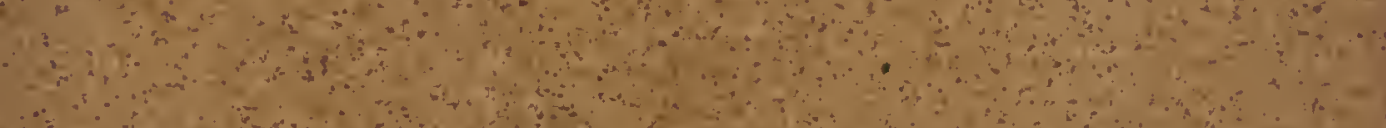

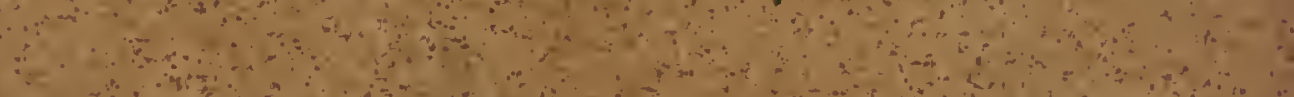
$\therefore a^{2}$

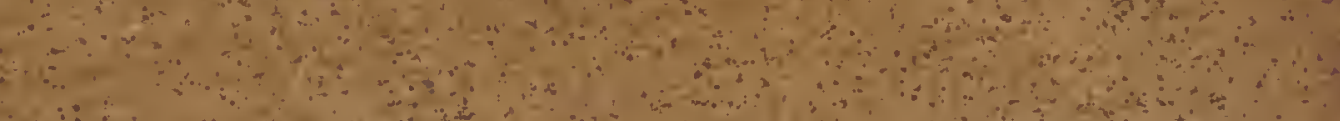

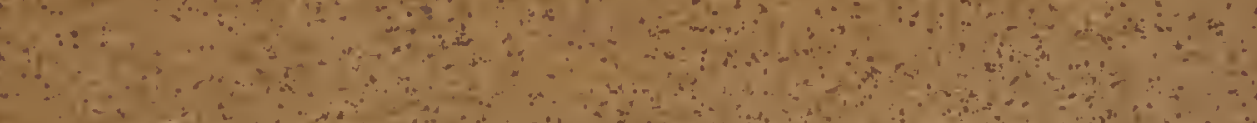
a

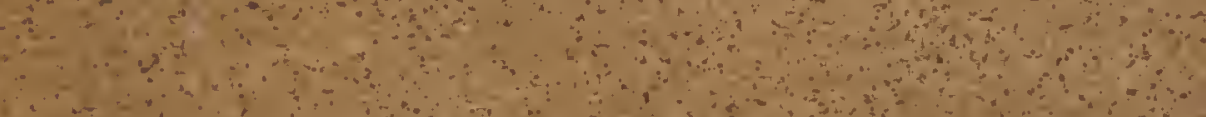

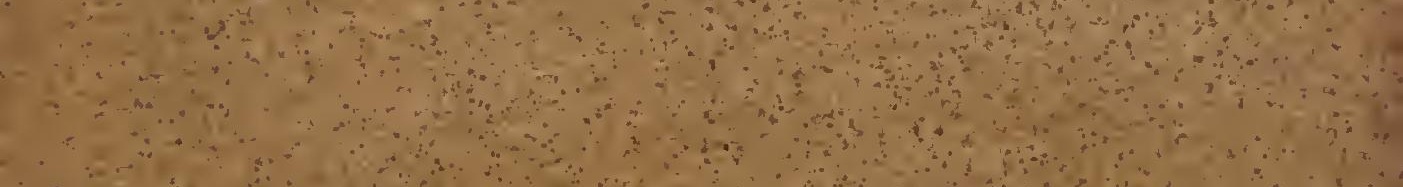

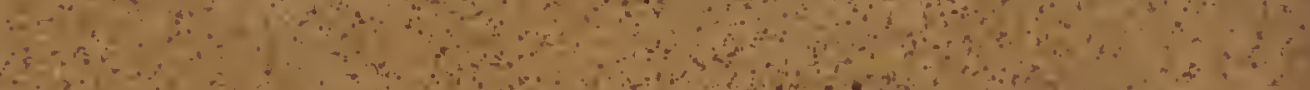
$\because 50$

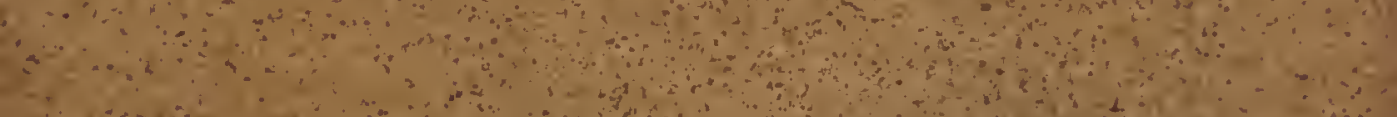

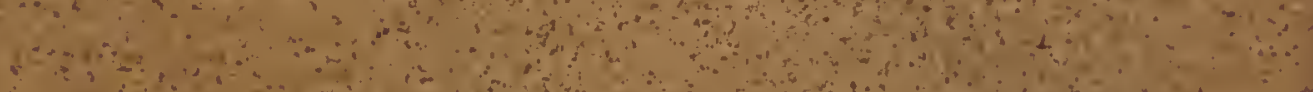

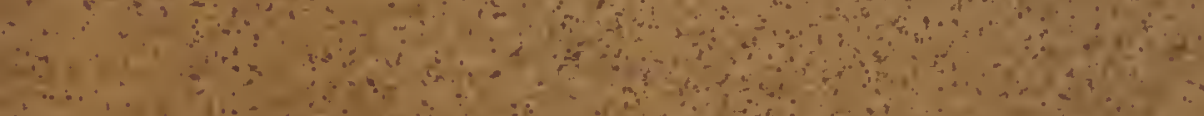

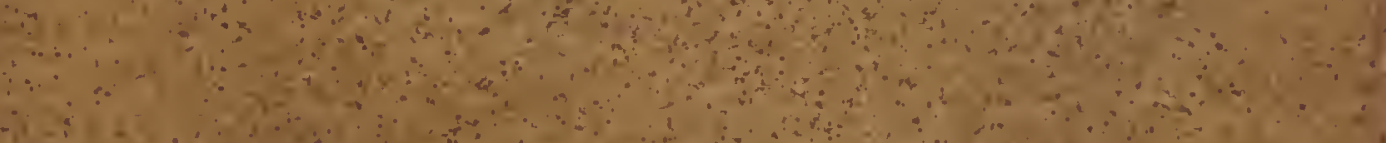

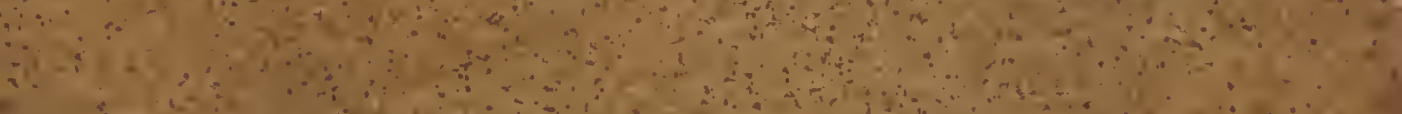

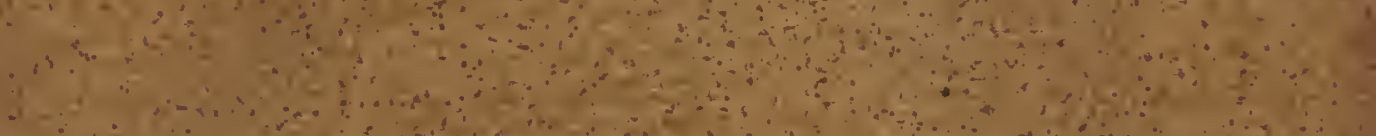

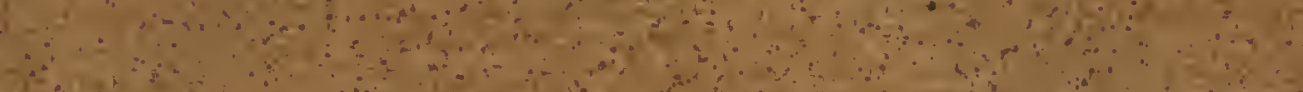

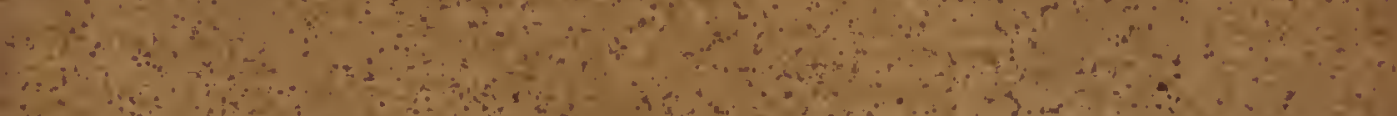
$\therefore$ a $\therefore a_{0}$ $\therefore i$ $\because \cdots \div$

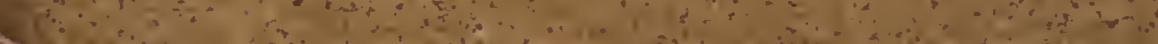

